\title{
INFLUÊNCIA DE EDUCAÇÃO, PESQUISA E ASSISTÊNCIA TÉCNICA NA PRODUTIVIDADE DA AGRICULTURA BRASILEIRA NA DÉCADA DE SETENTA
}

JOSÉ ROBERTO VICENTE

Orientador: Prof. EVARISTO MARZABAL NEVES

Dissertaçāo apresentada à Escola Superior de Agricultura Zuiz de Queiróz", da Universidade de São Paulo, para obtençāo do titulo de Mestre em Agronciną, área de concentração: Economia Agrária.

PIRACICABA

Estado de São Paulo - Brasil

Fevereiro - 1989 
Vicente, Josē Roberto

V632i Influência de educação, pesquisa e assistência técnica na produtivida de da agricultura brasileira na déc $\vec{a}$ da de setenta. Piracicaba, 1989. $193 \mathrm{p}$.

Diss. (Mestre) - ESALQ Bibliografia

1. Agricultura - Assistēncia técnica Brasil 2. Agricultura - Efeito da educação Brasil 3. Agricultura - Pesquisa - Brasil 4. Agricultura - Produtividade - Brasil I. Escola Superior de Agricultura Luiz de Queiroz, Piracicaba. CDD 338.10981 
INFLUENCIA DE EDUCAÇ,P.O, PESQUISA E ASSISTENCIA TECNICA NA PRODUTIVIDADE DA AGRICULTURA BRASILEIRA NA DECADA DE SETENTA

JOSE ROBERTO VICENTE

Aprovada em 23/05/1989

Comissão julgadora:

Prof. Dr. Evaristo Marzabal Neves

ESALQ/USP

Prof. Dr. Josë Ferreira de Noronha

ESALQ/USP

Dr. Gabriel Seraphico Peixoto da Silva

$\mathrm{IEA} / \mathrm{SP}$

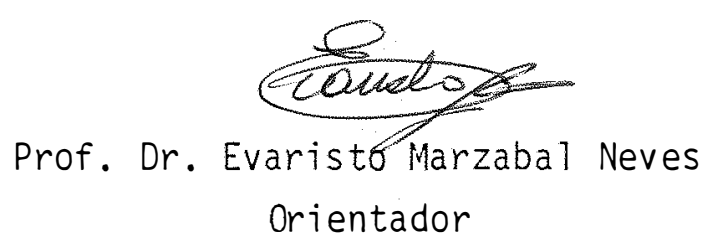


A meu pai, José (in memoriam);

'A minha mãe, Roma;

'A minha tia, Paula (in memoriam);

'A minha irmā, Rosely;

'A minha esposa, Carlota; e, A meus filhos, Alexandre e Carolina. 


$$
\text { Aos professores e funcionários do }
$$

Departamento de Economia e Sociologia Rural da ESALQ/USP, em especial ao prof. Evaristo Marzabal Neves, nosso orientador, e aos prof. Fernando Curi Perez, José Ferreira de Noronha e Paulo Fernando Cidade de Araújo, cujas opiniōes no projeto original e nas versōes preliminares permitiram aperfeiçoar este trabalho.

Ao pesquisador Cientifico Gabriel Luiz Seraphico Peixoto da Silva, do Instituto de Economia Agrícola (IEA), pelos comentários e sugestöes apresentadas.

Ao pesq. cientif. Maria Carlota Meloni Vicente, do IEA, pela revisão e sugestōes.

A prof. Julie Anderson, da Stanford University, pelas sugestōes.

Ao estatístico Vera Lúcia Ferraz dos Santos Francisco, pela elaboraçāo dos programas necessários para o processamento de dados. 
A Mário Pires de Almeida Ollivetti, acadêmico de Geografia e auxiliar agropecuário no IEA, Sandra Regina Ribeiro, acadêmica de Matemática e estagiária no IEA, José Antonio Marinovic D'Oro, auxiliar agropecuário no IEA, Marco Antonio Rocha de Oliveira, acadêmico de Economia e auxiliar agropecuário no IEA e, Maria do Carmo Mendes Cardoso, acadêmica de Matemática e 'auxiliar de estatístico no IEA, pela coleta, preparação e análise preliminar dos dados.

A Engenheira Agrônoma Estela Moreti Reck Marinelli, estagiária no IEA, pelo auxílio na revisão final.

Ao IEA, CNPq, CAPES e EMBRAPA, pelo suporte oferecido durante o curso e em todas as fases desta pesquisa.

Aos colegas da pós-graduação em Economia Agrária, em especial ao Aurélio, ao Baccarin, ao Barnes, ao Fassarella e ao Pacheco, cuja amizade contribuiu para amenizar as dificuldades encontradas no decorrer do curso. 
SUMáRIO

página

RESUMO $\ldots \ldots \ldots \ldots \ldots \ldots \ldots \ldots \ldots \ldots \ldots \ldots \ldots \ldots$

SUMMARY . . . . . . . . . . . . . . . . . ix

1. INTRODUÇÃ̃o ........................... 1

1.1 . objetivo........................... 7

2. METODOLOGIA........................... 8

2.1. Medidas de Produtividade.............. 8

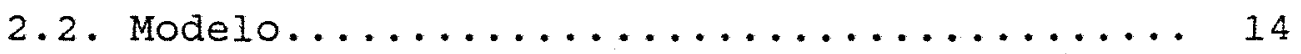

2.2.1 Caracteristicas do modelo......... 14

2.2 .2 Formulaçăo do modelo........... 15

2.3. Fontes de Dados..................... 18

2.4. Cálculo das variáveis.............. 20

2.4.1. Produçăo agrícola............ 20

2.4.2. Fator trabalho............. 21

2.4.3. Fator terra................ 21

2.4.4. Fator fertilizante.......... 22

2.4.5. Fator máquina............. 23

2.4.6. Fator investimento em culturas perenes..................... 24

2.4.7. Deficiências hídricas e geadas.... 25

2.4 .8 . Educaçăo............... 26 
página

2.4.9. Assistência Técnica......... 27

2.4.10. Número de artigos científicos publicados............... 27

2.4.11. Aptidão edafo-climática das terras 28

3. RESUltados E discUSSÃo................. 29

3.1. Evolução da Produção Agrícola, do Uso e da Produtividade de Fatores............. 29

3.1.1. Evolução da produção agricola.... 29

3.1.2. Evolução do uso de fatores....... 38

3.1.3. Evolução da produtividade de fatores................. 46

3.2. Resultados dos Modelos Ajustados........ 61

3.3. Retornos Marginais dos Investimentos em Educação, Assistência Técnica e Pesquisa.. 71

4. CONCLUSÖES......................... 78

IITERATURA CITADA................... 81

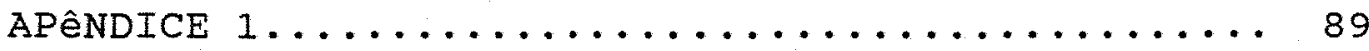

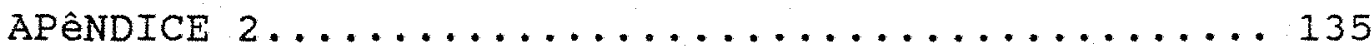

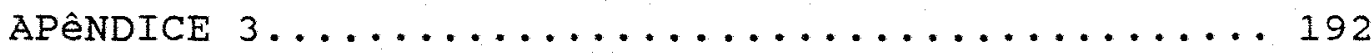


vii.

INFLUÊNCIA DE EDUCAÇÀO, PESQUISA E ASSISTÊNCIA TÉCNICA NA PRODUTIVIDADE DA AGRICULTURA BRASILEIRA NA DÉCADA DE SETENTA

Autor: JOSE ROBERTO VICENTE Orientador: Prof. Evaristo Marzabal Neves

RESUMO

o objetivo deste trabalho foi o de mensurar as contribuiçōes da educação, assistência técnica e pesquisa agrícola para a evolução da produtividade na agricultura brasileira, no periodo 1970-80.

Foram utilizados, basicamente, dados censitários de 1970, 1975 e 1980, à nivel de Estado. As produtividades foram obtidas pelo quociente de indices Fisher encadeados de produça por indices Fisher encadeados do uso dos fatores terra, trabalho, fertilizantes, máquinas e investimentos em culturas perenes. rambém foram construidos indices de produtividades parciais de terra e trabalho. Como variáveis explicativas utilizaram-se a escolaridade da população rural, uma estimativa do número de produtores assistidos pelos serviços de extensăo rural, - número de artigos cientificos publicados referentes a tecnologia agricola, uma medida da aptidăo agricola das 
viii.

terras e, como variáveis representativas de adversidades climáticas, deficiência hídrica e geada. Os modelos foram ajustados por minimos quadrados ordinários.

Pelos resultados obtidos, observou-se que os investimentos públicos e privados em educação, e os investimentos públicos em pesquisa e assistência técnica tiveram influência significativa sobre os ganhos de produtividade ocorridos no período. Com relação à pesquisa, năo foi possível isolar os efeitos dos artigos referentes às regiōes geográficas daqueles relacionados ao Estado de São paulo. Cálculos dos retornos marginais indicaram que os investimentos mais rentáveis seriam os efetuados em pesquisa agrícola, seguidos dos em assistência técnica e, por último, em escolaridade da população rural. Todavia, foi salientado que a variável utilizada para representar a educaçảo é pouco adequada para captar o efeito alocativo. 
ix.

INFLUENCE OF EDUCATION, RESEARCH AND EXTENSION ON THE PRODUCTIVITY OF THE BRAZILIAN AGRICULTURE IN THE SEVENTIES

Author: JOSE ROBERTO VICENTE Adviser: Prof. Evaristo Marzabal Neves

SUMMARY

The objective of this papper was to measure the contributions of education, rural extension and agricultural research to the productivity of the Brazilian agriculture during the period 1970-80.

The analysis was based on data of the censuses of 1970,1975 and 1980 at the state level. Total productivities were obtained through the quotients of chained Fisher indexes of production by chained Fisher indexes of factors, namely land, labor, fertilizers, machines and perennial crops. Partial productivity indexes of land and labor were also constructed. In the models, productivity indexes were postulated as functions of the rural population schooling, the number of producers assisted by the extension services, the number of scientific articles published in the field of agricultural technology, the aptitude of agricultural lands, and of 
climate adversities, namely hydric deficiency and frost. The models were adjusted through the ordinary least squares. The results showed that public and private investments in education, and public investments in research and extension influenced significantly the productivity gains occurred in the period 1970-80. Concerning to research, it was not possible to separate the effects of the scientific articles related to each region of the country from the effect of the articles related to the Säo Paulo state. Estimates of the marginal returns suggest that the most profitable investments would be those directed to agricultural research, followed by those directed to rural extension and at last those related to rural population schooling. Nevertheless it was pointed out that the measure of education introduced in the model is not appropriate to capture the allocative effect of schooling. 
1. INTRODUÇÃO

No processo de desenvolvimento econômico, ao setor agrícola são normalmente atribuídas as funçōes de produzir alimentos e matérias primas, liberar trabalhadores para os setores urbano-industriais, gerar poupanças e criar mercados para os produtos dos outros setores, além da obtenção de divisas para importação, via exportações de produtos agrícolas (JOHNSTON e MELLOR, 1961). A partir de meados da década de setenta, a agricultura brasileira foi adicionalmente requerida no sentido de substituir petróleo por fontes renováveis de energia.

Embora situaçōes de relativa abundância de terra e trabalho possam permitir a geração de excedentes agricolas através da incorporaçäo de novas áreas, a longo prazo, o atendimento das exigências colocadas sobre o setor passa a ser condicionado pela elevação da produtividade, 
que depende, por sua vez, do progresso tecnológico (1).

$$
\text { Desde o estudo pioneiro de solow (1957), }
$$

- progresso tecnológico tem sido arrolado como determinante do desenvolvimento econômico, uma vez que os aumentos de produção observados nào eram explicados pela proporcional utilização de fatores convencionais. Em meados da década de sessenta, esse conceito passou a ser aplicado diretamente à agricultura, reconhecendo-se 0 papel da pesquisa agronômica para incrementos na produção e na produtividade, através da geraçāo de novas técnicas produtivas em forma de conhecimentos diretamente aplicáveis à produção e de conhecimentos incorporados em fatores utilizados no processo produtivo (2). Também, nessa época, ganharam importância trabalhos evidenciando que a educaçäo formal e a extensāo rural aceleram o processo de adoção de novas tecnologias pela habilitaçảo da mảo-de-obra e pela capacitaçâo gerencial dos agricultores. Esse conceito, que permitiu incorporar variaçôes qualitativas no fator trabalho, contribuiu para explicar parte considerável dos residuos que se observava em estudos relacionando crescimento de produtividade à utilizaçảo de fatores de produção (ALVES, 1975).

Politicas objetivando elevações de produção e produtividade agricolas podem basear-se no aperfeiçoamento de fatores estruturais, como educação e (1) Para uma discussão detalhada, ver SIIVA (1982).

(2) Esses aspectos sắo melhor abordados por SILVA (1984). 
treinamento dos produtores, qualidade e quantidade dos serviços de pesquisa e extensâo, posse da terra e relações de trabalho no meio rural. Podem também, basear-se em mecanismos de mercado, como disponibilidade e custo do crédito, preços e produção de insumos e redução de incertezas sobre preços agrícolas através de preços mínimos de garantia (SMITH, 1983).

$\mathrm{Na}$ década de setenta, o esforço de modernização da agricultura brasileira, dando continuidade ao processo iniciado na década anterior, baseou-se no emprego maciço de mecanismos de mercado, principalmente na política de crédito, conjugada à intensificaçäo do uso de insumos modernos produzidos pelo setor urbano-industrial, e à expansão da fronteira agrícola ( $(3)$.

Embora a criaçäo da Empresa Brasileira de Pesquisa Agropecuária (EMBRAPA), em meados da década de setenta, tenha sido passo notável para unificar os até entăo dispersos sistemas de pesquisa estaduais e, mesmo, federais, foi no campo da assistência técnica e extensão rural que $\circ$ modelo de desenvolvimento adotado continuou concentrando esforços, em consonância com os mecanismos de mercado, como já efetuado na década de sessenta, para elevar a produtividade agrícola. Pressupunha-se, portanto, a existência de um estoque disponivel, e facilmente

(3) Para uma análise desse processo ver ANJOS, YAMAGUISHI e CARVALHO (1988). 
transferivel, de tecnologia (4). Tal politica parece ter atingido resultados bastante modestos em relação aos pretendidos, já que a principal fonte de variação da produção da maior parte das culturas do país foi a área cultivada, conforme, por exemplo, os estudos de FATRICK (1975), que analisou o período 1959-61 a 1967-69; de VERA FILHO e TOLLINI (1979), que estudaram o período 1947-75, e de CUNHA e DAGUER (1982), que trataram do período 1967-69 a 1977-79. Isso parece confirmar as colocaçöes de SCHULTZ (1965) sobre a especificidade locacional da tecnologia agrícola e a dificuldade de transferência entre países e entre regiöes do mesmo País, de resto verificada em estudos de EVENSON e KISLEV (1973, 1975) e EVENSON e JHA (1973).

Mesmo sem considerar as evidências mostradas por trabalhos internacionais (므), a literatura desenvolvida no Brasil a esse respeito dá sinais de que a opção de privilegiar a extensāo rural em detrimento da pesquisa e educação formal pode não ter sido a mais adequada: os investimentos em educação, em diversos estudos (LANGONI， 1972; CASTRO, 1973; GIBBON, 1975; RIBEIRO, 1979; THAME, VICENTE e VICENTE, 1987), apresentaram elevadas taxas internas de retorno (entre $15 \%$ e 48\%). PATRICK e

(4) A esse respeito, ver SILVA, FONSECA, MARTIN (1980b) e SILVA (1984).

(5) A respeito de influências da educaçăo na produtividade ver, por exemplo, GISSER (1962), BECKER (1964), SCHULTZ (1965), BLAUG (1965), WELCH (1970), FANE (1975), HUFFMAN (1970) e LOOCKHEED (1980); sobre pesquisa e extensão rural ver EVENSON (1967), EVENSON e KISLEV (1973 e 1975), EVENSON e JHÄ (1973), GRILICHES (1975) e HAYAMI E RUTTAN (1975). 
KEHRBERG (1975) estudando cinco áreas da regiäo leste do Brasil, encontraram taxas de retorno negativas em duas delas, enquanto que nas três mais desenvolvidas, as taxas eram positivas e superiores a $25 \%$

Com relação à pesquisa, AYER e SCHUH (1975) avaliaram o retorno social dos investimentos efetuados na cultura do algodāo em sāo Paulo, em 90\%. Seguindo, basicamente, o mesmo método, FONSECA, ARAUJo e PEDROSO (1979) avaliaram em 23\% a 25\% o retorno social para a cultura do café; PENNA e MONTEIRO (1976) em $60 \%$ a $79 \%$ a taxa para o cacau e, MORICOCHI, NEVES e ARAUJO (1981) em 18\% a $27 \%$ a taxa de retorno social da pesquisa em laranja. SILVA (1984), trabalhando com índices de produtividade agregada para o Estado de São Paulo, estimou para o produto marginal da pesquisa um valor ao redor de 75 . BARBOSA, CRUZ e AVILA (1988), estimaram que a taxa interna de retorno dos recursos aplicados na EMBRAPA está entre $29 \%$ e $49 \%$

Já com relaçăo a assistência técnica e extensāo rural, os resultados săo algo divergentes: ALVES e SCHUH (s.d.) năo chegaram a qualquer conclusăo tentando avaliar os efeitos dos programas de extensăo rural em Minas Gerais sobre a eficiência técnica e econômica dos agricultores; DIAS (1975) sugere efeitos positivos sobre a renda de produtores de baixo nivel tecnológico. RIBEIRO e WHARTON Jr. (1975) também encontraram taxas positivas de retorno em Minas Gerais. PATRICK e KEHRBERG (1975) no estudo anteriormente citado, encontraram taxas internas de 
6.

retorno negativas e positivas, concluindo pela maior eficiência da extensäo rural em áreas de agricultura tradicional. CARVALHO (1976) encontrou taxas de retorno elevadas para as atividades de assistência técnica, todavia, como lembra SILVA (1984), parte da hipótese insustentável de que sem os serviços de extensăo os produtores năo adotariam as novas técnicas geradas pela pesquisa. SILVA (1984), năo encontrou influência significativa dos investimentos em assistência técnica e extensăo rural sobre a produtividade agricola em são Paulo.

Esses estudos restringiram-se, via-de-regra, a determinado produto, determinadas regiōes ou, no caso da educaçäo, normalmente à produtividade do trabalho; os efeitos das variáveis explicativas - educação, pesquisa e extensăo - foram medidos geralmente de forma isolada, sem considerar as eventuais interaçŏes entre elas. Parece, portanto, que se justifica uma tentativa de generalizar essas conclusóes ampliando a área, o conjunto de culturas e analisando concomitantemente as influências da pesquisa, extensão rural e educação formal, que é o que se tenciona neste trabalho.

A década de setenta é particularmente adequada para tal tentativa, pois como lembra scHULTZ (1975), em épocas de modernização acelerada, com a consequente mudança rápida das condiçōes de produção, as habilidades pessoais em tratar com situaçỏes de desequilibrio (e, em consequência, os serviços de pesquisa e de extensão, além da educação formal) adquirem importância 
muito maior.

\section{1 objetivo}

o objetivo central deste estudo é a análise econômica da politica de investimentos em educação, pesquisa e assistência técnica, dirigida ao meio rural brasileiro, no periodo 1970-80. Especificamente, tenta-se, para o periodo em questāo, mensurar e explicar as contribuiçōes desses fatores, no Brasil, para a evolução da produtividade agricola. 
2. METODOLOGIA

\subsection{Medidas de Produtividade}

A mensuraçăo da produtividade foi efetuada pelo quociente de um indice de produção (que parte das quantidades produzidas de cada produto e seus respectivos preços), por um outro do uso de determinado fator ou fatores. Isso conduz ao "problema dos números-indices", ou da escolha de determinada fórmula mais adequada para representar o problema em questăo. Tradicionalmente, a comparaçăo entre as diversas fórmulas existentes era feita com base nos testes lógicos definidos por FISHER (1922), em seu texto clássico. Segundo esses critérios, entre as fómulas mais conhecidas, as de Laspeyres e Paasche não atendem aos testes de decomposição 
de causas (o produto do índice de quantidade pelo indice de preço calculados por essas fórmulas difere do indice de valor), de reversāo temporal (o produto do índice de quantidade do ano 0 em relação ao ano $t$ pelo indice do ano $t$ em relaçäo ao ano o difeie da unidade) e de circularidade (o qual exige que um número-índice deve ser independente da escolha de um terceiro ponto no tempo, podendo, portanto, ser decomposto por um produto de dois indices similares onde a base de um deles é o periodo corrente do outro); a fórmula de Fisher năo atende apenas 0 teste de circularidade, $\circ$ que pode ser contornado com 0 uso do encadeamento (ㅁ) . No estudo de EICHHORN (1976), encontra-se a colocaçāo de que o teste de circularidade não é compativel com os demais, nāo havendo fórmula que os satisfaça simultaneamente.

$\mathrm{Na}$ moderna teoria dos números-índices, além da necessidade de atualização constante da base de ponderação (aproximação discreta à integral de Divisia), vem merecendo destaque $\circ$ estudo das relaçōes entre especificaçōes funcionais admitidas pela análise econômica e fórmulas de números-índices. CHRISTENSEN (1975) demonstrou que a fórmula de Laspeyres é exata para uma funçāo de produçāo linear, que supōe substituiçāo perfeita de fatores no processo produtivo, e que a mesma proporciona medidas pobres de produtividade, o que já havia sido

(6) Para uma descriçăo completa dos testes ver SILVA e CARMO $(1986)$. 
demonstrado por SAMUELSON e SWAMY (1974) para a fórmula de Paasche. DIEWERT (1976) definiu como flexivel uma forma funcional agregativa que possibilite uma aproximação até segunda ordem, de uma função Iinear homogênea arbitrária, que possua derivadas primeira e segunda; chamou de superlativa uma fórmula de números-índices exata (isto é, consistente) para uma forma funcional flexivel. Demonstrou que o indice de Tornquist (também chamado de indice translog de Tornquist-Theil) é exato para uma forma agregativa translog homogênea (e, portanto, superlativo). Similarmente, demonstrou que a fórmula de Fisher é exata para uma funçāo agregativa quadrática de ordem dois homogenêa (e, portanto, superlativo)(Z).

As formulas superlativas, conforme DIEWERT (1976), também se caracterizam por aproximarem-se entre si até a segunda ordem, o que limita a amplitude das variaçōes medidas; essa caracteristica, que se mantém mesmo para funçōes agregativas não-homotêticas (DIEWERT, 1978) foi verificada empiricamente por SILVA e CARMO (1986) Com dados do Estado de São Paulo.

STAR e HALL (1976) encontraram os mesmos resultados para o crescimento da produtividade total nos EEUU trabalhando com dados anuais e com cortes seccionais de 10 anos (encadeados), o que mostra a viabilidade de obter conclusōes acuradas com dados censitários.

(7) Essas demonstraçōes foram ampliadas por LAU (1979). 
Demonstraram ainda, que a fórmula de Laspeyres, embora possa ser considerada uma aproximaçāo discreta à integral de Divisia se calculada encadeadamente, conduzia a resultados que superestimavam a taxa de aumento da produtividade em mais de 100\%. ALLEN e DIEWERT (1981), comparando $\circ$ desempenho de diversas fórmulas de números-índices em dados censitários, indicaram a de Fisher como a mais adequada.

Essas evidências fartamente registradas na Iiteratura, levaram à escolha da fómula de Fisher para - cálculo dos indices de produção e de uso de fatores necessários para este trabalho.

Formalmente,

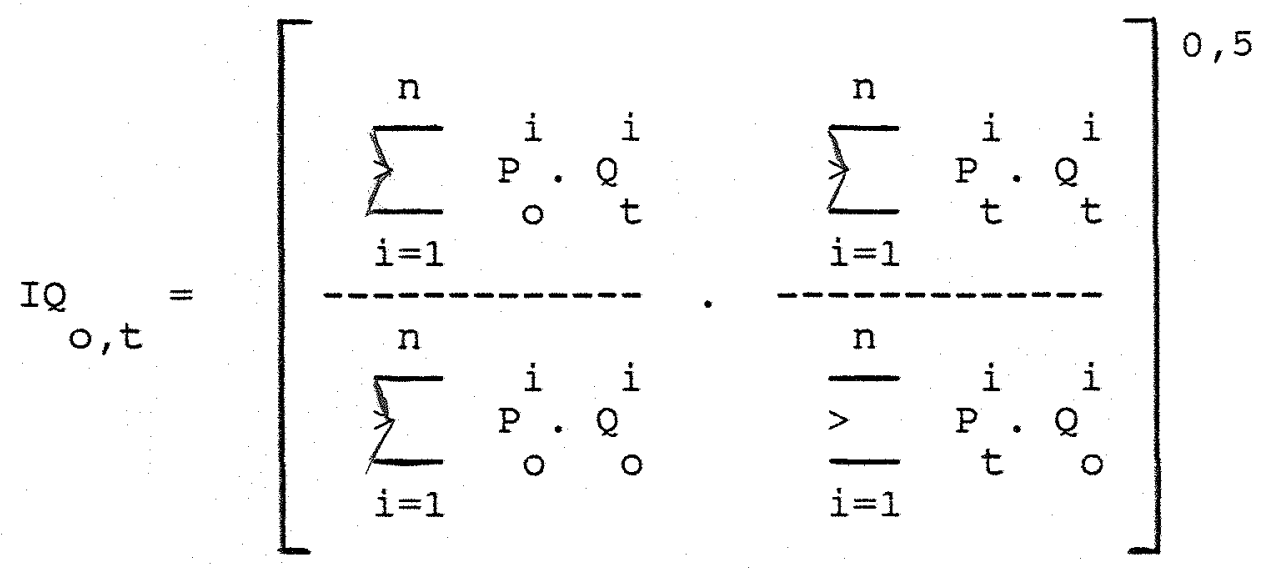

com o encadeamento,

$$
\begin{aligned}
& \text { IQ }=I Q_{0,1} \cdot I_{1,2}, \cdots \cdot I_{t-1, t} \text { onde: } \\
& I Q=\text { indice Fisher de quantidade; } \\
& P_{0}=\text { preço do produto (ou fator) no ano base; } \\
& P_{t}=\text { preço do produto (ou fator) no ano } t ;
\end{aligned}
$$




$$
\begin{aligned}
& Q_{0}=\text { quantidade produzida (ou utilizada) no ano base; } \\
& Q_{t}=\text { quantidade produzida (ou utilizada) no ano t; } e, \\
& i \text { = iésimo produto (ou fator). }
\end{aligned}
$$

Outra questāo que se coloca' é sobre o denominador do indice de produtividade. A medida mais frequentemente utilizada é a produtividade da terra, com a área agregada das culturas servindo como referência. Mais recentemente passou a ser considerada também a produtividade do trabalho. VERA FILHO e TOLLINI (1975) argumentaram que essas medidas podem acarretar erros em comparaçōes multilaterais, e sugerem a utilizaçāo de indices de produtividade total ou, pelo menos, indices de produtividades parciais referentes aos fatores mais importantes. ALVES (1979), embora reconhecendo a dificuldade de se calcular indices de produtividade total no Brasil, devido à carência de dados, defende seu uso como uma medida mais adequada; enfatiza que há casos em que um aumento na produtividade da terra é conseguido às custas de recursos mais dispendiosos para a economia do que aquele que está sendo poupado. SILVA (1984) utilizou esse conceito para medir o progresso tecnológico na agricultura paulista.

A esse respeito, parece consensual na Iiteratura que, sob os pressupostos de que os preços dos 
fatores constituem medidas aceitáveis de seus produtos marginais e de que a funçäo de produçäo apresenta retornos constantes à escala, a produtividade total de fatores seria uma medida adequada de progresso tecnológico, evitando os problemas de especificação da forma e tstimaçăo da funçāo de produçäo (NADIRI, 1970).

Diversos trabalhos vêm aperfeiçoando esse método e efetuando comparaçōes multilaterais, como JORGENSON e NISHIMIZU (1978), CAVES, CHRISTENSEN, SWANSON (1981), CAVES, CHRISTENSEN, DIEWERT (1982a) e (1982b), e BALTAGI e GRIFFIN (1988).

Para que a medida obtida seja aceitável é necessário, naturalmente, evitar tanto quanto possivel erros de medida e de agregaçäo, além da escolha de uma fórmula adequada, como lembram DOMAR (1961), JORGENSON e GRILICHES (1967) e, BERNDT e CHRISTENSEN (1974).

Tendo definido anteriormente a fórmula de Fisher como adequada aos propósitos deste trabalho, pelo acima exposto, optou-se também por construir um indice de uso de fatores tomados agregadamente. Este permitirá a obtençāo de indices de produtividade agregada, além dos indices de produtividades parciais dos fatores componentes tomados de forma isolada. A disponibilidade de dados dos Censos Agropecuários de 1970, 1975 e 1980 limitou os fatores possiveis de inclusão no indice agregado a terra, trabalho, fertilizantes, máquinas e investimentos em culturas perenes; acredita-se que esse procedimento 
proporcionou uma medida adequada da produtividade agricola.

\subsection{Modelo}

2.2.1 Características do Modelo

A opçăo pelo uso de números-indices na mediçăo da produtividade agregada de fatores, que é a variável a ser explicada, isolando-se a contribuiçāo dos vários fatores, é conhecida como abordagem contábil do crescimento, e foi utilizada por EVENSON e JHA (1973) e SILVA (1984). Segundo a concepção expressa por EVENSON e KISLEV (1973), a produtividade pode ser entendida como uma funçăo da tecnologia, do clima, do solo e das condiçŏes do tempo. A tecnologia, por sua vez, pode ser vista como uma função, envolvendo estruturas de defasagens, do estoque de conhecimentos gerados localmente, do estoque transferido de outras regioes ou países, da eficiência dos serviços de difusăo, que pode ser aumentada ou até substituída pelo nivel educacional dos produtores. (

Para operacionalizar $\circ$ modelo foram desconsideradas alteraçōes nas condiçōes de solo e clima, o que parece razoável uma vez que o tempo exigido para mudanças substanciais nesses fatores costuma ser superior ao horizonte coberto por esta pesquisa. Segundo SILVA

() Para uma exposiçāo detalhada, ver SILVA (1984). 
(1984), diminuiçöes na fertilidade do solo levariam à subestimaçāo dos efeitos da pesquisa pela dificuldade de mensurar o sucesso das tecnologias destinadas à manutenção da produtividade. Também não foi considerada a influência de alteraçōes na distriouição espacią de culturas; todavia, o efeito da localizaçāo geográfica sobre os rendimentos das culturas é de pouca importância no periodo aqui estudado, como pode ser visto em CUNHA e DAGUER (1982). Pesquisas efetuadas no exterior tampouco foram consideradas; mas, apesar de seu efeito ser reconhecidamente importante, sua contribuiçāo depende de adaptaçōes efetuadas pelos serviços locais de pesquisa, de difusāo através da extensāo rural e do nivel educacional dos produtores para adotá-las convenientemente. Com relaçăo à educaçāo, acredita-se que uma medida bastante adequada seria a escolaridade do tomador de decisones que, infelizmente, nāo tem sido coletada. Do lado da assistência técnica e extensāo rural também são desconhecidos dados de produtores assistidos fora dos organismos oficiais de extensāo rural.

\subsubsection{Formulaçāo do Modelo}

A formulação operacional do modelo é a seguinte:

$$
\text { IPr }=f(P, E, A T, C S, D H, G) \text { onde, }
$$


IPr é a produtividade agrícola, tomada a nível de Estado; $P$ é o número de artigos cientificos referentes a tecnologia agricola publicados;

E é a escolaridade da populaçăo rural;

AT é uma estimativa do percentual de produtores assistidos pelos serviços oficiais de assistência técnica e extensão rural;

CS é una medida da aptidão edafo-climática das terras do Estado;

DH é variável representativa das condiçōes do tempo, a deficiência hídrica, que se obteve através da interação entre temperatura, precipitaçāo pluviométrica e localização geográfica; e,

G é uma variável "dummy" representativa de geadas abrangentes no ano safra e no ano imediatemente anterior (9).

Como os dados utilizados são referentes aos Censos Agropecuários de 1970 , 1975 e 1980, foram introduzidas nos modelos duas variáveis "dumnies" para captar possiveis diferenças entre anos: a primeira assumiu valor zero em 1970 e valor um em 1975 e 1980 , enquanto a segunda assumiu valor zero em 1970 e 1975 e valor um em 1980.

(9) Detalhes sobre o cálculo das variáveis encontram-se no item 2.4. 
A variável pesquisa foi dividida em pesquisa regional (segundo as divisöes estabelecidas por SILVA, FONSECA e MARTIN, 1979) e em pesquisa desenvolvida em São Paulo referente aos principais produtos de cada Estado; isso foi feito tentando verificar a influência das instituiçōes de pesquisa do Estado de São Paulo fora das fronteiras estaduais, uma vez que se trata do, Estado que dispunha do mais amplo, diversificado e tradicional sistema de pesquisas destinado a agricultura no País, embora durante a década de setenta os investimentos nessas atividades fossem substancialmente menores que os destinados a extensāo rural (SILVA, FONSECA e MARTIN, 1981). Pesquisa, extensăo e educação refletem-se sobre a produtividade defasadamente, descontando-se o tempo gasto com a geração de novas técnicas, sua difusăo entre produtores e $\circ$ processo de aprendizado formal e informal, capacitando-os a tomar decisōes sobre qual e como adotar determinada técnica produtiva. Os dados sobre escolaridade, presentes apenas nos Censos Demográficos, impedem que sejam considerados os efeitos defasados dessa variável; com a pesquisa e extensão rural é possivel fazê-lo. Os efeitos da pesquisa, após determinado periodo para serem disseminados, passam por uma adoçăo máxima e depreciam-se até tornarem-se obsoletos. A extensăo rural, conquanto deva ter seus efeitos sentidos quase que imediatamente, deve também diminuir sua eficácia com o decorrer do tempo, em um horizonte muito mais curto 
do que o da pesquisa. Para o ajuste de modelos, efetuado por mínimos quadrados (HOFFMANN e VIEIRA, 1977), no presente estudo, partiu-se dos horizontes de açāo definidos por EVENSON e JHA (1973) para a pesquisa (19 anos) e por PATRICK e KEHRBERG (1975) para a assistência técnica e extensāo rural ( 3 anos). SILVA (1984) nāo encontrou diferenças nos resultados utilizando a pesquisa acumuladamente e através de uma estrutura de um polinômio de segundo grau, num modelo de defasagens distribuidas polinomiais.

\subsection{Fontes de Dados}

Os dados necessários para os cálculos das variáveis tiveram as seguintes fontes:

a.) área e produçāo das culturas - Fundaçāo Instituto Brasileiro de Geografia e Estatistica (IBGE) (Censos Agropecuários);

b.) quantidade de fatores - IBGE (Censos Agropecuários);

c.) preços de produtos e de fatores - Fundação Getúlio Vargas (FGV) (Preços Pagos pelos Agricultores, Preços Médios de Arrendamentos, Vendas de Terras, Salários, Serviços, Retrospectiva da Agropecuária), IBGE (Censos Agropecuários) e Instituto de Economia Agricola (IEA);

d.) artigos cientificos publicados - SILVA, FONSECA e MARTIN (1979) e SILVA (1986); 
e.) escolaridade da populaçāo rural - IBGE (Censos Demográficos);

f.) produtores assistidos pelos serviços de extensåo rural - IBGE (Anuários Estatísticos do Brasil) e Coordenadoria de Assistência Técnica Integral (CATI);

g.) aptidão edafo-climática - Ministério da Agricultura (Série Aptidāo Agrícola das Terras); ie,

h.) dados climáticos (temperaturas, precipitaçōes pluviométricas e ocorrência de geadas) - Instituto Nacional de Meteorologia (INEMET) (Boletins Agroclimatológicos) e IBGE (Anuários Estatisticos do Brasil)

A tabulação dos dados dos censos Agropecuários impede, como seria desejável, a construçāo de indices de produçăo de todas as culturas existentes. Dessa forma, nos três anos estudados $(1970,1975,1980)$, dados à nivel de cultura nas classes econômicas agricultura e agropecuária (10), referentes a área, produção e valor da produçāo, existem para algodăo (arbóreo e herbáceo), amendoim, arroz, banana, batata, cacau, café, cana, feijāo, laranja, mandioca, milho, soja, tomate, trigo e uva. Esse grupo de culturas representa, segundo os dados do IBGE, de $41 \%$ a $51 \%$ do valor total da produção do setor, incluindo pecuária e criaçōes, silvicultura, horticultura e atividades extrativas; considerando-se apenas as lavouras

(10) A pecuária foi excluída da análise pela dificuldade de medir convenientemente sua produtividade. 
(permanentes e temporárias) as dezessete culturas citadas representam de $78 \%$ a $86 \%$ do valor da produçāo.

Similarmente ao procedimento adotado para o uso de fatores onde, além do indice agregado apresentam-se iluaices do uso de cada fator considerado, foram construidos indices de produçāo para quatro grupos de produtos: culturas anuais (algodāo herbáceo, amendoim, arroz, batata, feijāo, milho, soja, tomate e trigo), culturas perenes (algodāo arbóreo, banana, cacau, café, cana, laranja, mandioca e uva), culturas de mercado interno (arroz, banana, batata, feijăo, mandioca, milho, tomate, trigo e uva) e, culturas de mercado externo (algodão, amendoim, cacau, café, cana, laranja e soja).

\subsection{Cálculo das Variáveis}

\subsubsection{Produçăo Agrícola}

Os dados de quantidade produzida pelos

agricultores das classes econômicas agricultura e agropecuária foram obtidos dos Censos Agropecuários de 1970, 1975 e 1980, levantados pela Fundaçāo Instituto Brasileiro de Geografia e Estatistica.

Os preços recebidos pelos produtores tiveram como fonte a Fundaçăo Getúlio Vargas; em casos de ausência de dados en determinado Estado, foram utilizados os declarados nos censos Agropecuários (valor da produção 
dividido pela quantidade produzida). Para a banana, quando a quantidade produzida era informada em cachos e $\circ$ preço estava disponivel apenas em quilo ou dúzia, as informaçōes necessárias para as transformaçōes foram obtidas em AMARO (s.d.), MEDINA (1978) e no PROGNÓSTICO CENTRO-SUL (1976)(tabelas A.1.1 a A.1.34, no apêndice 1).

\subsubsection{Fator Trabalho}

- número de trabalhadores foi obtido dos Censos Agropecuários, a partir do quadro Pessoal Ocupado, que divide os trabalhadores em responsável e membros da familia que trabalhem efetivamente, empregados permanentes, empregados temporários, parceiros e outros. Foram coletados os dados referentes às classes econômicas agricultura e agropecuária. Os salários rurais utilizados foram os publicados pela Fundação Getúlio Vargas (salário médio mensal, para a categoria mensalista), a partir dos quais calcularam-se os salários anuais. As lacunas eventuais nas séries foram completadas com os dados dos Censos Agropecuários (massa de salários pagos mais o valor da quota-parte da produçăo entregue a parceiros, dividido pelo número total de assalariados, inclusive parceiros), como efetuado anteriormente por THAME, VICENTE e VICENTE (1987) (tabela A.1.35). 
Foram utilizados dados de áreas cultivadas com as culturas selecionadas, dos censos Agropecuários, para as classes econômicas agricultura e agropecuária. Pará o cálculo dos valores, foram utilizados os preços de arrendamentos de terras agricolas em dinheiro para lavouras, publicados pela fundaçāo Getúlio vargas. Quando nāo havia preços de um dos semestres, tomou-se o do outro, que foi deflacionado pela variação do valor médio de arrendamentos no Brasil, nesse período. Na ausência dos dois semestres, o ano mais próximo para o qual os dados estivessem disponíveis foi tomado e seu valor deflacionado também pela variaçāo do valor médio de arrendamentos no Brasil. Para o Estado do Amapá, tomou-se a relaçāo preço de terra/preço de arrendamento da Região Norte, que foi aplicada ao preço das terras do Estado a fim de obter o dado de 1980 (tabela A.1.36).

\subsubsection{Fator Fertilizante}

o montante gasto com fertilizantes foi obtido das Despesas declaradas nos Censos Agropecuários (despesas com adubos e corretivos, classes econômicas agricultura e agropecuária). Como nos Censos Agropecuários nāo constam as quantidades utilizadas, para calculá-las tomou-se como base as fórmulas médias utilizadas nas regiōes Norte, Centro e Sul, definidas pelo Sindicato da Indústria 
de Adubos e Corretivos Agricolas do Estado de Sāo Paulo. Para estimar o custo de uma tonelada da fórmula média, partiu-se dos preços publicados pela Fundaçäo Getúlio Vargas, referentes aos adubos super Fosfato simples ( $20 \%$ de P205), Sulfato de Amônia $(20,5 \%$ de $N)$ e cloreto de Potássio (60\% de K20). Com esses preços, construiram-se os das fórmulas médias regionais, naturalmente, sem considerar os preços de processamento das misturas. Como os preços de adubos são publicados mensalmente, para o cálculo das médias anuais utilizaram-se todas as informaçōes disponiveis para cada Estado. As lacunas nas séries foram preenchidas pelo dado mais próximo do mesmo Estado, deflacionado pela média dos preços do adubo no Brasil, no mesmo período; esporadicamente, tomou-se o preço do adubo em Estado limitrofe, no caso daquelas informaçōes estarem mui distantes no tempo (tabelas A.1.37 e A.1.38).

\subsubsection{Fator Máquinas}

Embora existam dados publicados sobre aluguel de trator, serviços de araçāo por empreitada, etc, năo estăo disponiveis estimativas confiáveis sobre áreas mecanizadas en cada Estado. Por isso, para o cálculo do fator máquinas, partiu-se dos valores totais de máquinas declarados nos Censos Agropecuários (quadro de Valor dos Bens, item Máquinas e Instrumentos Agrários). Para representar 0 número de máquinas existente em cada ano, 
tomou-se o número de tratores. O preço unitário do fator foi obtido por divisăo. Esses dados foram transformados em fluxo, adotando-se uma taxa de $12 \%$ de juros para representar o custo de oportunidade, 10\% de depreciaçăo, e incluindo as despesas declaradas nos Censos Agropecuários referentes a combustiveis e lubrificantes. Para o cálculo da depreciaçăo, năo estavam disponíveis maiores informaçöes que possibilitassem partir dos valores dos equipamentos novos. Por isso, partiu-se do valor atual estimado, assumindo-se em $10 \%$ o montante depreciado no ano e valor de sucata igual a zero. A taxa de $12 \%$ de juros foi considerada supondo que o preço do aluguel de máquinas no mercado remunere, alem da depreciaçăo e dos custos operacionais, tanto quanto uma aplicaçăo alternativa do capital. Para estimar a quantidade de combustiveis e lubrificantes dividiu-se o valor total gasto pelo preço do litro de óleo diesel publicado pela Fundaçăo Getúlio Vargas (tabelas A.1.39 e A.1.40).

\subsubsection{Fator Investimentos em Culturas Perenes}

Nos cálculos desse fator, utilizou-se, basicamente, o procedimento adotado por SILVA (1984). Para as culturas de café, laranja e uva, o custo de capital anual foi fixado em 5\% do custo de formaçāo, com base em sua vida produtiva; no caso da banana e da cana, pelo mesmo motivo, o custo do capital anual foi estimado em $10 \%$ e $22 \%$ 
dos respectivos custos de formação. A fonte dos dados de custo foi o trabalho de SILVA (1984), enquanto que as áreas cultivadas foram obtidas nos censos Agropecuários. O custo do capital anual para o algodão arbóreo foi estimado em $20 \%$ de seu custo de formação, cujo valor foi obtido, para 1970, em BANCO DO NORDESTE DO BRASIL (1964), e para 1975 e 1980, em BARREIRA (1977). Em ambos os casos os dados foram deflacionados para o ano base pelo Indice 2 de conjuntura Econômica. o cacau teve custo do capital anual estimado em 5\% do custo de formaçăo, cuja fonte foi NoGUEIRA (1986), com dados deflacionados similarmente aos de algodăo arbóreo (tabelas A.1.1 a A.1.7).

\subsubsection{Deficiências Hídricas e Geadas}

$$
\text { A deficiência híarica constitui }
$$

importante fator condicionante da produtividade agricola, e é definida como a diferença entre a evapotranspiraçāo potencial e a real. A evapotranspiraçăo potencial corresponde à água necessária devido às condiçóes de evaporaçăo do solo e transpiraçăo das plantas, enquanto a real corresponde à água efetivamente evapotranspirada. Temperatura e comprimento de dia determinam a evapotranspiraçăo potencial, e precipitação pluviométrica e água armazenada no solo condicionam a evapotranspiração real. Para o cálculo da deficiência nidrica, utilizou-se o balanço hídrico estimado através do método de THORNTWAITE e 
MATHER (1955) e o roteiro proposto por ORTOLANI et alii (1970). O cálculo foi efetuado sequencialmente, à nível de Estado, com a média das temperaturas e precipitaçōes pluviométricas de todos os postos publicados pelo Instituto Nacional de Meteorologia no Boietim Agroclimatológico, conforme descrito com detalhes em SILVA, VICENTE e CASER (1986). O período adotado foi o compreendido pelos meses de setembro e março, seguindo evidências anteriores obtidas por SILVA (1984) e SILVA, CASER e VICENTE (1984), uma vez que testes efetuados em outros periodos resultaram infrutiferos. O nivel de capacidade de armazenamento de água pelo solo considerado, foi o de $100 \mathrm{~mm}$ (tabela A.1.41). variáveis "dummies" representativas de geadas abrangentes foram introduzidas, quando da ocorrência do fenômeno, nos anos de 1969, 1970, 1974, 1975, 1979 e 1980 para os Estados de Minas Gerais, Săo Paulo, Paraná, Santa Catarina e Rio Grande do Sul.

\subsubsection{Educaçăo}

o nivel de educaçăo foi representado pela escolaridade média da polulaçăo rural (anos de escola das pessoas de 5 anos ou mais) provenientes dos censos Demográficos de 1970 e 1980 e calculados por THAME, VICENTE e VICENTE (1987). Para o ano de 1975, tomou-se para cada uma das dezoito classes em que o dado original é apresentado, a média do número de pessoas existentes nos 
Censos de 1970 e 1980. A partir dessa interpolaçăo foi calculada a média geral por Estado (tabela A.1.42).

\subsubsection{Assistência Técnica}

Como "proxy" para o percentual de

produtores que recebiam orientaçăo técnica, tomou-se o número de familias de produtores assistidos pelos serviços de extensăo rural publicado nos Anuários Estatisticos do Brasil, para os três anos anteriores aos do censo Agropecuário, que foram ponderados conforme proposto por PATRICK e KERHRBERG (1975) (pesos de $0,5,0,3$ e 0,2, respectivamente). Esses dados foram divididos pelo número de estabelecimentos levantados e, o resultado, multiplicado por cem. Para o Estado de Săo Paulo, os dados referentes ao ano base 1980, foram representados pelo numero de produtores assistidos em 1981, que foi conseguido junto à Coordenadoria de Assistência Técnica Integral (CATI) (tabela A.1.43).

2.4.10. Número de Artigos Cientificos Publicados

A medida da variável pesquisa para $\circ$ Estado de Săo Paulo e para as regiöes do Brasil, teve como fonte os trabalhos de SILVA (1987) e SILVA, FONSECA e MARTIN (1977). Os dados anuais, após tentativas frustradas de obtençăo através das publicaçŏes especializadas em 
bibliografia agrícola, foram estimados pelas taxas médias de crescimento em cada um dos períodos existentes nos trabalhos supracitados (ajuste exponencial). Para representar a influência da pesquisa desenvolvida em são Paulo sobre os demais Estados, tomou-se o numero de artigos publicados naquele Estado e referentes a até três culturas ou, às que representassem $80 \%$ do valor da prodưçăo de cada Unidade da Federaçăo (tabelas A.1.44. a A.1.46).

\subsubsection{Aptidão Edafo-Climática das Terras}

A qualidade das terra agrícolas de cada Estado foi estimada a partir do percentual de terras para lavoura com aptidão boa e regular com os niveis de manejo $A$ e B, publicado pelo Ministério da Agricultura (SERIE APTIDÄO AGRICOLA DAS TERRAS). OS dados referentes aOS Estados de Minas Gerais, Mato Grosso, Goiás e Distrito Federal, năo publicados na série, foram obtidos por regressäo, utilizando-se como variável independente a produtividade agricola estadual agregada no ano de 1957 , obtida no ANUARIO ESTATISTICO DO BRASIL (1960) . O ano de 1957 foi escolhido, similarmente ao critério utilizado por HUFFMANN (1972), por estar fora da série objeto de ajuste e por ser considerado "normal" comparativamente aos anteriores e posteriores, em termos de rendimentos médios das culturas (tabela A.1.47). 


\section{RESULTADOS E DISCUSSĂO}

Este capitulo se subdivide em três partes. A primeira trata da análise das evoluçōes da produçăo agrícola, do uso e da produtividade de fatores. A segunda analisa os modelos ajustados e a terceira consiste no cálculo de retornos marginais aos investimentos em educaçăo, assistência técnica e pesquisa agrícola. A inclusăo da primeira parte é importante para a compreensāo das demais.

3.1. Evolução da Produçāo Agrícola, do Uso e da Produtividade de Fatores

3.1.1. Evoluçāo da Produçăo Agricola 
Entre 1970 e 1975, a produção agrícola agregada cresceu $44 \%$ no Brasil, com as Regiões sul ( $+72 \%)$, Centro-Oeste $(+68 \%)$, Nordeste $(+47 \%)$ e Norte $(+44 \%)$ apresentando os maiores incrementos. A Região sudeste apresentou ganhos de $11 \%$ e, com exceçăo do ístado de são Paulo, todos os demais Estados desta Regiāo sofreram reduçăo de produçăo. Nesses anos, deve ser idestacada a performance do Estado do Paraná, que experimentou aumento de $123 \%$ no valor da produçăo, superando săo Paulo como principal centro produtor do Pais, embora 0 maior crescimento tenha sido o de Rondônia ( $+323 \%$ ) (tabela 1 ).

As culturas anuais tiveram, nesse período, comportamento similar, com crescimento de $37 \%$ impulsionado, principalmente, pelas Regiōes Centro-oeste $(+73 \%)$, Sul $(+51 \%)$, Norte $(+45 \%)$ e Nordeste $(+38 \%)$, enquanto a Região Sudeste manteve-se praticamente estável $(-1 \%)$. Já as culturas perenes apresentaram crescimento superior (61\%) e, no caso, a Regiāo sul (+299\%) foi a principal responsável devido ao extraordinário crescimento do Estado do Paraná, seguida pelas Regiões Nordeste ( $+56 \%)$, Norte e Sudeste $(+25 \%)$; os niveis de produção do Centro-oeste foram os mesmos de 1970 (tabelas 2 e 3).

- crescimento das culturas de mercado interno foi substancialmente menor do que o das culturas de mercado externo (15\% e $89 \%$, respectivamente), e concentrou-se nas Regiöes Centro-Oeste $(+47 \%)$, Norte $(+42 \%)$ 
31.

TABELA 1. - Evolução da Produção Agrícola nas Unidades da Federaçāo, Brasil, 1970-80 (1).

\begin{tabular}{|c|c|c|c|c|c|c|}
\hline \multirow[b]{2}{*}{ Unidade da Federaçāo } & \multicolumn{3}{|c|}{ Indice 1} & \multicolumn{3}{|c|}{ Indice 2} \\
\hline & 1970 & 1975 & 1980 & 1970 & 1975 & 1980 \\
\hline Dorizanomdato & 100 & 177 & 120 & 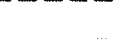 & $-T_{0}$ & 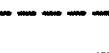 \\
\hline $\begin{array}{l}\text { Reglao Nordeste } \\
\text { Alagoás }\end{array}$ & 100 & $\begin{array}{l}147 \\
167\end{array}$ & $\begin{array}{l}129 \\
200\end{array}$ & $\overline{51}$ & $\overline{86}$ & $10 \overline{3}$ \\
\hline Bahia & 100 & 108 & 97 & 205 & 222 & 199 \\
\hline Ceará & 100 & 277 & 155 & 37 & 101 & 57 \\
\hline Paraiba & 100 & 229 & 150 & 28 & 64 & 42 \\
\hline Pernambuco & 100 & 130 & 132 & 91 & , 119 & 121 \\
\hline Piauí & 100 & 230 & 125 & 13 & 31 & 17 \\
\hline Rio Grande do Norte & 100 & 253 & 172 & 12 & 29 & 20 \\
\hline Sergipe & 100 & 124 & 139 & 14 & 17 & 19 \\
\hline Maranhão & 100 & 131 & 135 & 73 & 96 & 99 \\
\hline Regiäo Norte & 100 & 144 & 178 & - & - & - \\
\hline Acre & 100 & 89 & 94 & 6 & 6 & 6 \\
\hline Amazonas & 100 & 107 & 114 & 15 & 16 & 17 \\
\hline Amapá & 100 & 170 & 114 & 1 & 2 & 1 \\
\hline Pará & 100 & 149 & 179 & 25 & 38 & 46 \\
\hline Roraima & 100 & 184 & 408 & 1 & 1 & 3 \\
\hline Rondônia & 100 & 423 & 711 & 3 & 14 & 24 \\
\hline Regiăo Centro-Oeste & 100 & 168 & 242 & - & - & 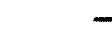 \\
\hline Mato Grosso (2) & 100 & 245 & 393 & 49 & 121 & 194 \\
\hline Distrito Federal & 100 & 170 & 429 & 1 & 1 & 3 \\
\hline Goiás & 100 & 129 & 165 & 100 & 129 & 165 \\
\hline Regiāo Sudeste & 100 & 111 & 150 & - & - & - \\
\hline Minas Gerais & 100 & 93 & 143 & 198 & 184 & 283 \\
\hline Espirito Santo & 100 & 86 & 134 & 46 & 40 & 62 \\
\hline Rio de Janeiro & 100 & 83 & 83 & 87 & 72 & 72 \\
\hline Sāo Paulo & 100 & 123 & 164 & 568 & 702 & 932 \\
\hline Regiāo Sul & 100 & 172 & 174 & - & - & - \\
\hline Paraná & 100 & 223 & 213 & 335 & 748 & 713 \\
\hline Santa Catarina & 100 & 114 & 140 & 84 & 95 & 117 \\
\hline Kio Grande do sul & 100 & 146 & 151 & 456 & 663 & 690 \\
\hline Brasil & 100 & 144 & 160 & - & - & -7 \\
\hline
\end{tabular}

(1) Indices Fisher encadeados; a base do índice 1 é o próprio Estado em 1970 e a base do índice 2 é a média dos Estados também em 1970.

(2) Inclui Mato Grosso do Sul.

FONTE: Elaborada a partir de dados básicos da Fundaçäo Instituto Brasileiro de Geografia e Estatistica (IBGE), da Fundaçăo Getúlio vargas (FGV) e do Instituto de Economia Agrícola (IEA). 
TABELA 2. - Evolução da Produção de Culturas Anuais nas Unidades da Federaçăo, Brasil, 1970-80 (1).

\begin{tabular}{|c|c|c|c|c|c|c|}
\hline \multirow{2}{*}{ Unidade da Federaçăo } & \multicolumn{3}{|c|}{ Indice 1} & \multicolumn{3}{|c|}{ Indice 2} \\
\hline & 1970 & 1975 & 1980 & 1970 & 1975 & 1980 \\
\hline-- & & & & & & \\
\hline Regiăo Nordeste & 100 & 138 & 106 & - & - & - \\
\hline Alagoas & 100 & 202 & 75 & 16 & 32 & it \\
\hline Bahía & 100 & 81 & 84 & 160 & 130 & 134 \\
\hline Ceará & 100 & 273 & 137 & 34 & 92 & 46 \\
\hline Paraíba & 100 & 242 & 130 & 23 & 56 & 30 \\
\hline Pernambuco & 100 & 136 & 92 & 53 & 72 & 49 \\
\hline Piauí & 100 & 210 & 119 & 16 & 34 & 20 \\
\hline Rio Grande do Norte & 100 & 233 & 157 & 10 & 22 & 15 \\
\hline Sergipe & 100 & 116 & 74 & 12 & 14 & 9 \\
\hline Maranhăo & 100 & 131 & 136 & 100 & 131 & 136 \\
\hline Regiāo Norte & 100 & 145 & 173 & - & - & - \\
\hline Acre & 100 & 87 & 86 & 8 & 7 & 7 \\
\hline Amazonas & 100 & 121 & 111 & 17 & 21 & 19 \\
\hline Amapá & 100 & 162 & 112 & 1. & 2 & 2 \\
\hline Pará & 100 & 149 & 177 & 32 & 47 & 56 \\
\hline Roraima & 100 & 174 & 436 & 1 & 1 & 3 \\
\hline Rondônia & 100 & 445 & 558 & 4 & 19 & 24 \\
\hline Regiāo Centro-Oeste & 100 & 173 & 244 & - & - & - \\
\hline Mato Grosso (2) & 100 & 252 & 395 & 66 & 167 & 261 \\
\hline Distrito Federal & 100 & 167 & 536 & 1 & 1 & 3 \\
\hline Goìás & 100 & 133 & 167 & 131 & 175 & 220 \\
\hline Regiăo Sudeste & 100 & 99 & 123 & - & - & - \\
\hline Minas Gerais & 100 & 95 & 132 & 183 & 174 & 241 \\
\hline Espirito Santo & 100 & 93 & 97 & 21 & 20 & 20 \\
\hline Rio de Janeiro & 100 & 55 & 58 & 33 & 18 & 19 \\
\hline São Paulo & 100 & 104 & 125 & 435 & 454 & 542 \\
\hline Regiăo Sul & 100 & 151 & 174 & - & - & - \\
\hline Paraná & 100 & 163 & 207 & 427 & 696 & 886 \\
\hline Santa Catarina & 100 & 119 & 145 & 108 & 128 & 157 \\
\hline Rio Grande do Sul & 100 & 149 & 156 & 607 & 905 & 948 \\
\hline Brasil & 100 & 137 & 154 & - & - & - \\
\hline
\end{tabular}

(1) Indices Fisher encadeados; a base do indice 1 é 0 próprio Estado em 1970 e a base do indice 2 é a média dos Estados também em 1970.

(2) Inclui Mato Grosso do sul.

FONTE: Elaborada a partir de dados básicos da Fundação Instituto Brasileiro de Geografia e Estatistica (IBGE), da Fundaçäo Getúlio vargas (FGV) e do Instituto de Economia Agricola (IEA). 
TABELA 3. - Evolução da Produçāo de Culturas Perenes nas Unidades da Federaçăo, Brasil, 1970-80 (1).

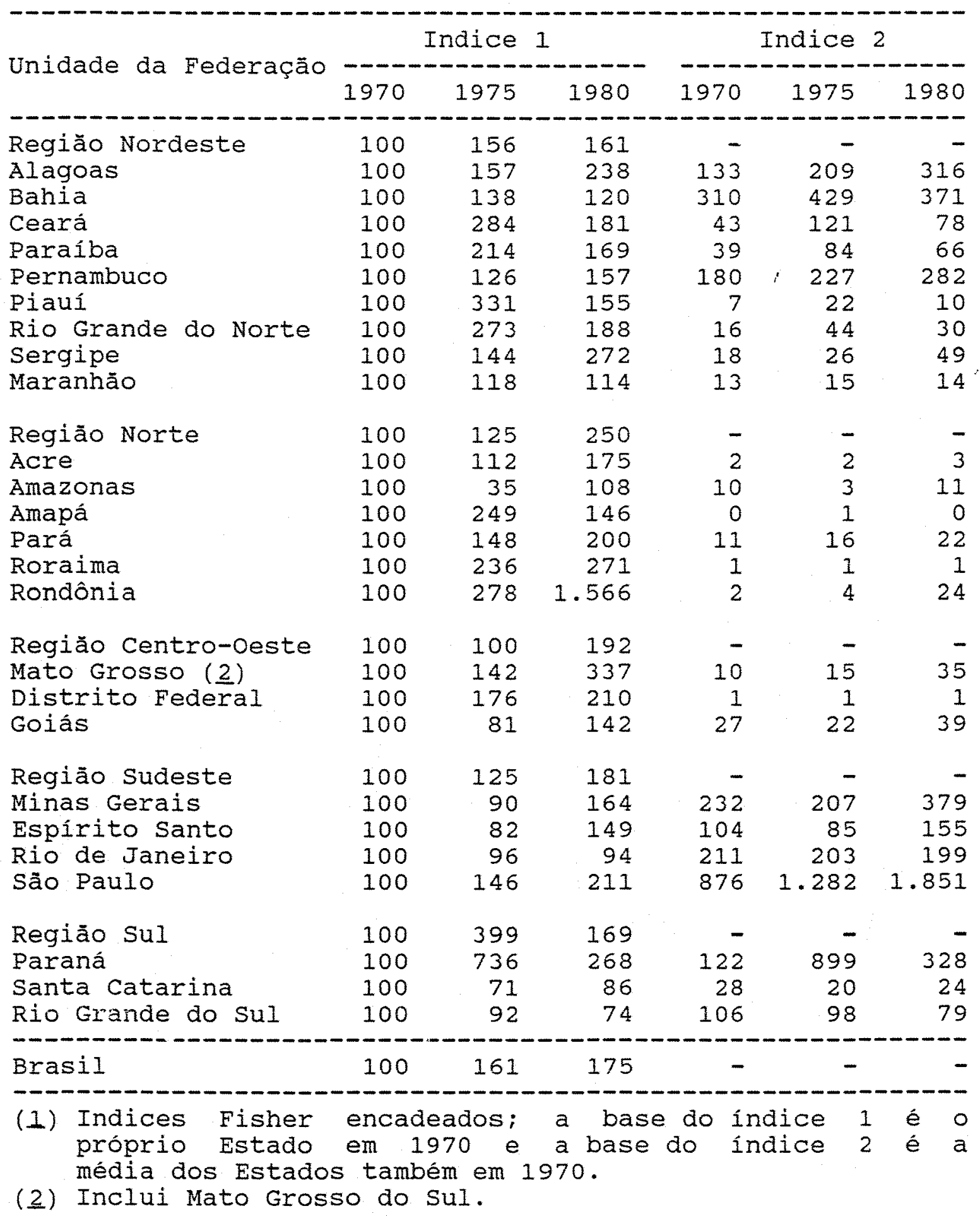

FONTE: Elaborada a partir de dados básicos da Fundação Instituto Brasileiro de Geografia e Estatistica (IBGE), da Fundaçāo Getúlio vargas (FGV) e do Instituto de Economia Agricola (IEA). 
e Nordeste ( $+33 \%)$, ao lado de relativa estagnação nas Regiōes Sudeste $(-2 \%)$ e ligeiro crescimento da Região Sul $(+6 \%)$ Esta última Regiāo liderou os aumentos de produçāo nas culturas de mercado externo ( $+277 \%)$, seguida pelo Centro-Oeste $(+190 \%)$, Norte $(+100 \%)$, Nordeste $(+57 \%)$ e Sudeste $(+21 \%)$. Nos dois casos, com exceção de são paulo, os Estados da Região Sudeste experimentaram deicréscimo ou estagnaçăo da produção (tabelas 4 e 5).

Entre 1975 e 1980 a produção agrícola também aumentou, embora menos (11\% no segundo período). A Regiăo Nordeste sofreu considerável queda de produção $(-12 \%)$ apesar da do Estado de Alagoas ter aumentado substancialmente. A Regiăo centro-oeste teve o maior crescimento $(+44 \%)$, seguida pela Regiăo sudeste ( $+35 \%)$, com São Paulo voltando à posição de liderança na produção agrícola devido aos maus resultados obtidos pelo paraná, responsáveis pela estagnação da Regiăo sul (+1\%). A Região Norte apresentou nesses anos, crescimento de $23 \%$ na produçāo agrícola (tabela 1 ).

As culturas anuais cresceram cerca de $13 \%$ entre 1975 e 1980 , resultado semelhante ao das culturas perenes, cujo acréscimo foi de $9 \%$, motivado pelos maus resultados do Estado do Paraná, que caiu de segundo para quarto lugar em importância para esse grupo de culturas. Nas Regiōes, as variaçōes foram as seguintes: Nordeste, $-23 \%$ e $+3 \%$; Norte, $+19 \%$ e $+100 \%$; Centro-Oeste, $+41 \%$ e +92\%; Sudeste, $+23 \%$ e $+45 \%$; , Sul, $+15 \%$ e $-58 \%$ (tabelas 2 e 3 ). 
TABELA 4. - Evolução da Produção de Culturas de Mercado Interno nas Unidades da Federaçāo, Brasil, 1970-80 (1).

\begin{tabular}{|c|c|c|c|c|c|c|}
\hline \multirow[b]{2}{*}{ Unidade da Federaçāo } & \multicolumn{3}{|c|}{ Indice 1} & \multicolumn{3}{|c|}{ Indice 2} \\
\hline & 1970 & 1975 & 1980 & 1970 & 1975 & 198 \\
\hline Regiāo Nordeste & 100 & 133 & 107 & - & - & \\
\hline Alagoas & 100 & 172 & 73 & 21 & 36 & \\
\hline Bahia & 100 & 85 & 92 & 187 & 160 & \\
\hline Ceará & 100 & 230 & 114 & 45 & 104 & \\
\hline Paraíba & 100 & 216 & 114 & 29 & 63 & \\
\hline Pernambuco & 100 & 133 & 108 & 69 & 92 & \\
\hline Piauí & 100 & 204 & 114 & 19 & 40 & \\
\hline Rio Grande do Norte & 100 & 163 & 99 & 13 & 21 & \\
\hline Sergipe & 100 & 113 & 79 & 15 & 16 & \\
\hline Maranhăo & 100 & 130 & 135 & 117 & 152 & \\
\hline Regiāo Norte & 100 & 142 & 171 & - & - & \\
\hline Acre & 100 & 86 & 90 & 10 & 9 & \\
\hline Amazonas & 100 & 110 & 122 & 23 & 25 & \\
\hline Amapá & 100 & 170 & 113 & 2 & 3 & \\
\hline Pará & 100 & 147 & 179 & 40 & 58 & \\
\hline Roraima & 100 & 163 & 413 & 1 & 2 & \\
\hline Rondônia & 100 & 441 & 533 & 5 & 22 & \\
\hline Regiāo Centro-oeste & 100 & 147 & 188 & - & - & \\
\hline Mato Grosso (2) & 100 & 194 & 289 & 60 & 115 & \\
\hline Distrito Federal & 100 & 170 & 324 & 1 & 2 & \\
\hline Goiás & 100 & 127 & 146 & 147 & 187 & \\
\hline Regiāo Sudeste & 100 & 98 & 117 & - & - & \\
\hline Minas Gerais & 100 & 90 & 119 & 214 & 192 & \\
\hline Espirito Santo & 100 & 96 & 103 & 30 & 28 & \\
\hline Rio de Janeiro & 100 & 61 & 61 & 58 & 36 & \\
\hline Sāo Paulo & 100 & 111 & 127 & 317 & 352 & \\
\hline Regiāo Sul & 100 & 106 & 113 & - & - & \\
\hline Paraná & 100 & 114 & 131 & 359 & 410 & \\
\hline Santa Catarina & 100 & 105 & 118 & 127 & 133 & \\
\hline Rio Grande do Sul & 100 & 102 & 100 & 594 & 606 & \\
\hline Brasil & 100 & 115 & 121 & - & - & \\
\hline
\end{tabular}

(1) Indices Fisher encadeados; a base do índice 1 é 0 próprio Estado em 1970 e a base do índice 2 é a média dos Estados também em 1970.

(2) Inclui Mato Grosso do sul.

FONTE: Elaborada a partir de dados básicos da Fundaçāo Instituto Brasileiro de Geografia e Estatistica (IBGE), da Fundaçāo Getúlio vargas (FGV) e do Instituto de Economia Agricola (IEA). 
TABELA 5. - Evolução da Produçāo de Culturas de Mercado Externo nas Unidades da Federação, Brasil, 1970-80 (1).

\begin{tabular}{|c|c|c|c|c|c|c|}
\hline \multirow{2}{*}{ Unidade da Federaçāo } & \multicolumn{3}{|c|}{ Indice 1} & \multicolumn{3}{|c|}{ Indice 2} \\
\hline & 1970 & 1975 & 1980 & 1970 & 1975 & 1980 \\
\hline Região Nordeste & 100 & 157 & 212 & - & - & - \\
\hline Alagoas & 100 & 165 & 244 & 99 & 163 & 241 \\
\hline Bahía & 100 & 118 & 222 & 234 & 276 & 519 \\
\hline Ceará & 100 & 414 & 271 & 23 & 95 & 62 \\
\hline Paraíba & 100 & 248 & 194 & 27 & 66 & 52 \\
\hline Pernambuco & 100 & 127 & 150 & 127 & 161 & 191 \\
\hline Piauí & 100 & 399 & 194 & 4 & 17 & 8 \\
\hline Rio Grande do Norte & 100 & 418 & 303 & 9 & 40 & 29 \\
\hline Sergipe & 100 & 152 & 288 & 13 & 19 & 37 \\
\hline Maranhāo & 100 & 137 & 129 & 6 & 8 & 7 \\
\hline Regiāo Norte & 100 & 200 & 600 & - & - & - \\
\hline Acre & 100 & 260 & 295 & 0 & 1 & 1 \\
\hline Amazonas & 100 & 68 & 60 & 3 & 2 & 2 \\
\hline Amapá & 100 & 167 & 163 & 0 & 0 & 0 \\
\hline Pará & 100 & 199 & 258 & 4 & 7 & 10 \\
\hline Roraima & 100 & 636 & 143 & 0 & 1 & 0 \\
\hline Rondônia & 100 & 224 & 2.997 & 1 & 2 & 24 \\
\hline Regiāo Centro-oeste & 100 & 290 & 565 & - & - & - \\
\hline Mato Grosso (2) & 100 & 402 & 720 & 34 & 136 & 243 \\
\hline Distrito Federal & 100 & 168 & 1.313 & 0 & 0 & 3 \\
\hline Goiás & 100 & 143 & 347 & 27 & 38 & 92 \\
\hline Região Sudeste & 100 & 121 & 178 & - & - & - \\
\hline Minas Gerais & 100 & 100 & 193 & 173 & 173 & 333 \\
\hline Espirito Santo & 100 & 77 & 179 & 72 & 56 & 129 \\
\hline Rio de Janeiro & 100 & 101 & 101 & 131 & 132 & 133 \\
\hline São Paulo & 100 & 130 & 185 & 960 & 1.250 & 1.777 \\
\hline Regiāo Sul & 100 & 377 & 363 & - & - & - \\
\hline Paraná & 100 & 436 & 367 & 297 & 1.294 & 1.090 \\
\hline Santa Catarina & 100 & 224 & 408 & 16 & 37 & 67 \\
\hline Rio Grande do Sul & 100 & 316 & 356 & 241 & 760 & 856 \\
\hline Brasil & 100 & 189 & 236 & - & - & - \\
\hline
\end{tabular}

(1) Indices Fisher encadeados; a base do indice 1 é 0 próprio Estado em 1970 e a base do indice 2 é a média dos Estados também em 1970.

(2) Inclui Mato Grosso do Sul.

FONTE: Elaborada a partir de dados básicos da Fundação Instituto Brasileiro de Geografia e Estatistica (IBGE), da Fundação Getúlio vargas (FGV) e do Instituto de Economia Agrícola (IEA). 
As culturas de mercado interno estiveram praticamente estagnadas no periodo $1975-80$ ( $+5 \%)$, enquanto que as de mercado externo cresceram 25\%. A nivel de regiāo, observaram-se as seguintes alteraçōes: Nordeste, $-20 \%$ e $+72 \%$; Norte, $+18 \%$ e $+208 \%$; Centro-Oeste, $+28 \%$ e $+94 \%$, Sudeste, $+19 \%$ e $+47 \%$; e, Sul, $+6 \%$ e $-4 \%$, respectivamente (tabelas 4 e 5 ).

Tomando-se o período 1970 a 1980, observa-se aumento de $60 \%$ na produçāo agrícola agregada, com os percentuais mais expressivos estando nas Regiöes Centro-Oeste, Norte e sul $(+142 \%, 78 \%$ e $+74 \%$, respectivamente) e os menores aumentos no sudeste ( $+50 \%$ e Nordeste $(+29 \%)$ (tabela 1). As culturas perenes contribuiram mais para esse incremento do que as anuais ( $+75 \%$ e $+45 \%$, respectivamente). A nível de regiào, os Indices evoluiram da seguinte forma: Nordeste, $+61 \%$ e $+6 \%$; Norte, $+150 \%$ e $+73 \%$; Centro-oeste, $+92 \%$ e $+144 \%$; Sudeste, $+81 \%$ e $+23 \%$; e, Sul, $+69 \%$ e $+74 \%$ (tabelas 2 e 3). As culturas de mercado externo cresceram $136 \%$ no periodo 1970-80, contra um crescimento de apenas $21 \%$ das culturas de mercado interno; nas Regioes, os indices assim evoluiram: Nordeste, $+112 \%$ e $+7 \%$; Norte, $+500 \%$ e $+71 \%$; Centro-Oeste, $+465 \%$ e $+88 \%$; Sudeste, $+78 \%$ e $+17 \%$; e, sul, $+263 \%$ e $+13 \%$ (tabelas 4 e 5). Segundo ANJOS, YAMAGUISHI e CARVALHO (1988), o retorno do investimento em modernização é maior nas culturas de exportação. o esforço concentrado da pesquisa em produtos de exportaçăo faz com que a 
produtividade dos produtos exportáveis se eleve ao longo do tempo, fato esse aliado ao estimulo de preço no mercado externo, o que reforça a vantagem comparativa dos investimentos em culturas de exportaçāo e resulta no crescimento de sua produçăo.

3.1.2. Evolução do Uso de Fatores

Diversos estudos indicam que o crescimento da produçăo, no Brasil, vem ocorrendo desce o início da década de sessenta até o inicio da de oitenta, principalmente pelo aumento da área cultivada (como, por exemplo, PATRICK, 1975, CUNHA e DAGUER, 1982 e ANJOS, YAMAGUISHI e CARVALHO, 1988). POr outro lado, a partir da década de sessenta, uma política de investimentos voltada para a indústria de insumos modernos foi intensificada, propiciando uma grande expansăo nesse mercado, facilitada também pela institucionalização do crédito rural, em meados da mesma década (BARROS, 1979). Com relaçăo à populaçāo rural, concomitantemente ao vertiginoso crescimento da populaçăo brasileira (25,9 milhöes de pessoas entre 1970 e 1980), ocorreu um vigoroso processo de urbanização que significou um decréscimo, em termos absolutos, da população rural (a uma taxa de crescimento anual de $-0,63 \%$ ).

No período 1970 a 1975 a utilizaçăo dos fatores terra, trabalho, fertilizantes, máquinas e 
investimentos em culturas perenes (referido, daqui em diante, como agregado), cresceu $18 \%$, com as Regiões Norte $(+67)$, Centro-oeste $(+42 \%)$ e sul (+27\%) apresentando os resultados mais expressivos, enquanto a Região Nordeste cresceu $20 \%$ e a Regiào sucieste sofreu queda de $3 \%$. Entre 1975 e 1980, O uso desses fatores manteve-se praticamente estagnado $(+3 \%)$, com aumentos nas Regiŏes centro-oeste $(+22 \%)$, Sudeste $(+19 \%)$ e Norte $(+19 \%)$, e diminuiçōes nas Regiōes SuI $(-2 \%)$ e Nordeste $(-7 \%)$. Tomando-se o período 1970-80, observa-se aumento de $22 \%$, com incremento no uso de fatores em todas as Regiöes (Norte $+100 \%$, Centro-Oeste $+75 \%$, Sul $+24 \%$, Sudeste $+15 \%$ e, Nordeste $+12 \%$ ) (tabela 6).

o fator terra teve seu uso aumentado em $24 \%$ entre 1970 e 1975, e os maiores incrementos ocorreram nas Regiōes Centro-Oeste $(+56 \%)$, Norte $(+50 \%)$ e Nordeste $(+44 \%)$ além de um aumento também significativo na Regiào Sul (+24\%); a Regiăo sudeste apresentou retraçăo de $6 \%$ na área dessas culturas. Da mesma forma que o agregado de fatores, a utilizaçăo da terra manteve-se praticamente estável entre 1975 e 1980 ( $+3 \%)$, com as Regiós em expansão da fronteira agrícola respondendo pelos maiores aumentos (Norte $+26 \%$, Centro-ceste $+24 \%$ ). A Regiāo sudeste apresentou considerável incremento de área $(+16 \%)$, provável reflexo do Proálcool e da expansão da citricultura em sāo Paulo; a Regiăo sul permaneceu relativamente estagnada $(+4 \%)$, enquanto que o Nordeste sofreu decréscimo $(-17 \%)$. Tomando-se $\circ$ periodo 1970-80 as áreas exploradas com as 
40 .

TABELA 6. - Evoluçăo do uso de Fatores nas unidades da Federação, Brasil, 1970-80 (1).

\begin{tabular}{|c|c|c|c|c|c|c|}
\hline \multirow{2}{*}{ Unidade da Federaçăo } & \multicolumn{3}{|c|}{ Indice 1} & \multicolumn{3}{|c|}{ Indice 2} \\
\hline & 1970 & 1975 & 1980 & 1970 & 1975 & 1980 \\
\hline Reqiäo Nordeste & 100 & 120 & 172 & - & - & \\
\hline Alagoas & 100 & 128 & 138 & 69 & 88 & 95 \\
\hline Bahia & 100 & 109 & 109 & 274 & 298 & 300 \\
\hline Ceará & 100 & 114 & 100 & 93 & 106 & 93 \\
\hline Paraíba & 100 & 147 & 101 & 56 & 83 & 57 \\
\hline Pernambuco & 100 & 105 & 98 & 139 & 146 & 136 \\
\hline Piauí & 100 & 130 & 121 & 23 & 30 & 28 \\
\hline Rio Grande do Norte & 100 & 139 & 130 & 31 & 43 & 40 \\
\hline Sergipe & 100 & 107 & 89 & 25 & 27 & 22 \\
\hline Maranhão & 100 & 138 & 127 & 146 & 201 & 184 \\
\hline Região Norte & 100 & 167 & 200 & - & - & - \\
\hline Acre & 100 & 126 & 166 & 6 & 7 & 10 \\
\hline Amazonas & 100 & 155 & 161 & 13 & 21 & 22 \\
\hline Amapá & 100 & 192 & 131 & 0 & 1 & 1 \\
\hline Pará & 100 & 143 & 167 & 35 & 50 & 58 \\
\hline Roraima & 100 & 289 & 328 & 0 & 1 & 1 \\
\hline Rondônia & 100 & 645 & 942 & 2 & 10 & 15 \\
\hline Região Centro-oeste & 100 & 142 & 175 & - & - & - \\
\hline Mato Grosso (2) & 100 & 174 & 240 & 54 & 94 & 130 \\
\hline Distrito Federal & 100 & 106 & 295 & 1 & 1 & 3 \\
\hline Goiás & 100 & 120 & 126 & 78 & 93 & 98 \\
\hline Região sudeste & 100 & 97 & 115 & - & - & - \\
\hline Minas Gerais & 100 & 103 & 117 & 196 & 201 & 230 \\
\hline Espirito Santo & 100 & 97 & 127 & 40 & 38 & 50 \\
\hline Rio de Janeiro & 100 & 91 & 95 & 42 & 38 & 40 \\
\hline Sāo Paulo & 100 & 95 & 115 & 367 & 347 & 421 \\
\hline Regiäo Sul & 100 & 127 & 124 & - & - & - \\
\hline Paraná & 100 & 120 & 113 & 376 & 452 & 426 \\
\hline Santa Catarina & 100 & 107 & 114 & 121 & 130 & 139 \\
\hline Rio Grande do Sul & 100 & 142 & 142 & 314 & 445 & 444 \\
\hline Erasil & 100 & 118 & 122 & - & - & \\
\hline
\end{tabular}

(1) Indices Fisher encadeados; inclui os fatores terra, trabalho, fertilizantes, máquinas e investimentos em culturas perenes. A base do indice 1 é 0 próprio Estado em 1970 e a base do indice 2 é a médía dos Estados também em 1970.

(2) Inclui Mato Grosso do Sul.

FONTE: Elaborada a partir de dados básicos da Fundaçāo Instituto Brasileiro de Geografia e Estatistica (IBGE), da Fundação Getúlio vargas (FGV) e do Instituto de Economia Agrícola (IEA). 
culturas consideradas neste estudo cresceram $28 \%$, com todas as Regiōes apresentando aumento (Centro-Oeste $+94 \%$, Norte $+88 \%$, Sul $+29 \%$, Nordeste $+19 \% e$, Sudeste $+9 \%$ ) (tabela 7 ).

Entre 1970 e 1975 o uso do fator trabalho cresceu $14 \%$ no Brasil, com us naiores incrementos verificando-se nas Regiöes Norte $(+56)$ e Centro-Oeste $(+21) ;$ as Regiōes Sul e Nordeste apresentaram o mesmo crescimento $(+16 \%)$, enquanto a Regiāo sudeste diminuiu o uso do fator $(-6 \%)$. Já entre 1975 e 1980 constatou-se uma diminuiçāo no uso do trabalho (-10\%), influenciada pelas Regioes sul (-19\%), Centro-Oeste $(-17 \%)$ e Nordeste $(-11 \%)$, além de estabilizaçāo na Regiāo sudeste; a exceçāo foi a Regiāo Norte, com aumento de 12\%. No período 1970 a 1980 , a utilização de trabalho manteve-se praticamente estável (+3\%), com as Regiöes apresentando comportamento diferenciado (aumento nas Regiòes Norte, $+76 \%$ e Nordeste, +3\%; níveis estáveis na Regiāo centro-oeste, e diminuições de $6 \%$ nas Regioes sul e Sudeste) (tabela 8).

Para o fator fertilizantes, os indices construídos excluem o Território do Acre, pela inexistência de dados de quantidade para o ano de 1970. Entre 2970 e 1975 os indices indicam aumento de 25\%, com as Regiōes Centro-oeste $(+350 \%)$, Nordeste $(+51 \%)$, Sul $(+44 \%)$ e Norte $(+25 \%)$ apresentando crescimento positivo, enquanto a Regiào Sudeste diminuiu o uso do fator (-8\%). No periodo 1975-80 houve uma intensificaçăo no uso desse fator, com os indices indicando aumento de $92 \%$ e marcas significativas em todas 
42 .

TABELA 7. - Evoluçāo do Uso do Fator Terra nas unidades da Federaçăo, Brasil, 1970-80 (1).

\begin{tabular}{|c|c|c|c|c|c|c|}
\hline \multirow{2}{*}{ Unidade da Federação } & \multicolumn{3}{|c|}{ Indice 1} & \multicolumn{3}{|c|}{ Indice 2} \\
\hline & 1970 & 1975 & 1980 & 1970 & 1975 & 1980 \\
\hline Regia Nordeste & 100 & 144 & 119 & - & - & \\
\hline Alagoas & 100 & 209 & 154 & 31 & 65 & $=$ \\
\hline Bahía & 100 & 88 & 96 & 172 & 151 & 166 \\
\hline Ceará & 100 & 233 & 168 & 71 & 166 & 119 \\
\hline Paraiba & 100 & 200 & 123 & 46 & 92 & 5 \\
\hline Pernambuco & 100 & 120 & 98 & 96 & 114 & 94 \\
\hline Piauí & 100 & 170 & 123 & 35 & 59 & 4 \\
\hline Rio Grande do Norte & 100 & 313 & 197 & 19 & 61 & 38 \\
\hline Sergipe & 100 & 133 & 73 & 10 & 13 & 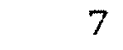 \\
\hline Maranhão & 100 & 112 & 116 & 97 & 108 & 112 \\
\hline Regiào Norte & 100 & 150 & 188 & - & - & \\
\hline Acre & 100 & 96 & 137 & 3 & 3 & \\
\hline Amazonas & 100 & 115 & 163 & 7 & 7 & 10 \\
\hline Amapá & 100 & 141 & 98 & 1 & 1 & \\
\hline Pará & 100 & 141 & 159 & 33 & 47 & 53 \\
\hline Roraima & 100 & 245 & 429 & 0 & 1 & \\
\hline Rondônia & 100 & 491 & 793 & 3 & 13 & 21 \\
\hline Região Centro-oeste & 100 & 156 & 194 & - & - & \\
\hline Mato Grosso (2) & 100 & 234 & 328 & 61 & 142 & 19 \\
\hline Distrito Federal & 100 & 108 & 510 & 0 & 0 & \\
\hline Goiás & 100 & 121 & 132 & 130 & 158 & 172 \\
\hline Regiào Sudeste & 100 & 94 & 109 & - & - & \\
\hline Minas Gerais & 100 & 91 & 107 & 213 & 194 & 22 \\
\hline Espirito Santo & 100 & 85 & 99 & 47 & 40 & 47 \\
\hline Rio de Janeiro & 100 & 77 & 79 & 38 & 29 & 30 \\
\hline São Paulo & 100 & 98 & 114 & 359 & 353 & 41 \\
\hline Regiào Sul & 100 & 124 & 129 & - & - & \\
\hline Paraná & 100 & 132 & 141 & 427 & 564 & 60 \\
\hline Santa Catarina & 100 & 94 & 113 & 93 & 88 & 10 \\
\hline Rio Grande do sul & 100 & 123 & 122 & 509 & 628 & 623 \\
\hline Brasil & 100 & 124 & 128 & - & - & \\
\hline
\end{tabular}

(1) Indices simples de área cultivada; a base do indice 1 é - próprio Estado em 1970 e a base do índice 2 é a média dos Estados também en 1970.

(2) Inclui Mato Grosso do Sul.

FONTE: Elaborada a partir de dados básicos da Fundaçăo Instituto Brasileiro de Geografia e Estatistica (IBGE), da Fundação Getúlio vargas (FGV) e do Instituto de Economia Agricola (IEA). 
TABELA 8. - Evoluçāo do Uso do Fator Trabalho nas unidades da Federação, Brasil, 1970-80 (1).

\begin{tabular}{|c|c|c|c|c|c|c|}
\hline \multirow{2}{*}{ Unidade da Federação } & \multicolumn{3}{|c|}{ Indice 1} & \multicolumn{3}{|c|}{ Indice 2} \\
\hline & 1970 & 1975 & 1980 & 1970 & 1975 & 1980 \\
\hline Região Nordeste & 100 & 116 & 103 & - & - & - \\
\hline Alagoas & 100 & 118 & 115 & 69 & 81 & 79 \\
\hline Bahia & 100 & 111 & 107 & 308 & 342 & 331 \\
\hline Ceará & 100 & 100 & 85 & 160 & 160 & 136 \\
\hline Paraíba & 100 & 140 & 88 & 95 & 133 & 83 \\
\hline Pernambuco & 100 & 99 & 88 & 182 & 181 & 160 \\
\hline Piaui & 100 & 125 & 117 & 76 & 95 & 89 \\
\hline Rio Grande do Norte & 100 & 122 & 112 & 49 & 60 & 55 \\
\hline Sergipe & 100 & 105 & 83 & 41 & 43 & 34 \\
\hline Maranhāo & 100 & 138 & 125 & 182 & 253 & 228 \\
\hline Regiāo Norte & 100 & 156 & 176 & - & - & - \\
\hline Acre & 100 & 128 & 165 & 5 & 6 & 8 \\
\hline Amazonas & 100 & 158 & 160 & 35 & 55 & 56 \\
\hline Àmapá & 100 & 195 & 131 & 1 & 2 & 2 \\
\hline Pará & 100 & 144 & 163 & 80 & 115 & 131 \\
\hline Roraima & 100 & 297 & 297 & 1 & 2 & 2 \\
\hline Rondônia & 100 & 706 & 981 & 2 & 17 & 23 \\
\hline Regiāo Centro-Oeste & 100 & 121 & 100 & - & - & - \\
\hline Mato Grosso (2) & 100 & 141 & 119 & 49 & 68 & 58 \\
\hline Distrito Federal & 100 & 104 & 161 & 1 & 1 & 1 \\
\hline Goiás & 100 & 107 & 86 & 67 & 72 & 58 \\
\hline Regiāo sudeste & 100 & 94 & 94 & - & - & - \\
\hline Minas Gerais & 100 & 99 & 97 & 204 & 203 & 199 \\
\hline Espirito Santo & 100 & 98 & 117 & 40 & 39 & 47 \\
\hline Rio de Janeiro & 100 & 92 & 94 & 33 & 30 & 31 \\
\hline sāo Paulo & 100 & 88 & 86 & 203 & 179 & 175 \\
\hline Regiāo Sul & 100 & 116 & 94 & - & - & - \\
\hline Paraná & 100 & 107 & 85 & 312 & 334 & 264 \\
\hline Santa catarina & 100 & 105 & 94 & 101 & 106 & 95 \\
\hline Rio Grande do sul & 1.00 & 135 & 107 & 205 & 276 & 219 \\
\hline Brasil & 100 & 114 & 103 & - & - & - \\
\hline
\end{tabular}

(1) Indices simples do número de trabalhadores; a base do índice 1 é o próprío Estado em 1970 e a base do indice 2 é a média dos Estados também em 1970.

(2) Inclui Mato Grosso do Sul.

FONTE: Elaborada a partir de dados básicos da Fundaçāo Instituto Brasileiro de Geografia e Estatística (IBGE), da Fundaçăo Getúlio Vargas (FGV) e do Instituto de Economia Agrícola (IEA). 
as Regiões ( $+289 \%$ no Centro-Oeste, $+280 \%$ no Norte, $+118 \%$ no Nordeste, $+80 \%$ no sudeste $e,+63 \%$ no sul). Considerando-se - periodo 1970-80, $\circ$ uso do fator fertilizantes foi aumentado em 139\% (nas Regiöes, $+1650 \%$ na centro-oeste, $+375 \%$ na Norte, $+226 \%$ na Nordeste, $+135 \%$ na Sul $e,+66 \%$ na Sudeste) (tabela 9). É interessante destacar que nos anos de 1974,1975 e 1980 os preços reais dos fertilizantes elevaram-se consideravelmente, e que os subsidios diretos aos preços de adubos devem ter conseguido atenuar esses aumentos apenas nas safras de 1976 e 1977 , mesmo assim atingindo apenas a parcela de $15 \%$ de produtores que tinham acesso a crédito rural.

o uso do fator máquinas cresceu explosivamente entre 1970 e 1975 (+115\%), com indices positivos em todas as Regiŏes (Centro-Oeste +226\%, Sul $+137 \%$, Nordeste $+133 \%$, Sudeste $+64 \%$ e, Norte $+39 \%$ ). Já 0 período 1975-80, apresentou evoluçăo mais modesta ( $+63 \%)$, com as Regiŏes Norte $(+346 \%)$, Nordeste $(+142 \%)$ e Centro-oeste ( $+93 \%$ ) respondendo pelos maiores aumentos, embora as duas Regiões mais mecanizadas do País, Sudeste e Sul, tenham apresentado substanciais incrementos $(+63 \%$ e +49\%, respectivamente). Entre 1970 e 1980 o uso do fator máquinas foi intensificado ( $+251 \%)$, especialmente no Centro-Oeste $(+530 \%)$, no Norte $(+500 \%)$ e no Nordeste $(+467 \%)$. Dos fatores considerados neste estudo, também nas Regiōes Sudeste e Sul foram as máquinas os que 
TABELA 9. - Evolução do Uso do Fator Fertilizantes nas Unidades da Federaçäo, Brasil, 1970-80 (1).

\begin{tabular}{|c|c|c|c|c|c|c|}
\hline \multirow{2}{*}{ Unidade da Federação } & \multicolumn{3}{|c|}{ Indice 1} & \multicolumn{3}{|c|}{ Indice 2} \\
\hline & 1970 & 1975 & 1980 & 1970 & 1975 & 1980 \\
\hline & & -- & & & & \\
\hline Regiāo Nordeste & 100 & 152 & 326 & - & - & - \\
\hline Alagoas & 100 & 152 & 239 & 96 & 146 & 229 \\
\hline Bahia & 100 & 142 & 398 & 50 & 72 & 200 \\
\hline Ceará & 100 & 122 & 1.320 & 8 & 9 & 100 \\
\hline Paraíba & 100 & 80 & 480 & 11 & 9 & 52 \\
\hline Pernambuco & 100 & 183 & 258 & 79 & 145 & 204 \\
\hline Piauí & 100 & 106 & 860 & 1 & 1 & 7 \\
\hline Rio Grande do Norte & 100 & 108 & 682 & 4 & 4 & 27 \\
\hline Sergipe & 100 & 100 & 180 & 20 & 20 & 36 \\
\hline Maranhäo & 100 & 358 & 6.098 & 0 & 2 & 26 \\
\hline Regiåo Norte & 100 & 125 & 475 & - & - & - \\
\hline Acre & $\ldots$ & $\ldots$ & $\ldots$ & $\ldots$ & $\ldots$ & $\cdots$ \\
\hline Amazonas & 100 & 69 & 1.497 & 0 & 0 & 6 \\
\hline Amapá & 100 & 237 & 1.718 & 0 & 0 & 1 \\
\hline Pará & 100 & 126 & 376 & 22 & 27 & 81 \\
\hline Roraima & 100 & 121 & 11.503 & 0 & 0 & 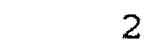 \\
\hline Rondônia & 100 & 34 & 12.476 & 0 & 0 & 4 \\
\hline Regiào Centro-Oeste & 100 & 450 & 1.750 & - & - & - \\
\hline Mato Grosso (2) & 100 & 1.500 & 8.059 & 6 & 85 & 456 \\
\hline Distrito Federal & 100 & 90 & 857 & 2 & 2 & 17 \\
\hline Goiás & 100 & 288 & 742 & 35 & 102 & 263 \\
\hline Regiäo Sudeste & 100 & 92 & 166 & - & - & - \\
\hline Minas Gerais & 100 & 166 & 381 & 153 & 254 & 583 \\
\hline Espirito Santo & 100 & 382 & 1.625 & 6 & 24 & 101 \\
\hline Rio de Janeiro & 100 & 83 & 97 & 31 & 25 & 29 \\
\hline Săo Paulo & 100 & 79 & 126 & 1.006 & 795 & 1.267 \\
\hline Regiăo Sul & 100 & 144 & 235 & - & - & - \\
\hline Paraná & 100 & 134 & 207 & 354 & 472 & 734 \\
\hline Santa Catarina & 100 & 185 & 517 & 40 & 74 & 208 \\
\hline Rio Grande do Sul & 100 & 1.47 & 232 & 576 & 850 & 1.336 \\
\hline & & & & & & \\
\hline Bra & 100 & 125 & 239 & - & - & - \\
\hline
\end{tabular}

(1) Indices simples de quantidade utilizada; a base do indice 1 é o próprio Estado em 1970 e a base do indice 2 é a média dos Estados também em 1970. Năo inclui dados do Estado do Acre.

(2) Inclui Mato Grosso do Sul.

FONTE: Elaborada a partir de dados básicos da Fundaçăo Instituto Brasileiro de Geografia e Estatistica (IBGE), da Fundaçăo Getúlio vargas (FGV) e do Instituto de Economia Agrícola (IEA). 
experimentaram maior crescimento $(+168 \%$ e $+253 \%$, respectivamente)(tabela 10). Esses indices encontram explicaçăo no crescimento extensivo da agricultura, especialmente na incorporaçăo de novas áreas em regiōes já exploráiắ ex expansāo da fronteira agrícola incentivada por programas especiais de crédito rural como o Polocentro, Polonordeste e Proterra (ANJOS, YAMAGUISHI 'e CARVALHO, 1988), e na intensificaçăo do emprego de capital que vem caracterizando o processo de modernizaçăo do setor nas áreas mais desenvolvidas do sul e sudeste.

Os investimentos em culturas perenes ou permanentes experimentaram crescimento de $26 \%$ entre 1970 e 1975, com indices positivos em todas as Regiŏes (Sul +67\%, Nordeste $+50 \%$, Norte, $+13 \%$, Centro-Oeste $+10 \%$ e, Sudeste +3\%). Já entre 1975 e 1980 o ritmo diminuiu ( $+16 \%$ ) e as Regiǒes tiveram comportamento distinto, com aumentos no Centro-Oeste $(+82 \%)$, Norte $(+55 \%)$ e Sudeste $(+40 \%)$, ao lado de estagnaçăo no Nordeste $(+2 \%)$ e declínio no sul (-24\%). No período 1970 a 1980 , os indices indicam aumento de $46 \%$, distribuidos por todas as Regiões $(+100 \%$ no Centro-Oeste, $+75 \%$ no Norte, $+53 \%$ nc Nordeste, $+44 \%$ no sudeste e, $+27 \%$ no Sul (tabela 11).

3.1.3. Evolução da Produtividade de Fatores

A produtividade agregada dos fatores terra, trabalho, fertilizantes, máquinas e investimentos em 
TABELA 10. - Evolução do Uso do Fator Máquinas nas Unidades da Federação, Brasil, 1970-80 (1).

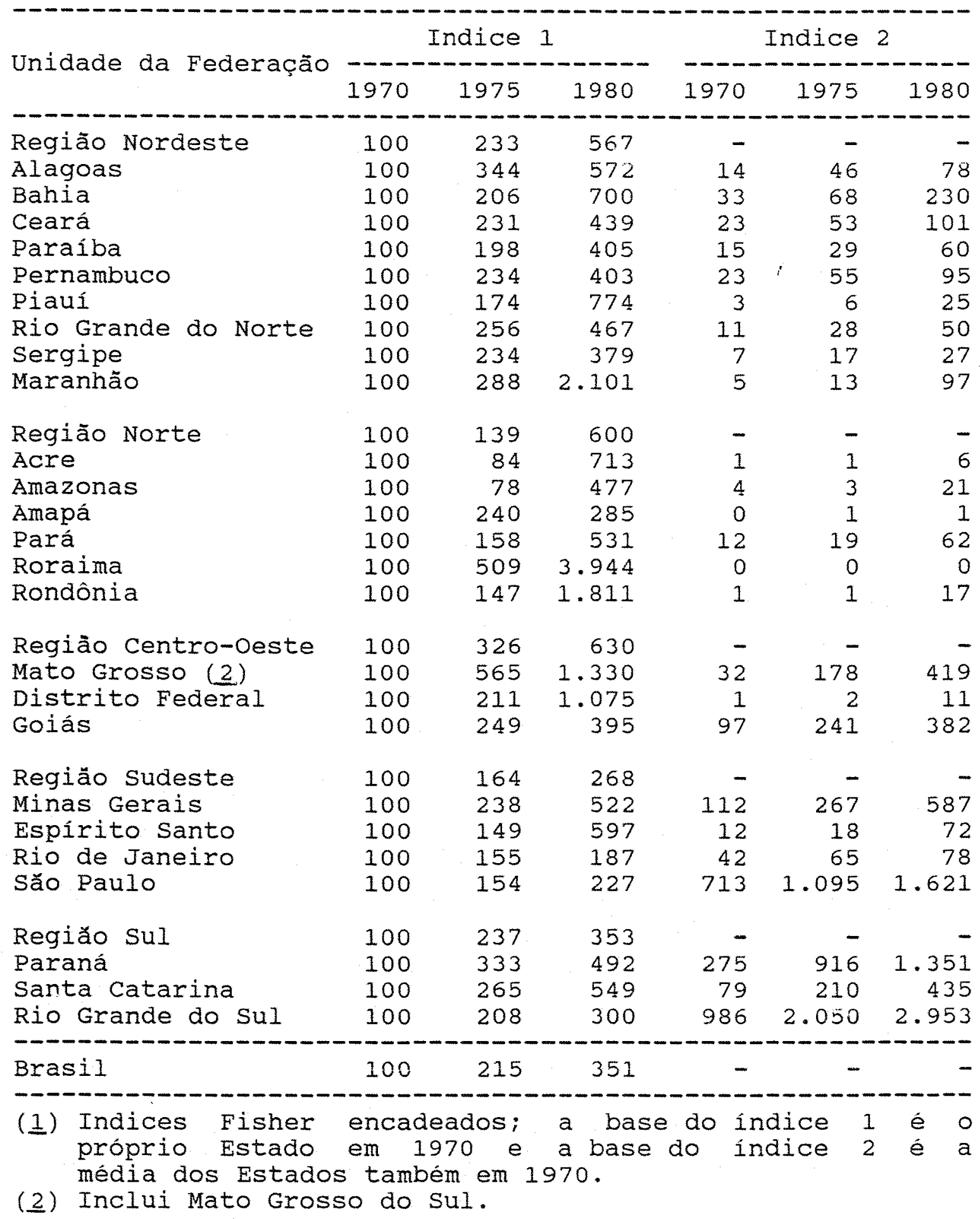

FONTE: Elaborada a partir de dados básicos da Fundaçäo Instituto Brasileiro de Geografia e Estatistica (IBGE), da Fundaçăo Getúlio vargas (FGV) e do Instituto de Economia Agricola (IEA). 
TABELA 11. - Evoluçăo do Fator Investimentos em Culturas Perenes nas Unidades da Federaçăo, Brasil, $1970-80$ (1).

\begin{tabular}{|c|c|c|c|c|c|c|}
\hline \multirow{2}{*}{ Unidade da Federaçäo } & \multicolumn{3}{|c|}{ Indice 1} & \multicolumn{3}{|c|}{ Indice 2} \\
\hline & 1970 & 1975 & 1980 & 1970 & 1975 & 1980 \\
\hline Regiäo Nordeste & 100 & 150 & 153 & - & - & \\
\hline Alagoas & 100 & 162 & 226 & 137 & 221 & 308 \\
\hline Bahia & 100 & 104 & 84 & 264 & 274 & 222 \\
\hline Ceará & 100 & 280 & 225 & 61 & 171 & 138 \\
\hline Paraíba & 100 & 253 & 255 & 45 & 115 & 115 \\
\hline Pernambuco & 100 & 123 & 136 & 251 & 309 & 341 \\
\hline Piauí & 100 & 261 & 195 & 11 & 30 & 2 \\
\hline Rio Grande do Norte & 100 & 369 & 351 & 20 & 73 & \\
\hline Sergipe & 100 & 101 & 134 & 15 & 15 & \\
\hline Maranhäo & 100 & 107 & 85 & 18 & 19 & - \\
\hline Regiăo Norte & 100 & 125 & 175 & - & - & \\
\hline Acre & 100 & 110 & 151 & 1 & 1 & \\
\hline Amazonas & 100 & 68 & 102 & 5 & 4 & \\
\hline Amapá & 100 & 163 & 127 & 0 & 1 & \\
\hline Pará & 100 & 111 & 114 & 17 & 18 & 9 \\
\hline Roraima & 100 & 218 & 97 & 0 & 1 & \\
\hline Rondônia & 100 & 181 & 1.181 & 1 & 2 & \\
\hline Regiāo Centro-oeste & 100 & 110 & 200 & - & - & \\
\hline Mato Grosso( $(\underline{2})$ & 100 & 131 & 391 & 9 & 12 & \\
\hline Distrito Fedéral & 100 & 97 & 115 & 1 & 1 & \\
\hline Goiás & 100 & 97 & 112 & 20 & 20 & \\
\hline Regiäo Sudeste & 100 & 103 & 144 & - & - & \\
\hline Minas Gerais & 100 & 85 & 128 & 248 & 211 & \\
\hline Espirito Santo & 100 & 90 & 126 & 111 & 100 & \\
\hline Rio de Janeiro & 100 & 85 & 98 & 176 & 149 & \\
\hline Săo Paulo & 100 & 114 & 163 & 780 & 891 & 1.26 \\
\hline Regiăo Sul & 100 & 167 & 127 & - & - & \\
\hline Paraná & 100 & 223 & 162 & 187 & 416 & \\
\hline Santa Catarina & 100 & 59 & 61 & 37 & 22 & \\
\hline Rio Grande cio sul & 100 & 94 & 80 & 84 & 79 & \\
\hline Brasil & 100 & 126 & 146 & - & - & \\
\hline
\end{tabular}

(1) Indices Fisher encadeados; a base do índice 1 é 0 próprio Estado em 1970 e a base do índice 2 é a média dos Estados também em 1970.

(2) Inclui Mato Grosso do Sul.

FONTE: Elaborada a partir de dados básicos da Fundação Instituto Brasileiro de Geografia e Estatistica (IBGE), da Fundaçăo Getúlio vargas (FGV) e do Instituto de Economia Agricola (IEA). 
culturas perenes, cresceu 22\% entre 1970 e 1975, o que pode ser explicado pelos crescimentos das produtividades parciais da terra $(+16 \%)$, trabalho ( $+26 \%)$, fertilizantes $(+15 \%)$ e investimentos em culturas perenes $(+28 \%)$; dos fatores citados, apenas máquinas apresentaram diminuição de produtividade $(-33 \%)$. A Região sul apresentou $\circ$ maior crescimento de produtividade agregada nesses anios $(+36 \%)$, também, os maiores aumentos nas produtividades parciais da terra $(+38 \%)$, do trabalho $(+48 \%)$ e dos investimentos em culturas perenes ( $+139 \%)$. Esta regiăo ocupou a segunda colocaçăo no crescimento da produtividade de fertilizantes $(+19 \%)$ e na de máquinas $(-27 \%)$. 0 Nordeste experimentou crescimento de produtividade de $22 \%$ para $\circ$ agregado, quase que totalmente devido ao aumento da produtividade do trabalho $(+26 \%)$, uma vez que os indices parciais de terra $(+2 \%)$, de fertilizantes $(-2 \%)$ e dos investimentos em culturas perenes $(+4 \%)$ permaneceram relativamente estáveis, enquanto que o fator máquinas apresentou queda de $37 \%$. No Centro-oeste, o crescimento de $17 \%$ no agregado, é explicado pela elevaçăo nas produtividades do trabalho ( $+55 \%$ ) e terra $(+8 \%)$, com decréscimos na produtividade de máquinas $(-36 \%)$, fertilizantes $(-23 \%)$ e investimentos em culturas perenes $(-12 \%)$. Na Regiāo sudeste a produtividade agregada cresceu 15\%, com os fatores terra e trabalho crescendo iqualmente (+18\%), da mesma forma que fertilizantes e investimentos em culturas perenes $(+21 \%) ;$ a produtividade das máquinas decresceu $32 \%$ A Regiăo Norte destoou das demais, 
apresentando produtividade negativa em termos agregados $(-13 \%)$, assim como nos fatores terra $(-4 \%)$ e trabalho $(-8 \%)$, estagnaçāo em investimentos em culturas perenes $(0 \%)$ e, aumento de produtividade nos fatores fertilizantes $(+16 \%)$ e máquinas ( $+8 \%)$ (tabelas 12 a 17$)$.

Tomando-se $\circ$ periodo $1975-80$ os niveis de crescimento foram menores para a produtividade do agregado de fatores $(+7 \%)$, com os indices parciais mostrando ganhos apenas para terra ( $+8 \%)$ e trabalho $(+23 \%)$, pequena queda para investimentos em culturas perenes (-6\%) e, maiores diminuições na produtividade dos fatores fertilizantes $(-42 \%)$ e máquinas $(-32 \%)$, consequência da intensificação de seu uso substituindo os fatores primários terra e trabalho. Centro-oeste e sudeste foram as Regiōes que apresentaram melhor comportamento no agregado $(+18 \%$ e +14\%, respectivamente), com 0 indice parcial de produtividade da terra crescendo igualmente nas duas Regióes ( $+16 \%)$ e comportamento também similar no fator investimenstos em cultura perenes $(+6 \%$ e $+4 \%$, respectivamente). O fator trabalho cresceu mais na Região Centro-oeste $(+75 \%$ no período) do que na sudeste ( $+35 \%)$, embora as produtividades parciais de fertilizantes e máquinas tenham caído mais nessa primeira região $(-63 \%$ e $-26 \%$, contra $-25 \%$ e $-18 \%$, respectivamente). As Regiōes Norte e sul mantiveram-se praticamente estáveis em termos agregados $(+3 \%)$, comportamento também observado nos indices de produtividade da terra ( $-2 \%$ e $-3 \%$, respectivamente); no 
51.

TABELA 12. - Evoluçäo da Produtividade de Fatores nas Unidades da Federaçăo, Brasil, 1970-80 (1).

\begin{tabular}{|c|c|c|c|c|c|c|}
\hline \multirow[t]{2}{*}{ Unidade da Federaçăo } & \multicolumn{3}{|c|}{ Indice 1} & \multicolumn{3}{|c|}{ Indice 2} \\
\hline & 1970 & 1975 & 1980 & 1970 & 1975 & 1980 \\
\hline Regiäo Nordeste & 100 & 122 & 116 & - & - & - \\
\hline Alagoas & 100 & 130 & 145 & 75 & 97 & 108 \\
\hline Bahía & 100 & 99 & 88 & 75 & 74 & 66 \\
\hline Ceará & 100 & 243 & 156 & 39 & 95 & 61 \\
\hline Paraíba & 100 & 157 & 149 & 50 & 78 & 74 \\
\hline Pernambuco & 100 & 124 & 135 & 66 & 82 & 89 \\
\hline Piauí & 100 & 176 & 103 & 58 & 102 & 60 \\
\hline Rio Grande do Norte & 100 & 182 & 133 & 37 & 68 & 50 \\
\hline Sergipe & 100 & 117 & 157 & 55 & 64 & 87 \\
\hline Maranhāo & 100 & 95 & 107 & 50 & 48 & 54 \\
\hline Região Norte & 100 & 87 & 89 & - & - & - \\
\hline Acre & 100 & 71 & 56 & 105 & 75 & 59 \\
\hline Amazonas & 100 & 69 & 71 & 113 & 78 & 80 \\
\hline Amapá & 100 & 88 & 87 & 227 & 200 & 196 \\
\hline Pará & 100 & 104 & 107 & 73 & 76 & 78 \\
\hline Roraima & 100 & 63 & 124 & 235 & 149 & 292 \\
\hline Rondônia & 100 & 66 & 75 & 217 & 142 & 164 \\
\hline Região Centro-oeste & 100 & 117 & 138 & - & - & - \\
\hline Mato Grosso (2) & 100 & 141 & 163 & 91 & 129 & 149 \\
\hline Distrito Federal & 100 & 159 & 146 & 72 & 115 & 105 \\
\hline Goiás & 100 & 107 & 132 & 129 & 138 & 169 \\
\hline Região Sudeste & 100 & 115 & 130 & - & - & 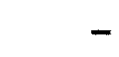 \\
\hline Minas Gerais & 100 & 91 & 122 & 101 & 92 & 123 \\
\hline Espirito Santo & 100 & 88 & 105 & 117 & 103 & 124 \\
\hline Rio de Janeiro & 100 & 92 & 87 & 208 & 192 & 182 \\
\hline Sāo Paulo & 100 & 130 & 143 & 155 & 202 & 221 \\
\hline Regiäo Sul & 100 & 136 & 140 & - & - & . \\
\hline Paraná & 100 & 186 & 188 & 89 & 165 & 167 \\
\hline Santa Catarina & 100 & 106 & 122 & 69 & 73 & 84 \\
\hline Rio Grande do Sul & 100 & 103 & 107 & 145 & 149 & 155 \\
\hline Brasil & 100 & 122 & 131 & - & - & - \\
\hline
\end{tabular}

(1) Indices Fisher encadeados de producá, indices Fisher encadeados do uso de fatores: inclui os fatores terra, trabalho, fertilizantes, máquinas e investimentos em culturas perenes. A base do indice 1 é 0 próprio Estado em 1970 e a base do indice 2 é a média dos Estados também em 1970.

(2) Inclui Mato Grosso do Sul.

FONTE: Elaborada a partir de dados básicos da Fundaçăo Instituto Brasileiro de Geografia e Estatística (IBGE), da Fundaçăo Getúlio Vargas (FGV) e do Instituto de Economia Agricola (IEA). 
TABELA 13. - Evoluçăo da Produtividade da Terra nas Unidades da Federaçāo, Brasil, 1970-80 (1 1 .

\begin{tabular}{|c|c|c|c|c|c|c|}
\hline \multirow{2}{*}{ Unidade da Federaçăo } & \multicolumn{3}{|c|}{ Indice 1} & \multicolumn{3}{|c|}{ Indice 2} \\
\hline & 1970 & 1975 & 1980 & 1970 & 1975 & 1980 \\
\hline Regiăo Nordeste & 100 & 102 & 109 & - & - & - \\
\hline Alagoas & 100 & 80 & 130 & 166 & 133 & 215 \\
\hline Bahia & 100 & 123 & 100 & 119 & 147 & 120 \\
\hline Ceará & 100 & 119 & 92 & 51 & 61 & 47 \\
\hline Paraíba & 100 & 115 & 121 & 61 & 70 & 74 \\
\hline Pernambuco & 100 & 109 & 134 & 96 & 104 & 128 \\
\hline Piauí & 100 & 135 & 102 & 38 & 52 & 39 \\
\hline Rio Grande do Norte & 100 & 81 & 88 & 59 & 48 & 52 \\
\hline Sergipe & 100 & 93 & 190 & 138 & 129 & 262 \\
\hline Maranhāo & 100 & 116 & 116 & 76 & 88 & 88 \\
\hline Regiăo Norte & 100 & 96 & 95 & - & - & - \\
\hline Acre & 100 & 93 & 68 & 233 & 218 & 159 \\
\hline Amazonas & 100 & 93 & 70 & 250 & 231 & 174 \\
\hline Amapá & 100 & 120 & 116 & 150 & 181 & 175 \\
\hline Pará & 100 & 106 & 112 & 76 & 81 & 86 \\
\hline Roraima & 100 & 75 & 95 & 144 & 108 & 137 \\
\hline Rondônia & 100 & 86 & 90 & 132 & 114 & 119 \\
\hline Região Centro-oeste & 100 & 108 & 125 & - & - & - \\
\hline Mato Grosso (2) & 100 & 105 & 120 & 81 & 85 & 97 \\
\hline Distrito Federal & 100 & 157 & 84 & 163 & 255 & 137 \\
\hline Goiás & 100 & 106 & 125 & 77 & 82 & 96 \\
\hline Região Sudeste & 100 & 118 & 137 & - & - & - \\
\hline Minas Gerais & 100 & 102 & 133 & 93 & 95 & 124 \\
\hline Espirito Santo & 100 & 100 & 134 & 98 & 99 & 132 \\
\hline Rio de Janeiro & 100 & 109 & 106 & 229 & 249 & 242 \\
\hline Săo Paulo & 100 & 126 & 143 & 158 & 199 & 227 \\
\hline Região sul & 100 & 138 & 134 & - & - & - \\
\hline Paraná & 100 & 169 & 151 & 78 & 132 & 118 \\
\hline Santa Catarina & 100 & 121 & 123 & 89 & 108 & 110 \\
\hline Rio Grande do Sul & 100 & 118 & 124 & 89 & 106 & 111 \\
\hline Brasil & 100 & 116 & 125 & - & - & - \\
\hline
\end{tabular}

(1) Indices Fisher encadeados de producăo / indices simples de área cultivada. A base do índice 1 é o próprio Estado em 1970 e a base do indice 2 é a média dos Estados também em 1970.

(2) Inclui Mato Grosso do Sul.

FONTE: Elaborada a partir de dados básicos da Fundaçâo Instituto Brasileiro de Geografia e Estatistica (IBGE), da Fundação Getúlio Vargas (FGV) e do Instituto de Economia Agricola (IEA). 
TABELA 14. - Evolução da produtividade do Trabalho nas Unidades da Federação, Brasil, 1970-80 (1).

\begin{tabular}{|c|c|c|c|c|c|c|}
\hline \multirow{2}{*}{ Unidade da Federação } & \multicolumn{3}{|c|}{ Indice 1} & \multicolumn{3}{|c|}{ Indice 2} \\
\hline & 1970 & 1975 & 1980 & 1970 & 1975 & 1980 \\
\hline Região Nordeste & 100 & 126 & 125 & - & - & \\
\hline Alagoas & 100 & 141 & 174 & 74 & 105 & 130 \\
\hline Bahia & 100 & 97 & 90 & 67 & 65 & 60 \\
\hline Ceará & 100 & 276 & 182 & 23 & 63 & 42 \\
\hline Paraíba & 100 & 163 & 170 & 30 & 49 & 51 \\
\hline Pernambuco & 100 & 131 & 151 & 50 & 66 & 76 \\
\hline Piauí & 100 & 184 & 107 & 18 & 33 & 19 \\
\hline Rio Grande do Norte & 100 & 207 & 154 & 23 & 49 & 36 \\
\hline Sergipe & 100 & 118 & 168 & 34 & 40 & 56 \\
\hline Maranhão & 100 & 94 & 108 & 40 & 38 & 43 \\
\hline Regiāo Norte & 100 & 92 & 101 & - & - & - \\
\hline Acre & 100 & 70 & 57 & 132 & 92 & 13 \\
\hline Amazonas & 100 & 67 & 71 & 43 & 29 & 31 \\
\hline Amapá & 100 & 87 & 87 & 91 & 79 & 79 \\
\hline Pará & 100 & 104 & 109 & 32 & 33 & 35 \\
\hline Roraima & 100 & 62 & 137 & 97 & 60 & 133 \\
\hline Rondônia & 100 & 60 & 72 & 146 & 87 & 105 \\
\hline Região centro-oeste & 100 & 155 & 230 & - & - & \\
\hline Mato Grosso ( $\underline{2})$ & 100 & 174 & 330 & 102 & 177 & 335 \\
\hline Distrito Federal & 100 & 163 & 266 & 76 & 124 & 203 \\
\hline Goiás & 100 & 121 & 193 & 145 & 179 & 287 \\
\hline Regiäo Sudeste & 100 & 118 & 159 & - & - & \\
\hline Minas Gerais & 100 & 94 & 147 & 97 & 91 & 143 \\
\hline Espirito Santo & 100 & 87 & 115 & 115 & 101 & 132 \\
\hline Rio de Janeiro & 100 & 91 & 89 & 263 & 238 & 234 \\
\hline Sāo Paulo & 100 & 140 & 190 & 281 & $393^{\circ}$ & 533 \\
\hline Regiào Sul & 100 & 148 & 185 & - & - & \\
\hline Paraná & 100 & 209 & 251 & 107 & 224 & 270 \\
\hline Santa Catarina & 100 & 109 & 148 & 83 & 90 & 122 \\
\hline Rio Grande do Sul & 100 & 108 & $2 \leq 2$ & 223 & 240 & 315 \\
\hline Brasil & 100 & 126 & 155 & - & - & \\
\hline
\end{tabular}

(1) Indices Fisher encadeados de producão / indices simples do número de trabalhadores. A base do indice 1 é o próprio Estado em 1970 e a base do índice 2 é a média dos Estados também em 1970.

(2) Inclui Mato Grosso do Sul.

FONTE: Elaborada a partir de dados básicos da Fundação Instituto Brasileiro de Geografia e Estatistica (IBGE), da Fundação Getúlio vargas (FGV) e do Instituto de Economia Agrícola (IEA). 
TABELA 15. - Evoluçăo da Produtividade de Fertilizantes nas Unidades da Federaçăo, Brasil, 1970-80 (1).

\begin{tabular}{|c|c|c|c|c|c|c|}
\hline \multirow{2}{*}{ Unidade da Federaçāo } & \multicolumn{3}{|c|}{ Indice 1} & \multicolumn{3}{|c|}{ Indice 2} \\
\hline & 1970 & 1975 & 1980 & 1970 & 1975 & 1980 \\
\hline Região Nordeste & 100 & 98 & 40 & - & - & - \\
\hline Alaguas & 100 & 109 & 84 & 54 & 59 & 45 \\
\hline Bahia & 100 & 76 & 24 & 409 & 310 & 99 \\
\hline Ceará & 100 & 227 & 12 & 480 & 1.089 & 56 \\
\hline Paraíba & 100 & 286 & 31 & 257 & 734 & 80 \\
\hline Pernambuco & 100 & 71 & 51 & 115 & 82 & 59 \\
\hline Piauí & 100 & 217 & 15 & 1.741 & 3.782 & 253 \\
\hline Rio Grande do Norte & 100 & 235 & 25 & 288 & 676 & 73 \\
\hline Sergipe & 100 & 124 & 77 & 69 & 86 & 53 \\
\hline Maranhäo & 100 & 36 & 2 & 17.471 & 6.370 & 386 \\
\hline Região Norte & 100 & 116 & 37 & - & - & 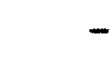 \\
\hline Acre & $\cdots$ & $\cdots$ & $\cdots$ & $\cdots$ & $\cdots$ & $\cdots$ \\
\hline Amazonas & 100 & 155 & 8 & 3.835 & 5.940 & 291 \\
\hline Amapá & 100 & 72 & 7 & 3.648 & 2.609 & 242 \\
\hline Pará & 100 & 118 & 47 & 118 & 139 & 56 \\
\hline Roraima & 100 & 152 & 4 & 3.882 & 5.895 & 138 \\
\hline Rondônia & 100 & 1.255 & 6 & 10.367 & 130089 & 590 \\
\hline Região Centro-oeste & 100 & 77 & 14 & - & - & - \\
\hline Mato Grosso (ㄹ) & 100 & 16 & 5 & 872 & 143 & 43 \\
\hline Distrito Federal & 100 & 188 & 50 & 31 & 58 & 15 \\
\hline Goiás & 100 & 45 & 22 & 282 & 126 & 63 \\
\hline Regiào sudeste & 100 & 121 & 74 & - & - & - \\
\hline Minas Gerais & 100 & 56 & 38 & 129 & 73 & 49 \\
\hline Espirito Santo & 100 & 22 & 8 & 748 & 168 & 61 \\
\hline Rio de Janeiro & 100 & 101 & 86 & 284 & 288 & 245 \\
\hline São Paulo & 100 & 156 & 130 & 57 & 88 & 74 \\
\hline Regiăo Sul. & 100 & 119 & 90 & - & - & 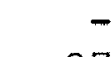 \\
\hline Paraná & 100 & 167 & 103 & 95 & 158 & 97 \\
\hline Santa Catarina & 100 & 62 & 27 & 208 & 128 & 56 \\
\hline Rio Grande do Sul & 100 & 99 & 65 & 79 & 78 & 52 \\
\hline Brasil & 100 & 115 & 67 & - & - & - \\
\hline
\end{tabular}

(1) Indices Fisher encadeados de produçăo / indices simples de uso do fator. A base do indice 1 é o próprio Estado em 1970 e a base do indice 2 é a média dos Estados também em 1970. Nâo inclui o Estado do Acre.

(2) Inclui Mato Grosso do Sul.

FONTE: Elaborada a partir de dados básicos da Fundação Instituto Brasileiro de Geografia e Estatistica (IBGE), da Fundação Getúlio vargas (FGV) e do Instituto de Economia Agricola (IEA). 
TABELA 16. - Evoluçâo da Produtividade de Máquinas nas Unidades da Federaçāo, Brasil, 1970-80 (1).

\begin{tabular}{|c|c|c|c|c|c|c|}
\hline \multirow{2}{*}{ Unidade da Federação } & \multicolumn{3}{|c|}{ Indice 1} & \multicolumn{3}{|c|}{ Indice 2} \\
\hline & 1970 & 1975 & 1980 & 1970 & 1975 & 1980 \\
\hline Regiăo Nordeste & 100 & 67 & 23 & - & - & 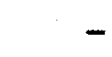 \\
\hline Alagoas & 100 & 49 & 35 & 378 & 185 & 132 \\
\hline Bahia & 100 & 52 & 14 & 626 & 328 & 87 \\
\hline Ceará & 100 & 120 & 35 & 158 & 190 & 56 \\
\hline Paraíba & 100 & 116 & 37 & 191 & 222 & 71 \\
\hline Pernambuco & 100 & 56 & 33 & 389 & 217 & 127 \\
\hline Piaui & 100 & 132 & 16 & 418 & 553 & 67 \\
\hline Rio Grande do Norte & 100 & 99 & 37 & 107 & 105 & 39 \\
\hline Sergipe & 100 & 53 & 37 & 195 & 104 & 72 \\
\hline Maranhăo & 100 & 45 & 6 & 1.597 & 720 & 102 \\
\hline Regiäo Norte & 100 & 108 & 30 & - & - & - \\
\hline Acre & 100 & 106 & 13 & 784 & 832 & 103 \\
\hline Amazonas & 100 & 137 & 24 & 343 & 470 & 82 \\
\hline Amapá & 100 & 71 & 40 & 397 & 281 & 159 \\
\hline Pará & 100 & 94 & 34 & 218 & 206 & 73 \\
\hline Roraima & 100 & 36 & 10 & 8.250 & 2.978 & 854 \\
\hline Rondônia & 100 & 288 & 39 & 355 & 1.023 & 139 \\
\hline Regiăo Centro-oeste & 100 & 64 & 38 & - & - & - \\
\hline Mato Grosso (2) & 100 & 43 & 30 & 156 & 68 & 46 \\
\hline Distrito Federal & 100 & 81 & 40 & 58 & 47 & 23 \\
\hline Goiás & 100 & 52 & 42 & 103 & 53 & 43 \\
\hline Regiăo Sudeste & 100 & 68 & 56 & - & - & - \\
\hline Minas Gerais & 100 & 39 & 27 & 176 & 69 & 48 \\
\hline Espirito Santo & 100 & 57 & 22 & 384 & 220 & 86 \\
\hline Rio de Janeiro & 100 & 54 & 44 & 207 & 111 & 92 \\
\hline Săo Paulo & 100 & 80 & 72 & 80 & 64 & 58 \\
\hline Regiăo sul & 100 & 73 & 49 & - & - & - \\
\hline Paraná & 100 & 67 & 43 & 122 & 82 & 53 \\
\hline Santa Catarina & 100 & 43 & 25 & 106 & 45 & 27 \\
\hline Rio Grande do sul & 100 & 70 & 51 & 46 & 32 & 23 \\
\hline Brasil & 100 & 67 & 46 & - & - & - \\
\hline
\end{tabular}

(1) Indices Fisher encadeados de produçăo / indices Fisher encadeados de uso do fator. A base do indice 1 e 0 próprio Estado em 1970 e a base do índice 2 é a média dos Estados também em 1970.

(2) Inclui Mato Grosso do Sul.

FONTE: Elaborada a partir de dados básicos da Fundaçăo Instituto Brasileiro de Geografia e Estatistica (IBGE), da Fundaçăo Getúlio vargas (FGV) e do Instituto de Economia Agrícola (IEA). 
TABELA 17. - Evoluçăo da Produtividade dos Investimentos em Culturas Perenes nas unidades da Federaçăo, Brasil, 1970-80 (1).

\begin{tabular}{|c|c|c|c|c|c|c|}
\hline \multirow{2}{*}{ Unidade da Federaçäo } & \multicolumn{3}{|c|}{ Indice 1} & \multicolumn{3}{|c|}{ Indice 2} \\
\hline & 1970 & 1975 & 1980 & 1970 & 1975 & 1980 \\
\hline & & & & & $-\infty$ & \\
\hline Regiäo Nordeste & 100 & 104 & 105 & - & - & . \\
\hline Alagoas & 100 & 97 & 105 & 97 & 94 & 102 \\
\hline Eahía & 100 & 133 & 143 & 117 & 156 & 167 \\
\hline Ceará & 100 & 101 & 81 & 70 & 71 & 56 \\
\hline Paraíba & 100 & 85 & 66 & 86 & 73 & 57 \\
\hline Pernambuco & 100 & 102 & 115 & 72 & 73 & 82 \\
\hline Piauí & 100 & 127 & 79 & 59 & 75 & 47 \\
\hline Rio Grande do Norte & 100 & 74 & 54 & 81 & 60 & 43 \\
\hline Sergipe & 100 & 142 & 204 & 119 & 170 & 243 \\
\hline Maranhăo & 100 & 110 & 134 & 71 & 78 & 95 \\
\hline Regiăo Norte & 100 & 100 & 143 & - & - & - \\
\hline Acre & 100 & 102 & 116 & 135 & 138 & 157 \\
\hline Amazonas & 100 & 52 & 106 & 187 & 97 & 199 \\
\hline Amapá & 100 & 152 & 115 & 94 & 143 & 108 \\
\hline Pará & 100 & 134 & 176 & 66 & 89 & 116 \\
\hline Roraima & 100 & 108 & 279 & 173 & 187 & 482 \\
\hline Rondônia & 100 & 153 & 133 & 110 & 168 & 145 \\
\hline Regiăo Centro-oeste & 100 & 88 & 94 & - & - & 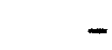 \\
\hline Mato Grosso ( $\underline{2})$ & 100 & 108 & 86 & 111 & 120 & 96 \\
\hline Distrito Federal & 100 & 181 & 183 & 114 & 206 & 207 \\
\hline Goiás & 100 & 84 & 127 & 137 & 114 & 174 \\
\hline Regiäo sudeste & 100 & 121 & 126 & - & - & - \\
\hline Minas Gerais & 100 & 105 & 127 & 94 & 98 & 119 \\
\hline Espirito Santo & 100 & 91 & 119 & 94 & 85 & 111 \\
\hline Rio de Janeiro & 100 & 114 & 97 & 120 & 136 & 116 \\
\hline São Paulo & 100 & 128 & 130 & 112 & 144 & 146 \\
\hline Regiăo SuI & 100 & 139 & 133 & - & - & \\
\hline Paraná & 100 & 330 & 165 & 65 & 216 & 108 \\
\hline Santa Catarina & 100 & 121 & 142 & 76 & 92 & 108 \\
\hline Rio Grande do sul & 100 & 98 & 93 & 127 & 124 & 118 \\
\hline Brasil & 100 & 128 & 120 & - & - & - \\
\hline
\end{tabular}

(1) Indices Fisher encadeados de produçăo / indices Fisher encadeados de uso do fator. A base do indice 1 é 0 próprio Estado em 1970 e a base do índice 2 é a média dos Estados também em 1970.

(2) Inclui Mato Grosso do Sul.

FONTE: Elaborada a partir de dados básicos da Fundaçăo Instituto Brasileiro de Geografia e Estatistica (IBGE), da Fundação Getúlio vargas (FGV) e do Instituto de Economia Agricola (IEA). 
fator trabalho, $\circ$ Sul apresentou elevaçăo de $25 \%$ na produtividade, resultado superior ao do Norte $(+10 \%)$. similarmente, nos fatores fertilizantes e máquinas, as quedas de produtividade observadas na Regiăo sul foram menores (-38\% e $-32 \%$, contra $-68 \%$ e $-73 \%$, respectivamente). A Regiăo Nordeste teve a produtividade agregada diminuida em 5\%, apresentando crescimento apenas na produtividade da terra $(+7 \%)$, estabilidade nos indices do trabalho ( $0 \%$ e investimentos em culturas perenes ( $+1 \%$ ) e decréscimos nas produtividades parciais de fertilizantes (-59\%) e de máquinas $(-64 \%)$.

Entre 1970 e 1980 , a produtividade agregada dos fatores cresceu $31 \%$ no Brasil, impulsionada pelas produtividades do trabalho ( $+55 \%)$, da terra $(+25 \%) e$ dos investimentos em culturas perenes $(+20)$, enquanto que, em contrapartida, os fatores fertilizantes e máquinas tiveram quedas de $33 \%$ e $54 \%$, respectivamente. A nivel de regiăo, os resultados seguiram, via-de-regra, a mesma hierarquia no crescimento das produtividades parciais: Sul, $+40 \%$ na produtividade agregada, $+85 \%$ na do trabalho, $+34 \%$ na da terra, $+33 \%$ na dos investimentos em culturas perenes, $-10 \%$ na de fertilizantes $e,-51 \%$ na de máquinas; Centro-Oeste, $+38 \%$ na produtividade agregada, $+130 \%$ na do trabalho, $+25 \%$ na da terra, $-4 \%$ na dos investimentos em culturas perenes, $-62 \%$ na de máquinas $e,-86 \%$ na de fertilizantes; Sudeste, $+30 \%$ na produtividade agregada, $+59 \%$ na do trabalho, $+37 \%$ na da terra, $+26 \%$ na dos 
58 .

investimentos em culturas perenes, $-26 \%$ na de fertilizantes e, $-44 \%$ na de máquinas; Nordeste, $+16 \%$ na produtividade agregada, +25\% na do trabalho, +9\% na da terra, +5\% na dos investimentos em culturas perenes, $-60 \%$ na de fertilizantes e, $-77 \%$ ía de máquinas. A Regiăo Norte foi a única a apresentar diminuiçäo na produtividade agregada, -11\%, com resultados positivos apenas para os investimentos em culturas perenes $(+43 \%)$, estagnaçăo na produtividade do trabalho $(+1 \%)$ e queda nas dos demais fatores (terra, -5\%; fertilizantes, $-63 \%$; e, máquinas, $-70 \%)(11)$.

PASTORE, ALVES $e$ RIZZIERI (1976)

estimaram em $2,0 \%$ a taxa média de crescimento da produtividade da terra no Brasil, no periodo 1955-65; no mesmo período, a taxa média de crescimento da produtividade do trabalho foi de $4,0 \%$ ao ano, segundo aqueles autores. As taxas médias calculadas no presente estudo indicam manutençăo dos níveis de crescimento para a produtividade do trabalho e, queda na intensidade de crescimento da produtividade da terra (tabelas 18 e 19). SILVA (1984), utilizando dados anuais do IEA, estimou em $3,37 \%$ ao ano, para o período 1968-80 no Estado de São Paulo, a taxa média de crescimento da produtividade da terra para o setor de culturas. Embora as fontes de dados e $\circ$ conjunto de culturas aqui utilizados sejam distintos, a taxa média

(11) Breves comentários sobre os índices à nivel de Estado acompanhados de figuras representativas de sua evoluçăo, encontram-se no Apêndice 2 . 
TABELA 18. - Taxas Médias Anuais de Crescimento da Produtividade da Terra na Agricultura, Unidades da Federaçâo, Brasil, 1970-80 (1).

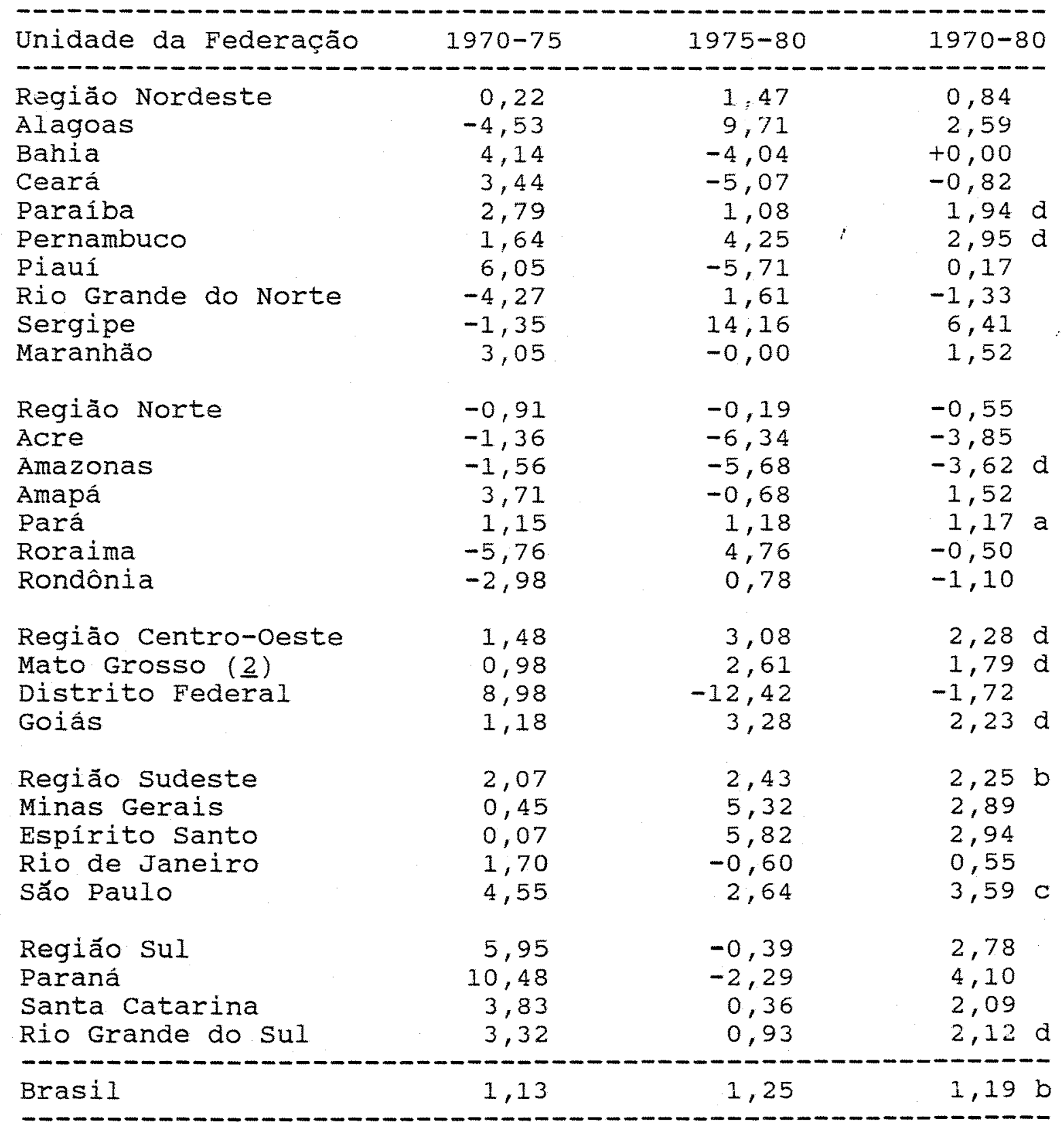

(1) Os procedimentos empregados nos cálculos das variáveis encontram-se no capitulo 2. Taxas calculadas através de ajuste exponencial; niveis de significância: $a=1 \%$; $\mathrm{b}=5 \% ; \mathrm{c}=10 \% ; \mathrm{d}=20 \%$.

(2) Inclui Mato Grosso do Sul.

FONTE: Dados da TABELA 13. 
60.

TABELA 19. - Taxas Médias Anuais de Crescimento da Produtividade do Trabalho na Agricultura, Unidades da Federaçăo, Brasil, 1970-80 (1 $)$.

\begin{tabular}{|c|c|c|c|c|}
\hline Unidade da Federaçäo & $1970-75$ & $1975-80$ & & $1970-80$ \\
\hline Regiăo Nordeste & 6,94 & 0,20 & & 3,57 \\
\hline Alagoas & 6,87 & 4,21 & & $5,54 \mathrm{c}$ \\
\hline Bahía & $-0,61$ & $-1,50$ & & $-1,05 d$ \\
\hline Ceará & 20,30 & $-8,33$ & & 5,99 \\
\hline Paraíba & 9,77 & 0,84 & & 5,31 \\
\hline Pernambuco & 5,40 & 2,84 & & $4,12 \mathrm{~d}$ \\
\hline Piauí & 12,20 & $-10,84$ & $i$ & 0,68 \\
\hline Rio Grande do Norte & 14,55 & $-5,92$ & & 4,32 \\
\hline Sergipe & 3,31 & 7,07 & & $5,19 \mathrm{~d}$ \\
\hline Maranhão & $-1,24$ & 2,78 & & 0,77 \\
\hline Regiăo Norte & $-7,07$ & 3,73 & & $-1,67$ \\
\hline Acre & $-7,13$ & $-4,12$ & & $-5,620$ \\
\hline Amazonas & $-8,01$ & 1,12 & & $-3,42$ \\
\hline Amapá & $-2,79$ & 0,00 & & $-1,39$ \\
\hline Pará & 0,78 & 0,94 & & $0,86 \mathrm{~b}$ \\
\hline Roraima & $-9,56$ & 15,86 & & 3,15 \\
\hline Rondônia & $-10,22$ & 3,65 & & $-3,29$ \\
\hline Regiăo Centro-oeste & 7,68 & 10,83 & & $9,25 \mathrm{c}$ \\
\hline Mato Grosso (2) & 11,08 & 12,80 & & $11,94 \mathrm{~b}$ \\
\hline Distrito Federal & 9,77 & 9,79 & & 9,78 a \\
\hline Goiás & 3,81 & 9,34 & & $6,58 \mathrm{c}$ \\
\hline Regiăo Sudeste & 1,70 & 4,72 & & $3,21 \mathrm{c}$ \\
\hline Minas Gerais & $-1,24$ & 8,94 & & 3,85 \\
\hline Espirito Santo & $-2,79$ & 5,58 & & 1,40 \\
\hline Rio de Janeiro & $-1,89$ & $-0,44$ & & $-1,17$ \\
\hline săo Paulo & 6,73 & 6,11 & & $6,42 b$ \\
\hline Regiäo Sul & 5,87 & 4,88 & & $5,38 \mathrm{~b}$ \\
\hline Paraná & 14,74 & 3,66 & & 9,20 \\
\hline Santa Catarina & 1,72 & 6,12 & & $3,92,0$ \\
\hline Rio Grande do Sul & 1,54 & 5,47 & & 3,510 \\
\hline Brasil & 2,72 & 5,12 & & 3,92 \\
\hline
\end{tabular}

(1) Os procedimentos empregados nos cálculos das variáveis encontram-se no capitulo 2. Taxas calculadas através de ajuste exponencial; níveis de significância: $a=1 \%$; $\mathrm{b}=5 \% ; \mathrm{c}=10 \% ; \mathrm{d}=20 \%$.

(2) Inclui Mato Grosso do Sul.

FONTE: Dados da TABELA 14 
calculada para o período 1970-80 é muito semelhante à encontrada por aquele autor (tabela 18). Dados do período 1970-76 citados por SILVA (1984), para a Comunidade Econômica Européia, apresentam taxas médias de crescimento de $0,85 \%$ a $2,60 \%$ ao ano para a produtividade total de fatores na agropecuária. Tomando-se como base a taxa média para o Brasil no período $1970-75$ (2,39\% aa., tabela 20), observa-se que esta seria superior às da Itália $10,85 \%$ aa.), Reino Unido (1,34\% aa.), França (1,47\% aa.) e Dinamarca $(2,07 \% \mathrm{aa.})$; todavia, caso as exploraçoes animais fossem incluidas, essas taxas seriam, provavelmente, menores. As taxas diversificadas à nível de Estado săo consistentes com a grande dispersäo encontrada por EVENSON e JHA (1973b), em Estados da India.

Naturalmente, a fato de serem calculadas com dados censitários e o consequente número minimo de observaçŏes, torna essas taxas inadequadas para representar a situaçăo de Estados que tiveram, nesses anos, situaçŏes anormalmente favoráveis ou desfavoráveis.

\subsection{Resultados dos Modelos Ajustados}

Os modelos foram ajustados em etapas, pela necessidade de definir o melhor horizonte de acumulaçăo para a variável pesquisa. Após testes com efeitos iniciando-se no terceiro e quinto anos e estendendo-se até o décimo, décimo quinto e vigésimo anos 
TABELA 20. - Taxas Médias Anuais de Crescimento da Produtividade de Fatores na Agricultura, Unidades da Federaçăo, Brasil, 1970-80 (I).

\begin{tabular}{|c|c|c|c|c|}
\hline Unidade da Federaçăo & $1970-75$ & $1975-80$ & & $1970-80$ \\
\hline Regiāo Nordeste & 4,13 & $-1,10$ & & 1,52 \\
\hline Alagoas & 5,25 & 2,16 & & 3,70 \\
\hline Bahia & $-0,14$ & $-2,35$ & & $-1,24$ \\
\hline Ceará & 17,80 & $-8,97$ & & 4,42 \\
\hline Paraiba & 8,96 & $-1,04$ & & 3,96 \\
\hline Pernambuco & 4,25 & 1,68 & & 2,97 \\
\hline Piauí & 11,34 & $-10,72$ & $i$ & 0,31 \\
\hline Rio Grande do Norte & 11,93 & $-6,24$ & & 2,85 \\
\hline Sergipe & 3,10 & 5,97 & & 4,54 \\
\hline Maranhăo & $-1,08$ & 2,35 & & 0,64 \\
\hline Regiăo Norte & $-2,79$ & 0,45 & & $-1,17$ \\
\hline Acre & $-6,80$ & $-4,70$ & & $-5,75$ \\
\hline Amazonas & $-7,50$ & 0,55 & & 3,47 \\
\hline Amapá & $-2,49$ & 0,38 & & $-1,43$ \\
\hline Pará & 0,83 & 0,56 & & 0,70 \\
\hline Roraima & $-9,09$ & 13,45 & & 2,18 \\
\hline Rondônia & $-8,44$ & 2,80 & & $-2,82$ \\
\hline Região Centro-oeste & 3,08 & 3,32 & & 3,20 \\
\hline Mato Grosso (2) & 6,90 & 2,92 & & 4,91 \\
\hline Distrito Federal & 9,30 & $-1,78$ & & 3,76 \\
\hline Goiás & 1,41 & 4,07 & & $2,74 d$ \\
\hline Região sudeste & 2,67 & 2,58 & & 2,62 \\
\hline Minas Gerais & $-1,91$ & 5,94 & & 2,02 \\
\hline Espirito Santo & $-2,53$ & 3,58 & & 0,53 \\
\hline Rio de Janeiro & $-1,66$ & $-1,08$ & & $-1,37$ \\
\hline Săo Paulo & 5,30 & 1,83 & & $3,57 \mathrm{~d}$ \\
\hline Regiăo Sul & 6,17 & 0,54 & & 3,35 \\
\hline Paraná & 12,38 & 0,23 & & 6,30 \\
\hline Santa Catarina & 1,19 & 2,77 & & $1,98 d$ \\
\hline Rio Grande do sul & 0,54 & 0,80 & & $0,67 \mathrm{~b}$ \\
\hline sil & 2,39 & 1,08 & & 1,74 \\
\hline
\end{tabular}

(1) Inclui os fatores terra, trabalho, fertilizantes, máquinas e investimentos em culturas perenes. Os procedimentos empregados nos cálculos das variáveis encontram-se no capitulo 2. Taxas calculadas através de ajuste exponencial; niveis de significância: $a=1 \%$; $b=5 \% ; c=10 \% ; d=20 \%$.

(2) Inclui Mato Grosso do Sul.

FONTE: Dados da TABELA 12. 
após a publicação, optou-se por utilizar o intervalo compreendido pelo quinto ao vigésimo anos. A assistência técnica entrou na equaçăo a partir dos produtores assistidos nos três anos anteriores ao Censo, ponderados através dis pesos adotados por PATRICK e KEHRBERG (1975) (respectivamente, $\quad 0,5,0,3$ e 0,2 ). 0 número de observaçóes, em todos os modelos, foi de 71, motivado pela exclusão do Amapá, Roraima, Rondônia e São Paulo no ano de 1970, devido à inexistência de dados sobre produtores assistidos pelos serviços de assistência técnica e extensão rural.

Nos modelos com 0 indice de produtividade agregada de fatores como variável dependente, quando a pesquisa regional e a desenvolvida em São Paulo sobre os principais produtos de cada Estado foram incluidas simultaneamente, ambas não apresentaram coeficientes significativos (equação 1 , tabela 21). Isso deve-se, provavelmente, à alta correlação entre ambas $(r=0,9534)$, afirmativa que é reforçada pela inclusăo alternada dessas variáveis em outras equações, quando adquirem significância praticamente sem alterar os demais coeficientes (equações 2 e 3, tabela 21). Esse fato levou à utilizaçăo da variável pesquisa como uma soma das duas anteriormente propostas.

A equação 4 da tabela 21 é significativa a $1 \%$ e os parâmetros estimados para deficiências hidricas, assistência técnica e pesquisa, além da constante, são também significativos. Os sinais dos coeficientes săo 
TABELA 21.- Equaçőes com Pesquisa, Assistência Técnica, Educaçẫo, Condiçóes do Tempo e Aptidấo Edafo-climática como Variáveis Explicativas do Indice de Produtividade de Fatores na Agricultura, Brasil, 1970-80 (1).

\begin{tabular}{|c|c|c|c|c|c|}
\hline & & & Equaçôes & & \\
\hline variavel & $(1)$ & (2) & (3) & $(4)$ & $(5)$ \\
\hline onstante & $\begin{array}{r}117,859 \\
(3,33) a\end{array}$ & $\begin{array}{r}107,537 \\
(3,13) \mathrm{a}\end{array}$ & $\begin{array}{l}113,726 \\
(3,32) a\end{array}$ & $\begin{array}{l}110,608 \\
(3,23) a\end{array}$ & $\begin{array}{l}67,306 \\
(1,85 ; 0\end{array}$ \\
\hline Dummy 1 & $\begin{array}{r}8,782 \\
(0,68)\end{array}$ & $\begin{array}{r}8,219 \\
(0,63)\end{array}$ & $\begin{array}{r}8,331 \\
(0,65)\end{array}$ & $\begin{array}{r}8,194 \\
(0,64)\end{array}$ & $\begin{array}{l}7,772 \\
(0,63)\end{array}$ \\
\hline Dummy 2 & $\begin{array}{r}-5,898 \\
(-0,44)\end{array}$ & $\begin{array}{l}-10,410 \\
(-0,82)\end{array}$ & $\begin{array}{r}-7,829 \\
(-0,62)\end{array}$ & $\begin{array}{l}-9,173 \\
(-0,73)\end{array}$ & $\begin{array}{l}-18,229 \\
(-1,46)\end{array}$ \\
\hline Def. Hídrica & $\begin{array}{c}-0,119 \\
(-2,58) b\end{array}$ & $\begin{array}{l}-0,110 \\
(-2,41) b\end{array}$ & $\begin{array}{c}-0,116 \\
(-2,55) b\end{array}$ & $\begin{array}{c}-0,113 \\
(-2,48) b\end{array}$ & $\begin{array}{c}-0,087 \\
(-1,96) \mathrm{c}\end{array}$ \\
\hline Geada & $\begin{array}{l}-13,865 \\
(-0,64)\end{array}$ & $\begin{array}{l}-14,502 \\
(-0,67)\end{array}$ & $\begin{array}{l}-14,601 \\
(-0,68)\end{array}$ & $\begin{array}{l}-14,721 \\
(-0,69)\end{array}$ & $\begin{array}{l}-12,102 \\
(-0,59)\end{array}$ \\
\hline Ap.Edaf.Clim. & $\begin{array}{l}-0,550 \\
(-1,13)\end{array}$ & $\begin{array}{l}-0,421 \\
(-0,89)\end{array}$ & $\begin{array}{l}-0,498 \\
(-1,05)\end{array}$ & $\begin{array}{l}-0,459 \\
(-0,97)\end{array}$ & $\begin{array}{l}-0,259 \\
(-0,57)\end{array}$ \\
\hline Educação & $\begin{array}{l}16,954 \\
(1,35)\end{array}$ & $\begin{array}{l}16,551 \\
(1,14)\end{array}$ & $\begin{array}{l}16,610 \\
(1,33)\end{array}$ & $\begin{array}{l}16,516 \\
(1,32)\end{array}$ & $\begin{array}{l}40,911 \\
(2,74) a\end{array}$ \\
\hline Assist.Técnic. & $\begin{array}{c}0,883 \\
(2,38) b\end{array}$ & $\begin{array}{c}0,864 \\
(2,33) b\end{array}$ & $\begin{array}{c}0,873 \\
(2,37) b\end{array}$ & $\begin{array}{c}0,867 \\
(2,35) b\end{array}$ & $\begin{array}{c}3,373 \\
(3,40) a\end{array}$ \\
\hline Pesq. Regional & $\begin{array}{l}-0,114 \\
(-0,49)\end{array}$ & $\begin{array}{c}0,168 \\
(2,11) b\end{array}$ & & & \\
\hline Pesq.Săo Paulo & $\begin{array}{r}0,031 \\
(1,13)\end{array}$ & & $\begin{array}{c}0,018 \\
(2,37) b\end{array}$ & & \\
\hline Pesq.Reg. + SP & & & & $\begin{array}{c}0,009 \\
(2,26) b\end{array}$ & $\begin{array}{c}0,010 \\
(2,57) b\end{array}$ \\
\hline Educ. X Ass.Téc & - & & & & $\begin{array}{l}-1,532 \\
(-2,70) a\end{array}$ \\
\hline $\begin{array}{l}\text { R2 } \\
\text { F } \\
\text { DW }\end{array}$ & $\begin{array}{c}46,473 \\
5,89 a \\
2,46\end{array}$ & $\begin{array}{c}45,350 \\
6,43 a \\
2,36\end{array}$ & $\begin{array}{c}46,264 \\
6,67 \mathrm{a} \\
2,43\end{array}$ & $\begin{array}{c}46,888 \\
6,57 a \\
2,40\end{array}$ & $\begin{array}{c}51,661 \\
7,24 \mathrm{a} \\
2,14\end{array}$ \\
\hline
\end{tabular}

(1) Detalhes sobre a construção das variáveis encontram-se no capitulo 2. Entre parênteses, valores da estatistica "t"; niveis de significância: $a=1 \% ; \quad b=5 \% ; c=10 \%$.

FONTE: Elaborado a partir de dados básicos da Fundação Instituto Brasileiro de Geografia e Estatistica (IBGE), da Fundaçấo Getúlio Vargas (FGV) e do Instituto de Economia Agricola 
consistentes com a espectativa teórica e a estatistica Durbin-Watson, considerando-se os limites para número de parâmetros igual a cinco, por nâo dispor-se de outros mais adequados, estaria na região inconclusiva sobre a existência de auiu-correiação de resíduos.

As interações possiveis entre pesquisa, assistência técnica e educação foram também adicionadas ao modelo mas, apenas a variável educaçäo $x$ assistência técnica melhorou os resultados e apresentou coeficiente significativo (12). O sinal negativo do parâmetro estimado pode ser um indicativo de que essas variáveis são substitutas. o nível de significância da variável assistência técnica melhorou e a educaçăo tornou-se significativa com a introdução da interação entre elas (equaçấo 5 , tabela 21).

Os resultados obtidos referentes a deficiências híricas, geada e, principalmente, pesquisa agrícola, são concordantes com os obtidos por SIIVA (1984 e 1986) para o Estado de São Paulo. Com relaçăo à assistência técnica, aquele autor não encontrou coeficientes significativos, apesar das evidências em contrário anteriormente obtida por ENGLER (1979). Deve-se ressaltar, porém, que as condiçōes do Estado de săo Paulo säo distintas das da maior parte do País, onde, corroborando as conclusöes de PATRICK e KERHBERG (1975), a 
existência de imensas regiôes com agricultura pouco desenvolvida constituir-se-ia no campo de atuação, por excelência, da assistência técnica e extensão rural.

Tomando-se $\circ$ indice de produtividade da terra como variável dependente e a pesquisa regional e a desenvolvida em Săo Paulo simultânea e desagregadamente, a equação é significativa a 1\% e os coeficientes de geadas, aptidão edafo-climática e pesquisa regional são, também, significativos e positivos, enquanto que a pesquisa em sâo Paulo aparece como năo-significativa, provavelmente em função de multicolinearidade (equaçäo 1, tabela 22). Similarmente ao efetuado nas equaçőes anteriores, quando as variáveis representativas da pesquisa foram incluidas alternada ou agregadamente, aparecem com coeficientes significativos e sinais consistentes (equações 2,3 e 4 , tabela 22). A interação educação $x$ assistência técnica apareceu como não-significativa e não afetou os demais resultados, continuando os parâmetros estimados para educação e assistência técnica sendo não-significativos (equaçäo 5, tabela 22).

Com o indice de produtividade do trabalho como variável dependente e com as variáveis pesquisa regional e desenvolvida em săo paulo incluidas simultânea e desagregadamente, a equação é significativa a $1 \%$ e os coeficientes estimados para as variáveis educação, assistência técnica e pesquisa paulista também o são (equaçäo 1, tabela 23). Alternando-se as variáveis 
TABELA 22.- Equaçóes com Pesquisa, Assistência Técnica, Educação, Condiçŏes do Tempo e Aptidão Edafo-Climática como Variáveis Explicativas do Indice de Produtividade da Terra na Agricultura, Brasil, 1970-80 (1).

\begin{tabular}{|c|c|c|c|c|c|}
\hline \multirow{2}{*}{ Variável } & \multicolumn{5}{|c|}{ Equaçőes } \\
\hline & (1) & $(2)$ & (3) & (4) & (5) \\
\hline Constante & $\begin{array}{l}-44,119 \\
(-1,16)\end{array}$ & $\begin{array}{l}-28,457 \\
(-0,77)\end{array}$ & $\begin{array}{l}-23,570 \\
(-0,62)\end{array}$ & $\begin{array}{l}-25,504 \\
(-0,68)\end{array}$ & $\begin{array}{l}3,561 \\
(0,09)\end{array}$ \\
\hline Dummy 1 & $\begin{array}{l}-1,349 \\
(-0,10)\end{array}$ & $\begin{array}{l}-0,494 \\
(-0,04)\end{array}$ & $\begin{array}{r}0,898 \\
(0,06)\end{array}$ & $\begin{array}{r}0,161 \\
(0,01)\end{array}$ & $\begin{array}{c}0,444 \\
(0,03)\end{array}$ \\
\hline Dummy 2 & $\begin{array}{r}-4,628 \\
(-0,33)\end{array}$ & $\begin{array}{c}2,218 \\
(0,16)\end{array}$ & $\begin{array}{r}4,974 \\
(0,36)\end{array}$ & $\begin{array}{r}3,781 \\
(0,27)\end{array}$ & $\begin{array}{r}9,860 \\
(0,69)\end{array}$ \\
\hline Def. Hidrica & $\begin{array}{l}0,049 \\
(0,98)\end{array}$ & $\begin{array}{l}0,034 \\
(0,69)\end{array}$ & $\begin{array}{l}0,030 \\
(0,59)\end{array}$ & $\begin{array}{l}0,032 \\
(0,63)\end{array}$ & $\begin{array}{c}0,014 \\
(0,28)\end{array}$ \\
\hline Geada & $\begin{array}{l}-51,579 \\
(-2,24) b\end{array}$ & $\begin{array}{l}-50,613 \\
(-2,17) b\end{array}$ & $\begin{array}{l}-47,921 \\
(-2,02) b\end{array}$ & $\begin{array}{l}-49,383 \\
(-2,10) b\end{array}$ & $\begin{array}{l}-51,141 \\
(-2,20) b\end{array}$ \\
\hline Ap.Edaf.Clim. & $\begin{array}{c}2,951 \\
(5,66) a\end{array}$ & $\begin{array}{c}2,755 \\
(5,36) a\end{array}$ & $\begin{array}{c}2,691 \\
(5,12) a\end{array}$ & $\begin{array}{c}2,717 \\
(5,32) a\end{array}$ & $\begin{array}{l}2,582 \\
(4,97) a\end{array}$ \\
\hline Educaçẫo & $\begin{array}{l}-4,302 \\
(-0,32)\end{array}$ & $\begin{array}{l}-3,690 \\
(-0,27)\end{array}$ & $\begin{array}{l}-2,593 \\
(-0,19)\end{array}$ & $\begin{array}{l}-3,177 \\
(-0,23)\end{array}$ & $\begin{array}{l}-19,552 \\
(-1,15)\end{array}$ \\
\hline Assist. Técnic. & $\begin{array}{r}0,349 \\
(0,88)\end{array}$ & $\begin{array}{r}0,379 \\
(0,95)\end{array}$ & $\begin{array}{r}0,404 \\
(0,99)\end{array}$ & $\begin{array}{r}0,392 \\
(0,97)\end{array}$ & $\begin{array}{l}-1,291 \\
(-1,14)\end{array}$ \\
\hline Pesq. Regional & $\begin{array}{c}0,068 \\
(2,27) b\end{array}$ & $\begin{array}{c}0,022 \\
(2,56) b\end{array}$ & & & \\
\hline Pesq.Säo Paulo & $\begin{array}{l}-0,048 \\
(-1,61)\end{array}$ & & $\begin{array}{c}0,017 \\
(1,97) \mathrm{C}\end{array}$ & & \\
\hline Pesq.Reg. + sp & & & & $\begin{array}{c}0,010 \\
(2,28) b\end{array}$ & $\begin{array}{c}0,009 \\
(2,19) b\end{array}$ \\
\hline Educ. X Ass.Téc & & & & & $\begin{array}{l}1,028 \\
(1,59)\end{array}$ \\
\hline $\begin{array}{l}\text { R2 } \\
F \\
D W\end{array}$ & $\begin{array}{c}55,391 \\
8,41 \mathrm{a} \\
1,68\end{array}$ & $\begin{array}{c}53,503 \\
8,92 \mathrm{a} \\
1,76\end{array}$ & $\begin{array}{c}51,615 \\
8,27 a \\
1,72\end{array}$ & $\begin{array}{c}52,578 \\
8,59 a \\
1,75\end{array}$ & $\begin{array}{c}54,475 \\
8,11 \mathrm{a} \\
1,77\end{array}$ \\
\hline
\end{tabular}

(1) Detalhes sobre a construçäo das variáveis encontram-se no capitulo 2. Entre parênteses, valores da estatistica "t"; niveis de significância: $a=1 \% ; \quad b=5 \% ; c=10 \%$.

FONTE: Elaborado a partir de dados básicos da Fundaçâo Instituto Brasileiro de Geografia e Estatística (IBGE), da Fundação Getúlio Vargas (FGV) e do Instituto de Economia Agricola (IEA). 
68.

TABELA 23.- Equaçốes com Pesquisa, Assistência Técnica, Educaçấo, Condiçôes do Tempo e Aptidão Edafo-Climática como Variáveis Explicativas do Indice de Produtividade do Trabalho na Agricultura, Brasil, 1970-80 (1).

\begin{tabular}{|c|c|c|c|c|c|}
\hline \multirow{2}{*}{ Variável } & \multicolumn{5}{|c|}{ Equaçốes } \\
\hline & (1) & (2) & (3) & (4) & $(5)$ \\
\hline Constante & $\begin{array}{l}21,574 \\
(0,38)\end{array}$ & $\begin{array}{l}-1,870 \\
(-0,04)\end{array}$ & $\begin{array}{l}21,760 \\
(0,42)\end{array}$ & $\begin{array}{l}10,211 \\
(0,92)\end{array}$ & $\begin{array}{l}-12,217 \\
(-0,21)\end{array}$ \\
\hline Dummy 1 & $\begin{array}{l}-4,684 \\
(-0,24)\end{array}$ & $\begin{array}{l}-5,964 \\
(-0,30)\end{array}$ & $\begin{array}{l}-4,664 \\
(-0,24)\end{array}$ & $\begin{array}{l}-5,606 \\
(-0,28)\end{array}$ & $\begin{array}{r}-5,825 \\
(-0,29)\end{array}$ \\
\hline Dummy 2 & $\begin{array}{l}21,594 \\
(1,06)\end{array}$ & $\begin{array}{l}11,346 \\
(0,58)\end{array}$ & $\begin{array}{l}21,681 \\
(1,12)\end{array}$ & $\begin{array}{l}16,461 \\
(0,85)\end{array}$ & $\begin{array}{l}11,771 \\
(0,58)\end{array}$ \\
\hline Def. Hídrica & $\begin{array}{l}-0,093 \\
(-1,32)\end{array}$ & $\begin{array}{l}-0,072 \\
(-1,02)\end{array}$ & $\begin{array}{l}-0,094 \\
(-1,35)\end{array}$ & $\begin{array}{l}-0,083 \\
(-1,19)\end{array}$ & $\begin{array}{l}-0,070 \\
(-0,98)\end{array}$ \\
\hline Geada & $\begin{array}{l}-4,985 \\
(-0,15)\end{array}$ & $\begin{array}{l}-6,430 \\
(-0,19)\end{array}$ & $\begin{array}{l}-4,952 \\
(-0,15)\end{array}$ & $\begin{array}{l}-6,326 \\
(-0,19)\end{array}$ & $\begin{array}{r}-4,969 \\
(-0,15)\end{array}$ \\
\hline Ap.Edaf.Clim. & $\begin{array}{r}0,479 \\
(0,64)\end{array}$ & $\begin{array}{r}0,772 \\
(1,05)\end{array}$ & $\begin{array}{r}0,477 \\
(0,66)\end{array}$ & $\begin{array}{r}0,622 \\
(0,86)\end{array}$ & $\begin{array}{r}0,726 \\
(0,98)\end{array}$ \\
\hline Educação & $\begin{array}{l}66,095 \\
(3,44) a\end{array}$ & $\begin{array}{l}65,179 \\
(3,34) \mathrm{a}\end{array}$ & $\begin{array}{l}66,110 \\
(3,47) a\end{array}$ & $\begin{array}{l}65,408 \\
(3,41) a\end{array}$ & $\begin{array}{l}78,043 \\
(3,24) a\end{array}$ \\
\hline Assist. Técnic. & $\begin{array}{l}-0,802 \\
(-1,41)\end{array}$ & $\begin{array}{r}-0,847 \\
(-1,47)\end{array}$ & $\begin{array}{l}-0,802 \\
(-1,43)\end{array}$ & $\begin{array}{l}-0,828 \\
(-1,46)\end{array}$ & $\begin{array}{r}0,470 \\
(0,29)\end{array}$ \\
\hline Pesq. Regional & $\begin{array}{r}0,001 \\
(0,01)\end{array}$ & $\begin{array}{c}0,070 \\
(5,68) a\end{array}$ & & & \\
\hline Pesq.sáo Paulo & $\begin{array}{c}0,071 \\
(1,68) \mathrm{C}\end{array}$ & & $\begin{array}{c}0,072 \\
(6,05) a\end{array}$ & & \\
\hline Pesq.Reg. + sP & & & & $\begin{array}{c}0,036 \\
(5,96) a\end{array}$ & $\begin{array}{c}0,037 \\
(5,99) a\end{array}$ \\
\hline Educ. X Ass.Té & & & & & $\begin{array}{l}-0,794 \\
(-0,87)\end{array}$ \\
\hline $\begin{array}{l}\text { R2 } \\
\text { F } \\
\text { DW }\end{array}$ & $\begin{array}{c}66,136 \\
13,24 a \\
2,35\end{array}$ & $\begin{array}{c}64,572 \\
14,13 a \\
2,27\end{array}$ & $\begin{array}{c}66,136 \\
15,14 \mathrm{a} \\
2,35\end{array}$ & $\begin{array}{c}65,748 \\
14,88 \mathrm{a} \\
2,33\end{array}$ & $\begin{array}{c}66,166 \\
13,25 \mathrm{a} \\
2,18\end{array}$ \\
\hline
\end{tabular}

(1) Detalhes sobre a construçấo das variáveis encontram-se no capitulo 2. Entre parênteses, valores da estatistica "t"; niveis de significância: $a=1 \% ; b=5 \% ; c=10 \%$.

FONTE: Elaborado a partir de dados básicos da Fundação Instituto Brasileiro de Geografia e Estatistica (IBGE), da Fundação Getúlio Vargas (FGV) e do Instituto de Economia Agrícola (IEA). 
representativas da pesquisa, estas aparecem como significativas, ao lado da educaçăo, o que se repete quando sẫo consideradas agregadamente. Incluindo a interaçẫo educação $x$ assistência técnica na equação, os resultados mantiveram-se inalterados quanto à significância dos parâmetros estimados (equações $2,3,4$ e 5, tabela 23).

o fato do valor da i estatistica Durbin-watson haver-se aproximado de dois com a introduçäo da variável interativa educação $x$ assistência técnica, com as três variáveis dependentes, está provavelmente indicando uma melhor especificação do modelo proporcionada por essa introdução.

A diversidade de resultados, em relação à significância das variáveis explicativas, quando se utiliza distintas medidas de produtividade, reforça as evidências registradas na literatura sobre a conveniência do uso de índices de produtividade agregada. A varíável geada apareceu como não-significativa nas equaçöes explicativas da produtividade total de fatores, resultado oposto aos encontrados por SILVA (1984); isso está provavelmente associado a dificuldade que se encontrou para medir essa variável no presente estudo, uma vez que seus efeitos sobre as culturas perenes dos Estados de Minas Gerais, São Paulo e Paraná ocorrem, principalmente, no ano seguinte ao da ocorrência do fenômeno, enquanto que, sobre as culturas de inverno nesses Estados e em Santa Catarina e Rio Grande do sul, os efeitos dão-se já na safra em curso. 
- pequeno número de observaçôes (três anos) impediu medir esses efeitos separadamente e, em termos agregados, eles apareceram como significativos apenas para a produtividade da terra. Quanto às deficiências hídricas, os resultados ootidos contrariam, aparentemente, os de SILVA, CASER, VICENTE (1984), que encontraram influência significativa desse fenômeno sobre a produtividade da terra; todavia, a variável aptidão edafo-climática considera as condicöes médias do tempo em cada Estado, substituindo, portanto, a deficiência hídrica na medida em que os anos aqui analisados não tenham se afastado das condições normais. Já com relação à produtividade do trabalho, as expectativas quanto aos resultados são dificultadas pelo fato de haver diminuição na quantidade de mão-de-obra contratada quando da ocorrência de perdas significativas devido a insuficiência de chuvas, ao menos por ocasião da colheita. É possivel, também, que uma melhor especificação da variável deficiência hídrica, com períodos distintos para cada Estado ou Região, melhorasse os resultados; todavia, deve-se salientar que o período setembro-março comtempla maior parte dos plantios e do desenvolvimento inicial das culturas em todo o país.

com esses resultados pode-se inferir que a pesquisa atua significativamente sobre a produtividade agregada de fatores, a produtividade da terra e a do trabalho; a pesquisa regional parece ter maior efeito sobre a produtividade da terra, enquanto que a pesquisa 
desenvolvida em Säo Paulo referente aos principais produtos de cada Estado atuaria mais sobre a produtividade do trabalho, fator mais homogêneo do que a terra. A educaçäo influenciaria a produtividade agregada de fatores e a produtividade do trabalho, enquanco que a assistência técnica agiria sobre a produtividade agregada via fatores modernos (máquinas e fertilizantes). Nesse caso, os resultados sáo menos conclusivos, uma vez que esperar-se-ia significância dessa variável nas equaçǒes com a produtividade da terra e/ou trabalho como variáveis independentes, o que não ocorreu. Talvez estudos em que se disponha de alguma medida de intensidade (número de visitas ao mesmo produtor, por exemplo) e de qualidade dos serviços de assistência técnica, possam esclarecer melhor seus efeitos.

Quando as variáveis foram medidas em logaritmos, os resultados pioraram. EVENSON e JHA (1973) obtiveram resultados semelhantes para a India, atribuindo a superioridade do ajuste linear, em relação a outro mais compativel com produtividades marginais decrescentes, a subinvestimentos em pesquisa, o que levaria a retornos constantes ou, mesmo, crescentes.

3.3. Retornos Marginais dos Investimentos em Educaçấo, Assistência Técnica e Pesquisa. 
regressão e dos custos médios da educação, pesquisa e assistência técnica foi possivel efetuar os cálculos dos retornos marginais de investimentos nessas atividades, definidos como as diferenças no valor da produçäo agricola, devidas às elevaçŏes nos indices médios de produtividade, motivadas por esses investimentos.

Para a escolaridade, partiu-se dos dacios calculados por LANGONI (1972) para os custos diretos (custos correntes da escola e custos de capital) por aluno, por ano e por curso em 1960 e 1969 , com base em dados do Ministério do Planejamento constantes do Plano Decenal, considerando que os custos correntes do estudante (principalmente livros) representavam $5 \%$ dos custos correntes da escola por aluno, para o nivel primário (o mais relevante no presente caso, uma vez que a escolaridade média da população rural era inferior a dois anos de estudo por pessoa). Para os cálculos de custos de capital foi considerada uma taxa real de juros de $12 \%$ como estimativa para o custo de oportunidade, chegando-se ao montante de Cr\$ 4.304,50 por ano de estudo e por aluno (em cruzeiros de 1980); não foram considerados custos indiretos.

Os custos dos produtores assistidos pelos programas de assistência técnica e extensão rural foram estimados a partir dos orçamentos da coordenadoria de Assistência Técnica Integral (CATI) para os anos de 1974 e 1975, expurgados dos recursos destinados ao Programa de Sementes, conforme SILVA, FONSECA e MARTIN (1981), e do 
número de produtores assistidos nesses mesmos anos, gentilmente cedidos pela CATI. Esse procedimento proporcionou o valor de $\operatorname{Cr} \$ 34.300,00$ (em cruzeiro de 1980) como custo médio por produtor assistido. Outras atividades desenvolvidas pela CAMI não diretamente relacionadas à assistência técnica (por exemplo, fiscalizaçöes diversas) estâo incluídas nesses custos, o que deve isuperestimar esses valores quando comparados aos de outros Estados que não os desenvolvam.

As atividades de pesquisa tiveram seu custo médio por artigo calculado a partir dos dados de SILVA (1980), que estimou em Cr\$ 11.875.952.910,00 0 investimento efetuado nas instituiçóes de pesquisa do Estado de São Paulo no período 1960-80 (em cruzeiros de 1980); o numero de artigos publicados no mesmo período em Säo Paulo (2.798), teve como fonte SILVA (1986). O custo médio de cada artigo foi estimado, entäo, em Cr\$ $4.244 .443,50$ (em cruzeiros de 1980).

Os resultados da tabela 24 tornam claro que os três aspectos abordados apresentam retornos positivos, notadamente a pesquisa. com relaçäo a escolaridade, os retornos parecem haver sido subestimados; os custos médios de um ano adicional de estudo utilizados dizem respeito tanto a setor urbano como ao rural, cujos valores devem ser, na realidade, menores, uma vez que um só professor orienta alunos de diversas séries e que a infra-estrutura utilizada é diminuta em relação à existente 
TABELA 24.- Retornos Marginais de Cr\$ 1 bilhäo Investidos em Eđucaçäo, Assistência Técnica e pesquisa na Agricultura, Brasil, 1970-80 (1). (em cruzeiro de 1980)

\begin{tabular}{|c|c|c|c|c|}
\hline Variável & $\begin{array}{c}\text { Elastici- } \\
\text { dades } \\
(\underline{2})\end{array}$ & $\begin{array}{l}\text { Indice de } \\
\text { Produtivi- } \\
\text { dade } \\
\text { (3) }\end{array}$ & $\begin{array}{l}\text { Aumentos } \\
\text { no Indice } \\
\text { devido ao } \\
\text { Investimento }\end{array}$ & $\begin{array}{c}\text { Retorno } \\
\text { Marginal } \\
\text { (4) }\end{array}$ \\
\hline Educaçăo & 0,1499 & 107,0423 & $+0,003$ & $\begin{array}{l}1,081 \\
1,54(\end{array}$ \\
\hline Ãss.Téc. & 0,1877 & 107,0423 & $+0,84$ & 8,611 \\
\hline $\begin{array}{l}\text { Pesq.Reg. } \\
\text { P.Reg.+SP }\end{array}$ & $\begin{array}{l}0,0618 \\
0,0507\end{array}$ & $\begin{array}{l}107,0423 \\
107,0423\end{array}$ & $\begin{array}{l}+14,56 \\
+11,95\end{array}$ & $\begin{array}{l}2.399,23\left(\frac{8}{8}\right. \\
1.969,15(8\end{array}$ \\
\hline
\end{tabular}

(1) Construída a partir dos coeficientes da equaçâo 5 da Tabela 21, exceto para pesquisa regional, cujo coeficiente utilizado foi o da equaçăo 3 da Tabela A.3.1..

(2) Médias das elasticidades do indice de produtividade em relaçẫo às variáveis educaçấo, assistência técnica e pesquisa, calculadas para todas as observaçőes; as referentes a educação e assistência técnica levam em consideração a interação entre ambas.

(3) Ponto Médio.

(4) Considerando-se 0 valor médio da produção dos anos de 1970, 1975 e 1980 para dezessete culturas, em bilhões de cruzeiros de 1980.

(5) Num horizonte de 35 anos, partindo-se da idade média de 30 anos para a populaçâo rural (que era a idade média de toda a populaçăo em 1970 e em 1980) e considerando que exercam atividades ate os 65 anos.

(6) Num horizcnte de 50 anos, partindo-se da idade média de 15 anos para a populaçấo rural beneficiada pelos investimentos em educação, e considerando que exerçam atividades até os 65 anos.

(Z) Num horizonte de 3 anos.

() Num horizonte de 20 anos, com retornos a partir do quinto.

FONTE: Dados da pesquisa, elaborados a partir de dados básicos da Fundação Instituto Brasileiro de Geografia e Estatistica (IBGE), da Fundaçăo Getúlio Vargas (FGV) e do Instituto de Economia Agrícola (IEA). 
em escolas urbanas. E bem verdade que programas destinados ao aumento da eficiência dos trabalhadores deveriam procurar aproximar as condições equcacionais do meio rural daquelas disponiveis no meio urbano, preservadas suas especificidades; os retornos marginais seriau, entäo, provavelmente muito maiores do que os aqui estimados. Outro aspecto que cabe ser levantado novamente, diz respeito a medida de escolaridade utilizada, que é a média de toda a população rural e não a do tomador de decisốes. Isso deve ter prejudicado a percepçăo do efeito considerado mais importante da educação, o efeito alocativo, que diria respeito năo somente à capacidade de alocar mais corretamente os recursos entre linhas de produção concorrentes, mas também à capacidade de determinar os tipos e quantidades de recursos a serem utilizados no processo de produçâo (WELCH, 1970). Essa afirmativa, de que o procedimento utilizado levaria, basicamente, à medida do efeito trabalhador, é reforçada calculando-se a elasticidade do indice de produtividade do trabalho com relaçâo à educaçấo a partir da equaçấo 5 da tabela 23, com - que se chega ao valor 0,9523. Portanto, um aumento de 10\% na escolaridade da populaçâo rural levaria a um aumento percentual quase idêntico no indice de produtividade do trabalho. Os retornos marginais atribuidos à assistência técnica e pesquisa podem, portanto, estar incorporando em alguma medida o efeito alocativo que seria proporcionado pela educaçäo do tomador de decisôes. 
Ainda com relaçåo aos dados da tabela 24, é necessário considerar que o horizonte de três anos dos retornos da assistência técnica passaria pela anterior adequaçấo dos serviços de extensão para ampliar o número de produlores ásistidos, da mesma forma que, se esses produtores adicionais cultivassem predominantemente culturas perenes, os retornos provavelmente iniciariam-se após alguns anos, quando essas culturas entrassem em produção, bem como teriam seus horizontes de atuação ampliados. Quanto às pesquisas, os dados como já colocado anteriormente, impossibilitaram a separação dos efeitos da pesquisa regional e da desenvolvida em sấo paulo. Portanto, os retornos da tabela 24 concernentes a pesquisa regional incorporam os efeitos da pesquisa desenvolvida em Sằ Paulo relativa aos principais produtos de cada Estado, que seriam, eventualmente, adaptadas pelas instituiçóes regionais. Os altos valores encontrados devem ser relativizados tendo em vista que os retornos iniciar-se-iam a partir do quinto ano após a publicação dos resultados das pesquisas, existindo, obviamente, um hiato entre a aplicação dos recursos e o término dos estudos, o que não foi aqui considerado.

Retornos elevados para a pesquisa agrícola em relação às atividades de extensão rural foram também encontrados por EVENSON e JHA (1973), na India. Aqueles autores lembram, todavia, que não se deve perder de vista $\circ$ papel intermediario entre pesquisadores e 
produtores que é exercido pelos extensionistas.

Finalmente, os resultados apresentados endossam, também, os obtidos por THOMPSON (1974), que trabalhando com dados censitários de 1970 concluiu que os investimentos em educação, pesquisa e extensão explicavaum uma proporção das diferenças regionais de produtividade, ao menos igual à explicada pelos fatores tradicionais, de certa forma contradizendo a tese de que, no Brasil, o aumento da produçấo é explicado apenas pela expansão da área cultivada e da utilizaçăo de mão-de-obra. 
78 .

4. CONCLUSŐES

Dos resultados obtidos no presente estudo é possivel retirar algumas conclusöes. Em primeiro lugar, os índices calculados indicaram que a produção agrícola cresceu $60 \%$ entre 1970 e 1980, com uma elevação no uso dos fatores terra, trabalho, fertilizantes, máquinas e culturas perenes, de $22 \%$, o que resultou em uma elevação de $31 \%$ na produtividade desses mesmos fatores (ou, uma taxa média anual de 1,94\%). A produtividade do trabalho foi a que mais contribuiu para essa elevação $(+3,92 \%$ ao ano). Esses resultados deveram-se, basicamente, às Regiones Sudeste, Sul e Centro-Oeste, cujas produtividades cresceram a taxas, em média, duas a três vezes maiores do que as da Regiắo Nordeste, enquanto que as da Região Norte foram negativas. 
en educação, extensão rural e pesquisa agricola exerceram influências significativas sobre os ganhos de produtividade obtidos; isso leva a supor que se a ênfase dada aos mecanismos de mercado a partir de meados da década de sessenta tivesse sido acompanhada de igual vigor na ampliação da pesquisa agrícola e educaçẫo da população rural, o que foi de certa forma efetuado apenas para a assistência técnica, a produtividade agricola poderia ter atingido niveis mais elevados. Esses investimentos, nas equações ajustadas, apresentaran altos retornos para pesquisa agricola e assistência técnica, sendo os niveis menores observados para a educaçăo atribuídos à dificuldade de medir o efeito alocativo a partir dos dados disponíveis para educação da população além dos custos utilizados estarem superestimados.

Com relação à pesquisa agrícola, os resultados obtidos näo permitiram medir separadamente os efeitos dos estudos regionais e dos desenvolvidos em São Paulo, da mesma maneira que não permitiram rejeitar a hipótese da influência dos artigos cientificos elaborados nesse último Estado sobre as demais Unidades da Federaçăo.

\section{A dificuldade crescente de incorporar}

novas áreas ao processo de produção, uma vez que as distâncias maiores em relação aos centros consumidores dos produtos e produtores dos insumos eleva os custos, impöe que a agricultura comercial, nessas regióes, seja altamente produtiva. 0 crédito rural institucional vem 
80.

experimentando racionamento na oferta e retração na quantidade demandada motivada pelos juros altos, o que o torna pouco adequado como instrumento de modernização. Esses fatos apontam para incrementos nos investimentos em equcação, pesquisa $\epsilon$ assistência técnica como uma alternativa racional visando conseguir aumentos de produçăo e produtividade na agricultura. Naturalmente, a eficiência desses investimentos pode ser aumentada com 0 auxilio de mecanismos de mercado, como, por exemplo, uma politica consistente e confiável de preços de garantia, que reduzisse os riscos associados à produção na agricultura.

A partir do inicio da década de oitenta, os retornos aos investimentos efetuados em pesquisa agrícola, via EMBRAPA, devem ter contribuído de forma decisiva para elevar a produtividade na agricultura, o que poderá ser comprovado empiricamente com a utilizaçấo de instrumental quantitativo similar ao aqui desenvolvido, tão logo os dados do Censo Agropecuário de 1985 estejam disponíveis. 
ALVES, E.R.A. Apresentação. In: ARAUJO, P.F.C. \& SCHUH, G.E. (coord.) Desenvolvimento da Agricultura. Sấo Paulo, Livraria Pioneira Editora, 1975. p. XI-XIX. (v.2 - Educaçấo, Pesquisa e Assistência Técnica).

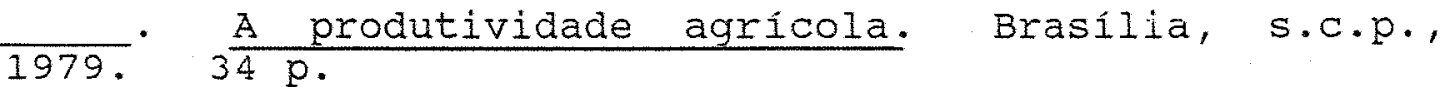

\& SCHUH, G.E. The Economic Evaluation of the Impact of Extension Programs: a suggested methodology and application to ACAR in Minas Gerais, Brazil. s.n.d., $32 \mathrm{p}$.

ALLEN, R.C. \& DIEWERT, W.E. Direct versus implicit superlative index number formulae. Rewiew of Economics and Statistics, Amsterdan, 63(3): 430-435, aug. 1981.

AYER, H.W. \& SCHUH, G.E. Taxa de retorno social e outros aspectos da pesquisa agrícola: o caso do algodão no Estado de Säo Paulo. In: ARAUJO, P.F.C. \& SCHUH, G.E. (coord.) Desenvolvimento da Agricultura. Sấo Paulo, Livraria Pioneira Editora, 1975. p. 117-137. (v.2 - Educaçấo, Pesquisa e Assistência Técnica).

AMARO, A.A. Aspectos Econômicos e Comerciais da Bananicultura. Säo Paulo, Secretaria de Agricultura e Abastecimento, IEA, s.d. 80 p. (näo publicado).

ANJOS, N.M.; YAMĀGUISHI, C.T.; CARVALHO, F.C. Ânálise do Setor Agrícola Brasileiro. São Paulo, secretaria da Agricultura, IEA, 1988. 162 p. (Relatório de Pesquisa $n^{2} 03 / 88$ )

ANUáRIO ESTATÍSTICO DO BRASIL. Rio de Janeiro, IBGE, $1957,1969-1982$.

BALTAGI, B.H. \& GRIFFIN, J.M. A general index of technical change. Journal of Political Economy, Chicago, 96(1): 20-41, jan. 1988 .

BANCO DO NORDESTE DO BRASIL S/A. Superintendência de Desenvolvimento do Nordeste. Mercado e Comercializacáo do Algodäo do Nordeste. Fortaleza, BNB/SUDENE, out. 1964. $286 \mathrm{p}$.

BARBOSA, M.M.T.L.; CRUZ, E.R.; AVILA, A.F.D. Benefícios sociais e econômicos de pesquisa da EMBRAPA: uma reavaliaçâo. In: CONGRESSO BRASILEIRO DE ECONOMIA E SOCIOLOGIA RURAL, 26. Fortaleza, 1988. Anais. Brasilia, SOBER, 1988. 
BARROS, J.R.M. Politica e desenvolvimento agricola no Brasil. In: VEIGA, A. (coord.) Ensaios sobre Política Aaricola Brasileira. Sấo Paulo, Secretaria da Agricultura, 1979 . p. 9-36.

BARREIRA, C. Parceria na Cultura do Algodẫo: sertóes de Quixeramobim. Brasilia, Fundaçăo UnB, $1977116 \mathrm{p}$. (Tese de Mestrado).

BECKER, G. Human Capital. New Jersey, Princeton University, 1964.

BERNDT, E.R. \& CHRISTENSEN, L.R. Testing , for the existence of a consistent aggregate index of labor inputs. American Economic Review, Nashville, $64(3)$ : 391-404, jun. 1974.

BINSWANGER, H.P. The measurement of technical change biases with many factors of production. American Economic Review, Nashville, 64(6): 964-976, dec. 1974.

BLAUG, M. The rate of return on investiment in education in Great Bretain. The Manchester School, Manchester, 23: 5-261, 1965 .

CARVALHO, C.H. Avaliacáo Econômica de um Servico de Extensão Rural: 0 caso da EMATER-MG em Minas Gerais. Viçosa, UFV, 1976. $102 \mathrm{p}$.

CASTRO, C.M. Investimento em Educacấo no Brasil: um estudo de duas comunidades industriais. Rio de Janeiro, IPEA/INPES, 1973. $220 \mathrm{p}$. (Monografia, 12).

CAVES, D.W.; CHRISTENSEN, L.R.; DIEWERT, W.E. Multilateral comparisons of output, input, and productivity using superlative index numbers. Economic Journal, Cambridge, 92(2): 73-86, mar. 1982 .

index $;$ The economic theory of index numbers and the measurement of input, output, and productivity. Econometrica, Bristol, 50(6): 1393-1414, nov. 1982 .
; SWANSON, J.A. Productivity growth, scale economies, and capacity utilization in U.S. railroads, 1955-74. American Economic Review, Nashville, 71(5): 994-1.002, dec. 1981.

CENSO AGROPECUáRIO. Rio de Janeiro, IBGE, 1970, 1975, 1980 . 
CENSO DEMOGRáFICO. Rio de Janeiro, IBGE, 1970, 1980.

CHRISTENSEN, L.R. Concepts and measurement of agricultural productivity. American Journal of Agricultural Economics, Lexington, 57(5): 910-915, dec. 1975 .

CONTADOR, C.R. Determinantes da tecnologia agrícola no Brasil. In: CONTADOR, C.R. (ed.) Tecnoloaia e Desenvolvimento Agrícola. Rio de Janeiro, IPEA/INPES, 1975: 131-179.

CUNHA, A.C. \& DAGUER, R.J. Crescimento agrícola: área $x$ produtividade. In: CONGRESSO BRASILEIRO DE ECONOMIA E SOCIOLOGIA RURAI, 20. Curitiba, 1982. Anais. Brasilia, SOBER, 1982.

DIAS, G.L.S. Avaliaçấo do serviço de extensấo rural: consideraçöes gerais sobre 0 impacto econômico da extensảo rural.

In: ARAUJO, P.F.C. \& SCHUH, G.E. (coord.) Desenvolvimento da Agricultura. Säo Paulo, Livraria Pioneira Editora, 1975. p. 207-238. (v.2 - Educação, Pesquisa e Assistência Técnica)

DIEWERT, W.E. Exact and superlative index numbers. Journal of Econometrics, Amsterdan, $4(2): 115-145$, may 1976 .

- Superlative index numbers and consistency in aggregation. Econometrica, Bristol, 46(4): 883-900, july 1978.

DOMAR, E.D. On the measurement of technological change. Economic Journal, London, 72(4):709-729, dec. 1961.

EICHHORN, W. Fisher's tests revisited. Econometrica, Bristol, $44(2):$ 247-256, mar. 1976.

ENGLER, J.J.C. o capital humano numa função de produçấo na agricultura de Săo Paulo. Pesquisa e Planejamento Econômico, $9(3): 845-884$, dez. 1979 .

EVENSON, R.E. The contribution of agricultural research to production. Jornal of Farm Economics, Ithaca, $49(5): 1.415-1.425$, dec. 1967.

\& JHA, D. The contribution of agricultural research system to agricultural production in India. Indian Journal of Agricultural Economics, Delhi, 28(4):212-230, ouc. 1973 . 
EVENSON, R.E. \& KISLEV, Y. Research and productivity in wheat and maize. Journal of Political Economy, Chicago, 81(6): 1.309-1.329, nov./dec. 1973 .
and \& $\frac{}{\text { Investiment in agricultural research }}$ data. Economic Development and Cultural Change, Chicago, $\underline{23(5): 507-521,1975 .}$

FANE, G. Education and harageital efficiency of farmers. Review of Economics and statistics, Amsterdan, 57(4): 452-461, nov. 1975.

FISHER, I. The making of index numbers. Boston, Houghton Miffiin Co., 1922.

FONSECA, M.A.S.; ARAUJO, P.F.C.; PEDROSO, I.A. Retorno Social aos Investimentos em Pesquisa na cultura do Café. Såo Paulo, Secretaria de Ägricultura, IEA, 1979. $25 \mathrm{p}$. (relatório de pesquisa $3 / 79$ ).

FUNDAÇẤO GETÚLIO VARGAS. Precos Paqos pelos Agricultores. Rio de Janeiro, FGV, Vários números.

Terras, Precos Médios de Arrendamentos, Vendas de Vários números. Janeiro, $\frac{\text { Retrospectiva da Agropecuária. Rio de }}{\text { FGV, Vários números. }}$

GIBBON, V.H. Taxas de retorno dos investimentos em educaçẩo no Brasil: uma análise desagregada. Revista Brasileira de Economia, Rio de Janeiro, 29(3): 109-133, jul. 1975.

GISSER, M. Schooling and Agricultural Labor Force. Chicago, University of Chicago, $64 \mathrm{p}$. (Tese de Doutorado).

GRILICHES, Z. Despesas em pesquisa e educaçấo na funçäo de produçấo agrícola agregada. In: ARAUJo, P.F.C. \& SCHUH, G.E. (coora.) Desenvolvimento da Agricultura. Sắo Paulo, Livraria Pioneira Editora, 1975. p. 101-116. (v.2 - Educaçẩ, Pesquisa e Assistência Técnica)

HAYAMI, Y. \& RUTTAN, V.W. Diferenças de produtividade agricola entre Naçőes. In: ARAUJO, P.F.C. \& SCHUH, G.E. (coord.) Desenvolvimento da Agricultura. São Paulo, Livraria Pioneira Editora, 1975. p. 77-99. (v.2 - Educaçäo, Pesquisa e Assistência Técnica) 
HOFFMANN, R. \& VIEIRA, S. Análise de Regressäo: uma introduçắo à econometria. Sắo Paulo, HUCITEC/EDUSP, 1977. $339 \mathrm{p}$.

HUFFMAN, W.E. Decision making: the role of education. American Journal of Acricultural Economics, Ithaca, 56(1):85-96, feb. 1974 .

JOHNSTON, B.F. \& MELLOR J.W. The role of agriculture in economic development. American Economic Review, Nashville, 51 (4):566-593, sept. 1961.

JORGENSON, D.W. \& GRILICHES, Z. The explanation of productivity change. Review of Economic Studies, London, 34(3): 249-283, jul. 1967 .

\& NISHIMIZU, M. U.S. and Japonese economic growth, 1952-1974: an international comparison. Economic Journal, London, 88(4): 707-726, dec. 1978.

LANGONI, C.G. A rentabilidade social dos investimentos em educaçăo no Brasil. In: Ensaios Econômicos, Homenagem a Otávio Gouvêa de Bulhöes. Rio de Janeiro, APEC Editora, 1972. p. 343-378.

LAU, L.J. On exact index numbers. Rewiew of Economics and Statistics, Amsterdan, 61(1): 73-82, feb. 1979.

LOOCKHEED, M.E. et alii. Farmer education and farm efficiency: a survey. Economic Development and Cultural Change, 29(1): 37-76, jan. 1980 .

MEDINA, J.C. Cultura. In: et alii. Banana: da cultura ao processamento e comercialização. Campinas, Secretaria da Agricultura, ITAL, 1978. p.7-62. (série Frutas Tropicais, 3).

MORICOCHI, L.; NEVES, E.M.; ARAUJO, P.F.C. Pesquisa e assistência técnica na citricultura: custos e retornos sociais. Revista de Economia Rural, Brasilia, 19(2): 189-203, abr./jun. 1981.

NADIRI, M.I. Some approaches to the theory and measurement of total factor productivity: a survey. Journal of Economic Literature, Nashville, 8(4):1137-1177, ouc. 1970 .

NOGUEIRA, E.A. Estudo sobre a Viabilidade Econômico-Financeira da Cacauicultura no Estado de säo Paulo. Säo Paulo, FGV, 1986. 133 p. (Tese de Mestrado) 
PASTORE, A.C.; ALVES, E.R.A.; RIZZIERE, J.A.B. A inovaçâo induzida e os limites à modernização na agricultura brasileira. Revista de Economia Rural, Brasilia, $14(1): 257-285$, jan. 1976 .

PATRICK, G.F. Fontes de crescimento na agricultura brasileira. In: CONTADOR, C.R Tecnologia e Desenvolvimento Agricola. Rio de Janeiro, IPEA/INPES, 1975. pp. 89-110. (Série Mcnograsica, 17)

\& KEHRBERG, E.W. Custos e retornos da educação em cinco áreas da Região Leste do Brasil. In: ARAUJO, P.F.C. \& SCHUH, G.E. (coord.) Desenvolvimento da Agricultura. São Paulo, Livraria Pioneira Editora, 1975. p. 17-34. (v.2 - Educaçäo, Pesquisa e Assistência Técnica)

PENNA, J.A. \& MONTEIRO, A.A. A taxa de retorno da pesquisa extensão agrícola do cacau brasileiro. Estudos Econômicos, Sâo Paulo, $6(3)$ : 51-82, set./dez. 1976.

PROGNóSTICO Região Centro-Sul 76/77. São Paulo, Secretaria da Agricultura, IEA, out. 1976. 277 p.

RIBEIRO, J.I. A contribuiçã́o da educação na produçăo agricola. Revista de Economia Rural, Brasilia, 17(4): 86-118, set. 1979 .

RIBEIRO, J.P. \& WHARTON Jr., C.R. O programa ACAR em Minas Gerais, Brasil. In: ARAUJO, P.F.C. \& SCHUH, G.E. (coord.) Desenvolvimento da Agricultura. Săo Paulo, Livraria Pioneira Editora, 1975. p.141-166. (v.2 Educação, Pesquisa e Assistência Técnica)

SAMUELSON, P.A. \& SWAMY, S. Invariant economic index numbers and canonical duality: survey and synthesis. American Economic Review, Nashville, 64(4):566-593, sep. 1974 .

SERIE APTIDÃO AGRICOLA DAS TERRzs. Brasilia, Ministério da Agricultura, Secretaria Nasional de Planejamento Agricola, BINAGRI, $21 \mathrm{v}$.

SCHULTZ, T.W. A Transformacão da Agricultura Tradicional. Rio de Janeiro, Zahar, 1965. $208 \mathrm{p}$.

The value of the ability to deal with
disequilibria. $\frac{\text { Journal of }}{872-876}$, jul. 1975.


SILVA, G.I.S.P. Reflexöes sobre o papel da agricultura no Brasil. Aaricultura em Săo Paulo, SP, 29(1/2): 1-20, 1982 .
Rural. $\frac{\text { Produtividade Agrícola, Pesquisa e Extensão }}{\text { Säo Paulo, IPE/USP, 1984. (Série Ensaios }}$ Econômicos, 40)

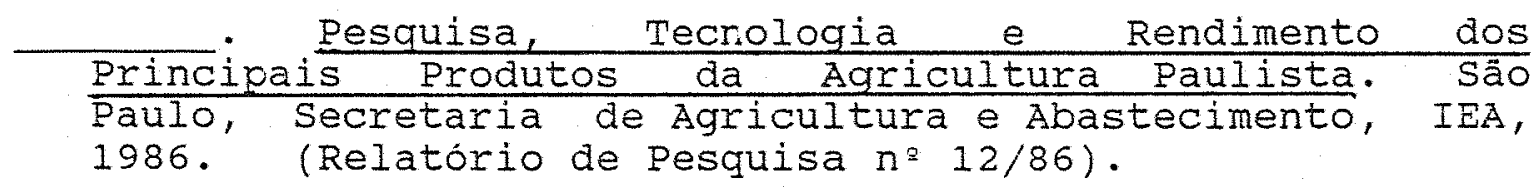

\& CARMO, H.C.E. Como medir a produtividade agricola: conceitos, métodos e aplicações no caso de săo Paulo. Agricultura em São Paulo, SP, 33(1/2): 139-170, 1986.

; CASER, D.V.; VICENTE, J.R. Efeitos das condições do tempo sobre a produtividade agrícola no Estado de São Paulo. Revista de Economia Rural, Brasilia, 23(1): 3-19, jan./mar. 1985.

; FONSECA, M.A.S.; MARTIN, N.B. Pesquisa e produçấo agrícola no Brasil. Agricultura em São Paulo, SP , 26 (2): 175-253, 1979 .

agricola e o problema da produção de ${ }^{\prime}$ al onentos: pesquisa evidências no caso de São Paulo. Revista de Economia Rural, Brasilia, 18(1): 37-59, jan./mar. 1980.

- $;$ - Investimento na geraçăo e difusăo de tecnologia agrícola no Brasil. Agricultura em Săo Paulo, SP, 28(1/2): 1-17, 1981.

; VICENTE, J.R.; CASER, D.V. Variacốes do Temoo e Produtividade Agricola: um subsidio à previsão de safras no Estado de Săo Paulo. Campinas, Fundaçăo Cargill, 1986. $148 \mathrm{p}$.

SMITH, C. A politica agricola brasileira: 1950-1967. In: ARAUJO, P.F.C. \& SCHUH, G.E. Desenvolvimento da Agricultura: estudo de caso. Săo Paulo, Iivraria Pioneira, 1983. v.4, p. 213-256. (Série Estudos Agrícolas).

SOLOW, R. Technical change and the agregate production function. Rewiew of Economics and Statistics, Amsterdan, 39(3):312-320, aug. 1957

STAR, S. \& HALL, R.E. An approximate Divisia index of total factor productivity. Econometrica, Bristol, 44(2): 257-263, mar. 1976. 
THAME, A.C.M.; VICENTE, J.R.; VICENTE, M.C.M. Escolaridade e Măo-de-obra Rural no Brasil, 1970-80. Agricultura em São Paulo, SP, 34(1/2): 141-183, 1987 .

THOMPSON, R.L. The Metaproduction Function for Brazilian Agriculture: an analysis of productivity and other aspects for agricultural growth. Indiana, Purdue University, 1974. $177 \mathrm{p}$. (Tese de PhD)

THORNTWAITE, C.W. \& MATTER, J.R. The Water Balance. Centerton, Laboratory of Climatology, 1955. $104 \mathrm{p}$.

VERA FILHO, F. \& TOLLINI, H. Progresso tecnológico e desenvolvimento agrícola. In: VEIGA, A. (coord.) Ensaios sobre Politica Agricola Brasileira. Săo Paulo, Secretaria da Agricultura, 1979. p. 87-136.

WELCH, F. Education in production. Journal of Political Economy, Chicago, 78(1): 35-39, jan. 1970. 
APêNDICE 1. Dados Básicos Utilizados e Váriáveis Calculadas 


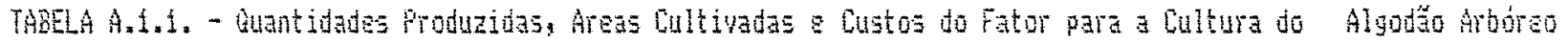

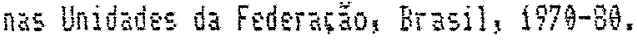

\begin{tabular}{|c|c|c|c|c|c|c|c|c|c|}
\hline \multirow{2}{*}{$\begin{array}{c}\text { Unidade } \\
\text { da } \\
\text { Federarato }\end{array}$} & \multicolumn{3}{|c|}{$\begin{array}{c}\text { Guentidade froduzida } \\
\text { (t) }\end{array}$} & \multicolumn{3}{|c|}{$\begin{array}{l}\text { Area Cultivada } \\
\text { (ha) }\end{array}$} & \multicolumn{3}{|c|}{$\begin{array}{l}\text { Custo do Fator } \\
\text { (Cis de o9/ha) }\end{array}$} \\
\hline & 1970 & 1975 & 1990 & 1970 & 1975 & 1900 & 1970 & 5075 & 1884 \\
\hline \multicolumn{10}{|l|}{ Wordeste } \\
\hline Alagoas & ij & 1.302 & ) & 굴 & 2.062 & $\theta$ & $: 1.737$ & 1.854 & 1.854 \\
\hline Bahia & 0 & 4.150 & 1.132 & ) & 7.700 & 2.390 & 1.737 & 1.054 & 1.054 \\
\hline Cents & 10.380 & 122.588 & 73.168 & 52.716 & 728.223 & 587.267 & 1.737 & 1.854 & 1.854 \\
\hline Paraiba & 15.683 & 69.624 & 19.629 & 56.412 & 498.741 & 2et.977 & 1.737 & 1.354 & 6.354 \\
\hline 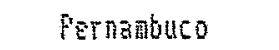 & 12.790 & 21.472 & 11.272 & 5.261 & 149.624 & 106.997 & 1.737 & 1.854 & 1.854 \\
\hline Piaui & 1.993 & 19.533 & 11.809 & 11.922 & 194.343 & 160.393 & 1.7 .37 & 1.854 & 1.854 \\
\hline nio Gde. Worte & 19.917 & 59.239 & $14 \times 287$ & $40.39 \mathrm{E}$ & 340.172 & 201.087 & 1.737 & 1.654 & 1.854 \\
\hline Gergipe & 3 & a & 0 & 5 & 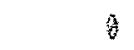 & 9 & 1.737 & 5.05 & 1.954 \\
\hline 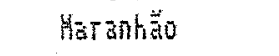 & 9.597 & 3.560 & 2.659 & 48.194 & 23.22 & 10.856 & 1.737 & 1.854 & $1.8 s^{4}$ \\
\hline \multicolumn{10}{|l|}{ Worte } \\
\hline $\mathrm{ACTE}$ & $\hat{\theta}$ & i) & 0 & $\theta$ & 4 & $\theta$ & 1.737 & 1.854 & 1.854 \\
\hline Anazonas & 3 & $\theta$ & 0 & $\theta$ & 3 & 0 & 1.797 & 1.854 & 1.854 \\
\hline AmEA & $\hat{b}$ & $\dot{y}$ & 0 & 9 & 9 & $y$ & 1.737 & 1.854 & 1.854 \\
\hline Pard & $\theta$ & 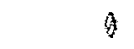 & $\theta$ & 9 & 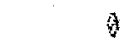 & 9 & 1.737 & 1.954 & 1.35 .4 \\
\hline Roraima & $\theta$ & 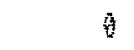 & 3 & 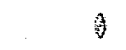 & 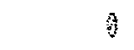 & 3 & 1.737 & 1.854 & 1.85 \\
\hline Rondonia & 4 & $\dot{\theta}$ & ) & 3 & $\theta$ & 3 & 1.737 & 1.854 & 1.854 \\
\hline \multicolumn{10}{|l|}{ Centro-ueste } \\
\hline Mato Grosso & f & 1 & 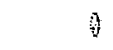 & i & i & 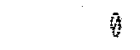 & 1.737 & 1.854 & 1.854 \\
\hline Vistr. Federal & 3 & ) & 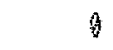 & 9 & 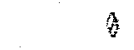 & 9 & 1.737 & 1.954 & 1.85 .4 \\
\hline Goias & 3 & 0 & $\vartheta$ & a & $\theta$ & t) & 1.737 & 1.054 & 1.354 \\
\hline \multicolumn{10}{|l|}{ Gudeste } \\
\hline Minas Gerais & 然 & 16 & 9 & 月 & 31 & 3 & 1.737 & 1.854 & 1.854 \\
\hline Espirito Santo & 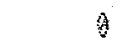 & $\theta$ & 0 & 9 & a & $\theta$ & 1.737 & 1.054 & 1.85 \\
\hline Rio de Janeiro & i & 0 & $\theta$ & 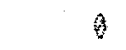 & f & $\theta$ & 1.737 & 1.054 & 1.854 \\
\hline Săo Paulo & ) & 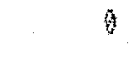 & 1 & s & 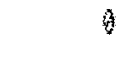 & $\theta$ & 1.737 & 1.854 & 1.854 \\
\hline \multicolumn{10}{|l|}{ sul } \\
\hline Patoná & $\theta$ & $\partial$ & 4 & 0 & in & A & 1.737 & 1.854 & 1.854 \\
\hline Santa Catarina & 3 & $\theta$ & 9 & $\theta$ & $y$ & 0 & 1.737 & 1.854 & 1.854 \\
\hline Gio bue. Sul & a & 1 & 4 & 9 & t) & 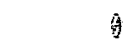 & 1.737 & 1.854 & 1.854 \\
\hline
\end{tabular}

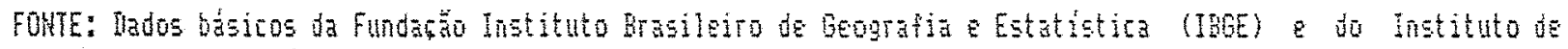
Economia Agrirola (IEA). 
TABELA A.1.2. - Guantidades Produzidas, Areas Cultivadas a Custos do Fator para a Cultura da Ganana

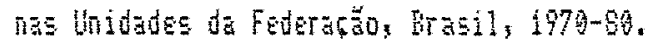

\begin{tabular}{|c|c|c|c|c|c|c|c|c|c|}
\hline \multirow{2}{*}{$\begin{array}{c}\text { Unidade } \\
\text { ds } \\
\text { Federabăo }\end{array}$} & \multicolumn{3}{|c|}{$\begin{array}{c}\text { Qusntidade Produzida } \\
\text { (t) }\end{array}$} & \multicolumn{3}{|c|}{$\begin{array}{c}\text { Ares Cultivada } \\
\text { that }\end{array}$} & \multicolumn{3}{|c|}{$\begin{array}{l}\text { Custo do Fator } \\
\text { (Ct) de } 3 / h a)\end{array}$} \\
\hline & 1979 & 1975 & 1790 & $17 \%$ & 1075 & 1900 & 1979 & 1975 & 1990 \\
\hline \multicolumn{10}{|l|}{ Wordeste } \\
\hline Hagoas & 4.755 & 5.695 & 4.513 & 8.887 & 4.759 & 4.813 & 4.176 & 4.287 & 4.458 \\
\hline Bahia & 18.495 & 27.872 & 49.930 & 35.972 & 29.203 & 37.937 & 4.178 & 4.289 & 4.420 \\
\hline Eearä & 14.308 & 21.240 & 11.586 & 23.948 & 22.75 .4 & 14.483 & 4.173 & 4,289 & 4.428 \\
\hline Paraiba & 2.869 & 5.696 & 6.696 & 6.330 & 5.412 & 5.852 & 4.176 & 4.209 & 4.429 \\
\hline ferna耼uco & 12.727 & 18.585 & 27.805 & 25.299 & 24.691 & 19.349 & 4.178 & 4.289 & 4.428 \\
\hline Pianí & 1.594 & 1.642 & 861 & 2.837 & 1.644 & 953 & $4 \times 176$ & 4.289 & 4.428 \\
\hline Rio Gde. Horte & 2.597 & 1.377 & 1.480 & 3.696 & 1.669 & 1.385 & 4.170 & 4.289 & 4,420 \\
\hline Sergipe & 1.236 & 1.777 & 1.694 & 2.114 & 1.727 & 1.194 & 4.179 & 4.289 & 4.429 \\
\hline 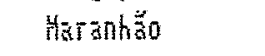 & 6.816 & 6.618 & 6.497 & 10.999 & 5.722 & 5.795 & 4.170 & 4.289 & 4.488 \\
\hline \multicolumn{10}{|l|}{ Worte } \\
\hline ACTE & 1.712 & 1.278 & 2.239 & 1.811 & 1.942 & 2.370 & $4 \times 178$ & 4.289 & 4.425 \\
\hline Amazonas & 4.547 & 362 & 10.680 & 7.788 & 516 & $11.97 \%$ & 4.170 & 4.289 & 4.420 \\
\hline Anละ & 298 & 978 & 451 & 661 & 1.134 & 945 & 4.178 & 4.289 & 4.428 \\
\hline Pará & 7.654 & 8.443 & 14.417 & 10.858 & 9.142 & 16.969 & 4.178 & 4.289 & 4.420 \\
\hline RoT in & 323 & 393 & 898 & 613 & 420 & 721 & 4.170 & 4.289 & 4.428 \\
\hline Rondônia & 1.459 & 3.131 & 2.133 & 2.767 & 3.934 & 2.863 & 4.178 & 4.209 & 4.428 \\
\hline \multicolumn{10}{|l|}{ Centro-0este } \\
\hline Hato Gros50 & 4.294 & 3.534 & 4.878 & 7.774 & $9.86 ?$ & 6.301 & 4.178 & 4.289 & 4.420 \\
\hline Distr. Federal & 293 & 500 & $36 \hat{2}$ & 769 & 479 & 291 & 4.170 & 4.207 & 4,420 \\
\hline $601 \frac{1}{65}$ & 19.993 & 11.251 & 17.351 & 27.467 & 10.545 & 20.598 & 4.178 & 4.289 & 4.428 \\
\hline \multicolumn{10}{|l|}{ Sudeste } \\
\hline Hinas Gerais & 14.749 & 11.577 & $18.74 \hat{C}$ & 29.643 & 12.199 & 29.142 & 4.178 & 4.289 & 4.428 \\
\hline Espirito Santu & 12.971 & 13.663 & 16.716 & 23.419 & 14.217 & 17.637 & $4 \times 170$ & 4.289 & 4.428 \\
\hline Rio de Janeito & 28.671 & 21.929 & 19.267 & 50.419 & c7.7. & 21.814 & 4.178 & 4.289 & 4.428 \\
\hline Sato pato & 29.452 & 33.769 & 35.653 & 46.784 & 29.780 & 28.414 & 4.178 & 4.289 & $4 .+28$ \\
\hline \multicolumn{10}{|l|}{ Sul } \\
\hline Patank & 5.150 & 3.315 & 7.192 & 9.462 & 3.839 & 6.395 & 4.178 & 4.289 & 4.428 \\
\hline Ganta Catarina & 14.432 & 1.878 & 14.657 & 24.226 & 1.951 & 12.367 & 4.178 & 4.289 & 4.428 \\
\hline Rio Bde. Sul & 7.742 & 4.829 & 5.887 & 11.966 & 6.281 & $5 \times 997$ & 4.178 & 4.289 & 4.428 \\
\hline
\end{tabular}

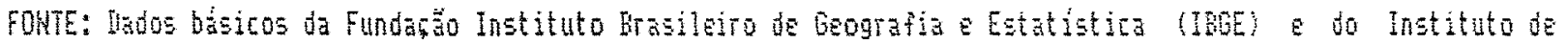
Economia Agricola (IEA). 
TAgEA A.1.3. - Quantidades Froduzidas, Areas Cultivadas a Custos do Fator para a Cultura du Cacali

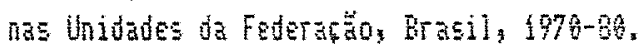

\begin{tabular}{|c|c|c|c|c|c|c|c|c|c|}
\hline \multirow{2}{*}{$\begin{array}{l}\text { Unidade } \\
\text { Já } \\
\text { Federatao }\end{array}$} & \multicolumn{3}{|c|}{$\begin{array}{l}\text { Auntidade hoduziod } \\
\text { (t) }\end{array}$} & \multicolumn{3}{|c|}{$\begin{array}{l}\text { Area Cultivada } \\
\text { (ha) }\end{array}$} & \multicolumn{3}{|c|}{$\begin{array}{l}\text { Custo do Eator } \\
\text { (C) de go/ha? }\end{array}$} \\
\hline & 1979 & 1975 & 1989 & 1979 & 1975 & 1900 & $197 \mathrm{~A}$ & 1975 & 1980 \\
\hline \multicolumn{10}{|l|}{ Hordeste } \\
\hline A]agoas & $\theta$ & 0 & 4 & 0 & $y$ & 0 & 5.95 & 5.135 & 5.135 \\
\hline Bahia & 193.962 & 280.662 & 327.153 & 377.585 & 421.124 & 427.350 & 5.135 & 5.435 & 5.135 \\
\hline Centít & $\theta$ & 4 & $\theta$ & 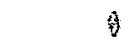 & $\theta$ & 0 & 5.135 & $5 \times 135$ & 5.135 \\
\hline Paraiba & $\theta$ & $a$ & $A$ & $\theta$ & $\theta$ & $\theta$ & 5.135 & 5.135 & 5.135 \\
\hline Permatouco & $\theta$ & 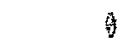 & 0 & 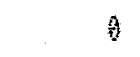 & $\theta$ & 0 & 5.135 & 5.135 & 5.135 \\
\hline Piauí & $\theta$ & 0 & 9 & 0 & a & i & 3.135 & 5.135 & 5.135 \\
\hline Rio Bde. Worte & $\theta$ & $\theta$ & 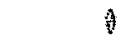 & 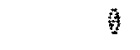 & 0 & i & 5.135 & 5.135 & 5.135 \\
\hline Sergipe & 9 & 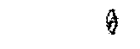 & $\theta$ & t & 0 & 9 & 5.135 & 5.135 & 5.135 \\
\hline ถูก สnh & $b$ & 11 & $\theta$ & 12 & 72 & 1 & 5.135 & 5.135 & 5.13 \\
\hline \multicolumn{10}{|l|}{ Horte } \\
\hline Acte & in & 1) & 8 & $\theta$ & $\theta$ & 0 & 5.135 & 5.135 & 5.135 \\
\hline Amazonas & 1.626 & 590 & 964 & 2.195 & 2.800 & 1.553 & 5.135 & 5.135 & 5.45 \\
\hline Anagá & 17 & A & $\theta$ & 19 & $\theta$ & 0 & 5.135 & 5.135 & 5.135 \\
\hline Parti & 1.279 & 1.772 & 7.226 & 15.795 & 7.858 & 13.228 & 5.135 & 5.135 & 5.135 \\
\hline Rorai & 0 & $y$ & $\theta$ & $y$ & a & $\theta$ & 5.135 & 5.135 & 5.135 \\
\hline Rondonta & $\theta$ & 12 & 2.902 & a & 55 & 7.412 & 5.135 & 5.435 & 5.135 \\
\hline \multicolumn{10}{|l|}{ Centro-1este } \\
\hline Hato Grosso & औ & 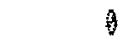 & 168 & ) & ) & 560 & 5.135 & 5.135 & 5.135 \\
\hline Distr. Foderal & ti & $\theta$ & $\hat{\theta}$ & $\Rightarrow$ & $\theta$ & $\hat{v}$ & 5.135 & 5.135 & 5.135 \\
\hline 60135 & 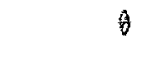 & $\theta$ & 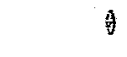 & $\Rightarrow$ & $\theta$ & in & 5.135 & 5.135 & 5.135 \\
\hline \multicolumn{10}{|l|}{ Sudeste } \\
\hline Hinas Gerais & 18 & 23 & 84 & 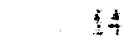 & 52 & 56 & 5.135 & 5.135 & 5.135 \\
\hline Espírito Santo & 5.754 & 9.28 & 11.762 & 19.656 & 21.462 & 15.240 & 5.135 & 5.135 & 5.135 \\
\hline Rio de Janeiro & $\theta$ & 9 & $y$ & 3 & औ & $\theta$ & 5.135 & 5.135 & 5.135 \\
\hline Săo Paulo & 33 & 160 & 155 & 127 & 442 & 163 & 5.135 & 5.135 & 5.135 \\
\hline \multicolumn{10}{|l|}{ Sul } \\
\hline Paranà & $\theta$ & g & 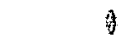 & 3 & i & t & 5.135 & 5.135 & 5,135 \\
\hline Santa Catarina & in & 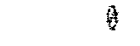 & $\theta$ & $g$ & 0 & $t$ & 5.135 & 5.135 & 5.135 \\
\hline fio Gde. Sul & औ) & 角 & is & 9 & A & 9 & 5.135 & 5.135 & 5.135 \\
\hline
\end{tabular}

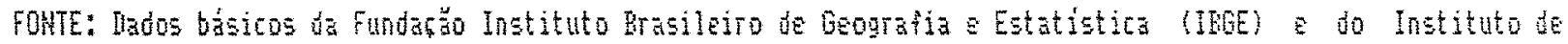
Econonia Agricola (IEA). 
TARELA A.1.4. - Guantidades Produzidas, Areas Cultivadas e Custos do Fator para a Cultura do cale

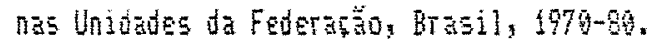

\begin{tabular}{|c|c|c|c|c|c|c|c|c|c|}
\hline \multirow{2}{*}{$\begin{array}{c}\text { Snibde } \\
\text { da } \\
\text { Federatá }\end{array}$} & \multicolumn{3}{|c|}{$\begin{array}{l}\text { Quantidade produzida } \\
\text { (t) }\end{array}$} & \multicolumn{3}{|c|}{$\begin{array}{c}\text { Area Cultivaúa } \\
\text { (ha) }\end{array}$} & \multicolumn{2}{|c|}{$\begin{array}{l}\text { Custo do Fator } \\
\text { (chl de bo/ha) }\end{array}$} & \multirow[b]{2}{*}{1780} \\
\hline & 1970 & 1975 & 1909 & 1976 & 1975 & $\$ 900$ & 1970 & 1975 & \\
\hline \multicolumn{10}{|l|}{ Hordeste } \\
\hline Alagoas & 219 & 182 & 34 & 571 & 31 & 90 & 4.235 & 4.130 & $6.64 \frac{4}{4}$ \\
\hline Bahia & 20.577 & 16. & 80.316 & 27.216 & 24.933 & 65.207 & 4.235 & 4.130 & 6.644 \\
\hline Cerară & 2.606 & 3.854 & 3.064 & 11.660 & 11.440 & 11.449 & 4.235 & 4.130 & 6.644 \\
\hline Paraiba & 223 & 30 & 114 & $77 b$ & 157 & 230 & 4.235 & 4.130 & 6.44 \\
\hline Pernambuco & 11.718 & 3.959 & 6.297 & 24.906 & 18.421 & $\{5,486$ & 4.235 & 4.130 & 6.644 \\
\hline Piauí & $\theta$ & $\theta$ & $\theta$ & 9 & 9 & 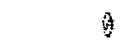 & 4.235 & 4.134 & 6.644 \\
\hline Ro bue. iturte & ) & in & 8 & 3 & $\theta$ & $\hat{\theta}$ & 4.235 & 4.139 & 6.344 \\
\hline Sergipe & 49 & 54 & $g$ & 102 & 146 & 0 & 4.235 & 4.130 & 6.644 \\
\hline 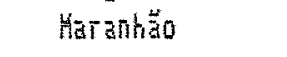 & 39 & 38 & 199 & int & 158 & 219 & 4.235 & 4.130 & 6.644 \\
\hline \multicolumn{10}{|l|}{ Norte } \\
\hline ACTE & 32 & 118 & 278 & 113 & 85 & 463 & 4.235 & 4.130 & 6.644 \\
\hline Amazonas & 289 & 175 & 32 & 424 & 410 & 34 & 4.235 & 4.130 & 6.644 \\
\hline A & 7 & 4 & 3 & 33 & 10 & 8 & 4.235 & 4.130 & 6.644 \\
\hline Pará & 383 & 555 & 731 & 632 & 817 & 1.313 & 4.235 & 4.190 & 6.644 \\
\hline fioraina & 1 & 3 & $\theta$ & 2 & i & $\theta$ & 4.235 & 4.139 & 6.644 \\
\hline Rondônia & 19 & 1.021 & 13.907 & 63 & 1.428 & 22.376 & +2.255 & 4.190 & 6.644 \\
\hline \multicolumn{10}{|l|}{ Centro-deste } \\
\hline Hato $6 r 0550$ & 4.899 & 15.757 & 27.957 & 3.656 & 19.081 & 43.249 & 4.235 & 4.139 & 6.644 \\
\hline Distr. Federal & 14 & 33 & $\mathrm{gec}$ & 33 & 85 & 561 & 4.235 & 4.139 & 6.644 \\
\hline Goiás & 1.954 & 2.688 & 15.780 & 3.236 & 4.723 & 11.505 & 4.235 & 4.130 & 6.644 \\
\hline \multicolumn{10}{|l|}{ Sudeste } \\
\hline Hinás Gerais & 288.313 & 253.889 & 456.718 & 283.827 & 283.763 & 446.197 & 4.235 & 4.130 & 3.644 \\
\hline Espirito Santo & 161.556 & 97.863 & 273.749 & 172.232 & 164.479 & 259.932 & 4.235 & 4.130 & 6.644 \\
\hline Kio de Janeiro & 5.978 & 2.796 & 7.722 & 10.070 & 4.748 & 7.758 & 4.235 & 4.130 & 6.644 \\
\hline Să Paulo & 445.299 & 795.532 & 741.684 & 617.234 & 651.422 & 739.235 & 4.235 & 4.130 & 6.647 \\
\hline \multicolumn{10}{|l|}{ Sul } \\
\hline Parana & 115.383 & 1.135 .541 & 352.410 & 355.929 & 890.740 & 572.236 & 4.235 & 4.130 & $6.6+4$ \\
\hline Santa Catarina & 1.344 & 715 & 132 & 2.260 & $8+3$ & 53 & 4.235 & 4.120 & 6.644 \\
\hline Rio bde, Sul & 0 & 0 & 9 & $\theta$ & $\theta$ & $\theta$ & 4.235 & 4.130 & 6.644 \\
\hline
\end{tabular}

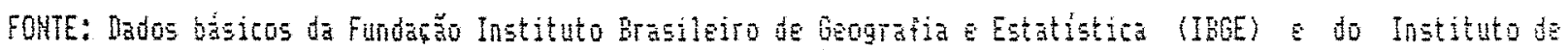
Economia Agricola (IEA). 
TABELA A.1.5. - Guantidades Produzidas, Areas Cultivadas e Custos do Fator para a Cultura da Cana-de-acucar

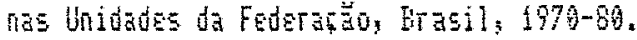

\begin{tabular}{|c|c|c|c|c|c|c|c|c|c|}
\hline \multirow{2}{*}{$\begin{array}{c}\text { Unidade } \\
\text { da } \\
\text { Foderarato }\end{array}$} & \multicolumn{3}{|c|}{$\begin{array}{l}\text { Quantidade froduzida } \\
\text { (ail t) }\end{array}$} & \multicolumn{3}{|c|}{$\begin{array}{l}\text { Area Cultivaúa } \\
\text { (ha) }\end{array}$} & \multicolumn{3}{|c|}{$\begin{array}{l}\text { Gusto do Fatur } \\
\text { (C) de So/ha) }\end{array}$} \\
\hline & 1979 & 1975 & 1980 & 1770 & 1975 & 1980 & $\therefore \quad 1970$ & 1975 & 1989 \\
\hline \multicolumn{10}{|l|}{ Wordeste } \\
\hline Alagoas & 7.234 & 11.505 & 17.760 & 164.711 & 271.086 & 379.480 & 7.797 & 9.492 & 11.654 \\
\hline Bahis & 1.999 & 736 & 798 & 43.281 & 31.983 & 23.962 & 7.767 & 7.492 & 11.654 \\
\hline Ceata & 1.064 & 1.117 & 1.1036 & 44.749 & 35.781 & 28.766 & 7.767 & 9.492 & 11,654 \\
\hline Paraiva & 1.4อ2 & 1.850 & 3.892 & 37.577 & 53.712 & 84.596 & 7.767 & 9.492 & 11.654 \\
\hline fernambuco & 11.023 & 14.129 & 17.890 & 271.268 & 332.231 & 378.189 & 7.767 & 9.402 & 11.654 \\
\hline Piaui & 177 & 339 & 123 & 9.362 & 13.154 & 5.199 & 7.767 & 9.492 & 11.654 \\
\hline Rio Gde. Horte & 365 & 559 & 1.697 & 11.757 & $15 \times 249$ & 36.198 & 7.767 & 9.402 & 11.654 \\
\hline Sergioe & 557 & 739 & 1.391 & 16.612 & 16.864 & 20.848 & 7.767 & 9.492 & 12.654 \\
\hline Maranha & 156 & 411 & 45 & 6.887 & 14.472 & 10.649 & 7.767 & 9.402 & 11.65 \\
\hline \multicolumn{10}{|l|}{ Norte } \\
\hline ACTE & 9 & $\hat{2 E}$ & 22 & 480 & 1.969 & 832 & 7.767 & 9.402 & 11.054 \\
\hline 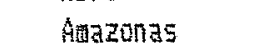 & 13 & 60 & 33 & 502 & 1.071 & 699 & 7.767 & 7.192 & 19.654 \\
\hline Ansp à & 1 & 1 & 1 & 30 & 64 & 47 & 7.767 & 9.302 & 11.654 \\
\hline Para & 131 & 359 & 378 & 3.820 & 11.334 & 7.473 & 7.767 & 9.492 & 11.654 \\
\hline Rotaind & in & 13 & $\theta$ & 24 & 590 & 3 & 7.767 & 9.462 & 11.654 \\
\hline Rondônia & 2 & 3 & 24 & 186 & 200 & 783 & 7.767 & 9.462 & 11.654 \\
\hline \multicolumn{10}{|l|}{ Eentro-0este } \\
\hline Hato $6 r 0 s 50$ & 53 & 68 & 652 & c.795 & 2.521 & 17.663 & 7.767 & 9.402 & 11.654 \\
\hline Distr. Federal & 2 & 4 & 5 & $2 \mathrm{a}$ & 399 & 235 & 7.767 & 9.492 & 11.654 \\
\hline boits & 196 & 614 & 667 & 8.130 & 15.350 & 10.875 & 7.767 & 9.402 & 11.654 \\
\hline \multicolumn{10}{|l|}{ Sudeste } \\
\hline dinas berais & 3.504 & 3.397 & 7.662 & 134.959 & 100.350 & 140.709 & 7.767 & 9.492 & 15.654 \\
\hline Espirito Santo & 413 & 476 & 690 & 18.492 & 12.539 & 57.413 & 7.767 & 9.462 & 11.654 \\
\hline fio de Janeiro & 5.465 & 6.456 & 4.828 & 177.171 & 161.522 & 890.299 & 7.767 & 9.402 & 11.654 \\
\hline Să Paulo & 29.846 & 34.276 & 71.597 & 560.495 & 681.906 & 1.061 .354 & 7.767 & 9.492 & 11.654 \\
\hline \multicolumn{10}{|l|}{ Sul } \\
\hline Paraná & 1.635 & 1.677 & 4.964 & 20.588 & 31.875 & 58.729 & 7.767 & 9.492 & 11.654 \\
\hline Santa Catarina & 797 & 939 & 796 & 25.182 & 21.418 & 17.379 & 7.767 & 9.402 & 11.654 \\
\hline Rio Gde. Sul & 701 & 814 & 870 & 34.880 & 37.920 & 32.193 & 7.767 & 9.492 & 11.654 \\
\hline
\end{tabular}

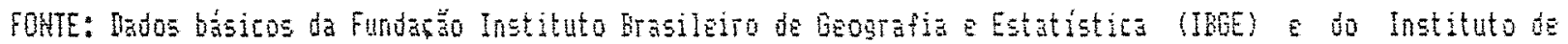
Econouia Agricola (IEA). 
TABLLA A.1.6. - Quantidade Produzidas Areas Cultivadas e Custos do Fator para a Cultura da Laranja nass Unidades da Federasăo, Brasil, $1970-80$.

\begin{tabular}{|c|c|c|c|c|c|c|c|c|c|}
\hline \multirow{2}{*}{$\begin{array}{c}\text { Whidade } \\
\text { da } \\
\text { Foderacáco }\end{array}$} & \multicolumn{3}{|c|}{$\begin{array}{l}\text { Gulintidade froduzida } \\
\text { lailhos de frotati }\end{array}$} & \multicolumn{3}{|c|}{$\begin{array}{l}\text { Area Cultivada } \\
\text { (ha) }\end{array}$} & \multicolumn{3}{|c|}{$\begin{array}{l}\text { Cueto do Fator } \\
\text { (Cr) de Ba/ha) }\end{array}$} \\
\hline & 1978 & 1975 & 1980 & 1978 & 1975 & 1980 & 1979 & 1975 & 1980 \\
\hline \multicolumn{10}{|l|}{ hordeste } \\
\hline MIสตันล & 81 & 71 & 74 & 552 & 998 & 1.061 & $1.49 ?$ & 2.139 & 2.732 \\
\hline Bahia & 429 & $\$ 99$ & 637 & 6.357 & 9.253 & 8.390 & 1.497 & 2,139 & 2.733 \\
\hline Ceara & 46 & 173 & 113 & 650 & 1.534 & 1.500 & 1.477 & 2.139 & 2.732 \\
\hline Paraiba & 59 & 296 & 73 & 985 & 1.813 & 1.174 & 1.497 & $2 \times 137$ & 2.739 \\
\hline Pernatubuco & 164 & 141 & 102 & 2.851 & $1.7+5$ & 1.831 & $1 \times 497$ & 2.137 & 2.730 \\
\hline Piaui & 39 & 112 & 22 & 309 & 1.997 & 261 & 1.497 & 2.139 & 2.73 \\
\hline Rio bde, Horts & 7 & 26 & 34 & 87 & 457 & 550 & 1.477 & 2.137 & 2.730 \\
\hline Sergipe & 195 & 315 & 925 & 4.267 & 4.785 & 15.081 & 1.497 & 2.139 & 2.793 \\
\hline 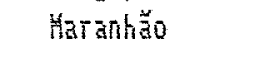 & 126 & 160 & 112 & 1.688 & 582 & 1.287 & 1.497 & 2.139 & 2.790 \\
\hline \multicolumn{10}{|l|}{ Norte } \\
\hline ACTE & 3 & 6 & 4 & 35 & 99 & 36 & 1.497 & 2.139 & 2.732 \\
\hline Amazonas & 75 & 23 & 25 & 655 & 473 & 343 & 1.477 & 2.139 & 2.730 \\
\hline AिMapà & 2 & 4 & $\frac{4}{4}$ & $b$ 은 & 70 & 22 & 1.497 & 2.139 & 2.732 \\
\hline Para & 71 & 122 & 59 & 934 & 1.823 & 891 & 1.497 & 2.139 & 2.732 \\
\hline Foraita & 2 & 3 & 4 & 25 & 88 & 31 & 1.497 & 2.139 & 3.730 \\
\hline Fondônia & 5 & 1 & 20 & 15 & 26 & 353 & 1.497 & 2.139 & 2.73 \\
\hline \multicolumn{10}{|l|}{ Centro-0este } \\
\hline Mato Grosso & 55 & 48 & 25 & 669 & 275 & 381 & 1.497 & 2.139 & 2.732 \\
\hline Distr. Federal & 4 & $b$ & $b$ & 81 & 42 & 125 & 1.397 & 2.139 & 2.738 \\
\hline Goià & 111 & 50 & 64 & 1.230 & 397 & 998 & 1.477 & 2.139 & 2.732 \\
\hline \multicolumn{10}{|l|}{ Sudeste } \\
\hline Hinas Gerais & 395 & 450 & 770 & 5.431 & 4.401 & 11.296 & 1.497 & 2.139 & 2.730 \\
\hline Espirito Santo & 128 & 493 & 116 & 2.212 & 3.590 & 2.455 & 1.497 & 2.139 & 2.730 \\
\hline Rio de Janeiro & 2.155 & 1.878 & 1.514 & 30.131 & 25.841 & $28.27 \%$ & 1.497 & 2.139 & 2.732 \\
\hline Să Faulo & 8.210 & 16.917 & 31.499 & 196.616 & 178.734 & 333.692 & 1.477 & 2.137 & 2.730 \\
\hline \multicolumn{10}{|l|}{ Sul } \\
\hline Faraná & 231 & 203 & 232 & 3.477 & 1.723 & 4.252 & 1.497 & 2.139 & 2.732 \\
\hline Santa Catarina & 217 & $\$ 51$ & 135 & 2.289 & 794 & 1.686 & 1.397 & 2.139 & 2.730 \\
\hline Pio Gde. Sul & 1.056 & 799 & 715 & 13.138 & 5.357 & 9.494 & 1.497 & 2.139 & 2.73 \\
\hline
\end{tabular}

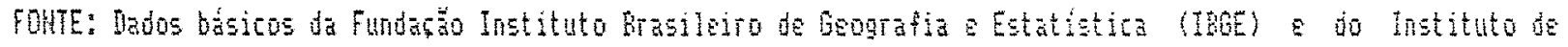
Economia Agricola (IEA). 


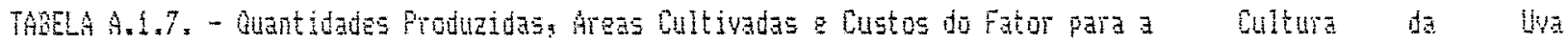

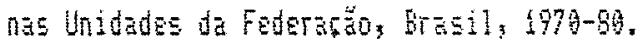

\begin{tabular}{|c|c|c|c|c|c|c|c|c|c|}
\hline \multirow{2}{*}{$\begin{array}{c}\text { Unidade } \\
\text { da } \\
\text { Federarato }\end{array}$} & \multicolumn{3}{|c|}{$\begin{array}{c}\text { Duantidaue froduzids } \\
\text { (t) }\end{array}$} & \multicolumn{3}{|c|}{$\begin{array}{l}\text { Area Cultivada } \\
\text { has }\end{array}$} & \multicolumn{2}{|c|}{$\begin{array}{l}\text { Cueto do Fator } \\
\text { (Cot de } 89 / \mathrm{ha} \text { ) }\end{array}$} & \multirow[b]{2}{*}{1900} \\
\hline & 1978 & 1975 & 1980 & 1970 & 1975 & 5900 & 1979 & 1975 & \\
\hline Hordeste & & & & & & & ; & & \\
\hline Alaguas & 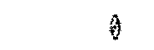 & $\Rightarrow$ & 9 & A & 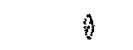 & 1 & 12.738 & 19.371 & 16.087 \\
\hline Dahia & 67 & 213 & 160 & 27 & 38 & 45 & 12.738 & 19.371 & 16.987 \\
\hline CEsti & 12 & 12 & 13 & 5 & 4 & 4 & 12.938 & 19.371 & 50.307 \\
\hline Paraiba & 199 & 38 & 150 & 54 & 127 & 68 & 12.938 & 19.371 & 16.807 \\
\hline Penanduco & 3.228 & 1.557 & 4.489 & 201 & 358 & $34 \vec{c}$ & 10.938 & 19.371 & 56.097 \\
\hline Piauí & 9 & $\theta$ & $\theta$ & $\eta$ & 7 & 8 & 12.920 & 67.371 & 16.007 \\
\hline Rio Gue, Horte & 0 & 1 & 8 & 7 & f & 9 & 12.930 & 19.37 & 16.687 \\
\hline Sergipe & $g$ & A & 9 & $\theta$ & 4 & 9 & 12.998 & 19.371 & 16.307 \\
\hline Hat anhtö & $\theta$ & $\theta$ & 9 & $\theta$ & f & 3 & 12.938 & 19.371 & 16.697 \\
\hline \multicolumn{10}{|l|}{ Worte } \\
\hline ACTE & 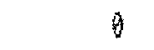 & 4 & $\hat{y}$ & $\theta$ & ) & 3 & 12.938 & 19.371 & 16.987 \\
\hline Amazonas & $\theta$ & g & $\theta$ & 0 & 9 & $\frac{3}{z}$ & 12.938 & 17.371 & 16.407 \\
\hline 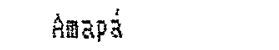 & $\theta$ & n & 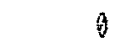 & $\theta$ & 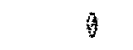 & $\theta$ & 12.738 & 19.371 & 16.807 \\
\hline Paré & $\theta$ & 8 & 9 & $\theta$ & 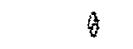 & 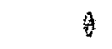 & 12.938 & 19.371 & 16.187 \\
\hline Sotsiga & a & s & $\theta$ & 8 & 0 & $\theta$ & 12.938 & 19.391 & 16.887 \\
\hline Bontônia & A & $\hat{A}$ & $\theta$ & 3 & $\hat{2}$ & $\theta$ & 12.738 & 19.371 & 16.697 \\
\hline \multicolumn{10}{|l|}{ Centro-Ueste } \\
\hline Hato Groseo & 13 & 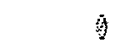 & 8 & 2 & 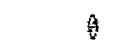 & $A$ & 12.738 & 17.371 & 16.087 \\
\hline Distr. Federal & 9 & 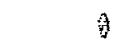 & $b$ & $\theta$ & 9 & $A$ & 12.930 & 19.371 & 10.007 \\
\hline Goìts & 26 & 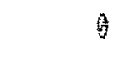 & 7 & 9 & 0 & 0 & 12.938 & 19.371 & 16.607 \\
\hline \multicolumn{10}{|l|}{ Sudeste } \\
\hline Hinas GeTais & 4.342 & 7.877 & 7.391 & 1.173 & 1.395 & 997 & 12.938 & 19.371 & 16.087 \\
\hline Espirito Santo & 71 & 485 & $46 \overline{3}$ & 46 & 53 & 53 & 12.938 & 19.371 & 36.287 \\
\hline Rio de Janeito & 44 & 109 & 40 & 41 & 12 & $b$ & 12.938 & 19.371 & 16.087 \\
\hline Sav Pato & 62.794 & 31.998 & 79.802 & 10.526 & 9.147 & 7.748 & 52.93e & 19.371 & 16.807 \\
\hline \multicolumn{10}{|l|}{ Sแl } \\
\hline Pară & 6.850 & 7.689 & 11.578 & 2.178 & 1.899 & $1, \frac{\tan }{721}$ & 12.930 & 19.371 & 16.907 \\
\hline Ganta Catarina & 31.879 & 26.626 & 22.825 & 3.733 & 2.412 & 2.548 & 12.738 & 19.374 & 16.607 \\
\hline Rio $6 d e$. 54 & 370.588 & 384.776 & 258.731 & 36.686 & 33.549 & 27.772 & 12.938 & 19.371 & 16.997 \\
\hline
\end{tabular}

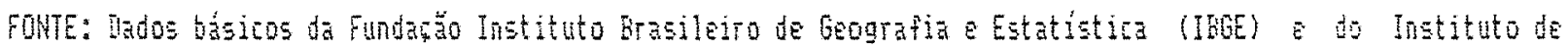
Econogia Agricola (IEA). 
TANAA A.1.8. - Quantidades Produzidas nas Ciases Econônicas Agricultura e Agropecuaria, Cultura

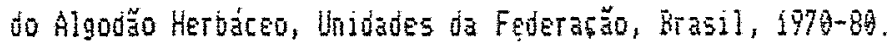

\begin{tabular}{|c|c|c|c|c|c|c|}
\hline \multirow{3}{*}{$\begin{array}{c}\text { Whidade } \\
\text { da } \\
\text { Fourabăo }\end{array}$} & \multicolumn{6}{|c|}{ Quñtidaus froouziog (t) } \\
\hline & \multicolumn{3}{|c|}{ Agricultura } & \multicolumn{3}{|c|}{ Agropecuária } \\
\hline & 1979 & 1975 & 1988 & 1979 & 1975 & 1989 \\
\hline \multicolumn{7}{|l|}{ fordeste } \\
\hline Alagoas & $4.98 \%$ & 53.347 & 7.870 & 290 & 0 & 370 \\
\hline Bahia & 24.329 & 17.625 & 23.594 & 3.353 & 1.790 & 1.415 \\
\hline Ceará & 0 & 32.992 & 21.086 & $\theta$ & 2.686 & 1.794 \\
\hline Paraíba & i & 22.321 & 22.193 & $\theta$ & 897 & 1.794 \\
\hline fernaguco & $\theta$ & 9.328 & 5.676 & $\overline{4}$ & 399 & 409 \\
\hline Piauí & 0 & 3.503 & 2.658 & $\theta$ & $\theta$ & 3 \\
\hline no 618 . Worte & 6 & 18.443 & 18.761 & 0 & 1.106 & 1.368 \\
\hline Sergipe & 1.243 & 5.938 & 624 & 100 & 9 & $\theta$ \\
\hline 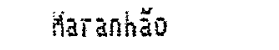 & $j$ & 1.188 & 494 & 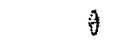 & i & $\theta$ \\
\hline \multicolumn{7}{|l|}{ Worte } \\
\hline Acre & 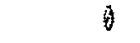 & $\theta$ & $\theta$ & $\theta$ & $\theta$ & $\theta$ \\
\hline Arazonas & $\theta$ & i) & 6 & 0 & 3 & की \\
\hline 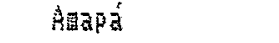 & 0 & $\theta$ & $\theta$ & $\theta$ & (3) & (3) \\
\hline Para & 205 & 175 & 2.199 & $y$ & 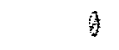 & is \\
\hline Rorai国a & 5 & 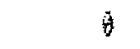 & 羊 & $\theta$ & $\theta$ & 8 \\
\hline Rondônia & 641 & 230 & 1.253 & 11 & 9 & $\theta$ \\
\hline \multicolumn{7}{|l|}{ Eentro-ieste } \\
\hline Gato orosso & 48.768 & 122.975 & 53.578 & 2.858 & 50 & 595 \\
\hline Distr. Federal & y & t) & $\theta$ & in & o & $\theta$ \\
\hline bờล์ & 56.526 & 45.396 & 54.123 & 5.245 & 1.63 & 647 \\
\hline \multicolumn{7}{|l|}{ Sudeste } \\
\hline tinas Gerays & 26.59 & 45.349 & 45.594 & 2.311 & 4.236 & 3.415 \\
\hline Espirito Santo & 326 & 1.751 & $\theta$ & 4 & 0 & $\theta$ \\
\hline ho de Janeito & 235 & 975 & 83 & 41 & $\theta$ & t \\
\hline Săo Pălo & $52 \pm .181$ & 363.754 & 415.710 & 69.137 & 13.625 & 7.630 \\
\hline \multicolumn{7}{|l|}{ Sil } \\
\hline Paraná & 382.675 & 265.989 & 444.249 & 8.554 & 3.263 & 3.917 \\
\hline Santa Catarina & is & 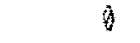 & $\theta$ & $\theta$ & $y$ & 6) \\
\hline Rio bog. Sul & $\theta$ & is & $\dot{y}$ & 9 & $\theta$ & $\theta$ \\
\hline
\end{tabular}

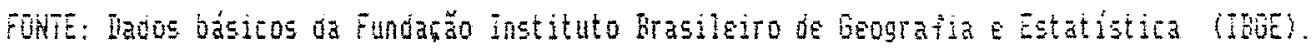




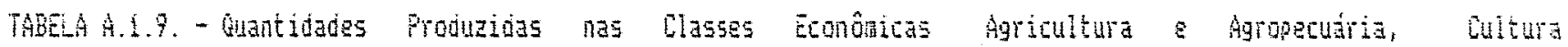

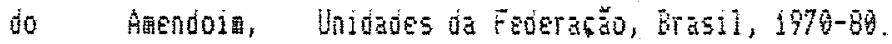

\begin{tabular}{|c|c|c|c|c|c|c|}
\hline \multirow{3}{*}{$\begin{array}{c}\text { Unidade } \\
\text { da } \\
\text { Federatado }\end{array}$} & \multicolumn{6}{|c|}{ Quantioade proouzioa (t) } \\
\hline & \multicolumn{3}{|c|}{ Agricultura } & \multicolumn{3}{|c|}{ RgTopecuatia } \\
\hline & 1978 & 1975 & 1980 & 1979 & 1975 & 2980 \\
\hline \multicolumn{7}{|l|}{ Horoeste } \\
\hline Aiagoas & $\$ 26$ & 522 & $2 e_{3}$ & 18 & 3 & $y$ \\
\hline Dahia & 2.214 & 3.376 & 3.495 & 119 & $\theta$ & $a$ \\
\hline Ceará & 493 & 2.650 & 420 & 15 & 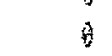 & y \\
\hline Parata & 493 & 1.148 & 402 & 12 & 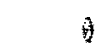 & $\theta$ \\
\hline Pernă & 44 & 149 & 18 & 12 & $\theta$ & 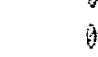 \\
\hline Piauí & 24 & 7 & 85 & 2 & 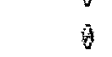 & $\theta$ \\
\hline Rio bue. Horte & 0 & 0 & $\theta$ & $\theta$ & $\theta$ & $\dot{\theta}$ \\
\hline Sergipe & 399 & 947 & 973 & 13 & 9 & 3 \\
\hline 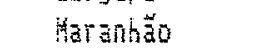 & 341 & 3 & is & 7 & $\theta$ & is \\
\hline \multicolumn{7}{|l|}{ horte } \\
\hline ACTE & 7 & 38 & 4 & $\theta$ & 3 & 8 \\
\hline Arazaunas & $\bar{\theta}$ & $\bar{y}$ & $\theta$ & a & 0 & $i$ \\
\hline firaps & $\theta$ & $\theta$ & $\theta$ & 4 & $\theta$ & 3 \\
\hline Pará & 164 & $\theta$ & 3 & 4 & $g$ & 6 \\
\hline Nora嘌 & ) & 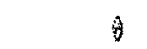 & $\theta$ & a & a & in \\
\hline Ronoônia & 326 & $1+1$ & 192 & 4 & 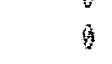 & $\theta$ \\
\hline \multicolumn{7}{|l|}{ Centro-besté } \\
\hline Bato brosso & 55.326 & 63.253 & 18.329 & 3.974 & 705 & 756 \\
\hline Distr. Federal & 35 & 32 & 11 & 安 & 0 & 0 \\
\hline bojas & 1.962 & 3.690 & 1.631 & 450 & $j$ & i \\
\hline \multicolumn{7}{|l|}{ Sudeste } \\
\hline dinas berais & 3.264 & 5.753 & $11.46 \mathrm{Z}$ & 188 & 9 & $\theta$ \\
\hline Espirito Santo & 258 & 557 & 357 & 60 & 0 & 3 \\
\hline tio og Janeiro & 50 & 110 & 91 & 4 & 0 & 0 \\
\hline Să Pauio & 365.238 & 218.326 & 239.743 & 38.995 & 8.48 & 8.67 \\
\hline \multicolumn{7}{|l|}{$S u \dot{1}$} \\
\hline Franá & 136.591 & 190.271 & 20.068 & 2.592 & $\theta$ & $a$ \\
\hline Santa Gatarina & 2.028 & 2.953 & $\begin{array}{r}1.579 \\
1.579\end{array}$ & 184 & 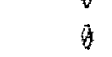 & $\theta$ \\
\hline Rio bue. 541 & 7.589 & 8.697 & 7.469 & 226 & $\theta$ & 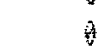 \\
\hline
\end{tabular}

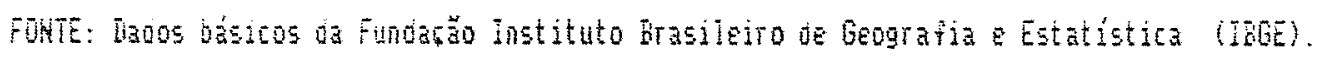




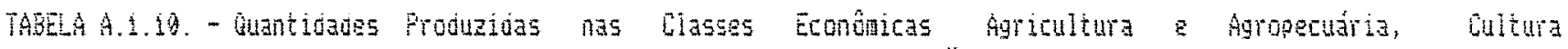
to Groz, Unidades da Federată

\begin{tabular}{|c|c|c|c|c|c|c|}
\hline \multirow{3}{*}{$\begin{array}{c}\text { Unidade } \\
\text { da } \\
\text { Federata }\end{array}$} & \multicolumn{6}{|c|}{ Quantidade frouluzida (t) } \\
\hline & \multicolumn{3}{|c|}{ Agricutura } & \multicolumn{3}{|c|}{ Aoropecuátia } \\
\hline & 1970 & 1975 & 1989 & 1970 & 1975 & 1900 \\
\hline \multicolumn{7}{|l|}{ Hordeste } \\
\hline Alagoas & 9.768 & 15.336 & 9.733 & 1.999 & $\theta$ & 73 \\
\hline Bania & 20.724 & $14 .+26$ & 42.428 & 3.841 & 3.496 & 4.648 \\
\hline Ceará & 17.969 & 67.668 & 39.258 & 3.793 & 4.299 & 2.193 \\
\hline Paraía & 7.732 & 25.351 & 7.172 & $b 92$ & 0 & 690 \\
\hline Pernamouco & 2.490 & 9.894 & 5.496 & 500 & $\theta$ & $\dot{y}$ \\
\hline Piauí & 43.132 & 117.659 & 59.262 & 2.951 & 3.772 & 3.130 \\
\hline hio boe. Horte & 1.448 & 4.889 & 878 & 220 & $\dot{\theta}$ & 0 \\
\hline Sergipe & 13.756 & 29.972 & 12.243 & 1.195 & 1.156 & 110 \\
\hline 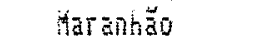 & 595.266 & 835.783 & 891.672 & 29.246 & 39.944 & 30.146 \\
\hline \multicolumn{7}{|l|}{ Horte } \\
\hline ACTE & 8.354 & 9.291 & 13.735 & 1.948 & 574 & 787 \\
\hline Amazonas & 1.870 & 2.978 & 7.395 & $7 i$ & $\theta$ & 197 \\
\hline A目的高 & 1.909 & 740 & 2.955 & $i$ & 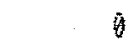 & $\theta$ \\
\hline Pará & 87.495 & 169.788 & 213.452 & 3.694 & 5.992 & 8.265 \\
\hline Roraisz & $81 i$ & 3.493 & 15.646 & 51 & 134 & 513 \\
\hline fondônia & 8.291 & 122.965 & 192.997 & 709 & 611 & 2.510 \\
\hline \multicolumn{7}{|l|}{ Gentro-ieste } \\
\hline hato Grosso & 287.821 & 734.941 & 1.254 .216 & 45.473 & 60.345 & 42.113 \\
\hline Distr. Federal & 410 & 464 & 9.691 & 73 & 285 & 184 \\
\hline boids & 495.613 & 758.927 & 948.066 & 255.306 & 155.642 & 122.411 \\
\hline \multicolumn{7}{|l|}{ Sudeste } \\
\hline Minas Gerais & 344.322 & 292.069 & 286.791 & 55.148 & 40.456 & 55.170 \\
\hline Espiritu Santo & 29.329 & 25.769 & 25.787 & 4.427 & 1.950 & 2.627 \\
\hline hio of JaneITo & 27.318 & 46.365 & 41.358 & 18.346 & c. $\hat{c}^{n}+4$ & 16.278 \\
\hline Să Paulo & 291.934 & 429.599 & 257.949 & 79.644 & 27.958 & 19.796 \\
\hline \multicolumn{7}{|l|}{ Sul } \\
\hline Paraná & 346.215 & 654.711 & 297.613 & 12.254 & 8.93 & 6.548 \\
\hline Santa Catarina & $16 \pm .581$ & $185.89 \mathrm{e}$ & 221.971 & 7.792 & 824 & 6.876 \\
\hline Kio Goe. Sul & 1.972 .969 & 1.629 .639 & 2. .773 .247 & 227.898 & 133.264 & 101.921 \\
\hline
\end{tabular}

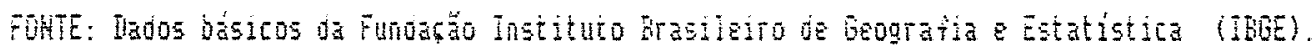




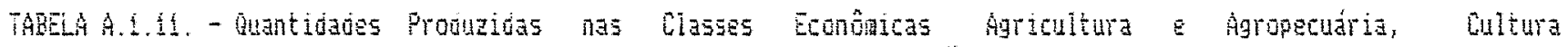
da Batata, Unidaes da Federara

\begin{tabular}{|c|c|c|c|c|c|c|}
\hline \multirow{3}{*}{$\begin{array}{c}\text { Hnidade } \\
\text { da } \\
\text { Federabato }\end{array}$} & \multicolumn{6}{|c|}{ Quantidade frooduzto (t) } \\
\hline & \multicolumn{3}{|c|}{ Agrieutura } & \multicolumn{3}{|c|}{ Agropecuátia } \\
\hline & 1970 & 1975 & 1980 & 1978 & 1975 & 1900 \\
\hline \multicolumn{7}{|l|}{ Wordeste } \\
\hline A่iagoas & 3 & $\theta$ & $\bar{\theta}$ & 0 & $i$ & $\theta$ \\
\hline Bahia & 3.176 & 7.630 & 2.592 & 844 & 5 & is \\
\hline Ceata & 59 & 95 & 60 & $\theta$ & $\theta$ & $\theta$ \\
\hline Paraía & 1.884 & 14.839 & 3.020 & 59 & 9 & t \\
\hline Ponambuco & 90 & 631 & $\theta$ & 3 & $\theta$ & f \\
\hline Piaút & $\theta$ & $g$ & 9 & $\theta$ & $\theta$ & $\theta$ \\
\hline Ho Goe. Morte & $\theta$ & $\theta$ & $y$ & $\theta$ & $\theta$ & 3 \\
\hline Sergipe & 257 & 649 & 414 & 22 & 0 & $\theta$ \\
\hline haranhă & $\theta$ & $\theta$ & 3 & 0 & $\hat{\theta}$ & 3 \\
\hline \multicolumn{7}{|l|}{ ivorte } \\
\hline ATE & $\theta$ & $\theta$ & 0 & $\theta$ & ) & 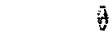 \\
\hline A困ง & 0 & $\theta$ & 0 & is & $\theta$ & $g$ \\
\hline 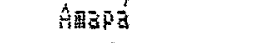 & $\theta$ & 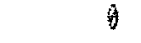 & 0 & $\theta$ & 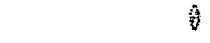 & $\theta$ \\
\hline Pará & 0 & $\theta$ & $y$ & i & 9 & . \\
\hline Roraina & (3) & $\theta$ & $\theta$ & $\theta$ & $\theta$ & $\theta$ \\
\hline Rondônia & $\theta$ & $\theta$ & $\theta$ & $g$ & 多 & $\theta$ \\
\hline \multicolumn{7}{|l|}{ Centro-deste } \\
\hline idato brosso & 25 & 16 & 0 & 8 & 0 & ) \\
\hline Distr. Foderal & 266 & 130 & 2.628 & 5 & $\bar{\theta}$ & 5 \\
\hline boias & 476 & 19 & 115 & 244 & $\theta$ & is \\
\hline \multicolumn{7}{|l|}{ Sudeste } \\
\hline Jinas berais & 122.210 & 138.156 & 260.569 & 25.667 & 6.759 & 8.606 \\
\hline Espirito Santo & 3.962 & 4.820 & 2.628 & 53 & 0 & $t$ \\
\hline nio de Janeiro & 5.866 & 8.795 & 3.773 & 145 & $\theta$ & $\hat{\theta}$ \\
\hline Săo Paulo & 248.537 & 252.297 & 277.519 & 22.555 & 8.594 & 2.624 \\
\hline \multicolumn{7}{|l|}{$\mathrm{sui}$} \\
\hline Faraná & 159.648 & 256.295 & 231.114 & 1.041 & 1.990 & $\overline{8} 6 \bar{c}$ \\
\hline Santa Catarina & 38.619 & 176.619 & 66.743 & 2.644 & $\theta$ & 3.816 \\
\hline Bio Gde. Sul & 163.358 & 395.566 & 298.511 & 2.961 & $\theta$ & $\theta$ \\
\hline
\end{tabular}

Fonit: Iados basicos da Fundacăo Instituto Brasileiro de Geografia e Estatistica (IBbe). 


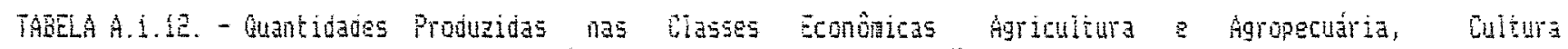
do Feijă

\begin{tabular}{|c|c|c|c|c|c|c|}
\hline \multirow{3}{*}{$\begin{array}{c}\text { Unidade } \\
\text { ua } \\
\text { Foortatá }\end{array}$} & \multicolumn{6}{|c|}{ Guantivade Produzida (t) } \\
\hline & \multicolumn{3}{|c|}{ Agracuitura } & \multicolumn{3}{|c|}{ Agropecuária } \\
\hline & 1970 & 1975 & 1980 & 1970 & 1975 & 190 \\
\hline \multicolumn{4}{|l|}{ Horoeste } & \multicolumn{2}{|c|}{$i$} & \\
\hline Alago85 & 14.945 & 53.754 & 15.393 & 641 & 1.028 & 715 \\
\hline Bania & 191.6994 & 125.366 & 164.392 & 16.034 & 12.674 & 8.152 \\
\hline Ceatá & 35.535 & 80.771 & 43.895 & 4.991 & 6.321 & 2.859 \\
\hline Paraiba & 27.901 & 57.419 & 16.674 & 2.254 & 1.144 & 1.90 \\
\hline Pernamouco & 47.752 & 85.828 & $49.22 \mathrm{E}$ & 3.710 & 4.461 & 2.667 \\
\hline Piát & 21.97 & 38.350 & 26.159 & 5.996 & 2.359 & 1.259 \\
\hline hio bue. Horts & 11.393 & 26.277 & 11.168 & 1.324 & 827 & 697 \\
\hline Sergipe & 4.560 & 8.937 & 3.371 & 364 & 271 & 839 \\
\hline Aaranhă & 20.618 & 20.712 & 26.667 & 450 & 811 & 83 \\
\hline \multicolumn{7}{|l|}{ Norte } \\
\hline Acre & 2.697 & 2.835 & 2.901 & 273 & 101 & 13 \\
\hline Arazonas & 2.255 & 2.990 & 3.600 & 116 & 0 & 9 \\
\hline A⿵冂卄 & 77 & 22 & 64 & 3 & 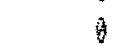 & in \\
\hline Paráa & 9.938 & 9.421 & 20.609 & 34 & 167 & 569 \\
\hline Rỡaima & \pm 94 & 484 & 514 & 12 & 8 & 8 \\
\hline Rondoniz & 2.390 & 7.020 & 10.991 & $1+1$ & 70 & 347 \\
\hline \multicolumn{7}{|l|}{ Eentro-ueste } \\
\hline Hato brosso & 29.146 & 27.281 & $43.3 \mathrm{E}^{5}$ & 2.767 & $47 \mathrm{C}$ & $\$ .768$ \\
\hline Distr. Federal & 247 & 27 & 326 & 71 & 193 & 21 \\
\hline Butas & 43.152 & 45.726 & 42.491 & 22.368 & 8.374 & 6.384 \\
\hline \multicolumn{7}{|l|}{ Sudeste } \\
\hline Minas Gerais & $190.49 \mathrm{c}$ & 164.105 & 146.942 & 20.715 & 14.207 & 29.343 \\
\hline Espirito Santo & 16.660 & 17.954 & 19.835 & 1.534 & 697 & 1.236 \\
\hline Ro de vaneiro & 3.909 & 4.197 & 4.940 & 775 & 246 & 366 \\
\hline Ga Paulo & 31.169 & 83.250 & 176.124 & 8.890 & 2.716 & 4.926 \\
\hline \multicolumn{7}{|l|}{ sul } \\
\hline P’saná & 427.273 & 341.673 & 392.898 & 19.458 & 2.970 & 9.760 \\
\hline Santa Catarina & 58.199 & 71.948 & 97.831 & 7.699 & 979 & 6.897 \\
\hline Rio Gue. Sul & 195.642 & 155.624 & 73.53 & 1.794 & 0 & 4.565 \\
\hline
\end{tabular}

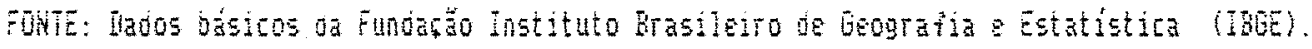




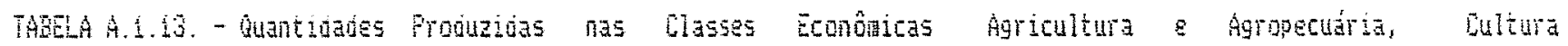

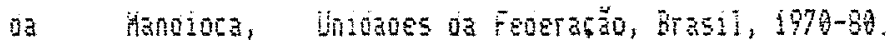

\begin{tabular}{|c|c|c|c|c|c|c|}
\hline \multirow{3}{*}{$\begin{array}{c}\text { Univade } \\
\text { da } \\
\text { Fegeratão }\end{array}$} & \multicolumn{6}{|c|}{ Ouantiuade froouzioa (t) } \\
\hline & \multicolumn{4}{|c|}{ Agricuitura } & \multicolumn{2}{|c|}{ Agropecuśria } \\
\hline & 1978 & 1975 & 1980 & 1979 & 1975 & 5989 \\
\hline \multicolumn{7}{|l|}{ Hordeste } \\
\hline Aiagoass & 194.907 & 146.987 & 115.374 & 3.898 & 1.649 & 2.127 \\
\hline Bahia & 2.988 .536 & 1.861 .674 & 1.545 .118 & 171.874 & 98.251 & 66.737 \\
\hline Bearí & 288.441 & 425.352 & 296.837 & 25.861 & 14.660 & 7.647 \\
\hline Paraiba & 217.771 & 269.347 & 173.775 & 8.971 & 2.974 & 6.065 \\
\hline Pernamouco & 614.651 & 666.284 & 566.179 & 16.541 & 14.539 & 23.720 \\
\hline Piauí & 137.720 & 179.497 & 118.074 & 10.69 & 22.382 & 5.782 \\
\hline nio Gde. Horts & 142.511 & 116.483 & 134.203 & 6.650 & 3.624 & 5.820 \\
\hline Serjige & 271.313 & 297.333 & 298.410 & 20.775 & 5.086 & 7.236 \\
\hline ไatannẵo & 759.712 & 879.754 & 724.192 & 5.845 & 20.850 & 14.491 \\
\hline \multicolumn{7}{|l|}{ Horte } \\
\hline ACTE & 102.297 & 84.986 & 62.362 & 9.062 & 2.235 & 1.731 \\
\hline Atrazonas & 594.435 & 762.318 & 649.817 & 26.159 & 7.622 & 3.977 \\
\hline 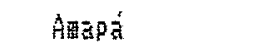 & 27.863 & 52.531 & 31.198 & 448 & 547 & $9 \mathrm{E}$ \\
\hline Pará & 1.043 .503 & 1.540 .526 & 1.575 .324 & 15.310 & 11.199 & 8.497 \\
\hline Roraina & 12. 442 & 9.571 & 14.238 & 724 & 186 & 273 \\
\hline Rondônia & 30.733 & 36.311 & 44.30 & 1.261 & 1.273 & 433 \\
\hline \multicolumn{7}{|l|}{ Centro-yests } \\
\hline idato brosso & 91.676 & 83.434 & 75.865 & 17.545 & $2.96 \mathrm{i}$ & 3.218 \\
\hline Distr. Feueral & 2.495 & 2.599 & 2.873 & 580 & 9 & 9 \\
\hline botás & 86.813 & 41.544 & 39.495 & 63.466 & 7.564 & 4. $E^{2} 4$ \\
\hline \multicolumn{7}{|l|}{ Sudeste } \\
\hline Hinas betajs & 331.597 & 219.645 & 255.104 & 28.190 & 20.390 & 27.991 \\
\hline Espirito Santo & 178.747 & 145.998 & 143.104 & 16.468 & 5.641 & 29.179 \\
\hline nio de Janeiro & 197.247 & 124.450 & 193.917 & 5.429 & 2.224 & 2.406 \\
\hline Să Paulo & 305.89 & 720.090 & 480.957 & 106.792 & $\theta$ & $\theta$ \\
\hline \multicolumn{7}{|l|}{ Sul } \\
\hline Patana & 541.479 & 265.143 & 467.577 & 79.979 & 11.576 & 33.912 \\
\hline Santa Catarina & 1.268 .736 & 777.018 & 708.293 & 114.214 & 5.294 & 39.789 \\
\hline Ho Bde. Sul & 1.753 .953 & 889.914 & 894.965 & 78.929 & 28.442 & 47.629 \\
\hline
\end{tabular}

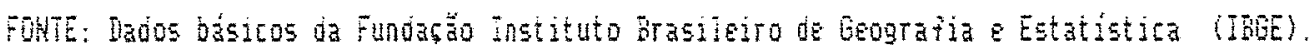




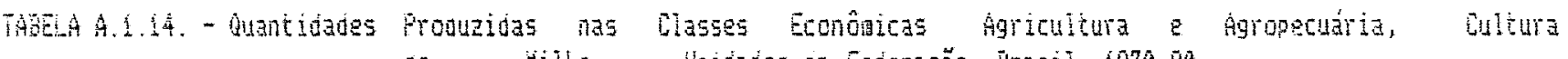

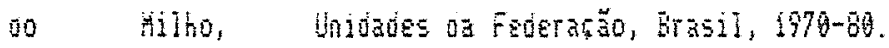

\begin{tabular}{|c|c|c|c|c|c|c|}
\hline \multirow{3}{*}{$\begin{array}{c}\text { Inidade } \\
\text { da } \\
\text { Federasa }\end{array}$} & \multicolumn{6}{|c|}{ Duantidade froouzioa $(t)$} \\
\hline & \multicolumn{3}{|c|}{ Agericuitura } & \multicolumn{3}{|c|}{ Agropecuatia } \\
\hline & 1979 & 1975 & 1580 & 1970 & 1975 & 1980 \\
\hline \multicolumn{7}{|l|}{ Horbete } \\
\hline Alagoas & 18.167 & 46.344 & 4.436 & 822 & 999 & 219 \\
\hline Baniz & 279.91 & 296.739 & 271.949 & 27.026 & 23.075 & 19.371 \\
\hline Cesta & 80.953 & 372.982 & 89.839 & 9.652 & 29.766 & 5.434 \\
\hline Paraba & $\$ 4.780$ & 118.850 & 27.765 & 5.973 & 2.59 & 2.017 \\
\hline Ferneduco & 79.792 & 165.701 & 66.242 & 6.759 & 50.793 & 4.187 \\
\hline Pialí & $4 \dot{4} .971$ & 119.926 & 51.249 & 3.579 & 6.186 & 3.378 \\
\hline Ro Gide. Horte & 8.872 & 42.485 & 7.418 & 824 & 1.601 & 618 \\
\hline Seryipe & 8.343 & 24.599 & 1.691 & 950 & 860 & 305 \\
\hline 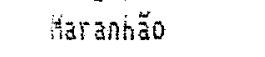 & 123.452 & 135.697 & 139.179 & 2.792 & 7.518 & 6.698 \\
\hline \multicolumn{7}{|l|}{ horte } \\
\hline ALTE & 10.157 & 10.555 & 12.879 & 1.32 & $27 \%$ & 644 \\
\hline Amazonas & 11.299 & 4.372 & 11.399 & 937 & A & 265 \\
\hline 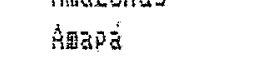 & 1.318 & 867 & 1.318 & 2 & 10 & 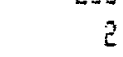 \\
\hline Pará & 64.814 & 76.196 & 197.296 & 1.728 & 2.410 & 4.96 \\
\hline Ruraina & 1.686 & 3.327 & 5.635 & 94 & 193 & 188 \\
\hline Ronôñia & 7.689 & 34.368 & 54.952 & 689 & $42 t$ & 1.678 \\
\hline \multicolumn{7}{|l|}{ Centro-uneste } \\
\hline dato brosso & 146.562 & 158.738 & 182.043 & 23.496 & 9.293 & 12.790 \\
\hline Distr. Federal & 1.204 & 1.687 & 2.215 & $2 \mathrm{E}$ & 304 & 130 \\
\hline boiás & 268.148 & 750.874 & 859.430 & 144.719 & 132.564 & 112.714 \\
\hline \multicolumn{7}{|l|}{ Sudeste } \\
\hline dinas berais & 924.458 & 923.696 & 1.503 .393 & 211.475 & 142.945 & 195.751 \\
\hline Espirito Santo & 129.664 & 111.968 & 104.826 & 14.680 & 5.398 & 7.963 \\
\hline hio do Janeno & 34.478 & 34.648 & 28.920 & 13.786 & 2.591 & 5.792 \\
\hline Să Pauio & 1.419 .585 & 1.587 .883 & 1.598 .979 & 441.353 & 132.606 & $197.3 b 2$ \\
\hline \multicolumn{7}{|l|}{54} \\
\hline caraná & 2.812 .433 & 2.967 .64 & 3.999 .727 & 162.695 & 55.612 & 169.945 \\
\hline Santa Catarina & 667.347 & 920.977 & 1.043 .112 & 126.782 & $11.0 \% 5$ & 98.455 \\
\hline Ho bue. Sul & 1.830 .045 & 1.779 .558 & 1.620 .723 & 51.459 & 81.600 & 139.379 \\
\hline
\end{tabular}

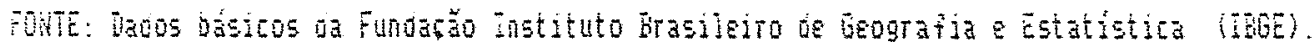




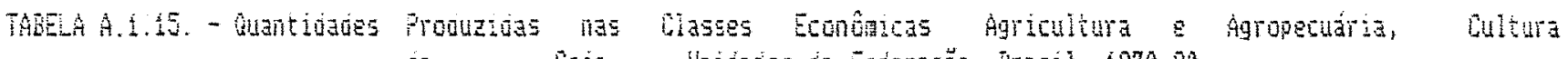

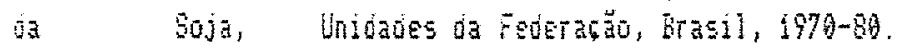

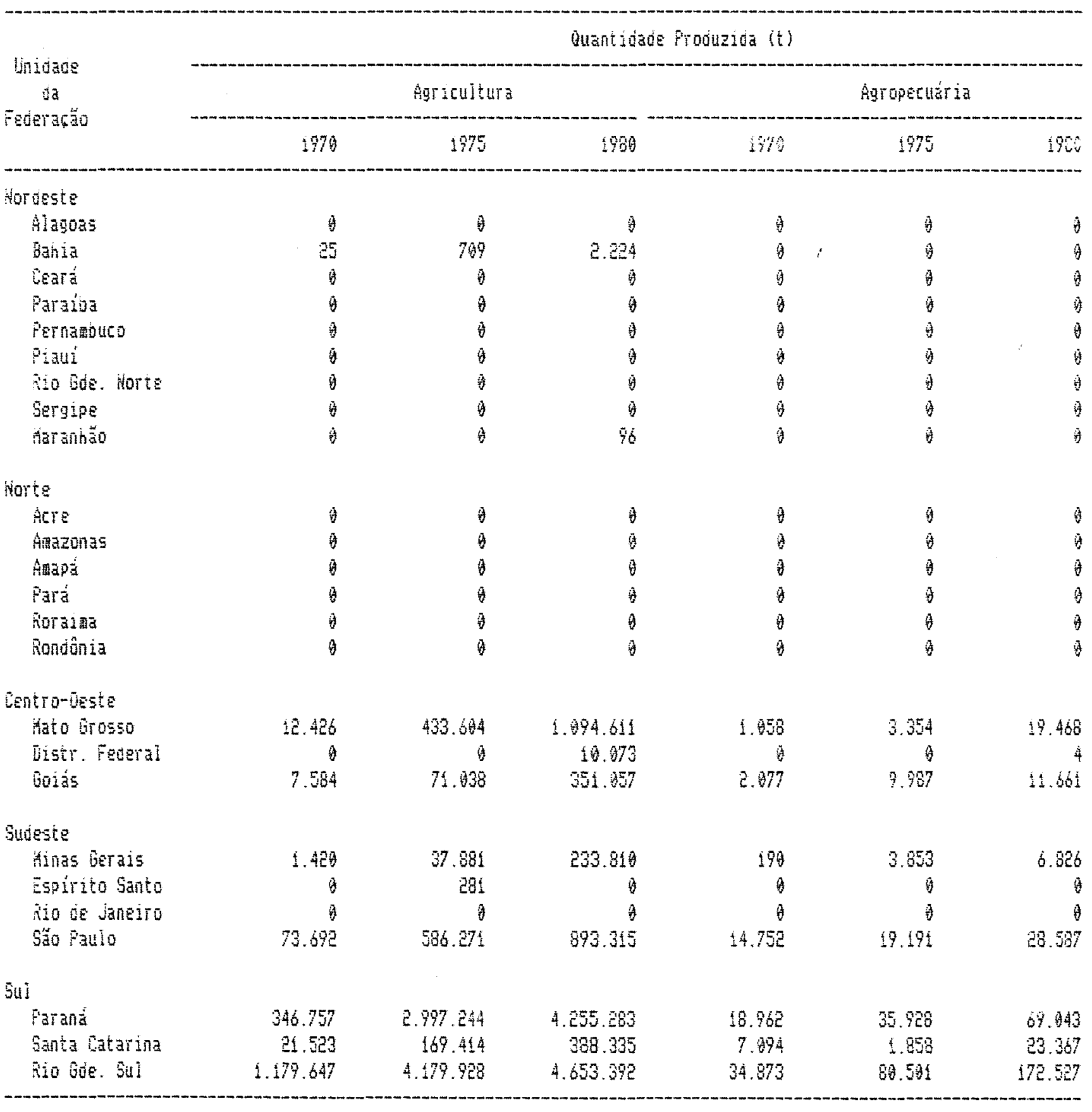

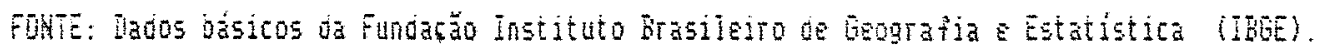




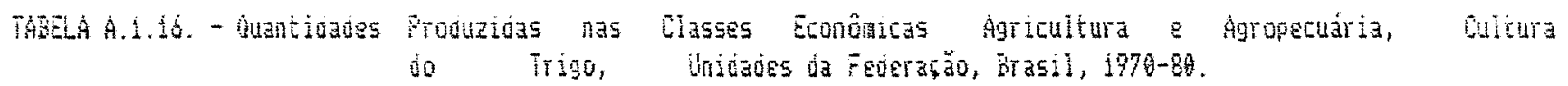

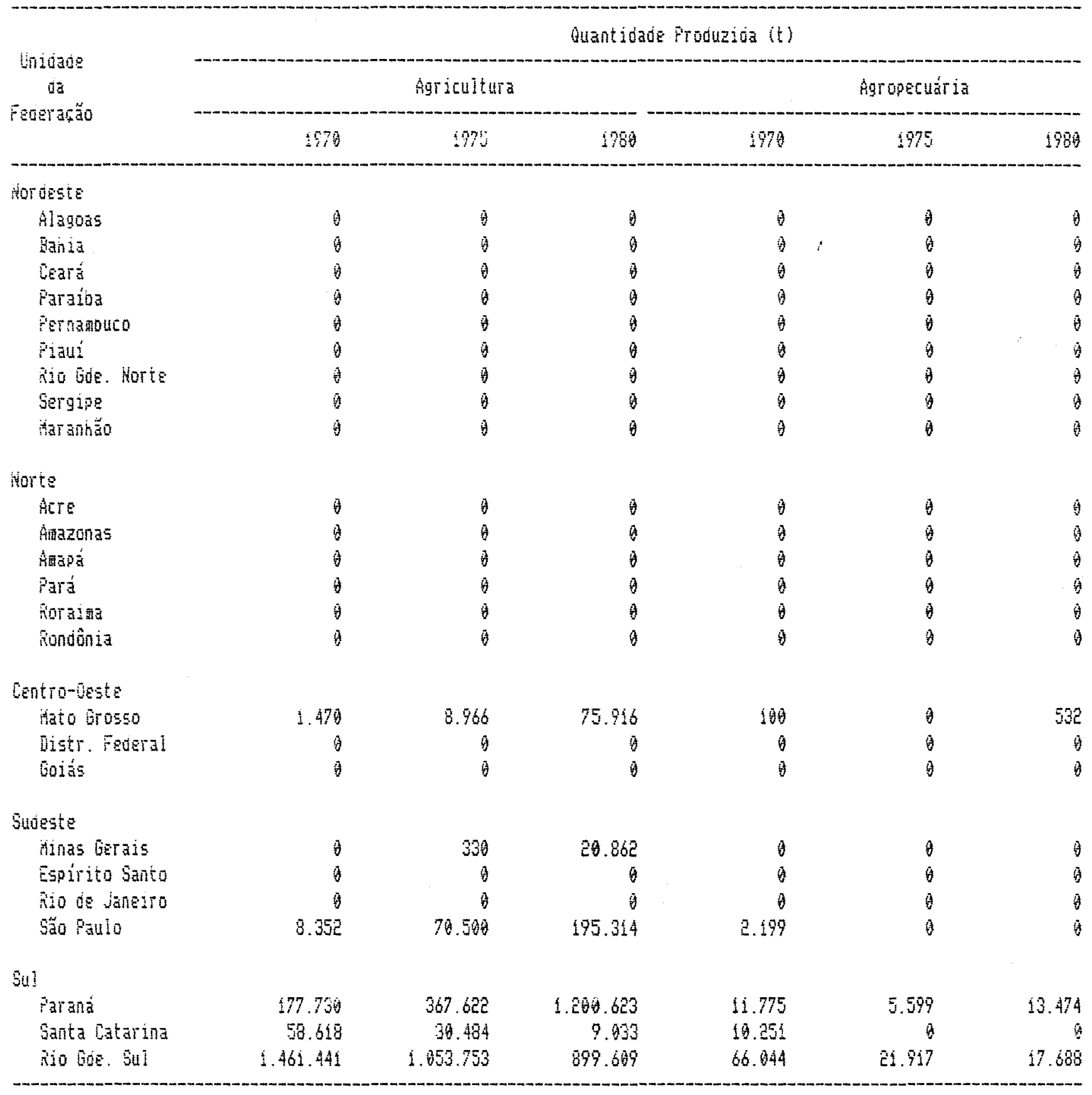

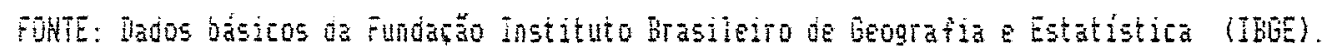




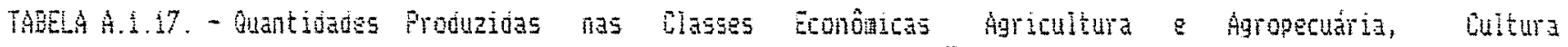
do Torate, Unidades da Feveră

\begin{tabular}{|c|c|c|c|c|c|c|}
\hline \multirow{3}{*}{$\begin{array}{c}\text { Gnidaue } \\
\text { da } \\
\text { Peveratăo }\end{array}$} & \multicolumn{6}{|c|}{ Quantiosog firoouzida (t) } \\
\hline & \multicolumn{3}{|c|}{ Agricuitura } & \multicolumn{3}{|c|}{ Agropecuaria } \\
\hline & 1970 & 1975 & 1980 & $197 \theta$ & 979 & 1900 \\
\hline \multicolumn{7}{|l|}{ Nordeste } \\
\hline Alagog: & $\dot{b}$ & 4 & 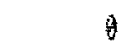 & 0 & 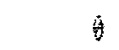 & ; \\
\hline Dahia & 34.600 & 69.796 & 31.752 & $a$ & $\theta$ & 623 \\
\hline Ceará & 5.571 & 24.349 & 25.990 & $\theta$ & 9 & in \\
\hline Paraía & 1.064 & 18.645 & 43.629 & $\theta$ & $\dot{y}$ & if \\
\hline Pernamouco & 99.243 & 59.233 & 72.994 & $\partial$ & 2.811 & 1.209 \\
\hline Piauí & 114 & 394 & 81 & 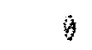 & 9 & 3 \\
\hline no boe. Horte & 405 & 2.877 & 6.888 & j & $\theta$ & 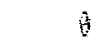 \\
\hline Sergine & 1.446 & 3.310 & 3.160 & 8 & 4 & is \\
\hline 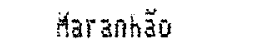 & 2.274 & 1.543 & 7.297 & $\theta$ & i) & $\theta$ \\
\hline \multicolumn{7}{|l|}{ Horte } \\
\hline$A C T E$ & 133 & 165 & $4+2$ & $\theta$ & $y$ & 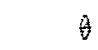 \\
\hline Anazonas & $37 i$ & 1.252 & 1.679 & ) & $\theta$ & 3 \\
\hline 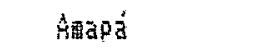 & 56 & 64 & 64 & 0 & $\theta$ & $\theta$ \\
\hline Pará & 780 & 720 & 189 & 9 & $\theta$ & 9 \\
\hline fioraima & $\dot{y}$ & 57 & 468 & $\theta$ & $\theta$ & $\theta$ \\
\hline Fondônia & 38 & 698 & 200 & $\theta$ & $\theta$ & 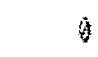 \\
\hline \multicolumn{7}{|l|}{ Centro-ueste } \\
\hline Hato brosso & 1.394 & 4.176 & 6.197 & $y$ & $\theta$ & is \\
\hline Distr. Federal & 1.590 & 5.586 & 5.744 & $\theta$ & 0 & 45 \\
\hline Goias & 3.491 & 39.390 & 43.797 & $\theta$ & $\theta$ & 0 \\
\hline \multicolumn{7}{|l|}{ Sudeste } \\
\hline Minas berais & 40.506 & $39.2 \%$ & 82.198 & 4 & 1.592 & 3.355 \\
\hline Espirito Santo & 11.847 & 18.994 & 21.216 & $\theta$ & 192 & 843 \\
\hline no de janeiro & 138.647 & 49.697 & $5 e .690$ & $\theta$ & 2.511 & 3.740 \\
\hline Sลั Paulo & 371.257 & 386.679 & 658.798 & $\theta$ & 15.382 & 4.560 \\
\hline \multicolumn{7}{|l|}{ Sul } \\
\hline Patant & 15.488 & 16.680 & 44.510 & 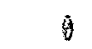 & $\theta$ & 0 \\
\hline Santa Catarina & 17.998 & 17.590 & 35.177 & a & $a$ & 6 \\
\hline hio boe. Sul & 16.690 & 66.628 & 50.031 & $\theta$ & $y$ & 0 \\
\hline
\end{tabular}

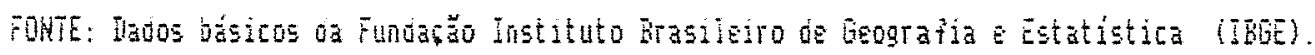




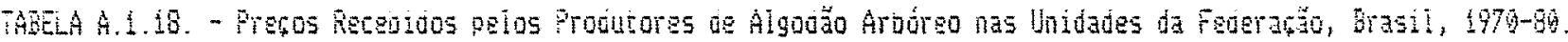

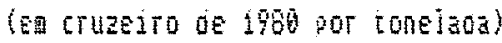

\begin{tabular}{|c|c|c|c|c|c|c|}
\hline \multirow{2}{*}{$\begin{array}{c}\text { Unudade } \\
0 a \\
\text { Fecerarăo }\end{array}$} & \multicolumn{3}{|c|}{ Segunoo irodos do that } & \multicolumn{3}{|c|}{ Segunco lados da bi } \\
\hline & 1979 & 1975 & 1980 & 1970 & 1975 & 1969 \\
\hline \multicolumn{7}{|l|}{ Nordeste } \\
\hline Mlagoas & 25.226 & 25.226 & 25.226 & 25.226 & 25.226 & 25.286 \\
\hline Bahia & 16.569 & 25.226 & 25.226 & 30.560 & 25.286 & 25.226 \\
\hline Cezró & 22.891 & 25.663 & 37.131 & 17.710 & 25.604 & 37.131 \\
\hline Paraiba & 24.615 & 29.854 & 4.5 .298 & 15.160 & 29.854 & 4.5 .290 \\
\hline fermanouco & 24.110 & 20.170 & 40.315 & 12.880 & 80.178 & 40.315 \\
\hline Fiau? & 15.855 & 23.131 & 32.639 & 23.167 & 23.131 & 32.639 \\
\hline hio boe. Horte & $22 .+404$ & 32.574 & 48.328 & 15.410 & 32.54 & 48.320 \\
\hline Sergipe & $\theta$ & 3 & 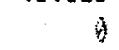 & 0 & 0 & $\theta$ \\
\hline Gar anhăo & 12.712 & 13.958 & 17.81 & 7.360 & 13.958 & 17.814 \\
\hline \multicolumn{7}{|l|}{ itorte } \\
\hline Acre & $\theta$ & $j$ & 0 & 0 & 0 & i \\
\hline Anazonas & $\hat{\theta}$ & j & $\theta$ & 9 & 0 & 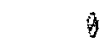 \\
\hline A西的方 & i) & $\theta$ & $\theta$ & in & g & i \\
\hline Para & 3 & a & $\theta$ & $\theta$ & a & in \\
\hline Boraida & 0 & $\hat{b}$ & ) & $y$ & $\theta$ & j \\
\hline Rondônia & i & 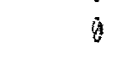 & a & 0 & q & 5 \\
\hline \multicolumn{7}{|l|}{ Eentro-deste } \\
\hline dato orosso & $y$ & $y$ & is & $\theta$ & $g$ & 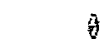 \\
\hline Distr. Federal & 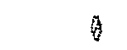 & (5) & a & i & $\dot{\theta}$ & 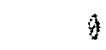 \\
\hline Goids & 9 & in & $y$ & $\theta$ & $\theta$ & 3 \\
\hline \multicolumn{7}{|l|}{ Sudoste } \\
\hline Minas Gerais & 25.226 & 25.226 & 23.226 & 25.226 & 25.226 & 25.226 \\
\hline Espirito Santo & 6 & 0 & $a$ & $\theta$ & 6 & a \\
\hline Rio de Janeiro & 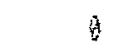 & $j$ & 0 & 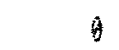 & 1 & 5 \\
\hline Săo Panio & 0 & $\hat{\theta}$ & $\theta$ & $\theta$ & 定 & i \\
\hline \multicolumn{7}{|l|}{ Sul } \\
\hline Paraná & $\theta$ & $y$ & 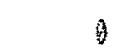 & $\theta$ & $\theta$ & $\theta$ \\
\hline Santa Catarna & 9 & ) & $\theta$ & $\eta$ & $g$ & 0 \\
\hline Rio bue. Sul & 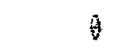 & $y$ & $\theta$ & i) & $\theta$ & $\theta$ \\
\hline
\end{tabular}

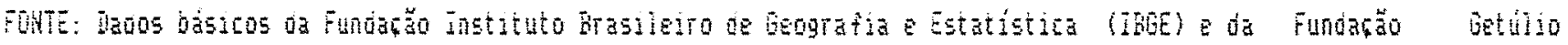
Vargas (rov) 


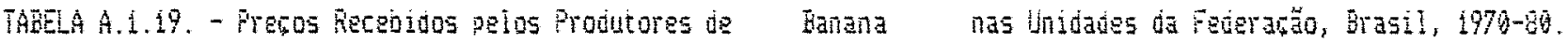

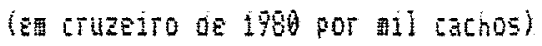

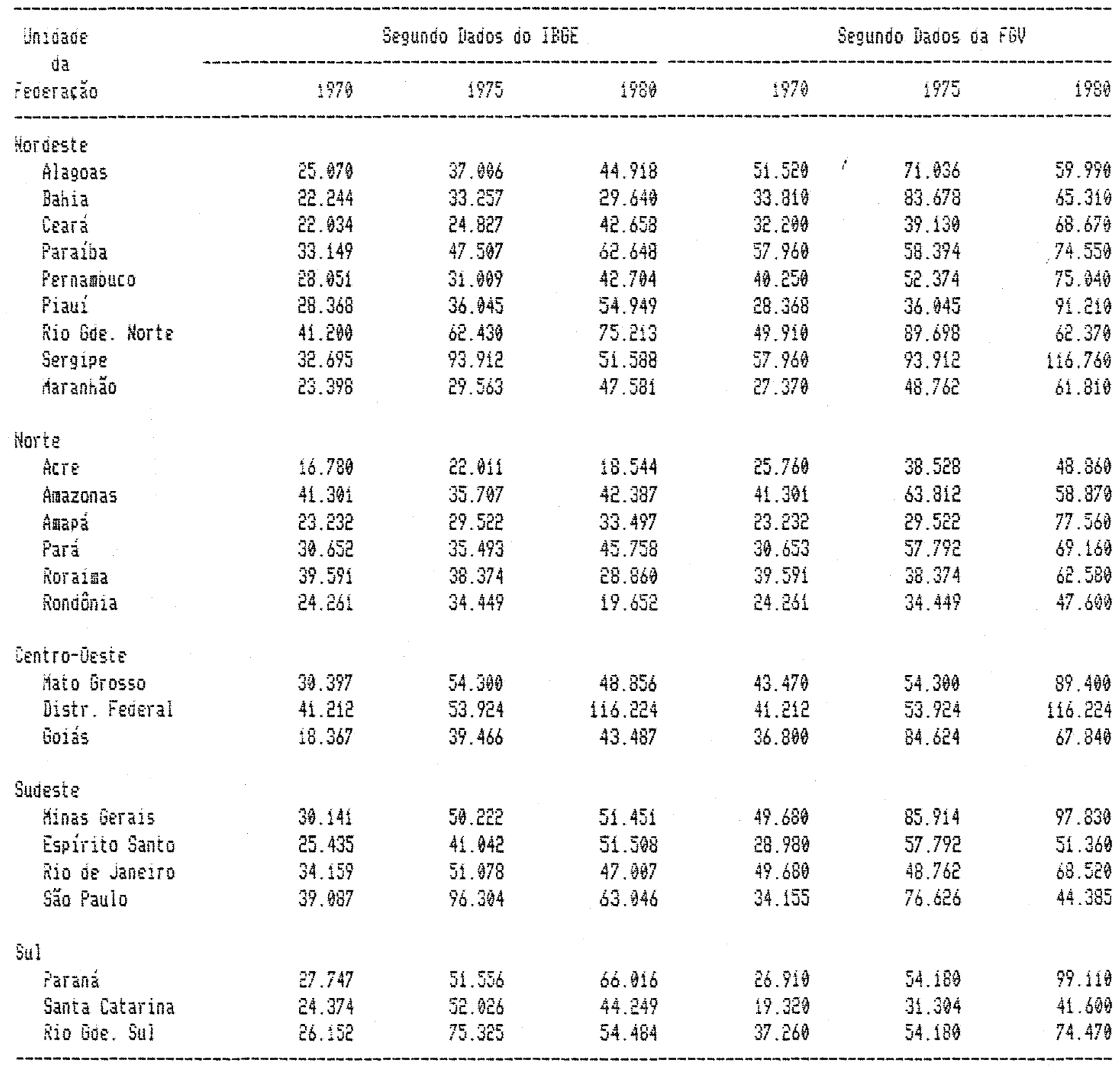

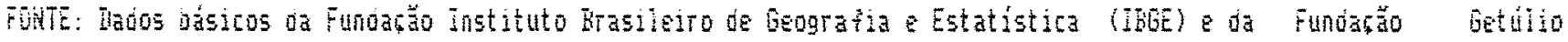
Vargas levul. 


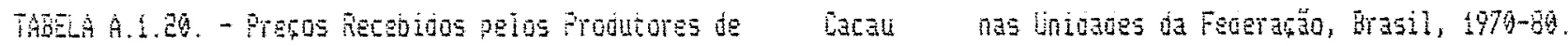

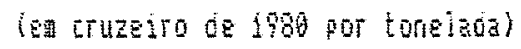

\begin{tabular}{|c|c|c|c|c|c|c|}
\hline \multirow{2}{*}{$\begin{array}{c}\text { Ginjoge } \\
\text { oa } \\
\text { Federatăo }\end{array}$} & \multicolumn{3}{|c|}{ Gequndo indos do ibte } & \multicolumn{3}{|c|}{ Sequndo irdos da Fov } \\
\hline & 1978 & 1975 & 1980 & 1979 & 1975 & $\$ 980$ \\
\hline \multicolumn{7}{|l|}{ Hordeste } \\
\hline Mlaquas & 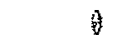 & 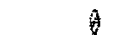 & $\theta$ & t & $\theta$ & $\theta$ \\
\hline Bania & 39.735 & 56.901 & 77.256 & 41.492 & 50.342 & 78.667 \\
\hline Ceari & $\hat{y}$ & $\theta$ & in & ij & $\theta$ & $\theta$ \\
\hline Paraba & $\theta$ & $\theta$ & 0 & b & $\theta$ & $\theta$ \\
\hline Penamouco & $y$ & $y$ & $\theta$ & g & $\theta$ & i \\
\hline Pianí & 9 & 9 & $g$ & 9 & $\theta$ & 4 \\
\hline To boe. Horte & $\theta$ & 출 & 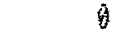 & $j$ & is & ) \\
\hline Sergipe & 6 & $y$ & $\theta$ & 9 & $\theta$ & 6 \\
\hline 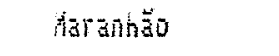 & 7.667 & 7.667 & 7.667 & 7.667 & 7.667 & 7.667 \\
\hline \multicolumn{7}{|l|}{ Norte } \\
\hline ACTE & $\hat{y}$ & 1 & 6 & j & 4 & $\frac{5}{3}$ \\
\hline A A & 24.065 & 38.838 & 59.194 & 24.951 & 38.838 & 52.53 \\
\hline 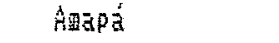 & 9.475 & 9.455 & $\theta$ & 9.471 & 9.455 & $y$ \\
\hline Fará & 31.128 & 58.715 & 61.161 & 31.128 & 58.715 & 62.133 \\
\hline Roridia & 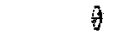 & $i$ & $\theta$ & f & $\theta$ & $\theta$ \\
\hline Rondonia & 67.962 & 67.849 & 67.649 & 67.962 & 87.049 & 87.847 \\
\hline \multicolumn{7}{|l|}{ Centro-deste } \\
\hline Hato brosso & 41.102 & $\$ 1.10$ & 41.119 & 41.60 & 41.120 & 41.120 \\
\hline Histr. Federal & $g$ & 8 & $\theta$ & 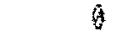 & 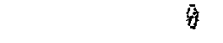 & t) \\
\hline boits & $y$ & $y$ & $\theta$ & 8 & 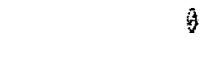 & $\theta$ \\
\hline \multicolumn{7}{|l|}{ Sudeste } \\
\hline dinas berais & 19.567 & $19 . \pm 67$ & 19.167 & 19.167 & 19.567 & 19.567 \\
\hline Espirito Santo & 33.113 & 63.994 & 76.838 & 36.723 & 54.943 & 73.393 \\
\hline BO de Janeito & is & 0 & $\theta$ & i) & $\theta$ & $\theta$ \\
\hline Să Faulo & 41.12 & 41.199 & 41.123 & 41.121 & 41.119 & 41.123 \\
\hline \multicolumn{7}{|l|}{ Suj } \\
\hline Paraná & 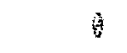 & $\dot{\theta}$ & $\theta$ & $y$ & $\theta$ & 0 \\
\hline Santa Catarina & is & 3 & $\theta$ & 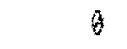 & $\theta$ & 5 \\
\hline Rio bde. Sul & $\theta$ & 1 & 6 & $\dot{\theta}$ & 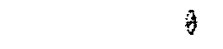 & $y$ \\
\hline
\end{tabular}

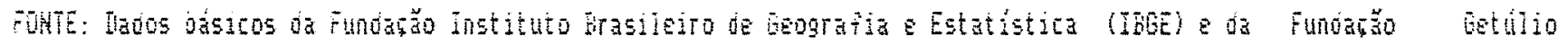
Vargas (Fol). 


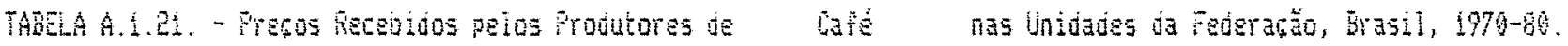

(Ea cruzezo de 198 por tonelada)

\begin{tabular}{|c|c|c|c|c|c|c|}
\hline \multirow{2}{*}{$\begin{array}{c}\text { Uniuade } \\
\text { je } \\
\text { Pederăso }\end{array}$} & \multicolumn{3}{|c|}{ Sequndo Iados do TaleE } & \multicolumn{3}{|c|}{ Goundo Iadoos da Fol } \\
\hline & 1970 & 1975 & 1980 & 1970 & 597 & 1980 \\
\hline \multicolumn{7}{|l|}{ Worosste } \\
\hline Alagogs & 27.301 & 29.297 & 29.274 & 15.870 & 15.870 & 15.870 \\
\hline Bahia & 27.422 & 33.246 & 27.454 & 27.422 & 54.894 & 50.330 \\
\hline Céará & 26.413 & 44.274 & 47.312 & 15.870 & 37.668 & 42.630 \\
\hline Paraía & 19.981 & 19.881 & 41.230 & 19.981 & 19.891 & 41.230 \\
\hline Pernatiouco & 23.840 & 43.650 & 49.133 & 22.480 & 53.496 & .37 .690 \\
\hline Piauí & $\theta$ & $\theta$ & $\theta$ & $\sqrt{3}$ & 8 & a \\
\hline Rio boe. Worte & $\theta$ & $\theta$ & $\theta$ & a & $\dot{3}$ & 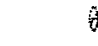 \\
\hline Sergine & 27.224 & 27.179 & 27.177 & 27.224 & 27.179 & 27.179 \\
\hline 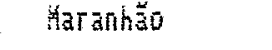 & 36.890 & 19.320 & 19.320 & 36.869 & 10.320 & 10.320 \\
\hline \multicolumn{7}{|l|}{ Worte } \\
\hline ACTE & 30.188 & 81.790 & 64.363 & 30.188 & 81.749 & 37.620 \\
\hline Arazanas & 62.315 & 62.315 & 62.35 & 62.315 & 62.315 & 62.359 \\
\hline A国殒的主 & 23.990 & 22.982 & 23.900 & 23.960 & 22.962 & 23.690 \\
\hline Para & 36.166 & 31.120 & 53.564 & 36.166 & 31.120 & 94.564 \\
\hline Roraina & 40.000 & 45.924 & in & 46.390 & 45.924 & it) \\
\hline Rondônia & 53.263 & 89.263 & 35.993 & 53.263 & 69.263 & 45.300 \\
\hline \multicolumn{7}{|l|}{ Centro-deste } \\
\hline hato brosso & $21.30 \mathrm{E}$ & 38.592 & 39.618 & 14.269 & 31.218 & 30.120 \\
\hline Distr. Federal & 13.142 & 13.143 & 49.456 & 13.143 & 13.143 & 49.456 \\
\hline $601 \div 5$ & 19.996 & 37.346 & 36.548 & 16.109 & 67.854 & 36.270 \\
\hline \multicolumn{7}{|l|}{ Sudeste } \\
\hline Hinas Gerais & 21.545 & 44.833 & 40.643 & 18.860 & 25.542 & 36.450 \\
\hline Esoirito Santo & 19.847 & 34.046 & 49.527 & 16.790 & 25.112 & 32.290 \\
\hline no de janeiro & 17.714 & 50.680 & 41.990 & 20.910 & 44.892 & 33.310 \\
\hline 5ะ̃ Pauio & 24.593 & 43.595 & 45.671 & 25.990 & 32.55 & 40.870 \\
\hline \multicolumn{7}{|l|}{ Sul } \\
\hline Paraná & 23.86 & 46.991 & 46.784 & 24.614 & 38.184 & 35.940 \\
\hline Santa Catarina & 13.985 & 16.792 & 36.450 & 10.810 & 10.792 & 36.459 \\
\hline fio 60 . Sul & $\theta$ & $\theta$ & $\theta$ & $y$ & 0 & 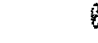 \\
\hline
\end{tabular}

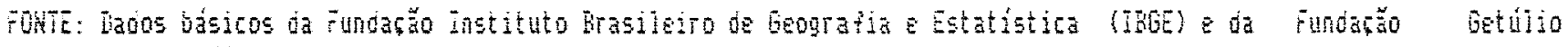
Vargas (FGU). 


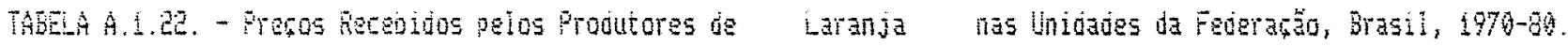

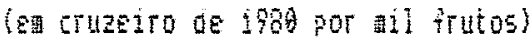

\begin{tabular}{|c|c|c|c|c|c|c|}
\hline \multirow{2}{*}{$\begin{array}{c}\text { inioade } \\
0 a \\
\text { Fonaräo }\end{array}$} & \multicolumn{3}{|c|}{ Segundo lados do IBGE } & \multicolumn{3}{|c|}{ Segunóo Iizuos da fị } \\
\hline & $\operatorname{sing}$ & 1975 & 1960 & 1979 & 1975 & 1989 \\
\hline \multicolumn{7}{|l|}{ Horugte } \\
\hline hiaguas & 620 & 1.306 & 723 & 1.364 & 1.426 & 723 \\
\hline Bahia & 794 & 925 & 689 & 1.681 & 1.569 & 991 \\
\hline Ceari & 308 & 1.662 & 1.276 & 1.815 & $1.66 \mathrm{c}$ & 1.276 \\
\hline Paraiba & 600 & 1.040 & 898 & 1.981 & 1.049 & 1.629 \\
\hline Pernsauteo & 627 & 780 & 801 & $7 \mathrm{ac}$ & 1.243 & 1.166 \\
\hline Piă & 632 & 1.432 & 1.225 & 632 & 1.432 & 1.432 \\
\hline Sio bue, durte & 920 & 1.086 & 1.127 & 2.134 & 1.806 & 1.107 \\
\hline Sergipe & 794 & 676 & 449 & $1.19 \mathrm{~d}$ & 798 & 623 \\
\hline 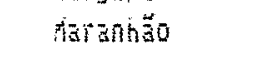 & 454 & 690 & 964 & 713 & 1.193 & 960 \\
\hline \multicolumn{7}{|l|}{ fiorte } \\
\hline ALTE & 1.575 & 1.735 & 1.655 & 1.518 & 1.735 & 1.008 \\
\hline A Alazonas & 1.69 & 2.991 & e. 477 & 1.929 & 2.991 & 2.689 \\
\hline 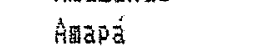 & 1.202 & 1.000 & 2.150 & 1.202 & 1.200 & 1.691 \\
\hline Para & 862 & 1.751 & 1.972 & 862 & 1.751 & 1.790 \\
\hline Suraina & 1.73 & 1.730 & 1.951 & 1.733 & 1.730 & 1.814 \\
\hline Bondônia & 2.127 & 2.123 & 1.723 & 2.127 & 2.123 & 1.723 \\
\hline \multicolumn{7}{|l|}{ Centro-beste } \\
\hline Sato Grosso & $83 i$ & 1.414 & 1.467 & 1.530 & 2.372 & 1.005 \\
\hline Distr. Federal & 1.383 & 1.469 & $\frac{1}{2} .523$ & 1.083 & 1.469 & 1.523 \\
\hline 60145 & 832 & 1.960 & 1.010 & 1.24 & 2.955 & 1.148 \\
\hline \multicolumn{7}{|l|}{ Suueste } \\
\hline hinas berais & 554 & 918 & 815 & 858 & 1.099 & 948 \\
\hline Espirito Santo & 583 & 1.010 & 912 & 722 & 1.010 & 825 \\
\hline ho de anento & 564 & $73 \mathrm{E}$ & 827 & 1.426 & 1.336 & 880 \\
\hline Săo Pauto & 442 & 449 & 452 & 412 & 321 & 384 \\
\hline \multicolumn{7}{|l|}{ Sul } \\
\hline Paraña & 576 & 1.265 & 1.214 & 1.934 & 2.383 & 1.383 \\
\hline Santa Catarina & 583 & 1.236 & 1.062 & 867 & 1.440 & 1.476 \\
\hline So bde. Sui & 607 & 1.372 & 1.136 & 1.396 & 882 & 1.112 \\
\hline
\end{tabular}

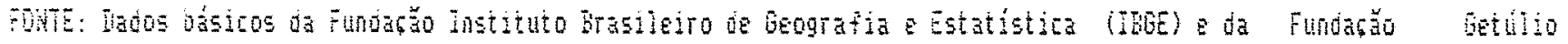
Vargas ribu. 


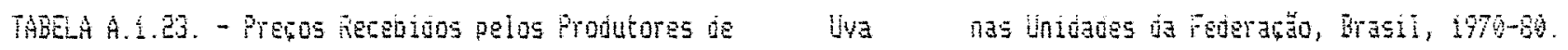

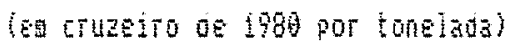

\begin{tabular}{|c|c|c|c|c|c|c|}
\hline \multirow{2}{*}{$\begin{array}{c}\text { Unidede } \\
\text { da } \\
\text { Federatzo }\end{array}$} & \multicolumn{3}{|c|}{ Segundo lados do IBbe } & \multicolumn{3}{|c|}{ Sequndo lizós da fbV } \\
\hline & 1579 & 1975 & 1960 & 1979 & 1975 & 1980 \\
\hline \multicolumn{7}{|l|}{ Átorueste } \\
\hline Ailagoss & $y$ & is & ) & 9 & in & i \\
\hline óania & 25.403 & 25.993 & 25.493 & 25.993 & 25.493 & 25.495 \\
\hline Ceara & 57.500 & 57.500 & 57.590 & 57.590 & 57.560 & 57.590 \\
\hline Paraíba & 27.431 & $27.43 \mathrm{i}$ & 37.43 & 27.491 & 27.431 & 27.431 \\
\hline Permaguco & 9.184 & 9.167 & 10.656 & 9.184 & 7.184 & 73.379 \\
\hline Pigui & 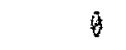 & i & 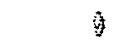 & $\theta$ & 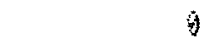 & $\theta$ \\
\hline no boe. Horte & 0 & a & A & $\theta$ & $y$ & $\theta$ \\
\hline Sergipe & (4) & $\theta$ & a & $\theta$ & 9 & 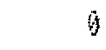 \\
\hline 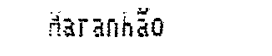 & in & 3 & 9 & 3 & $\theta$ & is \\
\hline \multicolumn{7}{|l|}{ forts } \\
\hline Acrs & $y$ & $y$ & 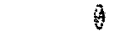 & f & $\theta$ & $\theta$ \\
\hline Airazginas & $\theta$ & 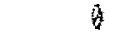 & $\theta$ & $\theta$ & $\theta$ & G \\
\hline 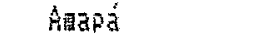 & ) & 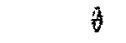 & 9 & $\theta$ & $\theta$ & 6 \\
\hline Pará & 3 & in & 0 & $\hat{4}$ & 0 & is \\
\hline Roraiga & $\theta$ & $\theta$ & 0 & 0 & $\theta$ & $\theta$ \\
\hline Rondônia & $\theta$ & b & $\theta$ & 百 & $\theta$ & s \\
\hline \multicolumn{7}{|l|}{ Centro-ieste } \\
\hline tato Grosso & 26.538 & 26.58 & 26.538 & 26.530 & 26.530 & 26.500 \\
\hline Distr. Feoeral & $\theta$ & 0 & 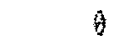 & ) & $\theta$ & 9 \\
\hline Boiละ & 81.385 & 31.385 & $\theta$ & 81.385 & 81.385 & 3 \\
\hline \multicolumn{7}{|l|}{ Sucieste } \\
\hline Hinas Gerais & 7.601 & $7.69 i$ & 7.641 & 7.691 & 7.601 & 7.691 \\
\hline Espirito Santo & 26.239 & 26.239 & 26.239 & 26.239 & 26.239 & 26.239 \\
\hline Rio de Janeito & 26.659 & 26.615 & 26.615 & 26.659 & 26.615 & 26.615 \\
\hline Săo Paulo & 15.783 & $20.97 \%$ & 19.841 & 15.783 & 20.978 & $19.84 \mathrm{E}$ \\
\hline \multicolumn{7}{|l|}{ Sul } \\
\hline Paraná & 21.895 & 29.273 & 33.47 & 21.895 & 29.673 & $60.95 \%$ \\
\hline Santa Catarina & 5.337 & 5.780 & $\frac{15.209}{1}$ & 5.337 & 5.980 & 10.260 \\
\hline kio Gós. Sul & 4.495 & 5.995 & 9.360 & 4.495 & 5.095 & 5.960 \\
\hline
\end{tabular}

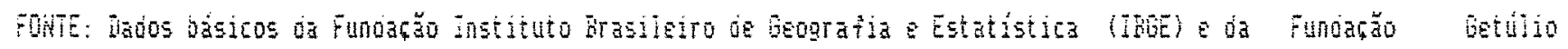
Vargas (Fin). 


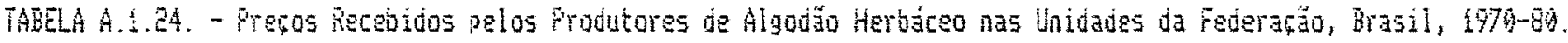
(ex cruzeiro de igeo por tonelaua)

\begin{tabular}{|c|c|c|c|c|c|c|}
\hline \multirow{2}{*}{$\begin{array}{c}\text { Undade } \\
\text { da } \\
\text { rederafäo }\end{array}$} & \multicolumn{3}{|c|}{ 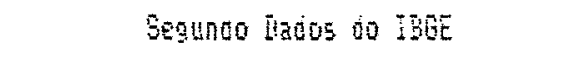 } & \multicolumn{3}{|c|}{ Segundo irados da fou } \\
\hline & 190 & 1975 & 1580 & 1979 & 1375 & 1989 \\
\hline \multicolumn{7}{|l|}{ Hordeste } \\
\hline Hiasoas & $2 \mathrm{c} .7 \mathrm{de}$ & 17.286 & 43.537 & 11.960 & 17.206 & 20.849 \\
\hline Bahia & 14.288 & 16.571 & 25.466 & 14.288 & 17.028 & 23.710 \\
\hline CEatá & 17.710 & 24.627 & 36.260 & 17.719 & 22.016 & 26.240 \\
\hline Paraía & 15.130 & 24.275 & 38.916 & 15.180 & 23.048 & 26.859 \\
\hline Pernąuto & 12.860 & $24.2+\tilde{r}$ & 39.766 & 12.800 & 19.760 & 23.659 \\
\hline Piaui & $\theta$ & 23.850 & 23.850 & 0 & 23.350 & 23.830 \\
\hline Nio bue. Murts & 15.410 & 23.321 & 37.537 & 15.410 & 21.156 & 27.579 \\
\hline Sergipe & 20.736 & 17.630 & 17.940 & $11.07 \%$ & 17.630 & 17.949 \\
\hline 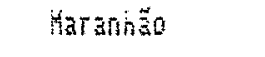 & 7.360 & 12.728 & 14.000 & 7.369 & 12.720 & 14.990 \\
\hline \multicolumn{7}{|l|}{ Horte } \\
\hline ACTE & $\theta$ & 9 & 0 & $\hat{\theta}$ & z & $\hat{\theta}$ \\
\hline Átazonas & ) & $\theta$ & $\theta$ & 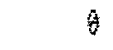 & $\theta$ & 3 \\
\hline 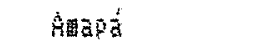 & $\theta$ & a & $\theta$ & 1 & $\theta$ & is \\
\hline Pará & 8.527 & 26.950 & 26.658 & 0.527 & 26.958 & 26.950 \\
\hline norsina & is & 9 & $\theta$ & $y$ & 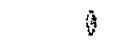 & 3 \\
\hline Ronưonia & 18.230 & 18.207 & 13.207 & 13.238 & 18.697 & 58.267 \\
\hline \multicolumn{7}{|l|}{ Centro-ueste } \\
\hline Rato brosso & 18.353 & 17.763 & 17.296 & 12.88 & 17.114 & 17.380 \\
\hline Distr. Faderat & a & $\dot{a}$ & $\theta$ & 0 & $\theta$ & 9 \\
\hline Dojas & 19.986 & 24.286 & 21. 4 霓5 & 13.570 & $2 \mathrm{e} .10 \mathrm{e}$ & 22.350 \\
\hline \multicolumn{7}{|l|}{ Sudeste } \\
\hline Hinas berais & 14.627 & 21.917 & 23.628 & 12.429 & 19.866 & 22.829 \\
\hline Espitito Santo & 12.476 & 22.360 & 12.476 & 12.476 & 22.360 & 12.476 \\
\hline fio de janeito & 13.750 & 11.481 & $\$ 1.481$ & \pm 1.590 & 11.481 & 11.481 \\
\hline Sสั้อ Pauto & 17.057 & 22.434 & 21.384 & 16.100 & 28.726 & 22.210 \\
\hline \multicolumn{7}{|l|}{ sui } \\
\hline Patanà & $15.96 c^{2}$ & 18.537 & 17.206 & 13.340 & 19.694 & 19.280 \\
\hline Santa Catarina & 0 & $\theta$ & $\hat{\theta}$ & 0 & $b$ & $\dot{b}$ \\
\hline fiio $60 \mathrm{e}$. 3u & $\theta$ & $\theta$ & $\theta$ & 0 & $y$ & 3 \\
\hline
\end{tabular}

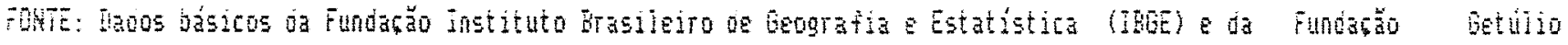
Vargas (Fov). 


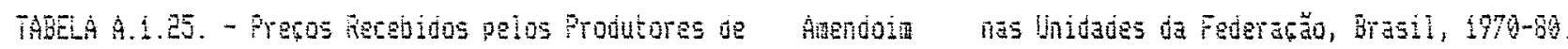
(ex cruzeiro de 3900 por toneiaoa)

\begin{tabular}{|c|c|c|c|c|c|c|}
\hline \multirow{2}{*}{$\begin{array}{c}\text { Dnjoade } \\
\text { oa } \\
\text { Federarăo }\end{array}$} & \multicolumn{3}{|c|}{ Seglindo Jados do Thet } & \multicolumn{3}{|c|}{ Segunoo Hados os Fol } \\
\hline & 579 & 1975 & 1980 & 1979 & 1975 & 1790 \\
\hline \multicolumn{7}{|l|}{ Horoeste } \\
\hline Alaguas & \pm 0.451 & 9.710 & 14.940 & \pm 0.451 & 9.718 & 14.940 \\
\hline Banta & 11.619 & 32.422 & 19.138 & 16.569 & 32.422 & 19.130 \\
\hline Cemá & 9.870 & 15.910 & 11.240 & 1.730 & 55.910 & 11.240 \\
\hline Paraía & 14.344 & 14.720 & 14.729 & 14.720 & 14.720 & 14.790 \\
\hline Penamatuco & 17.250 & $16.68 \mathrm{e}$ & 16.982 & 17.250 & 16.082 & 10.982 \\
\hline Piani & 14.154 & 18.990 & 18.930 & 14.154 & 18.930 & 18.730 \\
\hline nio Goe. Worte & $\theta$ & $y$ & $y$ & 0 & j & $\hat{y}$ \\
\hline Sergipe & 23.300 & 17.286 & 17.286 & 14.630 & 17.286 & 17.286 \\
\hline 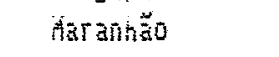 & 9.451 & 9.451 & 13.500 & 9.451 & 9.451 & 13.589 \\
\hline \multicolumn{7}{|l|}{ Horte } \\
\hline Acre & 23.300 & 73.590 & 12.130 & 23.940 & 73.100 & 12.130 \\
\hline A A & 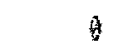 & is & $i$ & 3 & 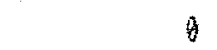 & $\theta$ \\
\hline มีติต์ & 3 & $y$ & 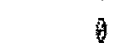 & $y$ & $\theta$ & 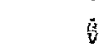 \\
\hline Para & 10.131 & 11.860 & 11.890 & 10.131 & 11.880 & 11.880 \\
\hline horaimà & i) & $\hat{y}$ & i) & $\theta$ & 0 & A \\
\hline Rủndêñ & 22.721 & 22.684 & 10.979 & 22.72 & 22.684 & $19.97 \%$ \\
\hline \multicolumn{7}{|l|}{ Bentro-beste } \\
\hline Hato brosso & 11.33 & 13.377 & 7.650 & 9.439 & $\$ 3.150$ & 5.235 \\
\hline Eistr. Federal & 20.371 & 20.371 & 20.371 & 20.371 & 20.371 & 29.371 \\
\hline Go1 & 7.021 & 17.458 & 13.669 & 112.770 & 17.458 & 13.690 \\
\hline \multicolumn{7}{|l|}{ Sufeste } \\
\hline Anas berais & 1.974 & 18.146 & 18.950 & $37.7 \mathrm{eg}$ & 18.146 & 18.950 \\
\hline Espirito Santo & 11.203 & 17.372 & 19.709 & 11.730 & $17.37 \mathrm{z}$ & 10.700 \\
\hline hio de Janeiro & 10.741 & 16.512 & 11.670 & 13.899 & 16.512 & 11.670 \\
\hline Săo Paùo & 10.891 & 15.390 & 10.619 & 10.350 & 15.738 & 10.679 \\
\hline \multicolumn{7}{|l|}{ sui } \\
\hline Paraná & 9.710 & 17.716 & 11.370 & 9.430 & $\$ 7.716$ & 11.370 \\
\hline Santa Catarina & 12.633 & 17.892 & 13.578 & 10.819 & 17.892 & 13.570 \\
\hline No boe. Sul & 7.315 & 16.426 & 15.690 & 10.350 & 16.426 & 15.690 \\
\hline
\end{tabular}

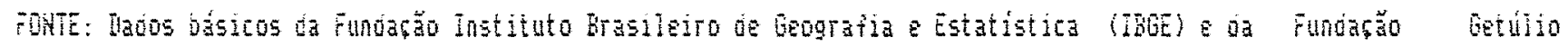
Vargas (Fu). 


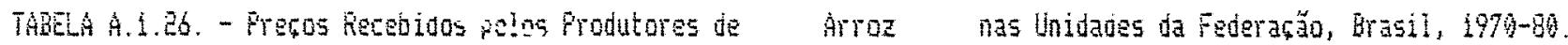

(eft ctuzeito de 1980 por tonelada)

\begin{tabular}{|c|c|c|c|c|c|c|}
\hline \multirow{2}{*}{$\begin{array}{c}\text { Unidade } \\
\text { ja } \\
\text { Federazaú }\end{array}$} & \multicolumn{3}{|c|}{ Sequndo Ilados do IBbE } & \multicolumn{3}{|c|}{ Segundo Iados da FDV } \\
\hline & 1970 & 1975 & 1980 & 1970 & 1975 & 1980 \\
\hline \multicolumn{7}{|l|}{ Horuete } \\
\hline Mlagoss & 7.608 & 15.996 & 15.156 & 8.740 & 15.996 & 11.690 \\
\hline Bahia & 8.169 & 14.528 & 11.122 & 10.810 & 17.880 & 11.650 \\
\hline Ceará & 7.957 & 13.580 & 13.876 & 10.810 & 16.684 & 13.400 \\
\hline Paraiba & 10.024 & 14.878 & 13.649 & 9.896 & 14.878 & 7.110 \\
\hline Pernantuco & 9.636 & 15.824 & 12.530 & 8.740 & 15.824 & 12.530 \\
\hline Piauí & 7.805 & 11.789 & 12.753 & 7.805 & 11.769 & 12.230 \\
\hline kito Gude. Horte & 11.583 & $16.98 \mathrm{c}$ & 14.580 & 10.810 & 16.082 & 14.586 \\
\hline Sergipe & 7.547 & 15.487 & 13.823 & 7.200 & 12.814 & 10.720 \\
\hline Maranhä & 6.12 & 10.218 & 7.460 & 7.820 & 12.470 & 7.740 \\
\hline \multicolumn{7}{|l|}{ Horte } \\
\hline ALTE & 9.890 & 10.507 & 11.928 & 10.580 & 11.782 & 10.009 \\
\hline Amazonas & 12.265 & 17.716 & 14.232 & 12.205 & 17.716 & 11.930 \\
\hline Aิapá & 8.616 & 11.561 & 9.613 & 8.016 & 11.201 & 8.490 \\
\hline Paré & 5.698 & 10.369 & 9.428 & 5.698 & 13.244 & 10.230 \\
\hline Rurăina & 14.115 & 18.466 & 10.814 & 14.115 & 18.466 & 10.980 \\
\hline nondonia & 9.015 & $8.79 \%$ & 7.4 .48 & 9.915 & 8.799 & 8.7 .34 \\
\hline \multicolumn{7}{|l|}{ Centro-1)este } \\
\hline Wato brosso & 7.535 & 12.424 & 8.941 & 7.130 & 55.566 & 7.749 \\
\hline Distr. Feueral & 9.238 & 13.250 & 11.121 & 9.238 & 15.256 & 11.121 \\
\hline Going & 7.059 & 13.936 & 9.580 & 8.050 & 17.114 & 16.660 \\
\hline \multicolumn{7}{|l|}{ Sudeste } \\
\hline Minas Gerais & 7.460 & 15.769 & 11.690 & 7.820 & 17.974 & 12.970 \\
\hline Espirito Santo & 8.982 & 16.276 & 12.550 & 7.599 & 16.856 & 12.770 \\
\hline Rio de Janeiro & 7.521 & 16.459 & 12.158 & 7.590 & 16.684 & $1 \hat{2} .710$ \\
\hline Săo Paulo & 9.967 & 15.998 & 11.479 & 8.749 & 19.264 & 12.750 \\
\hline \multicolumn{7}{|l|}{ sul } \\
\hline Paraná & 7.107 & 12.905 & 11.256 & 8.510 & 17.200 & 13.920 \\
\hline Santa Catarina & 7.167 & 14.137 & 9.684 & 7.130 & 15.650 & 19.610 \\
\hline Kio Gde. Sul & 7.114 & 14.501 & 11.237 & 7.130 & 13.588 & 12.380 \\
\hline
\end{tabular}

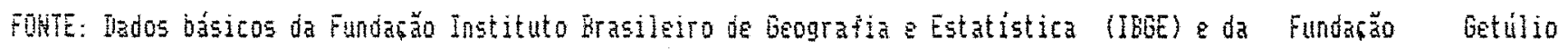
Vargas (FGN). 


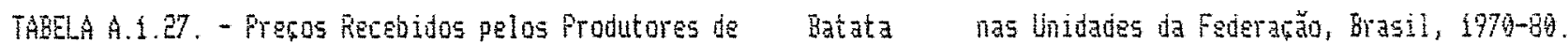
(E⿱一𫝀口 cruzeiro de 1980 por tunelada)

\begin{tabular}{|c|c|c|c|c|c|c|}
\hline \multirow{2}{*}{$\begin{array}{c}\text { Unidade } \\
\text { da } \\
\text { Pederarăo }\end{array}$} & \multicolumn{3}{|c|}{ Segundo Ilados do IDGE } & \multicolumn{3}{|c|}{ Segundo liados da FGV } \\
\hline & 1979 & 1975 & 1980 & 1979 & 1975 & 1989 \\
\hline \multicolumn{7}{|l|}{ hordeste } \\
\hline Alagoas & 15.333 & 28.638 & 4 & 27.600 & 28.638 & 0 \\
\hline Bahia & 7.791 & 24.760 & 28.590 & 24.150 & 24.768 & 28.560 \\
\hline Cestá & 8.966 & 8.962 & 8.767 & 21.390 & 21.390 & 21.390 \\
\hline Faraiba & 7.919 & 19.264 & 18.240 & 16.560 & 19.264 & 18.246 \\
\hline fenatauco & 8.656 & 22.618 & 21.940 & 20.790 & 22.618 & 21.940 \\
\hline Piauí & $\theta$ & 3 & 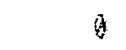 & 9 & 0 & $\theta$ \\
\hline nío bue. Norte & $\theta$ & $\theta$ & 0 & ) & $i$ & a \\
\hline Sergipe & $\$ 0.552$ & 28.736 & 28.490 & 27.370 & 28.936 & 20.490 \\
\hline Mă antăo & $j$ & 9 & $b$ & $\dot{\theta}$ & $\theta$ & is \\
\hline \multicolumn{7}{|l|}{ Norte } \\
\hline ACTE & is & $\theta$ & 0 & $\theta$ & $\theta$ & $\theta$ \\
\hline Amazonas & b & $\theta$ & i) & 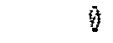 & $\theta$ & $\theta$ \\
\hline 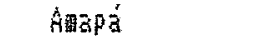 & 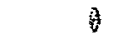 & $\theta$ & $\theta$ & $\theta$ & 0 & is \\
\hline Pará & $\tilde{y}$ & y & 0 & $\theta$ & $\Rightarrow$ & t \\
\hline Roraina & $\theta$ & g & $\theta$ & $y$ & $\theta$ & $y$ \\
\hline rondôn1a & 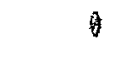 & 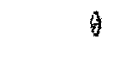 & $\dot{b}$ & (3) & 0 & i \\
\hline \multicolumn{7}{|l|}{ Centro-dests } \\
\hline Aato brosso & 8.280 & 17.290 & 17.114 & 12.680 & 17.114 & 17.114 \\
\hline Distr. Federal & 12.985 & 12.985 & 12.985 & 12.795 & 12.785 & 12.785 \\
\hline botas & 8.546 & 22.360 & 28.260 & 14.950 & 22.360 & 68.200 \\
\hline \multicolumn{7}{|l|}{ Sudeste } \\
\hline Hinas berais & 5.677 & 8.949 & 12.792 & 8.970 & 9.374 & 16.930 \\
\hline Espirito Santo & 7.281 & 11.869 & 19.840 & 10.560 & 11.860 & 19.844 \\
\hline Rio de Janeiro & 6.292 & 10.664 & 18.140 & 8.970 & 10.664 & 18.146 \\
\hline Săo Paulo & 7.296 & 7.662 & 18.710 & 8.280 & 10.654 & 18.920 \\
\hline \multicolumn{7}{|l|}{ sul } \\
\hline Faraná & 5.998 & 6.822 & 10.668 & 7.130 & 8.513 & 16.310 \\
\hline Santa Catarina & 6.654 & 8.984 & 14.478 & 7.590 & 8.684 & 16.864 \\
\hline tio Gje. Sul & 3.328 & 7.912 & 16.510 & 6.67 a & 7.912 & 16.516 \\
\hline
\end{tabular}

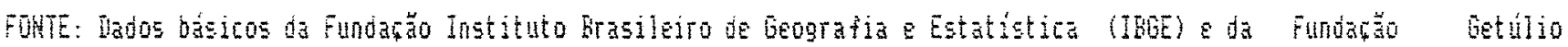
bargas (rov). 


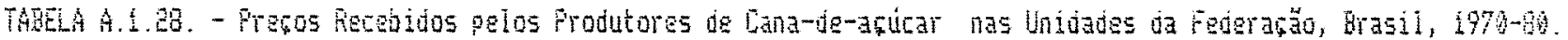
(ell cruzeiro de 19 go por tonelada)

\begin{tabular}{|c|c|c|c|c|c|c|}
\hline \multirow{2}{*}{$\begin{array}{c}\text { Unidade } \\
\text { da } \\
\text { Federatăo }\end{array}$} & \multicolumn{3}{|c|}{ Segundo ilados do IBLE } & \multicolumn{3}{|c|}{ Sequndo latos da Fov } \\
\hline & 1970 & 1975 & 1980 & 1970 & 1975 & 1909 \\
\hline \multicolumn{7}{|l|}{ Hordeste } \\
\hline Alaguas & 579 & 843 & 200 & 595 & 738 & 895 \\
\hline Bahiz & 545 & 852 & 1.915 & $67 \%$ & 688 & 705 \\
\hline Cearà & 569 & 768 & 1.064 & 647 & 650 & 797 \\
\hline Paraiba & 683 & 887 & 1.956 & 612 & 795 & 843 \\
\hline Fernadutudo & 612 & 839 & 952 & $46 z$ & 619 & 769 \\
\hline Piauí & 899 & 976 & 1.194 & 690 & 776 & $7 \%$ \\
\hline Rio Go. Worte & 664 & 854 & 1.14 & 656 & 669 & 851 \\
\hline Sergipe & 58 & 729 & 1.559 & 56 & 726 & 1.199 \\
\hline Mararth & 531 & 53 & 1.218 & 301 & 531 & 1.230 \\
\hline \multicolumn{7}{|l|}{ Horts } \\
\hline $\mathrm{ACTE}$ & 873 & 873 & 873 & 873 & 873 & 873 \\
\hline A A & 1.190 & 1.197 & 1.196 & 1.199 & 1.190 & 1.196 \\
\hline 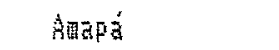 & 2.259 & 2.247 & 2.247 & 2.259 & 2.247 & 2.247 \\
\hline Pará & 395 & 395 & 305 & 385 & 305 & 385 \\
\hline Foraina & 1.857 & 1.854 & 1.054 & 1.857 & 1.554 & 1.54 \\
\hline Bondônia & 2.727 & 2.722 & $2.72 \mathrm{a}$ & 2.727 & $2.72 \mathrm{e}$ & $2.7 e$ \\
\hline \multicolumn{7}{|l|}{ Bentro-Beste } \\
\hline Hato $6 r 0 s 50$ & 942 & 2.579 & $7 \% 0$ & 476 & 2.570 & 790 \\
\hline Distr. Federal & 2.930 & 2.430 & 2. 9190 & 2.693 & 2.635 & $2.95 \%$ \\
\hline Goiás & 705 & 869 & 741 & 371 & 860 & 741 \\
\hline \multicolumn{7}{|l|}{ Sudeste } \\
\hline Hinas Gerais & 471 & 747 & 711 & 412 & 496 & 578 \\
\hline Espirito Santo & 464 & 693 & 745 & 438 & 563 & 55 \\
\hline kio de Janeito & 449 & 690 & 699 & 485 & 616 & 557 \\
\hline Săo Fuío & 461 & 695 & 697 & 445 & 647 & 978 \\
\hline \multicolumn{7}{|l|}{ Sul } \\
\hline Paraná & 476 & 719 & $68 \mathrm{z}$ & 391 & 433 & 529 \\
\hline Santa Catarina & 474 & 682 & 263 & 460 & 802 & 627 \\
\hline No bos. Sul & 517 & 484 & 484 & 480 & 484 & 484 \\
\hline
\end{tabular}

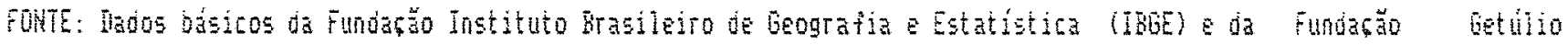
Vargas (Fov). 


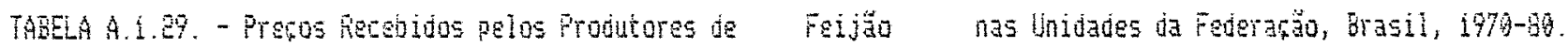
(ér cruzeiro de liso por tunelada)

\begin{tabular}{|c|c|c|c|c|c|c|}
\hline \multirow{2}{*}{$\begin{array}{c}\text { Unidade } \\
\text { da } \\
\text { Pederatá }\end{array}$} & \multicolumn{3}{|c|}{ Sequndo bados do intie } & \multicolumn{3}{|c|}{ Sequndo Ilados da ral } \\
\hline & 1978 & 1975 & 1990 & 1970 & 1975 & 1980 \\
\hline \multicolumn{7}{|l|}{ Mortuste } \\
\hline Alanoes & 24.375 & 26.85 & 70.483 & 86.450 & 23.504 & 46.730 \\
\hline Dania & 17.968 & 22.795 & 12.223 & 28.860 & 29.154 & 50.360 \\
\hline Cents & $24.29 \%$ & 10.851 & 46.794 & 27.140 & 18.748 & 40.970 \\
\hline Paraía & 23.815 & 23.073 & 55.922 & 27.830 & 99.358 & 49.670 \\
\hline Pernasubu & 21.906 & 23.724 & 45.942 & 27.680 & 25.926 & 48.970 \\
\hline Piaui & 20.869 & 17.865 & 40.074 & 29.869 & 17.835 & 42.430 \\
\hline hio bue. Horte & 22.880 & 19.910 & 57.347 & 27.660 & 21.328 & 46.960 \\
\hline Serging & 21.669 & 26.394 & 60.462 & 29.990 & 29.920 & $52.7 \%$ \\
\hline Varanhz̃o & 16.799 & 24.39 & 49.97 & 39.590 & 28.638 & 42.749 \\
\hline \multicolumn{7}{|l|}{ Norte } \\
\hline ACTE & 20.256 & 30.394 & 49.490 & 34.59 & 38.528 & 45.669 \\
\hline Airazonas & 16.697 & $33.97 \%$ & 33.479 & 16.647 & 33.979 & $33.47 \%$ \\
\hline Aมpá & 21.595 & 21.769 & 49.760 & 21.695 & 21.767 & 49.760 \\
\hline Pará & 19.420 & 26.576 & 38.930 & 19.420 & 31.132 & 39.009 \\
\hline Roraima & 22.203 & 42.930 & 29.216 & 22.293 & 42.939 & $59.95 \%$ \\
\hline Rondônia & 18.836 & 49.083 & 34.957 & 18.836 & 49.983 & 49.335 \\
\hline \multicolumn{7}{|l|}{ Gentro-deste } \\
\hline Hato $6 r 0550$ & 14.969 & 32.226 & 39.650 & 18.560 & 30.960 & 41.270 \\
\hline Distr. Foderal & 16.797 & 42.563 & 46.689 & 16.798 & 42.563 & 46.689 \\
\hline Bo่ส́s & 17.234 & 27.149 & 41.973 & 23.230 & 28.466 & 44.240 \\
\hline \multicolumn{7}{|l|}{ Sudete } \\
\hline Hinas Gerais & 17.767 & 29.349 & 40.024 & 21.390 & 24.749 & 45.856 \\
\hline Espirito Santo & 18.991 & 21.752 & 42.725 & 22.980 & 21.328 & 44.939 \\
\hline Rio de Janeiro & 21.340 & 25.711 & 56.064 & 27.379 & 23.968 & 43.950 \\
\hline Să Paulo & 17.214 & 30.693 & 51.596 & 17.940 & 32.594 & 45.950 \\
\hline \multicolumn{7}{|l|}{ sul } \\
\hline Paraná & 14.138 & 16.990 & 43.262 & 15.870 & 21.586 & 37.870 \\
\hline Ganta Catarina & 15.721 & 15.129 & 32.780 & 17.710 & 14.104 & 33.364 \\
\hline Rio bde. Sul & 5.839 & 15.730 & 36.881 & 21.390 & 15.738 & 38.686 \\
\hline
\end{tabular}

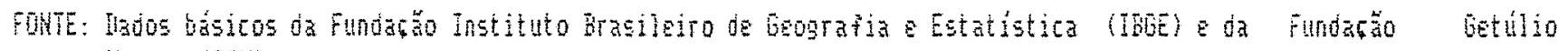
Vargas (Fin). 


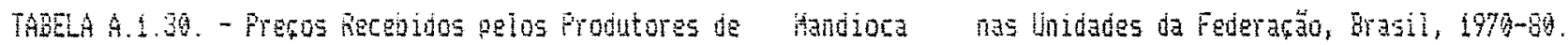

(er ituzeiro de 1980 por tonelaúa)

\begin{tabular}{|c|c|c|c|c|c|c|}
\hline \multirow{2}{*}{$\begin{array}{c}\text { Unidade } \\
\text { da } \\
\text { Petsrăăo }\end{array}$} & \multicolumn{3}{|c|}{ Segundo IRdos do IEGE } & \multicolumn{3}{|c|}{ Segundo Dados da Fin } \\
\hline & 1970 & 1975 & 1989 & 1970 & 1975 & 980 \\
\hline \multicolumn{7}{|l|}{ Worueste } \\
\hline Aiaguas & 2.672 & 4.596 & 4.828 & 2.530 & 3.579 & 2.894 \\
\hline Bahia & 1.615 & 2.552 & 3.434 & 1.655 & 2.751 & 2.599 \\
\hline Ceará & 2.911 & 2.494 & 3.874 & 1.803 & 2.589 & 3.792 \\
\hline Paraiba & 2.809 & 3.780 & 3.965 & 1.753 & 3.024 & 3.376 \\
\hline Pernambuco & 2.81 & 3.794 & 4.184 & 1.945 & 2.419 & 3.532 \\
\hline Piauí & 1.198 & 1.750 & 2.699 & 1.198 & $1.75 \%$ & 2.916 \\
\hline Rio be. Worts & 2.545 & 3.756 & 3.898 & 1.913 & 2.910 & 3.035 \\
\hline Sergipe & 2.410 & 3.835 & 4.149 & 1.807 & 4.765 & 2.227 \\
\hline 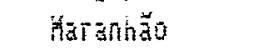 & 1.270 & $2.18 \mathrm{c}$ & 4.207 & 1.931 & 2.787 & 1.795 \\
\hline \multicolumn{7}{|l|}{ Norte } \\
\hline ACTE & 3.317 & 4.991 & 4.506 & 3.317 & 5.923 & 4.296 \\
\hline Angzonas & 1.991 & 3.396 & 3.297 & 1.791 & 5.157 & 2.686 \\
\hline AMapá & 3.315 & 4.917 & 4.835 & 3.315 & 4.199 & 4.035 \\
\hline Pará & 4.39 & 1.985 & 3.975 & 1.392 & 4.155 & 1.969 \\
\hline Roraina & 1.955 & 6.999 & 5.480 & 1.755 & 6.999 & 3.790 \\
\hline Rondônia & 4.742 & 5.550 & 6.657 & 4.742 & 5.556 & $4.17 \%$ \\
\hline \multicolumn{7}{|l|}{ Centro-ueste } \\
\hline dato orosso & 3.231 & $5 . \overline{94} 6$ & 5.373 & 1.571 & 3.317 & 4.436 \\
\hline Bistr. Federal & 5.049 & 5.649 & 5.849 & 5.949 & 5.949 & 5.949 \\
\hline Butás & 1.456 & 3.029 & 3.756 & 1.760 & 3.386 & 3.694 \\
\hline \multicolumn{7}{|l|}{ Gudeste } \\
\hline Minas berais & 1.335 & 2.793 & 2.989 & 22.932 & 2.903 & 1.764 \\
\hline Espirito Santo & 1.545 & 3.294 & 3.171 & 1.331 & 2.711 & 2.227 \\
\hline Rio de Janeiro & 2.250 & 4.771 & 4.884 & 1.421 & 4.309 & 3.574 \\
\hline São Paulo & 1.490 & 2.430 & 2.950 & 1.399 & 2.430 & 2.950 \\
\hline \multicolumn{7}{|l|}{ Sul } \\
\hline Paranà & 1.608 & 4.143 & 3.006 & 1.530 & 2.92 & 2.168 \\
\hline Santa Catarina & 1.211 & 2.683 & 3.469 & 960 & 1.873 & 2.731 \\
\hline hio bue. Sul & 1.995 & 5.724 & 5.458 & 1.318 & 1.791 & 5.178 \\
\hline
\end{tabular}

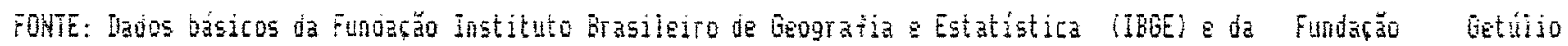
Vargas (Fov). 


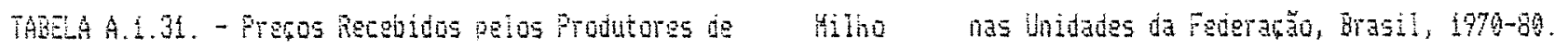
(et ctuzeiro de 1980 pot tunelada)

\begin{tabular}{|c|c|c|c|c|c|c|}
\hline \multirow{2}{*}{$\begin{array}{c}\text { Mudade } \\
\text { da } \\
\text { Seneraräo }\end{array}$} & \multicolumn{3}{|c|}{ Segundo bas do 1800} & \multicolumn{3}{|c|}{ Senndo Tados da rou } \\
\hline & 197 & 1975 & 1980 & 1970 & 1975 & 1780 \\
\hline \multicolumn{7}{|l|}{ Moruesta } \\
\hline Maguas & 7.333 & 7.627 & 13.687 & 9.660 & 7.912 & 9.800 \\
\hline bahia & 4.833 & 6.490 & 7.394 & 6.909 & 7.316 & 7.750 \\
\hline Cearía & 7.836 & 6.534 & 11.256 & 8.050 & 6.766 & 7.600 \\
\hline Paraía & 9.095 & 7.514 & 11.888 & 7.666 & 7.310 & 18.376 \\
\hline Pernanouco & 7.900 & 7.868 & 10.327 & B.20日 & 7.740 & 9.630 \\
\hline Piauí & 5.496 & 5.812 & 8.772 & 5.496 & 3.812 & 8.50 \\
\hline hio boe. Horte & 9.916 & 7.683 & 14.605 & 10.580 & 8.858 & 50.490 \\
\hline Sergipe & 7.645 & 7.539 & 13.892 & 8.510 & 8.514 & 9.759 \\
\hline Aat anträo & 4.356 & 6.262 & 7.212 & 7.360 & 9.288 & 7.590 \\
\hline \multicolumn{7}{|l|}{ Worte } \\
\hline ACTE & 6.584 & 7.169 & 0.721 & 6.440 & 8.342 & 7.940 \\
\hline Avazonas & 8.360 & 12.298 & 11.663 & 5.360 & 12.298 & 8.586 \\
\hline 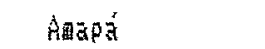 & 9.775 & 13.119 & 12.768 & 7.775 & 13.110 & 7.490 \\
\hline Pará & 5.927 & 7.193 & 8.821 & 5.627 & 9.976 & 8.770 \\
\hline Rotaina & 9.132 & 8.366 & 11.429 & 9.132 & 8.366 & 11.250 \\
\hline Rondonia & 4.326 & 6.767 & 5.750 & 4.326 & 6.767 & 7.910 \\
\hline \multicolumn{7}{|l|}{ Centro-ieste } \\
\hline Aato Grosso & 5.418 & 5.375 & 5.904 & 4.378 & 6.192 & 6.685 \\
\hline Dist. Feuerai & 4.661 & 7.363 & $8.69 \%$ & 4.661 & 7.363 & 8.690 \\
\hline Boiี้ & 3.299 & 5.554 & 5.752 & 3.510 & 6.278 & 6.160 \\
\hline \multicolumn{7}{|l|}{ Sufeste } \\
\hline minas berais & 4.082 & 6.519 & 7.039 & 4.830 & 6.536 & 7.200 \\
\hline Espirito Santo & 4.4 .34 & 6.525 & 7.349 & 4.830 & 7.224 & 7.959 \\
\hline ño de vaneito & 5.476 & 8.491 & 10.930 & 5.750 & 8.686 & 8.870 \\
\hline Să Pauio & 4.948 & 6.208 & 5.960 & 4.699 & 6.809 & 6.980 \\
\hline \multicolumn{7}{|l|}{ SuI } \\
\hline Paraná & 3.122 & 5.155 & 5.393 & 3.450 & 6.106 & 0.090 \\
\hline Santa Caúarina & 3.750 & 5.986 & 0.558 & $4.37 \%$ & 7.138 & 6.830 \\
\hline Gio bue. Sul & 3.57 & 6.148 & 7.926 & 4.140 & 6.270 & 7.260 \\
\hline
\end{tabular}

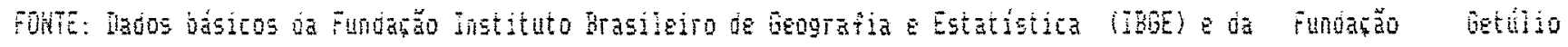
Vargas (rou). 


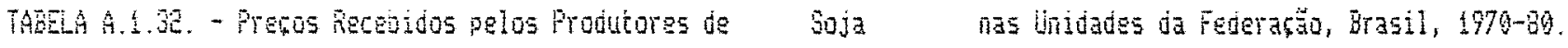
teg cruzeiro de 9800 por tuneiada)

\begin{tabular}{|c|c|c|c|c|c|c|}
\hline \multirow{2}{*}{$\begin{array}{c}\text { Undusos } \\
\text { da } \\
\text { Foortatio }\end{array}$} & \multicolumn{3}{|c|}{ Segundo indos do IBGE } & \multicolumn{3}{|c|}{ Segundo bados da Fiv } \\
\hline & 1979 & 1975 & 1980 & 1979 & 1975 & 1900 \\
\hline \multicolumn{7}{|l|}{ Hordeste } \\
\hline Mlayuss & $\theta$ & $\theta$ & $\theta$ & $y$ & 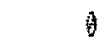 & $\sqrt{3}$ \\
\hline Daniz & 11.960 & 11.969 & 14.960 & 11.960 & 11.760 & 11.96 \\
\hline Ceara & $\theta$ & $\theta$ & $j$ & 0 & 0 & 3 \\
\hline Farióa & 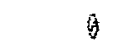 & $\theta$ & 8 & $b$ & $\theta$ & 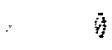 \\
\hline Pernaguto & H & $A$ & $\theta$ & i & $\theta$ & 齐 \\
\hline Piauí & 9 & $\theta$ & $\theta$ & 3 & 9 & a \\
\hline Bo boe. Horts & $\theta$ & $\theta$ & $\theta$ & $\bar{y}$ & 9 & $\frac{5}{3}$ \\
\hline Sergipe & A & $\theta$ & 0 & 0 & 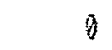 & 9 \\
\hline Taranhă & $y$ & 9.364 & 9.364 & 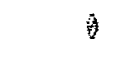 & 7.364 & 9.364 \\
\hline \multicolumn{7}{|l|}{ irorte } \\
\hline Acre & 0 & 0 & 0 & t & 4 & f \\
\hline Ainazonas & $\theta$ & $b$ & 0 & $\theta$ & 9 & 3) \\
\hline Arap & $j$ & $\theta$ & $\theta$ & 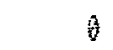 & $\hat{g}$ & it \\
\hline Fari & it & is & 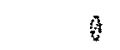 & 9 & 0 & ) \\
\hline Roraina & 1 & $\theta$ & i) & $\theta$ & $j$ & i \\
\hline Bondûnia & is & 9 & 9 & 0 & 4 & 3 \\
\hline \multicolumn{7}{|l|}{ Centro-beste } \\
\hline Hato brosso & 9.134 & 10.587 & 9.184 & 9.134 & 19.234 & 9.099 \\
\hline Vistr. Federal & 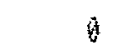 & 9.738 & 9.738 & ) & 9.738 & 9.738 \\
\hline 601:5 & 9.151 & 11.359 & 8.637 & 9.151 & 11.180 & 9.270 \\
\hline \multicolumn{7}{|l|}{ Sudeste } \\
\hline Hinas berais & 8.771 & 12.994 & 10.495 & 8.771 & 11.266 & 9.210 \\
\hline Espirito Santo & 9.364 & 9.364 & 9.364 & 9.364 & 9.364 & 9.364 \\
\hline ho de janeito & 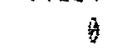 & $\theta$ & $\theta$ & i & $\theta$ & $\theta$ \\
\hline Sẵ Pauio & 9.190 & 11.650 & 9.113 & 9.890 & 11.438 & 9.739 \\
\hline \multicolumn{7}{|l|}{ अi } \\
\hline Paraná & 7.525 & 11.253 & 3.899 & 7.590 & 11.438 & 9.729 \\
\hline Santa Catarina & 6.590 & 10.731 & 9.064 & 6.59 & 10.962 & 9.270 \\
\hline ho bde. Sul & 7.283 & 11.254 & 7.410 & 7.360 & 19.664 & 9.330 \\
\hline
\end{tabular}

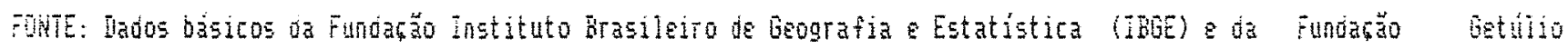
Vargas (rov). 
TABEA A.1.33. - Presos kecedidos pelos Produrores de Trigo nas lnidades da Federaräo, Brasil, 1970-Ba. (en cruzeiro de logo por tonelada)

\begin{tabular}{|c|c|c|c|c|c|c|}
\hline \multirow{2}{*}{$\begin{array}{c}\text { Unidade } \\
\text { oa } \\
\text { Federăto }\end{array}$} & \multicolumn{3}{|c|}{ Segundo lados do IBot } & \multicolumn{3}{|c|}{ Segundo lasos da rol } \\
\hline & 1979 & 1775 & 1980 & 1972 & 1975 & 1980 \\
\hline \multicolumn{7}{|l|}{ Mordeste } \\
\hline Alagoas & 列 & 3 & $\theta$ & A & 3 & 군 \\
\hline Bahia & $\theta$ & 9 & 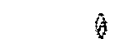 & $\theta$ & $\hat{\theta}$ & 3 \\
\hline Ceatá & q & 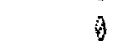 & $\theta$ & $\theta$ & i & 3 \\
\hline Faraía & $a$ & a & $a$ & 0 & 6 & $\theta$ \\
\hline 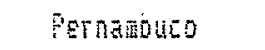 & 9 & $\theta$ & 0 & 3 & 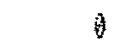 & 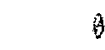 \\
\hline Fiaui & 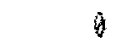 & 9 & 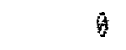 & 0 & $\theta$ & 0 \\
\hline Rio boe vorte & $j$ & $\theta$ & 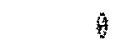 & 0 & $\dot{\theta}$ & $\dot{\theta}$ \\
\hline Sergipe & 8 & $\theta$ & a & $\ddot{\theta}$ & 9 & $\theta$ \\
\hline 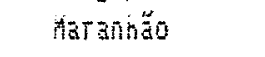 & $\theta$ & $\theta$ & $\theta$ & $\theta$ & i & $y$ \\
\hline \multicolumn{7}{|l|}{ Worte } \\
\hline ACTE & $j$ & $\theta$ & 0 & 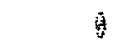 & 1 & $\theta$ \\
\hline Arazonds & q & ) & $\theta$ & 3 & 3 & 0 \\
\hline Meps & $\theta$ & $\theta$ & $\theta$ & $\theta$ & 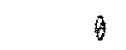 & $\theta$ \\
\hline Pata & i & $g$ & $\theta$ & 0 & $g$ & 6 \\
\hline Rorai酸 & $\theta$ & $y$ & $\theta$ & $\theta$ & $\theta$ & $\theta$ \\
\hline rondonia & is & $\theta$ & $\theta$ & in & ) & 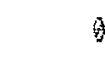 \\
\hline \multicolumn{7}{|l|}{ Centro-0este } \\
\hline Bato Grosso & 9.918 & 9.918 & 11.636 & 9.710 & 9.918 & 9.720 \\
\hline Iistr. Federal & 0 & 0 & 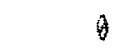 & 0 & $\dot{y}$ & 3 \\
\hline botas & $y$ & $\theta$ & $y$ & $\partial$ & 0 & $\theta$ \\
\hline \multicolumn{7}{|l|}{ Sudeste } \\
\hline Hinas berads & 11.270 & 14.368 & 11.840 & 11.070 & 14.362 & 11.840 \\
\hline Espirito Santo & $\theta$ & $\theta$ & $\theta$ & 0 & 0 & 0 \\
\hline Ho de Janeiro & i & 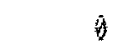 & $\theta$ & 8 & $\theta$ & 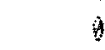 \\
\hline Să 7allo & 10.091 & 14.360 & 11.840 & 19.89 & 14.362 & 11.848 \\
\hline \multicolumn{7}{|l|}{ sul } \\
\hline 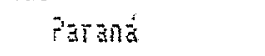 & 9.847 & 2.465 & 10.910 & 11.270 & 13.244 & 9.460 \\
\hline Santa Catarina & 9.815 & 12.996 & 8.230 & 10.350 & 12.900 & 8.230 \\
\hline Sio Gue. Sul & 10.439 & 13.243 & 19.612 & 10.500 & 2.384 & 7.920 \\
\hline
\end{tabular}

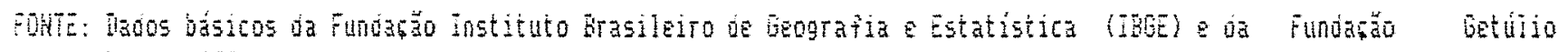
Vargas (Fon. 


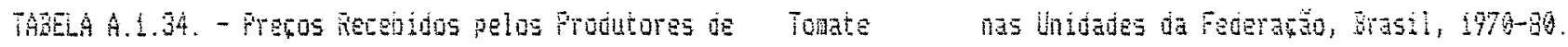

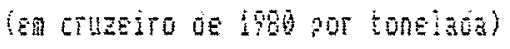

\begin{tabular}{|c|c|c|c|c|c|c|}
\hline \multirow{2}{*}{$\begin{array}{c}\text { Unoaue } \\
\text { da } \\
\text { Fsuetarắ }\end{array}$} & \multicolumn{3}{|c|}{ Segunoo bados do inbe } & \multicolumn{3}{|c|}{ Sequndo indos da } \\
\hline & 1970 & 1975 & 1900 & 197 & 1975 & 1780 \\
\hline \multicolumn{7}{|l|}{ Horueste } \\
\hline Alagoas & 7.567 & 23.134 & 27.430 & 7.607 & 23.134 & 27.430 \\
\hline Baniáa & 8.666 & 24.830 & 8.634 & 8.666 & 24.900 & 20.490 \\
\hline Bara & 10.371 & 21.500 & 13.649 & 10.391 & 21.509 & 3.640 \\
\hline Baraba & 12.557 & 19.170 & 13.290 & 12.359 & 19.170 & 19.80 \\
\hline Perranduco & 5.868 & 5.892 & 5.99 & 3.280 & 16.254 & 30.75 \\
\hline Paui & 15.335 & 25.319 & 25.319 & 15.3 .95 & 25.319 & 25.318 \\
\hline Ho Goe. Worte & 9.081 & 21.30 & 17.540 & 9.801 & 21.328 & 17.549 \\
\hline Sergipe & 9.257 & 20.383 & 18.190 & 9.257 & 20.360 & 18.10 \\
\hline 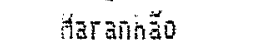 & $18.7 \mathrm{EE}$ & 32.164 & 21.480 & 18.722 & 32.164 & 21.480 \\
\hline \multicolumn{7}{|l|}{ borte } \\
\hline ACTE & 37.697 & 79.950 & 51.500 & 37.697 & 79.758 & 31.180 \\
\hline Amazonas & 19.994 & 63.726 & 41.500 & 19.994 & 63.726 & 41.59 \\
\hline ARap⿱亠䒑 & 23.396 & 22.962 & 23.930 & 23.900 & 26.76 & 23.60 \\
\hline Bata & 17.604 & 41.194 & 29.576 & 17.694 & 41.194 & 29.94 \\
\hline Sorai ia & 49.80 & 49.724 & $39.7 \mathrm{E}$ & $49.87 \mathrm{C}$ & 49.709 & $49.7 \mathrm{cg}$ \\
\hline Rondonia & 40.59 & 49.486 & 41.319 & 49.553 & 49.486 & 41.35 \\
\hline \multicolumn{7}{|l|}{ Eentro-ieste } \\
\hline Hato $6 r 0 \leq 50$ & 13.620 & 36.283 & 22.97 & 13.60 & 36.293 & 23.445 \\
\hline Iistr. Federal & 9.290 & 9.200 & 12.804 & 9.239 & 9.290 & 12.884 \\
\hline boids & 14.185 & $28.78 \mathrm{c}$ & 20.830 & 14.185 & 28.902 & 29.836 \\
\hline \multicolumn{7}{|l|}{ Stugste } \\
\hline Hinas Gerais & 8.788 & 11.461 & 11.505 & 11.730 & 12.470 & 19.850 \\
\hline Espirito santo & 7.190 & 9.608 & 3.637 & 7.159 & 14.928 & 12.54 \\
\hline nio de janeito & 7.54 & 11.342 & 11.908 & 18.810 & 10.512 & 16.346 \\
\hline 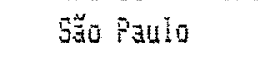 & 8.496 & 8.221 & 6.654 & 11.270 & 12.364 & 10.59 \\
\hline \multicolumn{7}{|l|}{ sul } \\
\hline Faraná & 9.896 & 21.672 & 18.910 & 7.829 & 24.62 & 18.49 \\
\hline Santa Catarina & 8.764 & 21.750 & 18.970 & 8.650 & 21.750 & 19.976 \\
\hline nio bog. Sul & 16.148 & 16.349 & 19.150 & 19.148 & 13.349 & 17.159 \\
\hline
\end{tabular}

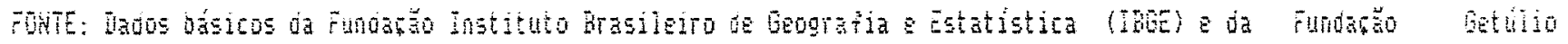
Vargas (Bon). 


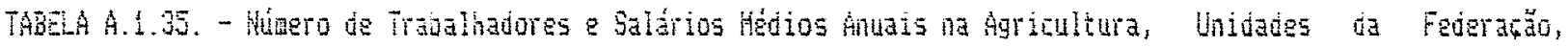
$\$ 970-80$.

\begin{tabular}{|c|c|c|c|c|c|c|c|c|c|}
\hline \multirow{3}{*}{$\begin{array}{c}\text { Unidaude } \\
\text { de } \\
\text { Federarao }\end{array}$} & \multirow{2}{*}{\multicolumn{3}{|c|}{$\begin{array}{l}\text { hutaro de Trabalhadores } \\
\text { (U) }\end{array}$}} & \multicolumn{6}{|c|}{ Salar io hedio Anual (ea Cruzeiro of 5980 ) } \\
\hline & & & & \multicolumn{3}{|c|}{ Segundo IIados do istae } & \multicolumn{3}{|c|}{ Segundo lavos da Fov } \\
\hline & 5778 & 1975 & $\$ 900$ & 1970 & 1975 & 1980 & 1570 & 4975 & 1980 \\
\hline \multicolumn{10}{|l|}{ Horoeste } \\
\hline Alagoas & 386.972 & $458.4 E^{5}$ & 444.770 & 18.439 & 36.549 & 31.840 & 32.292 & 39.867 & 40.608 \\
\hline Bahia & 1.729 .944 & 1.724 .2851 & 1.856 .552 & 13.493 & 29.369 & 25.303 & 30.912 & 40.699 & 43.680 \\
\hline Eeráá & 896.936 & 899.723 & 763.189 & 6.926 & 19.259 & 18.910 & 20.562 & 30.547 & 36.894 \\
\hline Paraíba & 539.638 & 744.897 & 466.360 & 10.666 & 17.621 & 20.831 & 21.114 & 32.198 & 37.824 \\
\hline Pernäbuco & 1. $0 \mathrm{ec} .151$ & 1.014 .577 & 895.346 & 29.449 & 38.659 & 27.644 & 25.392 & 32.362 & 44.110 \\
\hline Piauí & 426.920 & 531.225 & 497.137 & 45.566 & 42.947 & 17.873 & 10.372 & 37.311 & 37.980 \\
\hline hió bue. Horte & 276.430 & 336.495 & 398.475 & $9.48 \%$ & 24.30 & 21.193 & 22.980 & 32.588 & 192.990 \\
\hline Sergipe & 230.751 & 242.367 & 191.328 & 18.789 & 25.654 & 24.942 & 21.666 & 39.474 & 43.938 \\
\hline Harannลีด & 1.023 .971 & 1.431.475i & 1.239 .659 & 9.294 & 35.724 & 99.331 & 29.808 & 38.514 & 44.058 \\
\hline \multicolumn{10}{|l|}{ Horte } \\
\hline $\mathrm{AGT}$ & 26.305 & 33.710 & 43.495 & 20.936 & $\mathrm{C}^{5} .47 \mathrm{Z}$ & 31.494 & 46.368 & 50.600 & 60.528 \\
\hline Anazonas & 195.943 & 310.089 & 312.946 & 22.539 & 16.966 & 18.729 & 14.854 & 46.595 & 53.344 \\
\hline 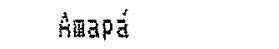 & 5.986 & 13.634 & 9.147 & 19.672 & 14.978 & 33.797 & 13.905 & 50.024 & 54.646 \\
\hline Pará & 449.935 & 648.152 & 735.530 & 13.499 & 28.246 & 26.456 & 14.835 & 47.524 & 52.350 \\
\hline Roraina & 3.826 & 11.349 & 11.381 & $17.7 \mathrm{~g} 4$ & 12.090 & 28.163 & 13.392 & 48.172 & 48.240 \\
\hline Rondônia & 13.180 & 93.192 & 129.331 & 19.762 & 36.934 & 37.591 & 18.779 & 57.555 & 66.390 \\
\hline \multicolumn{10}{|l|}{ Cantro-Ueste } \\
\hline Hato Grosco & 272.397 & 384.160 & 324.690 & 25.252 & $\$ 3.193$ & 46.191 & 37.1 & 47.317 & 54.918 \\
\hline Jistr. Federal & 4.549 & 4.736 & 7.326 & 32.502 & 49.316 & 198.812 & 32.568 & 53.260 & 51.954 \\
\hline Boiàs & 377.179 & 492.104 & 323.960 & 23.650 & 28.75 & 31.972 & 32.568 & 53.200 & 51.054 \\
\hline \multicolumn{10}{|l|}{ Sudeste } \\
\hline finas Gerais & 1.53 .584 & 1.137 .5261 & 1.114 .251 & 16.100 & 26.25 & 33.089 & 29.394 & 49.123 & 53.364 \\
\hline Espírito Santo & 225.986 & 221.307 & 263.275 & 19.740 & 22.363 & 35.355 & 26.910 & 46.698 & 56.334 \\
\hline Ro de Janeito & $\$ 85.248$ & 179.617 & $173.34 \mathrm{E}$ & 20.246 & 36.553 & 37.177 & 32.154 & 43.049 & 56.976 \\
\hline Să Paulo & 1.136 .578 & 1.94 .36 & 789.966 & 35.74 & 51.559 & 51.768 & 44.298 & 5136 & 54.372 \\
\hline \multicolumn{10}{|l|}{ sul } \\
\hline Paraná & 1.748 .976 & 1.873 .4431 & $1.48 \mathrm{c} .649$ & 22.793 & 39.993 & 34.047 & 37.260 & 53.974 & 55.548 \\
\hline Santa Catarina & 567.890 & 593.974 & 535.897 & 14.848 & 23.245 & 26.420 & 39.172 & $51.85 \mathrm{~s}$ & 69.978 \\
\hline Nio Gue. Sul & 1.148 .786 & 1.554 .8861 & 1.228 .597 & 33.524 & 42.921 & 40.188 & 40.434 & 50.516 & 58.188 \\
\hline
\end{tabular}

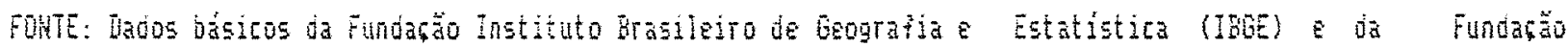
Gotulio Vargas (Fou). 
TABELA A.1.36. - Areas Totais Cultivadas e Precos de Arrendanento de Terras Agricolas nas lninades óa

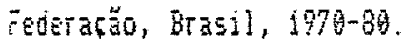

\begin{tabular}{|c|c|c|c|c|c|c|c|c|c|}
\hline \multirow{3}{*}{$\begin{array}{c}\text { Unidade } \\
\text { da } \\
\text { Poderabuo }\end{array}$} & \multirow{2}{*}{\multicolumn{3}{|c|}{$\begin{array}{c}\text { Ared Stitivada } \\
\text { (籼 ha) }\end{array}$}} & \multicolumn{6}{|c|}{ PTequs de Artendatento (en Cruzeiro de $1980 / \mathrm{ha}$ ) } \\
\hline & & & & \multicolumn{3}{|c|}{ SEpundo İados do IBGE } & \multicolumn{3}{|c|}{ Sequndo loúos dá FiV } \\
\hline & 1970 & 1975 & 1989 & 1979 & 1975 & 1980 & 1970 & 1975 & 1989 \\
\hline \multicolumn{10}{|l|}{ Woroste } \\
\hline Alaguas & 339 & 710 & 524 & 937 & 1.816 & 2.374 & 994 & 1.552 & 2.844 \\
\hline Bahia & 1.872 & 1.662 & 1.819 & 453 & 1.917 & 1.716 & 1.710 & 8.837 & 3.497 \\
\hline Centán & 789 & 1.827 & 1.311 & 287 & 764 & 588 & 1.524 & 2.32 & 2.52 \\
\hline Paraba & 597 & 1.911 & 625 & 559 & 1.143 & 988 & 1.012 & 2.999 & 2.579 \\
\hline Pemanduco & 1.049 & 1.257 & 1.931 & 770 & 1.330 & 2.679 & 1.651 & 2.399 & 2.335 \\
\hline Piaul & 384 & 352 & 472 & 320 & 918 & 899 & 1.330 & 2.251 & 2.428 \\
\hline Fio boe. Horte & 214 & 679 & 42 & 235 & 646 & 794 & 1.506 & 2.469 & 2.188 \\
\hline sergipe & 110 & $1+6$ & 81 & 951 & 1.692 & 2.439 & 1.119 & 2.455 & 2.219 \\
\hline 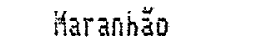 & 1.061 & 1.189 & 1.228 & 454 & 1.394 & 1.338 & 1.673 & 1.737 & 1.977 \\
\hline \multicolumn{10}{|l|}{ borte } \\
\hline Acre & 29 & 28 & 40 & $\hat{\mathrm{c}}$ & 5 & 3 & 1.538 & 4.913 & 2.960 \\
\hline A Aazzonas & 67 & 77 & 109 & 16 & 50 & 51 & 1.348 & 3.990 & 1.712 \\
\hline Amat: & 8 & 12 & 8 & A & 237 & 36 & 784 & 1.433 & 1.316 \\
\hline Pará & 367 & 547 & 583 & 89 & 552 & 129 & 1.415 & 4.375 & 1. 914 \\
\hline Roraina & 5 & 12 & 22 & 1 & 2 & 8 & 1.450 & 2.65 & 2.438 \\
\hline Rondûnia & 23 & 139 & 225 & 4 & 1.996 & 565 & 2.797 & 4.952 & 4.547 \\
\hline \multicolumn{10}{|l|}{ Centro-0este } \\
\hline Aato Grosso & 666 & 1.558 & 2.188 & 234 & 697 & 473 & 2.897 & 3.966 & 3.794 \\
\hline Distr. Federal & $\dot{4}$ & 5 & 21 & 486 & 131 & 47 & 2.467 & 3.600 & 3.384 \\
\hline Goias & 1.427 & 1.732 & 1.889 & 455 & 1.347 & 909 & 2.467 & 3.608 & 3.384 \\
\hline \multicolumn{10}{|l|}{ Sudeste } \\
\hline Hinas Gerais & 2.337 & 2.131 & 2.598 & 266 & 832 & 726 & 2.084 & 4.033 & 3.777 \\
\hline Espirito Santo & 510 & 442 & 516 & 624 & 1.317 & 2.489 & 2.629 & 5.887 & 5.771 \\
\hline Sio de Janeito & 416 & 319 & 327 & 827 & 1.506 & 1.490 & 2.147 & 5.104 & 5.555 \\
\hline să Palo & 3.940 & 3.875 & 4.590 & 2.468 & 5.186 & 5.931 & 2.256 & 4.166 & 4.34 \\
\hline \multicolumn{10}{|l|}{ sul } \\
\hline Paraná & 4.686 & 6.198 & 6.627 & 1.954 & $7.4 \bar{c}$ & 4.583 & 2.207 & 4.554 & 5.767 \\
\hline Ganta Catarina & 1.827 & 967 & 1.862 & 954 & 2.936 & 3.146 & 2.917 & 7.164 & 5.854 \\
\hline hio boe. Sul & 5.591 & 6.895 & 6.846 & 863 & 2.598 & 2.273 & 1.702 & 2.619 & 2.696 \\
\hline
\end{tabular}

Fonte: Lados básicos da Fundacăo Instituto frasileiro de Geografia \& Estatistica (iBbe) $\varepsilon$ da Fundacăo Getili io Vargas (Fin). 


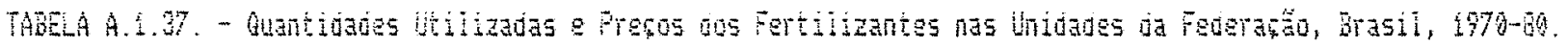

\begin{tabular}{|c|c|c|c|c|c|c|}
\hline \multirow{2}{*}{$\begin{array}{c}\text { Univave } \\
\text { Ga } \\
\text { Caterarăo }\end{array}$} & \multicolumn{3}{|c|}{ Guantioade } & \multicolumn{3}{|c|}{ 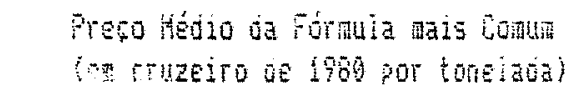 } \\
\hline & 597 & 1975 & 1899 & 1970 & 1975 & 1909 \\
\hline \multicolumn{7}{|l|}{ Aordeste } \\
\hline Alagoas & 70.137 & 186.933 & 167.953 & $11.27 \mathrm{z}$ & 19.325 & 18.9 \\
\hline Sahia & 32.347 & 46.182 & 190.660 & 20.831 & 23.504 & 19.807 \\
\hline Centá & 4.367 & 5.38 & 57.680 & 14.393 & 2.170 & 19.791 \\
\hline Paraba & 7.479 & 5.798 & 35.830 & IE. & 35.710 & 16.445 \\
\hline PEnavou & 49.919 & 89.521 & 126.396 & $13.38 \mathrm{~s}$ & 22.52 & 20.675 \\
\hline Pianí & 379 & 490 & 3.257 & 16.875 & 37.461 & 20.812 \\
\hline Sio bue. Horte & 3.261 & 3.511 & 2E. $2 \mathrm{En}$ & 19.55 & 80.564 & 15.854 \\
\hline Gergipe & 14.498 & 24.990 & 25.426 & 11.720 & 22.623 & $\$ 9.55$ \\
\hline Aaranhäo & $\mathrm{EE}$ & 795 & 13.545 & 15.65 & 23.924 & 24.340 \\
\hline \multicolumn{7}{|l|}{ forte } \\
\hline ALTE & is & 3 & 1.23 & 13.696 & 39.162 & 7.32 \\
\hline Airazonas & 56 & 107 & 2.759 & 17.710 & 49.272 & 26.437 \\
\hline 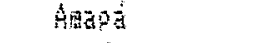 & 58 & 43 & $39 ?$ & 1. 4.69 & 26.394 & 10.476 \\
\hline Pará & 10.182 & 12.85 & 30.319 & 7.52 & 32.280 & $2 \mathrm{w} .400$ \\
\hline Rữi番a & $j$ & 3 & 721 & 22.023 & 46.545 & 50.881 \\
\hline Conudonia & 11 & 4 & 1.359 & 35.341 & 53.846 & 23.716 \\
\hline \multicolumn{7}{|l|}{ Dentro- $6 \mathrm{ste}$} \\
\hline Aato 300550 & 3.34 & $30.57 \mathrm{z}$ & 433.866 & 3.791 & 26.157 & 10.259 \\
\hline Uistr. Federal & 1.847 & 1.666 & 15.832 & 8.951 & 22.252 & 17.64 \\
\hline Boizs & 35.766 & \pm 63.037 & 265.241 & 3.198 & 26.335 & 17.40 \\
\hline \multicolumn{7}{|l|}{ Sudeste } \\
\hline Hinas berais & 153.155 & 254.060 & 582.966 & 8.867 & 18.850 & 10.792 \\
\hline Espirito Santo & 5.69 & 19.606 & 83.477 & 9.998 & 18.164 & 17.450 \\
\hline Kio de Janeiro & 33.30 & 27.391 & 32.170 & 7.576 & 29.848 & 17.337 \\
\hline Să Panto & 1.377 .374 & 1.090 .670 & 1.734 .320 & 6.3 .46 & 18.371 & 15.149 \\
\hline \multicolumn{7}{|l|}{ sul } \\
\hline Pataná & 413.116 & 551.557 & 357.066 & 7.684 & 20.377 & 15.753 \\
\hline Santa Catarina & 29.715 & 53.886 & 153.640 & 11.182 & 35.72 & 17.718 \\
\hline Mo Gde. Sul & 449.882 & 663.564 & 1.642 .673 & 19.597 & 28.643 & 16.363 \\
\hline
\end{tabular}

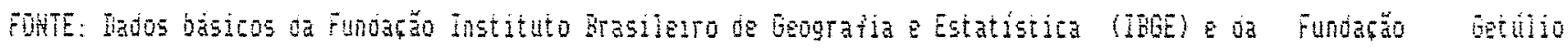
Wargas (Fon). 
TABELA A.1.38.- Formulaçốes Médias de Fertilizantes Utilizadas nas Regiöes, Brasil, 1970-80.

$\begin{array}{lccc} & 1970(1) & 1975 & 1980 \\ \text { Norte }(\underline{2}) & 14-16-15 & 14-14-17 & 15-18-13 \\ \text { Centro }(\underline{3}) & 09-11-09 & 09-17-11 & 09-20-13 \\ \operatorname{sul}(4) & 07-22-11 & 07-29-14 & 07-22-16\end{array}$

(1) Calculada a partir da média de nitrogênio de 1974 e os demais elementos, pelo consumo aparente do ano de 1970.

(2) Compreende os Estados do Amazonas até a Bahia.

(3) São Paulo, Rio de Janeiro, Minas Gerais, Espirito Santo, Paraná, Mato Grosso e Goiás.

(@) Santa Catarina e Rio Grande do sul.

FONTE: Circular $n^{2} 100 / 84$ do Sindicato das Indústrias de Adubos e Corretivos Agricolas no Estado de STo Paulo e, para 1970, dados básicos da circular $37 / 71$. 


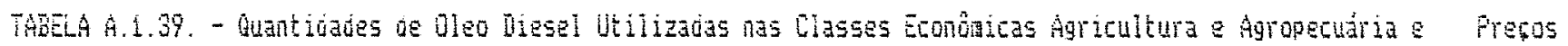
nas Unidades da Federabăo, Brasil, $1970-80$.

\begin{tabular}{|c|c|c|c|c|c|c|c|c|c|c|c|c|}
\hline \multirow{3}{*}{$\begin{array}{c}\text { Uniojae } \\
\text { ü } \\
\text { Feueratäo }\end{array}$} & \multicolumn{6}{|c|}{ Guantidade litilizada (aî iltos) } & \multicolumn{6}{|c|}{ 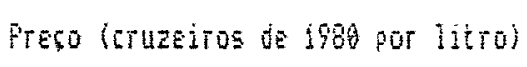 } \\
\hline & \multicolumn{3}{|c|}{ Agricuitura } & \multicolumn{3}{|c|}{ Agropecuária } & \multicolumn{6}{|c|}{ Seg. iavos do inge seg. iavos da Fu } \\
\hline & 1979 & 1975 & 1880 & 1970 & 1975 & 1989 & 1979 & 1975 & 1980 & 1970 & 1975 & 1989 \\
\hline Hordeste & & & & & & & & ' & & & & \\
\hline Miัgoas & 3.347 & 20.799 & 39.690 & 140 & 1.132 & 285 & 9 & is & 16 & 9 & 12 & 15 \\
\hline Bania & 3.293 & 7.633 & 28.467 & 826 & 1.247 & 1.557 & 10 & 14 & 17 & 10 & $1 \mathrm{I}$ & 19 \\
\hline Ceará & 1.441 & 3.972 & 8.786 & 692 & 1.775 & 975 & 19 & 13 & 17 & 10 & 13 & 15 \\
\hline Faraiba & 1.895 & 5.376 & 13.631 & 498 & 195 & 481 & 11 & 14 & 18 & 10 & 12 & 15 \\
\hline Fermanouco & 4.468 & 18.125 & 34.125 & 248 & 844 & 473 & 10 & 13 & 17 & 19 & 13 & 5 \\
\hline Piauí & 153 & 375 & 2.415 & $4 z$ & 37 & 136 & 11 & 14 & 18 & 10 & 13 & 15 \\
\hline Rio Gos. Worte & 1.172 & 3.964 & 7.272 & 465 & 361 & 885 & 16 & 13 & 17 & 10 & 13 & 15 \\
\hline Sergipe & 644 & 1.835 & 3.773 & 171 & 323 & 256 & 10 & 11 & 16 & 10 & 12 & 10 \\
\hline 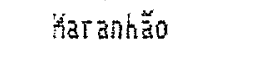 & 6 & 342 & 8.625 & 256 & 148 & 437 & 10 & 14 & 17 & 10 & 13 & 15 \\
\hline \multicolumn{13}{|l|}{ vorte } \\
\hline ACTE & 5 & 14 & 281 & 13 & 63 & 26 & 19 & 15 & 28 & 30 & 21 & 15 \\
\hline Antinazonas & 477 & 1.146 & 3.533 & 504 & 135 & 12 & 10 & 15 & 20 & 10 & 13 & 15 \\
\hline 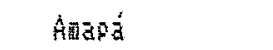 & 13 & 168 & 135 & 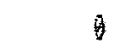 & 12 & $i$ & 12 & 12 & 16 & 19 & 13 & 17 \\
\hline Pará & 1.004 & 2.651 & 9.834 & 190 & 295 & 241 & 10 & 15 & 17 & 10 & 13 & 15 \\
\hline Roraige & 6 & 7 & 371 & $j$ & 1 & 3 & 15 & 13 & 19 & 10 & 13 & 15 \\
\hline Ruonuônia & 42 & 114 & 1.947 & $\frac{2}{3}$ & $i$ & 57 & 12 & 16 & 19 & 10 & 13 & 15 \\
\hline \multicolumn{13}{|l|}{ Centro-ieste } \\
\hline Aato brosso & 2.850 & 58.571 & 146.925 & 2.936 & 6.357 & 6.745 & 11 & 14 & 16 & 11 & 14 & 15 \\
\hline Distr. Federal & 76 & 248 & 2.594 & 27 & 93 & 19 & $1 \frac{1}{1}$ & 11 & 15 & 10 & 12 & 15 \\
\hline Golás & 9.545 & 44.722 & 88.939 & 5.695 & 14.907 & 11.933 & 1 & 13 & 16 & 10 & $\hat{B E}$ & 15 \\
\hline \multicolumn{13}{|l|}{ Sudeste } \\
\hline Minas berass & 41.656 & 45.516 & 205.344 & 3.512 & $7.75 j$ & 14.466 & 9 & 13 & 16 & 10 & 13 & 15 \\
\hline Espirito Santo & 935 & 2.676 & 10.595 & 623 & 359 & 942 & 19 & 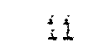 & 16 & 9 & 12 & $\$ 5$ \\
\hline hio te janeito & 6.317 & $\$ 7.380$ & 18.593 & 1.330 & 572 & 1.129 & 9 & 12 & 16 & 9 & $\hat{12}$ & 15 \\
\hline รăo Paulo & 197.298 & 255.523 & 401.135 & 31.460 & 21.694 & 24.659 & 9 & is & 15 & 9 & 11 & 15 \\
\hline \multicolumn{13}{|l|}{ sul } \\
\hline Parana & 28.556 & 159.712 & 232.894 & 3.737 & 4.819 & 7.819 & 10 & 13 & $\$ 5$ & 9 & $\mathrm{t} \bar{c}$ & 15 \\
\hline Santa Catarina & 3.540 & 18.284 & 35.660 & 583 & 132 & 1.084 & 10 & 13 & 15 & 19 & 12 & 15 \\
\hline ho bre. Sul & 105.870 & 270.536 & 348.562 & 13.909 & 11.524 & 16.636 & 10 & 13 & 15 & 10 & dE & 15 \\
\hline
\end{tabular}

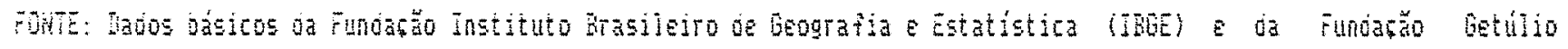
Vargas lonv. 


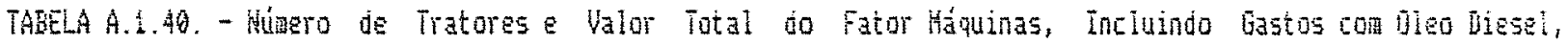
Undodes da Feuerašo, Brasii, $1970-80$.

\begin{tabular}{|c|c|c|c|c|c|c|c|c|c|}
\hline \multirow{3}{*}{$\begin{array}{c}\text { Uniuade } \\
\text { dà } \\
\text { Federarăa }\end{array}$} & \multirow{2}{*}{\multicolumn{3}{|c|}{$\begin{array}{l}\text { Wuiaro de Tratores } \\
\text { (U) }\end{array}$}} & \multicolumn{6}{|c|}{ 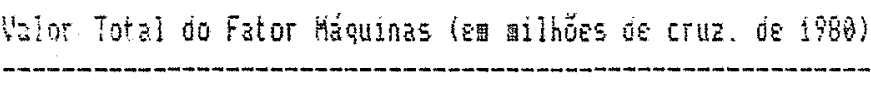 } \\
\hline & & & & \multicolumn{3}{|c|}{ Segunoo lados do IBbe } & \multicolumn{3}{|c|}{ Seguñó llados da FVV } \\
\hline & 1979 & 1975 & 1990 & 1970 & 1975 & 1980 & 1970 & 1975 & 1900 \\
\hline \multicolumn{10}{|l|}{ Norjeste } \\
\hline Alagoas & 796 & 2.014 & 3.197 & 97 & 885 & 1.290 & 97 & 854 & 1.248 \\
\hline Bahia & 1.179 & 2.397 & 8.150 & 236 & 679 & 2.115 & 235 & 685 & 2.949 \\
\hline Ceara & 480 & 1.075 & 2.091 & 167 & 367 & 760 & 165 & 365 & 739 \\
\hline Paraía & 540 & 1.036 & 2.910 & 107 & 412 & 605 & 195 & 49 & 556 \\
\hline Pernaสouco & 1.114 & 2.085 & 3.495 & 168 & 827 & $1.32 b$ & 168 & $8 \mathrm{C} 7$ & 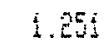 \\
\hline Piauí & 91 & 155 & 655 & 23 & 52 & 210 & 23 & 52 & 20 \\
\hline no bde. Horte & 396 & 1.605 & 1.816 & 78 & 315 & $45 i$ & 77 & 314 & $43 \frac{1}{1}$ \\
\hline Sergipe & 316 & 721 & 1.123 & 51 & 153 & 211 & 51 & 154 & 280 \\
\hline Haranhăo & 72 & 222 & 1.370 & 33 & 80 & 598 & 33 & 79 & 576 \\
\hline \multicolumn{10}{|l|}{ Horte } \\
\hline Acre & 11 & 7 & 79 & $b$ & 5 & 86 & 6 & 5 & 25 \\
\hline Amazonas & 44 & 27 & 232 & 32 & 55 & 236 & 32 & $\mathrm{Se}$ & 190 \\
\hline Amapa & 7 & 8 & 18 & 2 & 3 & 5 & 2 & 3 & 5 \\
\hline Pará & 666 & 948 & 3.159 & 34 & 179 & 629 & 84 & 175 & 510 \\
\hline Roraima & $\theta$ & 8 & 48 & $\theta$ & 2 & 40 & 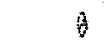 & 2 & 39 \\
\hline Rondônia & 15 & 21 & 267 & 7 & 16 & 137 & 7 & 16 & 132 \\
\hline \multicolumn{10}{|l|}{ Centro-jeste } \\
\hline Aato brosso & 1.795 & 7.524 & 17.678 & 266 & 3.735 & 7.333 & 226 & 3.735 & 7.504 \\
\hline Vistr. Federal & 87 & 167 & 757 & 8 & $2 !$ & 153 & 8 & 21 & 151 \\
\hline G018́5 & 4.414 & 9.493 & 14.599 & 696 & 2.678 & 4.727 & 63 & 2.657 & 4.69 \\
\hline \multicolumn{10}{|l|}{ Sudeste } \\
\hline Minas Gerais & 5.69 & 19.876 & 23.677 & 891 & 2.749 & 6.213 & 694 & 2.766 & 6.061 \\
\hline Espitito Santo & 596 & gato & 3.422 & 38 & 247 & 672 & 87 & 210 & 60 \\
\hline Nio oe jeneito & 2.497 & $3.2 \mathrm{z}$ & 4.986 & 304 & 740 & 769 & 309 & 727 & 745 \\
\hline São Paulo & 50.617 & 71.693 & 99.690 & 5.174 & 13.719 & 21.438 & 5.162 & \pm 3.596 & 31.51 \\
\hline \multicolumn{10}{|l|}{ sul } \\
\hline Yarana & 14.897 & 46.946 & 68.048 & 1.999 & 13.566 & 16.890 & 1.964 & 12.953 & 60.754 \\
\hline Santa Catarina & 4.598 & 11.592 & 24.999 & 568 & 2.673 & 4.011 & 566 & 2. 261 & 3.992 \\
\hline nio bos. Sul & 32.431 & 65.911 & 97.025 & 7.067 & 81.978 & 28.965 & 7.649 & 21.45 & 28.804 \\
\hline
\end{tabular}

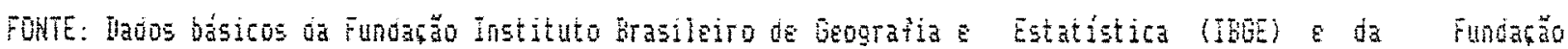
Getulio Vargas (FUV). 
TABELA A.1.41 - Deficiências Hidricas Ocorridas no Periodo Setembro-Março nas Unidades da Federaçăo, Brasil, 1970-80. $(A R M=100 \mathrm{~mm})$

\begin{tabular}{|c|c|c|c|c|}
\hline Unidade da Federação & $1969 / 70$ & $1974 / 75$ & & $1979 / 80$ \\
\hline Alagoas & 331 & 455 & & 271 \\
\hline Bahia & 153 & 100 & & 104 \\
\hline Ceará & 542 & 379 & & 496 \\
\hline Paraiba & 412 & 342 & & 261 \\
\hline Pernambuco & 322 & 345 & & 344 \\
\hline Piauí & 428 & 273 & & 412 \\
\hline Rio Grande do Norte & 763 & 613 & $i$ & 562 \\
\hline Sergipe & 319 & 376 & & 318 \\
\hline Maranhão & 208 & 218 & & 278 \\
\hline Acre & 7 & 14 & & 42 \\
\hline Amazonas & 9 & 0 & & 4 \\
\hline Amapá & 497 & 212 & & 258 \\
\hline Pará & 362 & 58 & & 151 \\
\hline Roraima & 28 & 311 & & 117 \\
\hline Rondônia & 674 & 39 & & 0 \\
\hline Mato Grosso & 26 & 53 & & 132 \\
\hline Distrito Federal & 98 & 100 & & 51 \\
\hline Goiás & 118 & 112 & & 64 \\
\hline Minas Gerais & 68 & 80 & & 40 \\
\hline Espirito Santo & 113 & 65 & & 114 \\
\hline Rio de Janeiro & 23 & 64 & & 40 \\
\hline Sấo Paulo & 38 & 33 & & 0 \\
\hline Paraná & 0 & 1 & & 0 \\
\hline Santa Catarina & 5 & $1 \overline{7}$ & & 0 \\
\hline Rio Grande do Sul & 25 & 0 & & 20 \\
\hline
\end{tabular}

FONTE: Calculado a partir de dados básicos do Instituto Nacional de Meteorologia (INEMET). 
TABELA A.1.42 - Escolaridade da Populaçăo Rural nas unidades da Federaçäo, Brasil, 1970-80. (em anos de escola por pessoa de 5 anos ou mais)

\begin{tabular}{|c|c|c|c|c|}
\hline Unidade da Federação & 1970 & 1975 & & 1980 \\
\hline Alagoas & 0,35 & 0,33 & & 0,65 \\
\hline Bahia & 0,43 & 0,55 & & 0,64 \\
\hline Ceará & 0,70 & 0,51 & & 0,66 \\
\hline Paraiba & 0,51 & 0,65 & & 0,81 \\
\hline Pernambuco & 0,50 & 0,71 & & 0,91 \\
\hline Piaui & 0,35 & 0,50 & & 0,63 \\
\hline Rio Grande do Norte & 0,63 & 0,79 & & 0,95 \\
\hline Sergipe & 0,40 & 0,55 & $i$ & 1,44 \\
\hline Maranhão & 0,52 & 0,66 & & 0,99 \\
\hline Acre & 0,85 & 0,55 & & 0,61 \\
\hline Amazonas & 0,69 & 0,76 & & 0,85 \\
\hline Amapá & 1,34 & 1,64 & & 1,85 \\
\hline Pará & 0,95 & 1,23 & & 1,44 \\
\hline Roraima & 0,85 & 1,18 & & 1,35 \\
\hline Rondônia & 1,09 & 1,27 & & 1,35 \\
\hline Mato Grosso & 0,97 & 1,25 & & 1,54 \\
\hline Distrito Federal & 1,70 & 2,20 & & 2,43 \\
\hline Goiás & 0,87 & 1,13 & & 1,46 \\
\hline Minas Gerais & 0,76 & 1,28 & & 1,59 \\
\hline Espirito Santo & 1,24 & 1,55 & & 1,90 \\
\hline Rio de Janeiro & 1,10 & 1,70 & & 2,01 \\
\hline São Paulo & 1,71 & 2,03 & & 2,41 \\
\hline Paraná & 1,22 & 1,55 & & 1,99 \\
\hline Santa Catarina & 1,99 & 2,38 & & 2,80 \\
\hline Rio Grande do Sul & 2,26 & 2,12 & & 2,86 \\
\hline
\end{tabular}

FONTE: Calculado a partir de dados básicos da Fundação Instituto Brasileiro de Geografia e Estatística (IBGE). 
TABELA A.1.43 - Estimativa do Número de Produtores Assistidos pelos Serviços de Assistência Técnica e Extensăo Rural nas Unidades de Federaçâo, Brasil, 1970-80.

(número médio ponderado dos três anos anteriores ao censo)

\begin{tabular}{|c|c|c|c|}
\hline Unidade da Federaçâo & 1970 & 1975 & 1980 \\
\hline lagoas & 2.900 & 1.600 & 16.054 \\
\hline $\operatorname{ah} \hat{i} a$ & 2.590 & 4.920 & 98.690 \\
\hline Ceará & 14.210 & 9.920 & 51.260 \\
\hline Paraíba & 17.520 & 4.920 & 33.970 \\
\hline Pernambuco & 22.180 & 9.640 & 63.500 \\
\hline Piaui & 4.950 & 8.180 & 32.540 \\
\hline Rio Grande do Norte & 6.120 & 6.920 & 16.160 \\
\hline Sergipe & 5.250 & 8.020 & 16.320 \\
\hline Maranhão & 3.180 & 9.340 & 50.370 \\
\hline Acre & 880 & 980 & 8.140 \\
\hline Amazonas & 1.110 & 2.480 & 20.950 \\
\hline Ảmapá & $\cdots$ & 540 & 2.080 \\
\hline Pará & 1.990 & 11.180 & 21.610 \\
\hline Roraima & $\ldots$ & 1.140 & 3.330 \\
\hline Rondônia & $\ldots$ & 1.400 & 5.600 \\
\hline Mato Grosso & 7.250 & 3.680 & 18.570 \\
\hline Distrito Federal & 640 & 1.500 & 960 \\
\hline Goiás & 15.590 & 18.680 & 25.460 \\
\hline Minas Gerais & 47.890 & 118.160 & 143.350 \\
\hline Espirito Santo & 11.440 & 6.020 & 42.250 \\
\hline Rio de Janeiro & 10.150 & 11.200 & 34.660 \\
\hline Sâo Paulo & $\cdots$ & 82.500 & 81.200 \\
\hline Paraná & 19.790 & $51 \cdot 360$ & 102.570 \\
\hline Santa Catarina & 43.870 & 41.620 & 71.640 \\
\hline Rio Grande do Sul & 35.430 & 26.680 & 83.060 \\
\hline
\end{tabular}

FONTE: Calculado a partir de dados básicos da Fundação Instituto Brasileiro de Geografia e Estatistica (IBGE). 
TABELA A.1.44.- Número de Artigos Cientificos de Pesquisa Agrícola Publicados no Brasil segundo Regióes, 1950-77.

\begin{tabular}{|c|c|c|c|}
\hline Regiäo & $1950-59$ & $1960-69$ & $1970-77$ \\
\hline SuI & 108 & 91 & 518 \\
\hline Sudeste (1) & 104 & 140 & 678 \\
\hline Nordeste & 67 & 111 & 413 \\
\hline Norte & 57 & 28 & 102 \\
\hline Centro-Oeste & - & - & 34 \\
\hline ão paulo & 841 & 1.412 & $1.393(\underline{2})$ \\
\hline
\end{tabular}

(1) Não inclui sấo Paulo.

(2) Refere-se ao periodo $1970-79$.

FONTE: SILVA, FONSECA, MARTIN (1979) e SILVA (1986).

TABELA A.1.45.- Número de Artigos Cientificos Publicados sobre os Principais Produtos Agrícolas, Estado de São Paulo, 1950-79.

\begin{tabular}{|c|c|c|c|c|c|c|}
\hline Produto & $1950-54$ & $1955-59$ & $1960-64$ & $1965-69$ & $1970-74$ & $1975-79$ \\
\hline Café & 55 & 65 & 99 & 60 & 64 & 67 \\
\hline Algođão & 24 & 24 & 50 & 53 & 32 & 43 \\
\hline citros & 13 & 29 & 36 & 19 & 13 & 18 \\
\hline Cana-de-açúcar & 20 & 18 & 30 & 22 & 11 & 20 \\
\hline Amendoim & 3 & 13 & 21 & 17 & 17 & 19 \\
\hline Soja & 4 & 6 & 6 & 6 & 9 & 30 \\
\hline Milho & 19 & 20 & 37 & 21 & 21 & 37 \\
\hline Batata & 26 & 18 & 47 & 26 & 14 & 8 \\
\hline Feijão & 0 & 2 & 17 & 48 & 27 & 28 \\
\hline Arroz & 9 & 2 & 18 & 14 & 22 & 19 \\
\hline Mandioca & 10 & 4 & 5 & 9 & 2 & 6 \\
\hline Trigo & 1 & 3 & 5 & 8 & 19 & 18 \\
\hline Tomate & 16 & 6 & 19 & 16 & 17 & 21 \\
\hline Banana & 2 & 4 & 7 & 3 & 12 & 14 \\
\hline
\end{tabular}

FONTE: SILVA (1986). 
TABELA A.1.46 - Produtos Considerados para a Construção da Variável Pesquisa Desenvolvida em Sẫo Paulo Influenciando as Demais Unidades da Federação, Brasil, 1970-80.

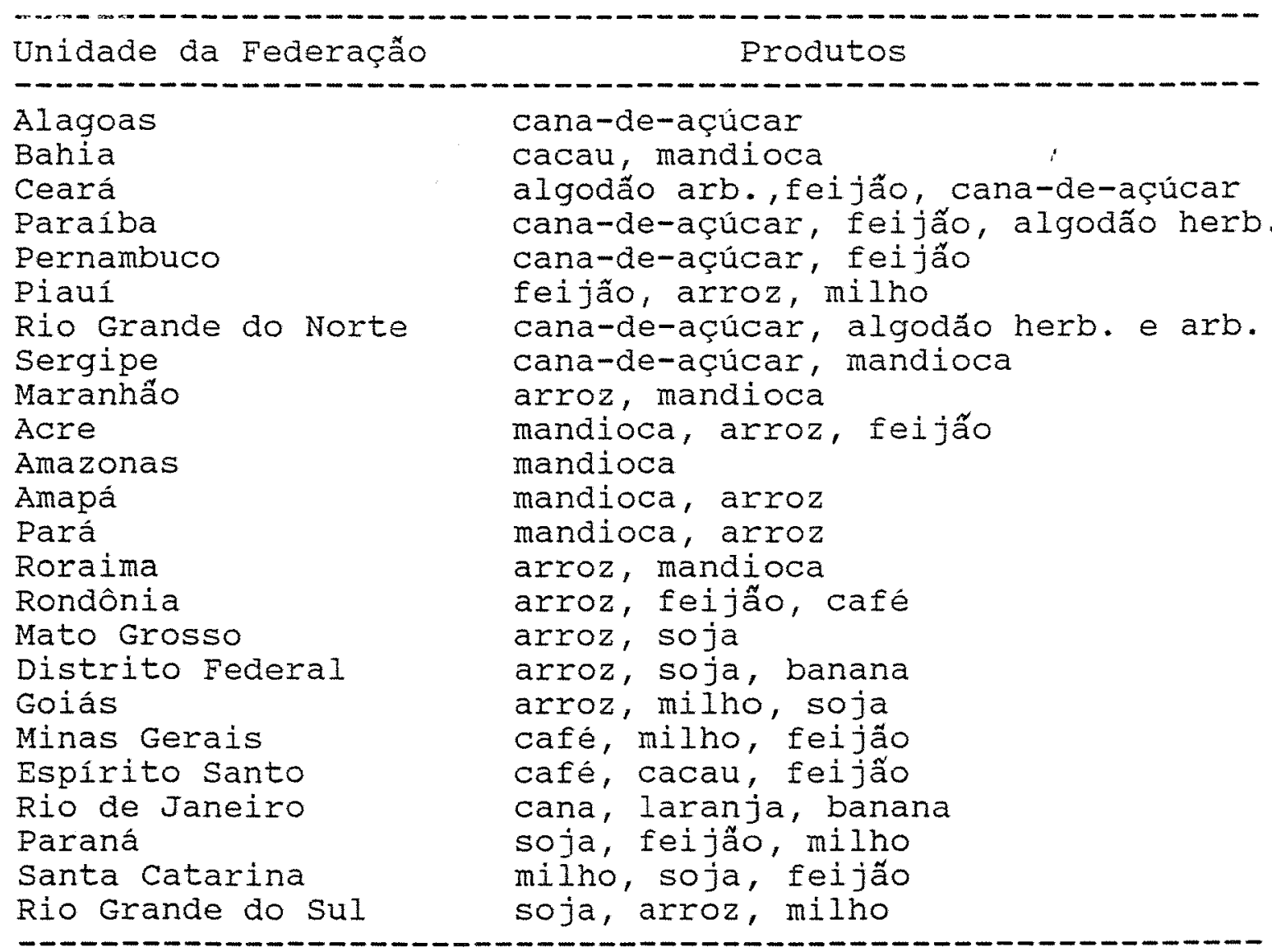

FONTE: Dados básicos da Fundaçäo Instituto Brasileiro de Geografia e Estatistica (IBGE). 
TABELA A.1.47 - Terras Agrícolas com Aptidão Boa e Regular para Lavouras com Niveis de Manejo A e B nas Unidades da Federação, Brasil, 1970-80.

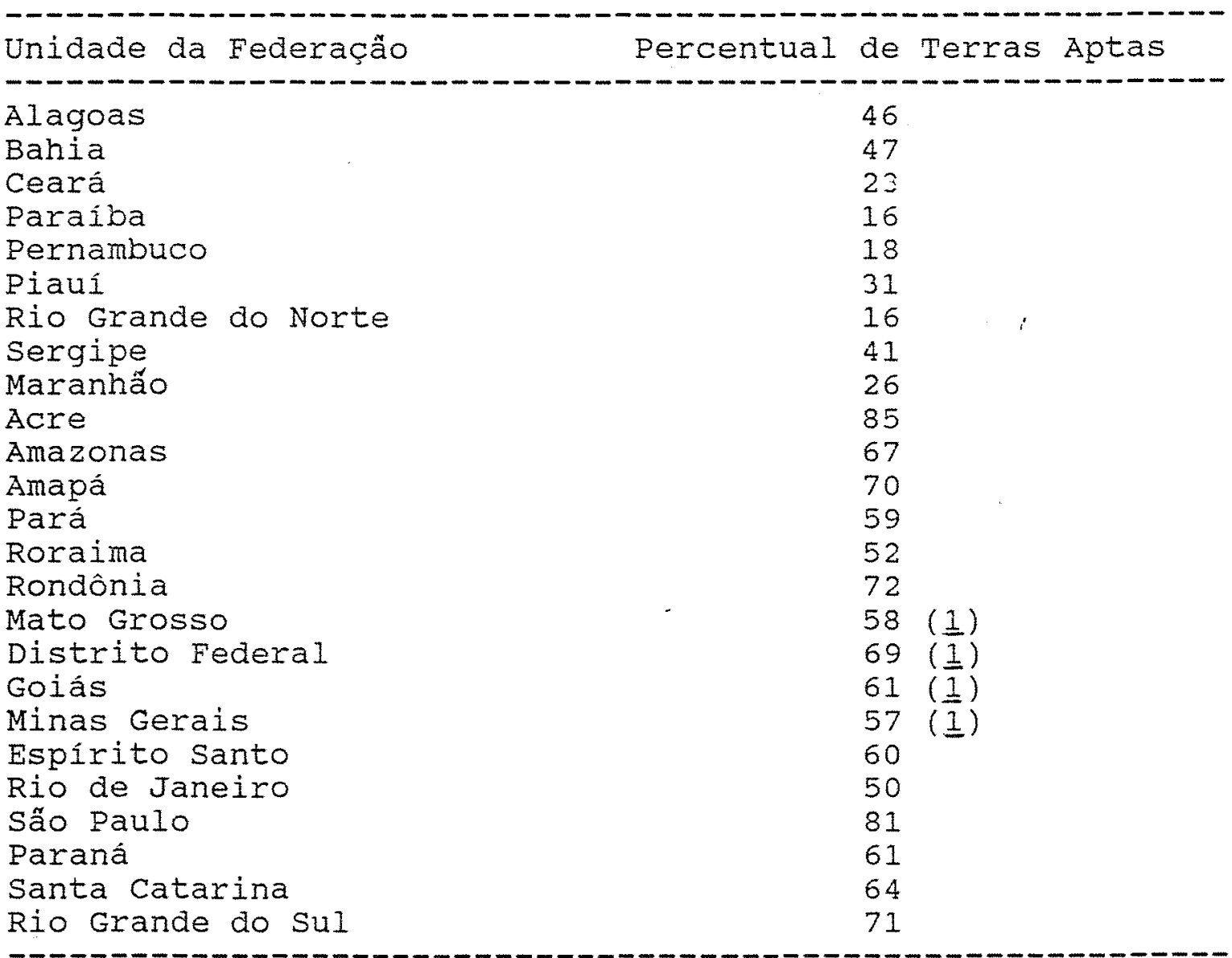

(1) Estimado por regressäo.

FONTE: Calculado a partir de dados básicos do Ministério da Agricultura. 
APENDICE 2. Evolução da Produção Agrícola, do Uso e da Produtividade de Fatores nas Unidades da Federação 


\section{A.2.1. Alagoas}

Em Alagoas, a produção agrícola cresceu $67 \%$ entre 1970 e 1975 e $100 \%$ entre 1970 e 1980; no primeiro caso os quatro grupos de culturas (anuais, perenes, de mercado interno $e$ de mercado externo) cresceram, principalmente as culturas anuais com aumentos na quantidade produzida de algodão, arroz, feijăo e milho. No periodo $1970-80$ as culturas anuais e de mercado interno decresceram, enquanto os continuos aumentos nas produtividades de culturas perenes e de mercado externo, deveram-se à cana-de-açúcar, que é o principal produto agricola do Estado, representando algo próximo a $90 \%$ do valor da produção das culturas consideradas neste estudo. A utilização dos fatores de produção terra, trabalho, fertilizantes, máquinas e investimentos em culturas perenes, tomados agregadamente, cresceu $28 \%$ entre 1970 e 1975, e 38\% entre 1970 e 1980; os fatores terra e trabalho experimentaram queda no periodo 1975-80, todavia, atingiram em 1980, niveis superiores aos de 1970.

com relaçấo a produtividade, em niveis agregados, observou-se evolurăo tanto no periodo 1970-75 quanto no período 1975-80, com os indices da produtividade parcial do trabalho atingindo as maiores taxas, embora entre 1975 e 1980 a produtividade da terra tenha crescido a taxas superiores (figuras 1, 2 e 3 ).

\section{A.2.2. Bahia}



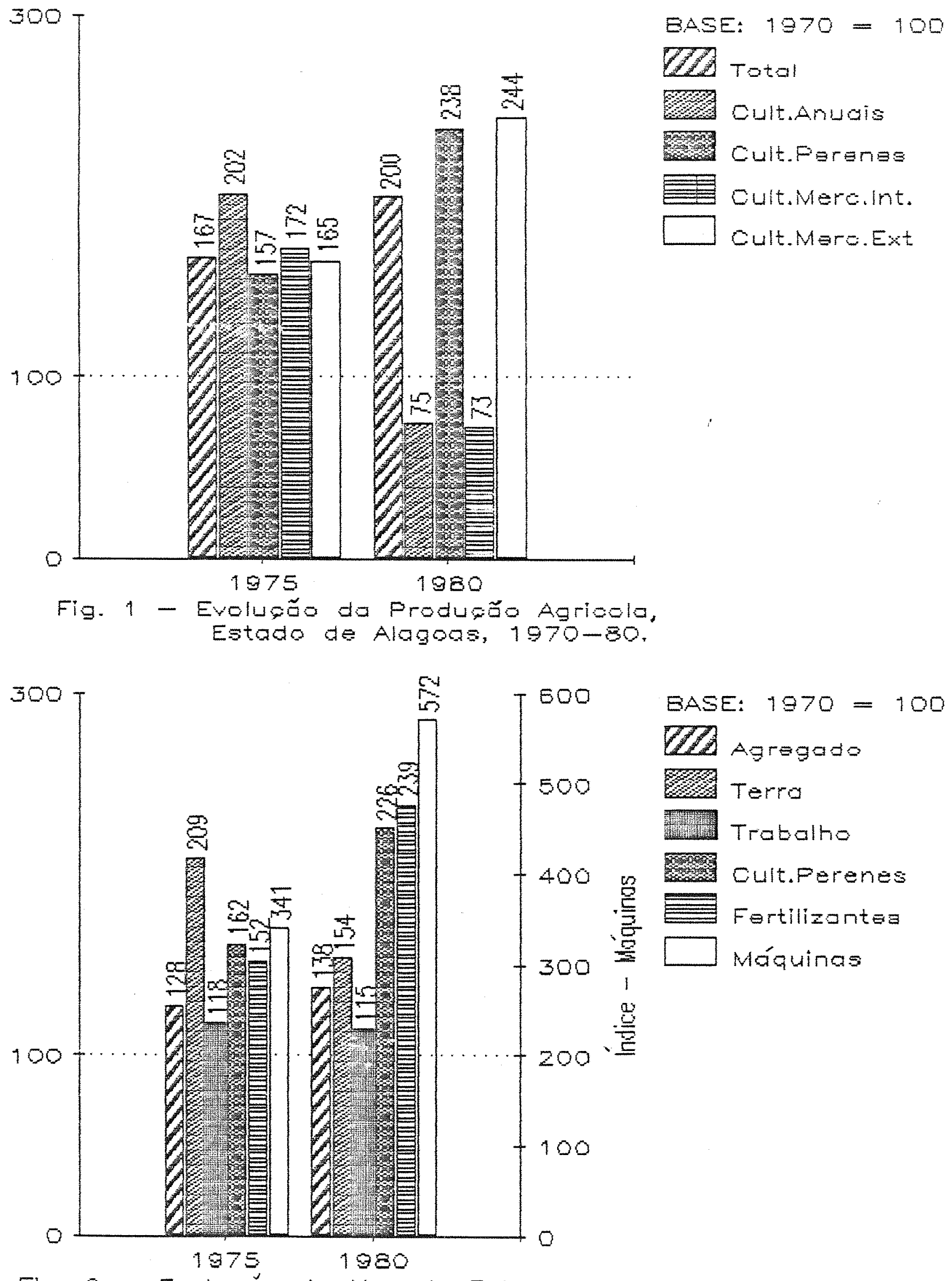

Fig. 2 - Evolugdo do Uao de fotores. Estado de Alagoas, $1970-80$. 


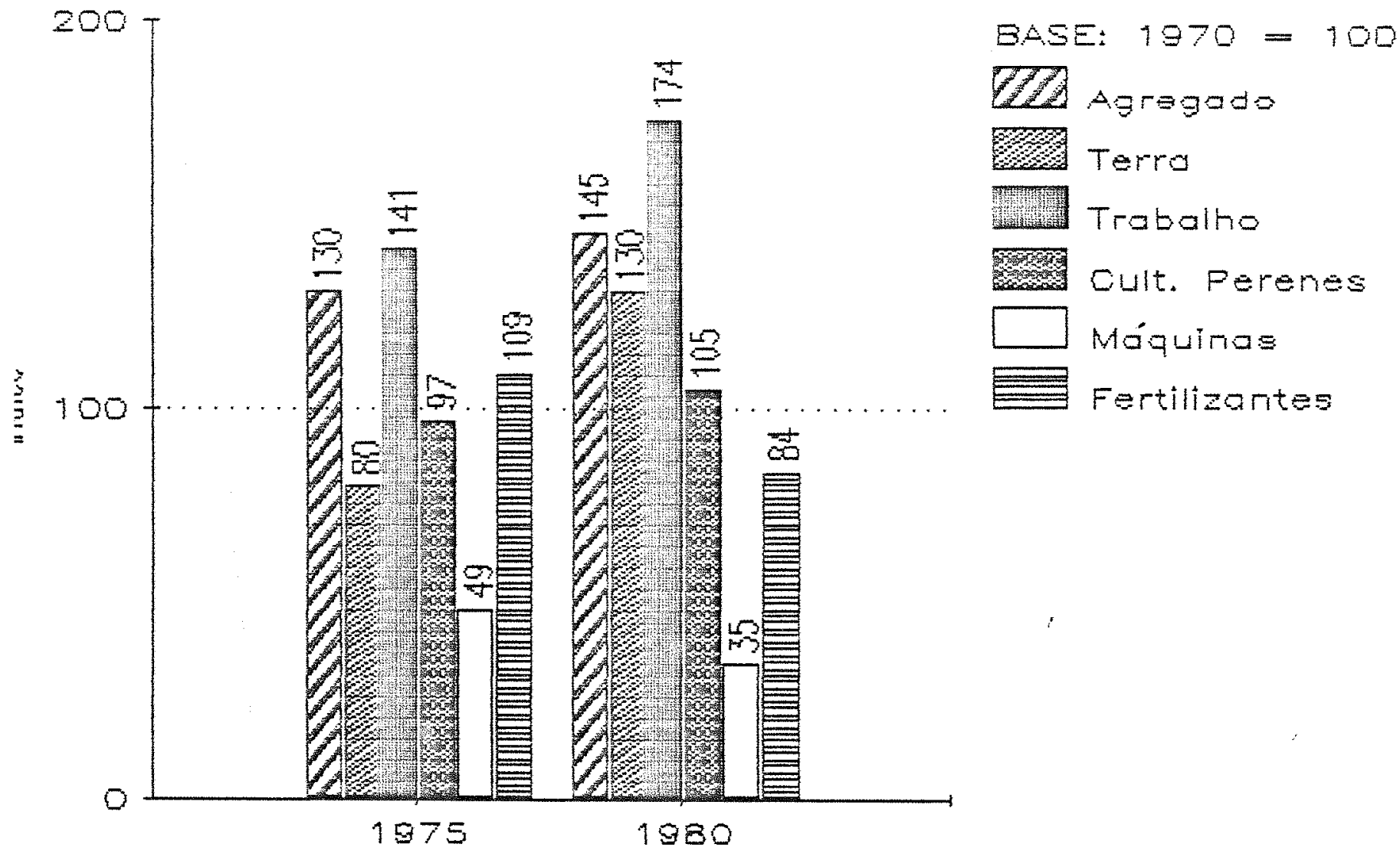

Fig. 3 - Evolucáo da Produtividade de Fatores, Estado de Alagoas, $1970-80$.

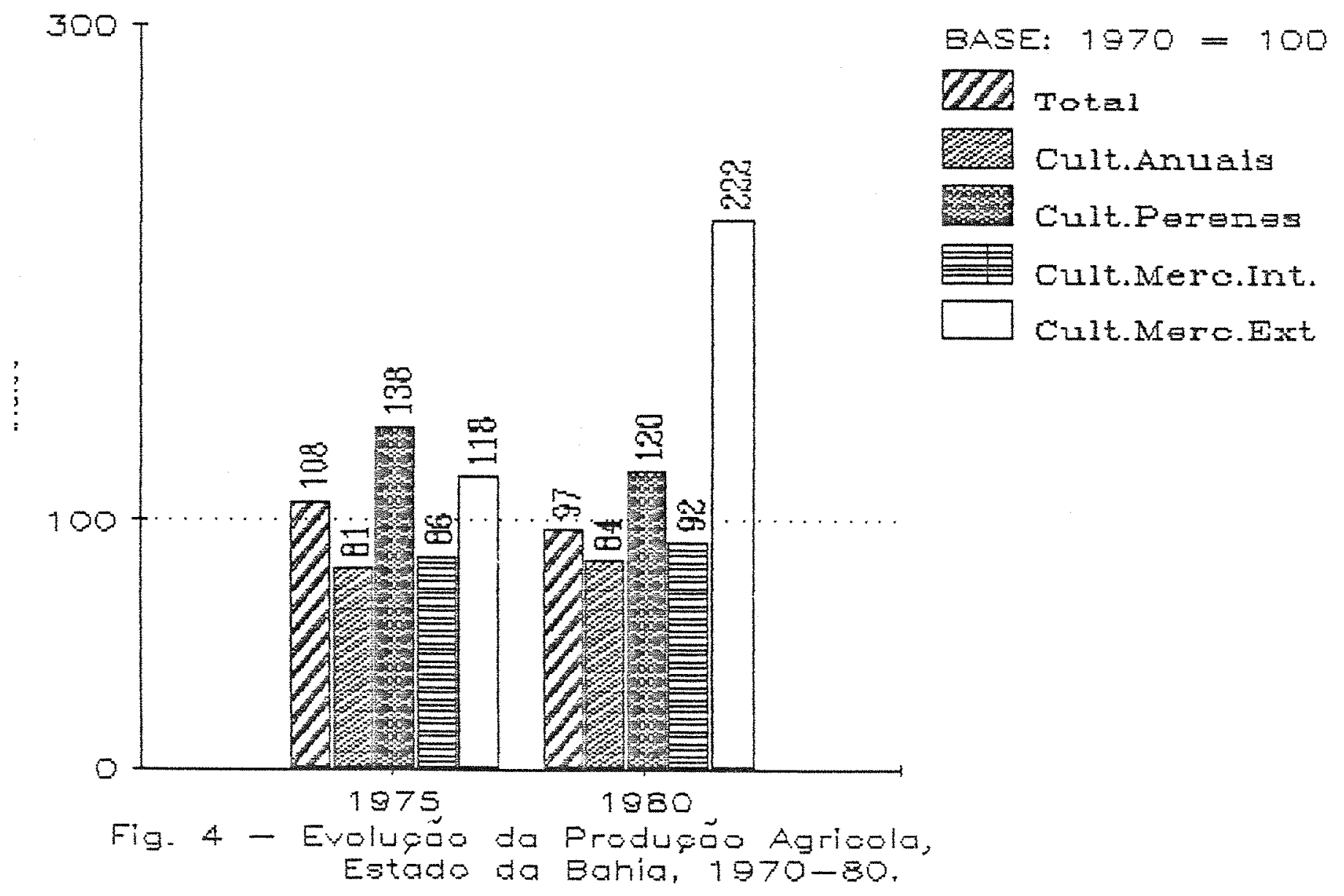


A produçẫo agricola experimentou ligeiro crescimento entre 1970 e 1975 na Bahia e, queda entre 1975 e 1980, atingindo, nesse último ano, níveis ligeiramente inferiores aos de 1970. As culturas perenes e de mercado externo arressntaram elevação de produção associada ao desempenho do cacau; as culturas anuais e de mercado interno atingiram em 1980 níveis inferiores aos de 1970. A utilizaçấo de fatores cresceu cerca de 10\% entre 1970 e 1975, mantendo-se estável no período 1970-80, com terra e investimentos em culturas perenes apresentando, em 1980, niveis inferiores aos de 1970.

A produtividade agregada, que havia se mantido estável entre 1970 e 1975, decresceu no período 1975-80, com exceção dos fatores investimentos em culturas perenes e terra, embora esse último fator não tenha mantido os aumentos de produtividade ocorridos anteriormente. As condições do tempo foram bastante adversas por volta de 1980, fazendo com que, mesmo o incremento no uso dos fatores fertilizantes e máquinas, não se refletisse em aumentos nas produtividades da terra e do trabalho (figuras 4,5 e 6 ; .

\section{A.2.3. Ceará}

A produçăo agricola cresceu $177 \%$ entre 1970 e 1975 no Estado do Ceará, com os quatro grupos de culturas apresentando incrementos superiores a $100 \% \mathrm{e}$, as culturas de mercado externo aumentando mais de $300 \%$; esses 


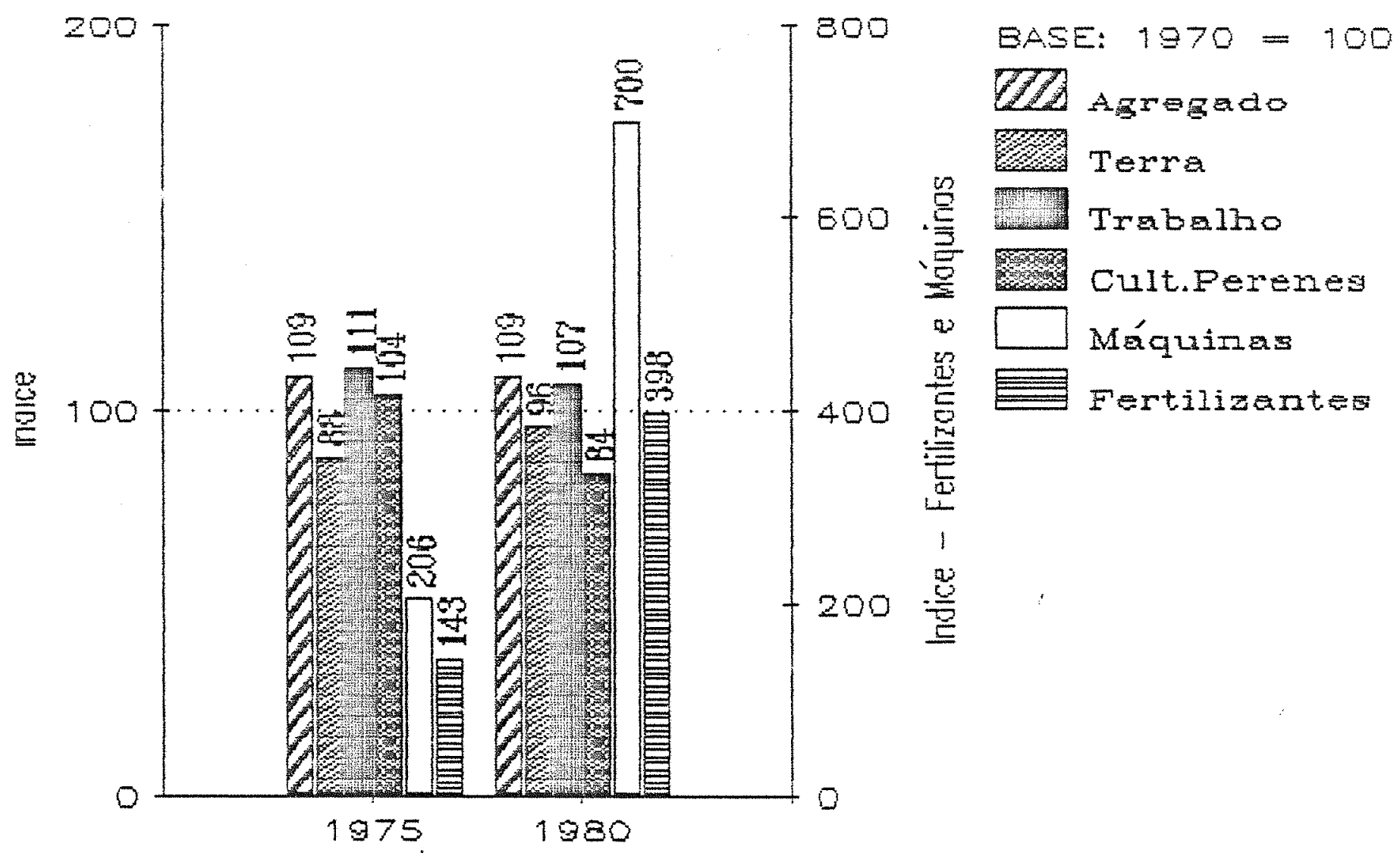

Fig. 5 - Evolugáo do Uao da Fatoras, Estado da Bania, 1970-80.
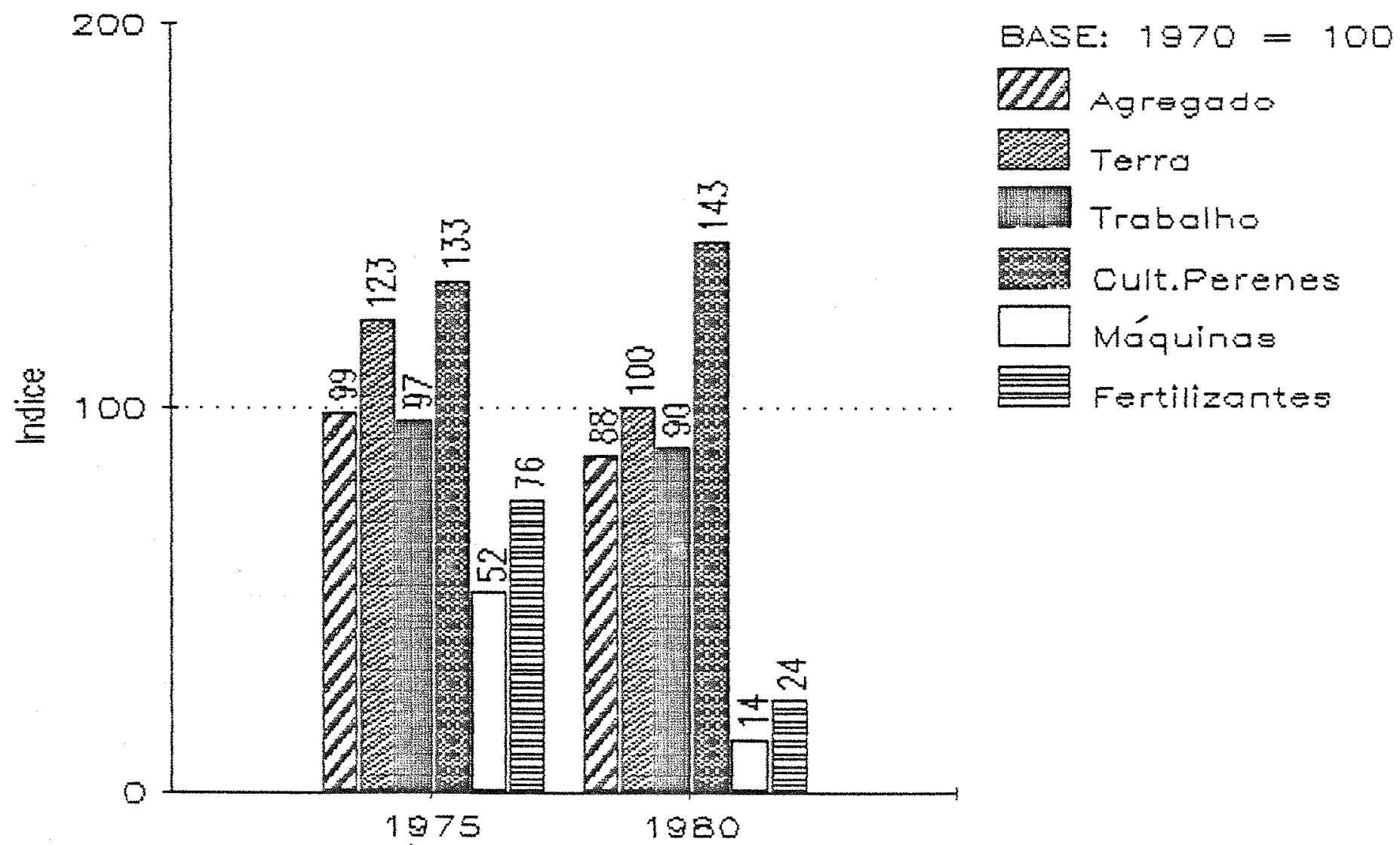

Fig. 6 - Evolugáo da Produtividade de Fatores, Estado da Bahia, 1970-80. 
indices devem-se, principalmente, aos desempenhos do algodâo arbóreo, milho, mandioca e feijầo. As quedas de produção ocorridas no periodo $1975-80$, para as culturas anteriormente citadas, levaram o indice de produçăo ágregada a indicar aumerito de 55\% ra produção entre 1970 e 1980; mesmo com produção menor em relação a 1975, o algodão produziu em 1980 volume cerca de dez vezes maior do que o produzido em 1970, fato que, conjugado à elevaçăo de preços reais entre esses dois anos, elevou os indices de culturas perenes e de mercado externo para niveis superiores aos demais. Para o uso de fatores, observou-se entre 1970 e 1975 intensificaçŏes em terra, investimentos em culturas perenes e máquinas, ao lado de estabilidade no uso do trabalho, com o agregado crescendo 14\%. Já no periodo 1975-80, ocorreram intensificações nos fatores fertilizantes e máquinas, com diminuição relativa nos demais, o que reduziu o indice agregado de 1980 ao mesmo nível observado em 1970, e a utilização de trabalho a niveis inferiores aos desse último ano.

Os indices de produtividade mostraram, analogamente ao uso de fatores, comportamentos distintos, uma vez que entre 1970 e 1975 todos êles apresentaram elevação, em que pese a relativa estabilidade dos investimentos em culturas perenes, enquanto que no período 1975-80, todos os fatores diminuiram em produtividade fazendo com que somente o trabalho apresentasse em 1980 nivel superior ao de 1970; como o peso relativo desse fator 
era grande neste Estado, também a produtividade agregada aumentou no perído 1970-80 (figuras 7,8 e 9).

\section{A.2.4. Paraíba}

Na Paraíba a produção agrícola mais do que dobrou entre 1970 e 1975, com os grupos de produtos apresentando crescimento em niveis próximos entre si, com aumentos de produçăo principalmente em cana, algodão arbóreo, feijão, mandioca e milho; a queda de produção ocorrida entre 1975 e 1980 não foi suficiente para reduzir os indices aos niveis de 1970. No periodo 1970-80, os grupos de culturas perenes e de mercado externo foram os que apresentaram crescimento mais elevado. O uso de fatores apresentou queda entre 1975 e 1980, compensando a elevação ocorrida entre 1970 e 1975, e voltando, em 1980, aos niveis observados em 1970, devido principalmente à diminuiçấo no uso de trabalho, uma vez que os demais fatores fixaram-se em patamares superiores aos do ano base.

A produtividade agregada apresentou aumento superior a $50 \%$ entre 1970 e 1975 e, pequena queda entre 1975 e 1980, destacando-se a contribuiçăo do fator trabalho (figuras 10,11 e 12 ).

\section{A. 2.5. Pernambuco \\ Em Pernambuco a elevação da produção} agricola ocorreu de maneira equilibrada entre 1970 e 1975, com aumentos nas principais culturas do Estado (cana, 


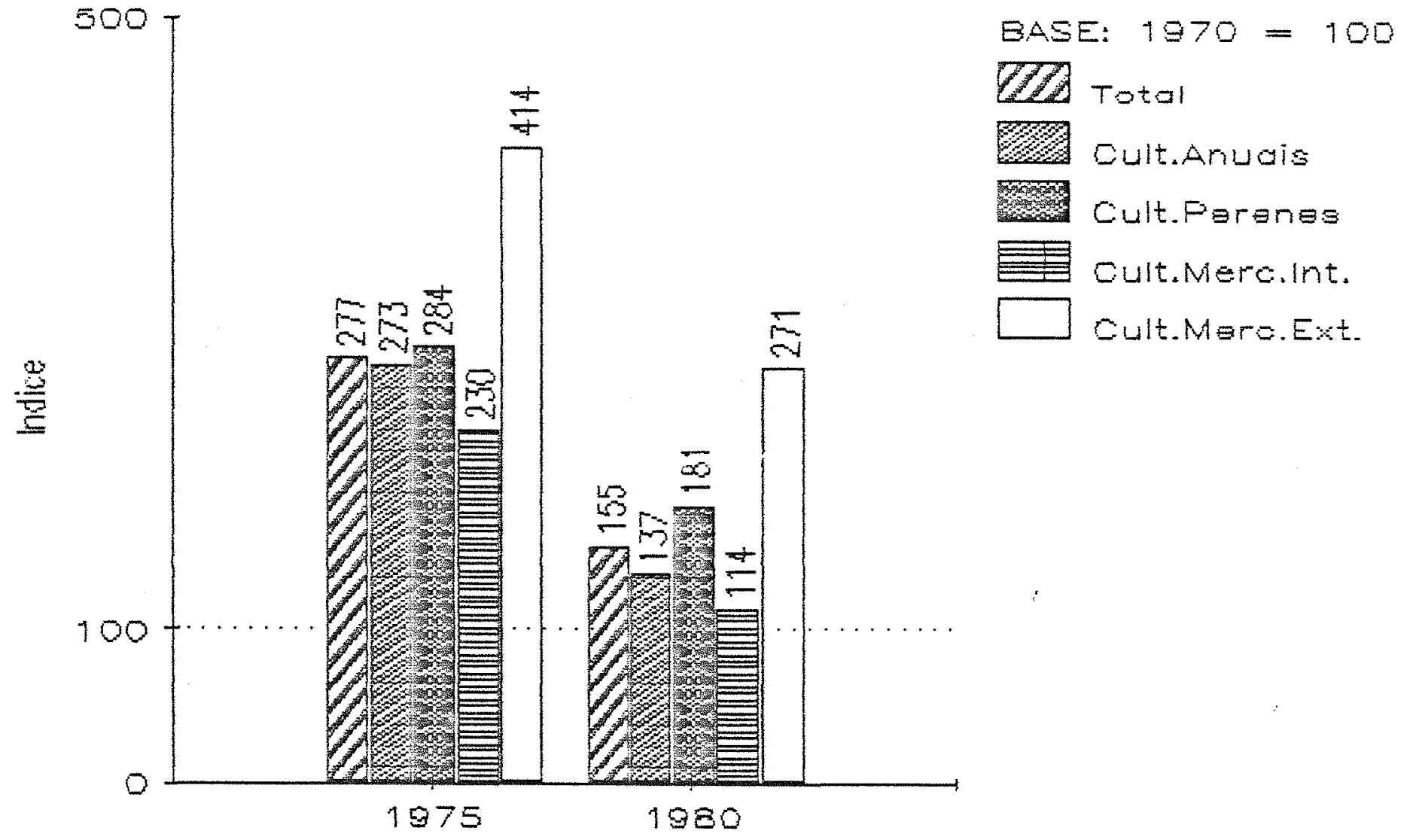

Fig. 7. - Evolução da Produção Agrícola, Estado do Cearā, 1970-80.

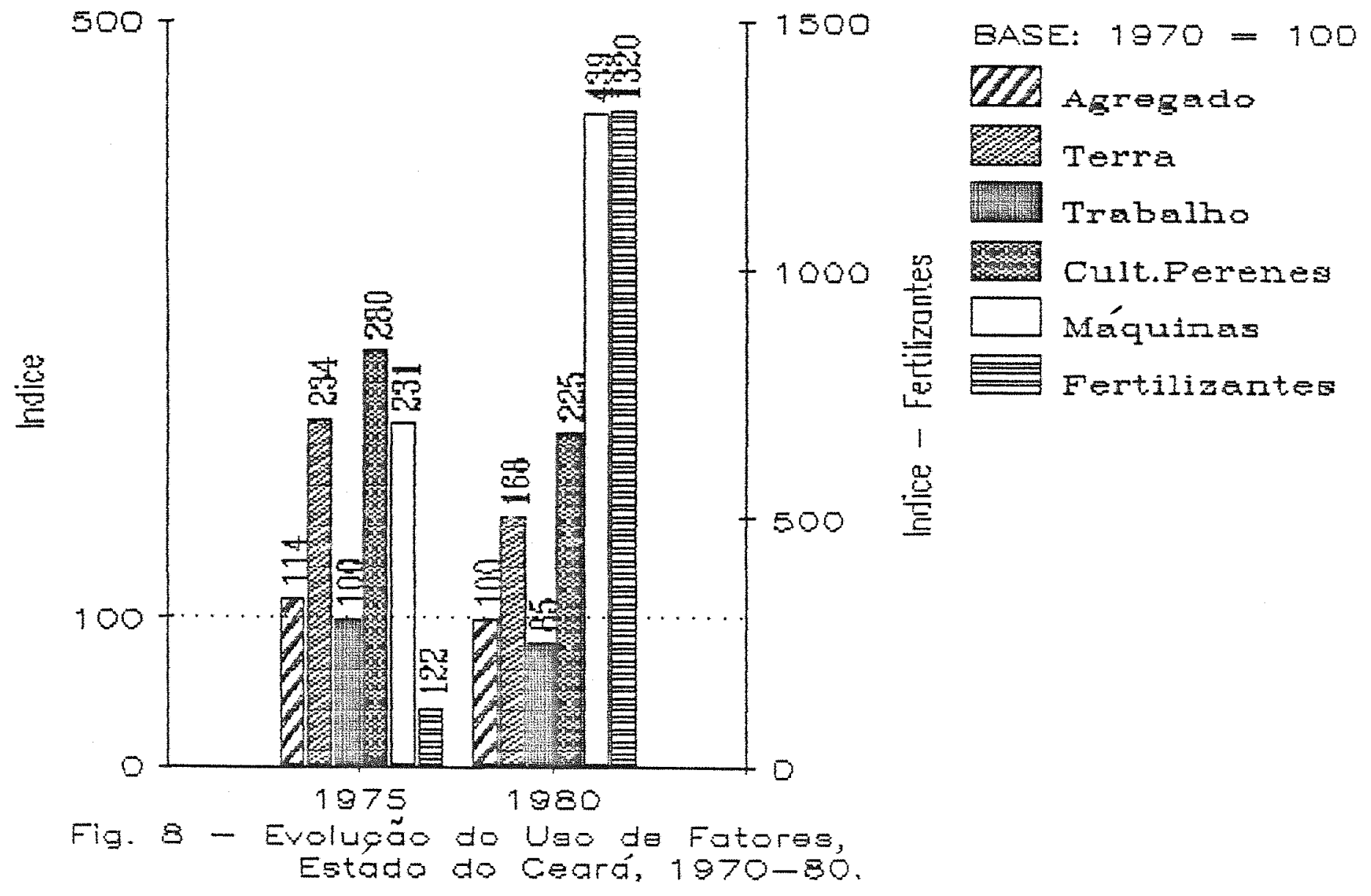




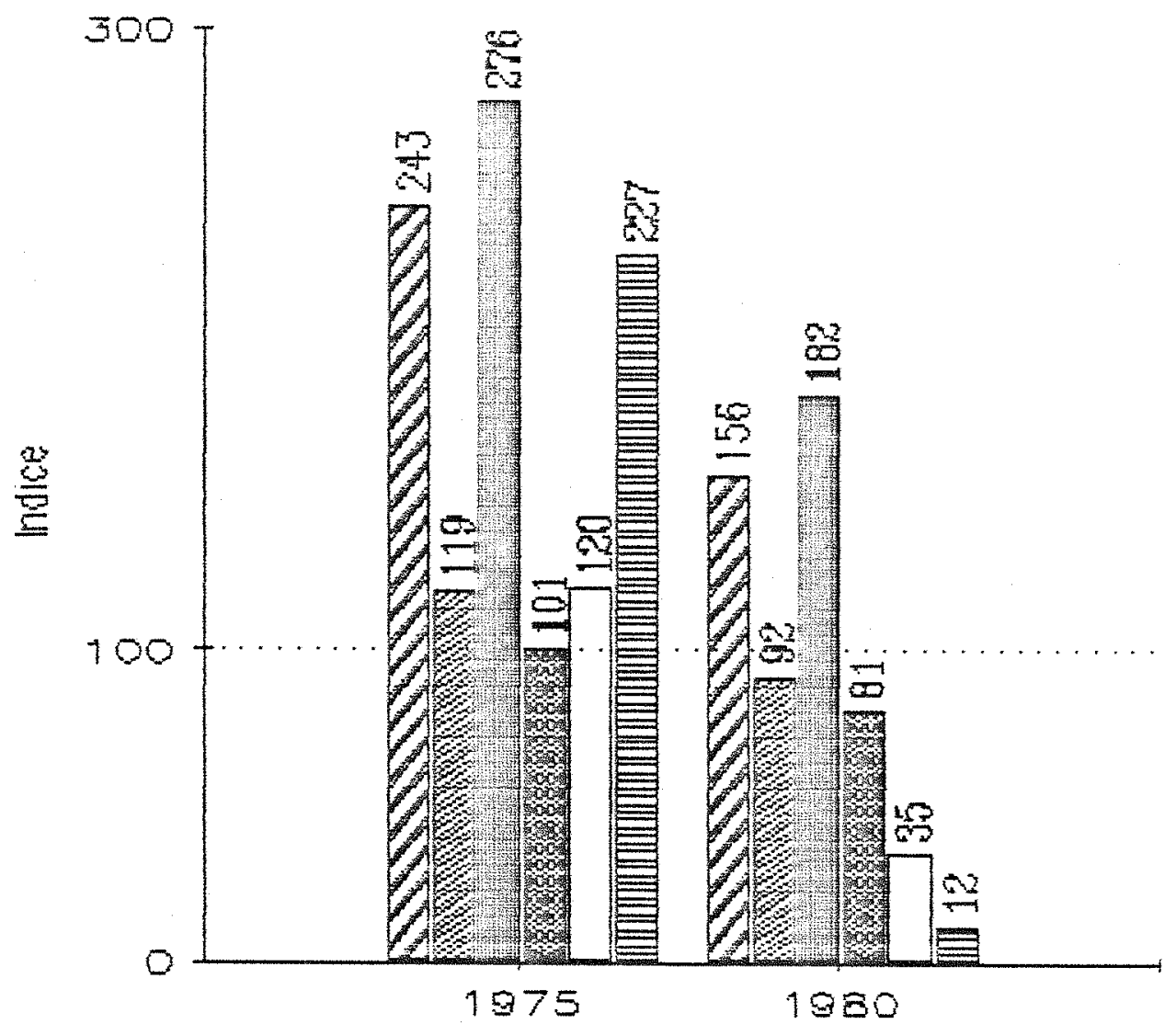

BASE: $1970=100$ Q2 Agregado 梠 Terra Trabalho rervart.Perenes $\square$ Máquinas 言 Fertilizantes

Fig. 9 - Evolugáo da Produtividade de Fatores, Estado do Ceara, 1970-80.

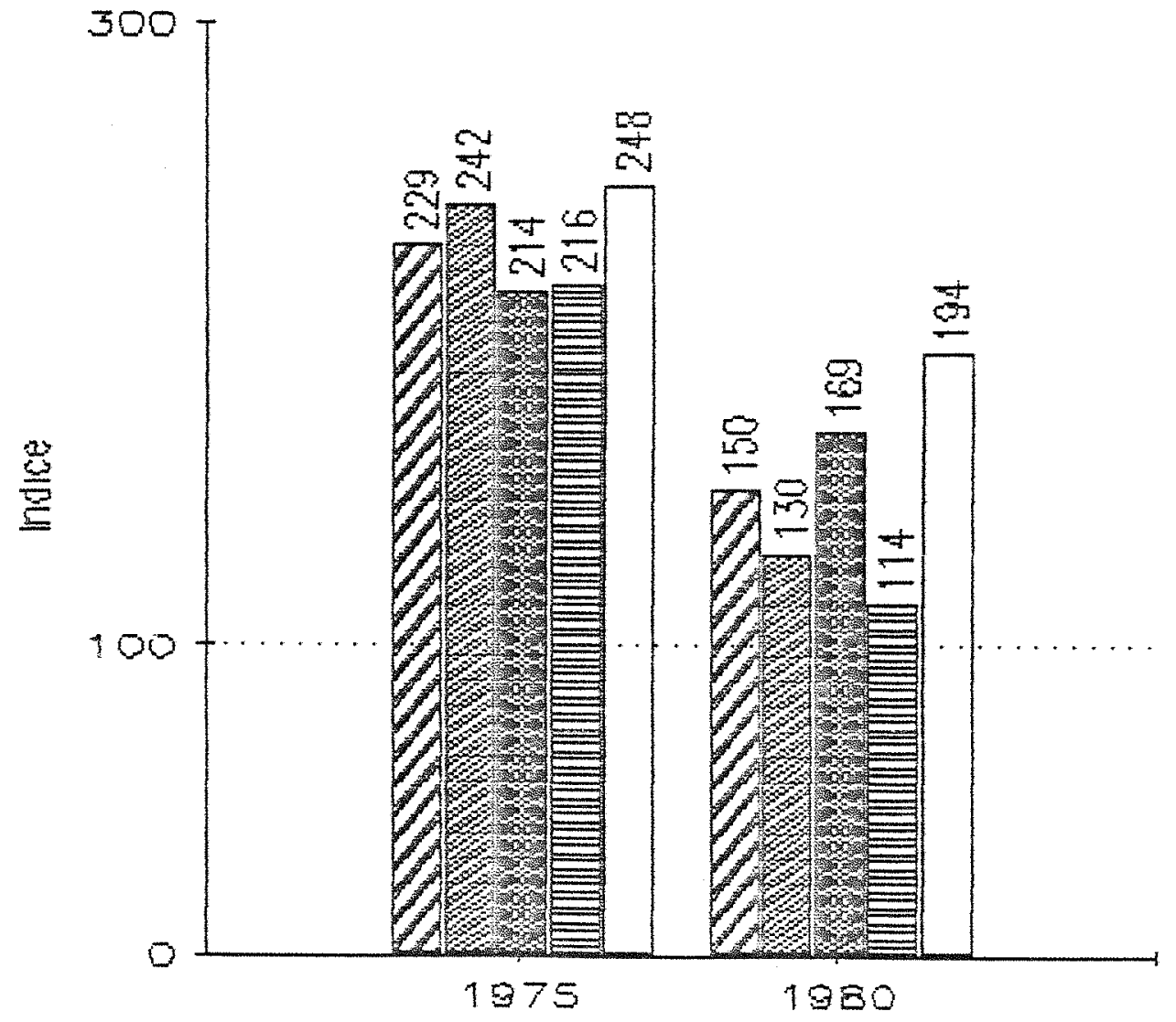

BASE: $1970=100$ Q20 Tatal 得 Cult.Anuais

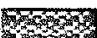
7. Cult.Ferenge cult.Merc.int. $\square$ Cult.Maro.Ext.

Fig. 10. - Evolução da Produção Agrícola, Estado da Paraỉba, 1970-80. 


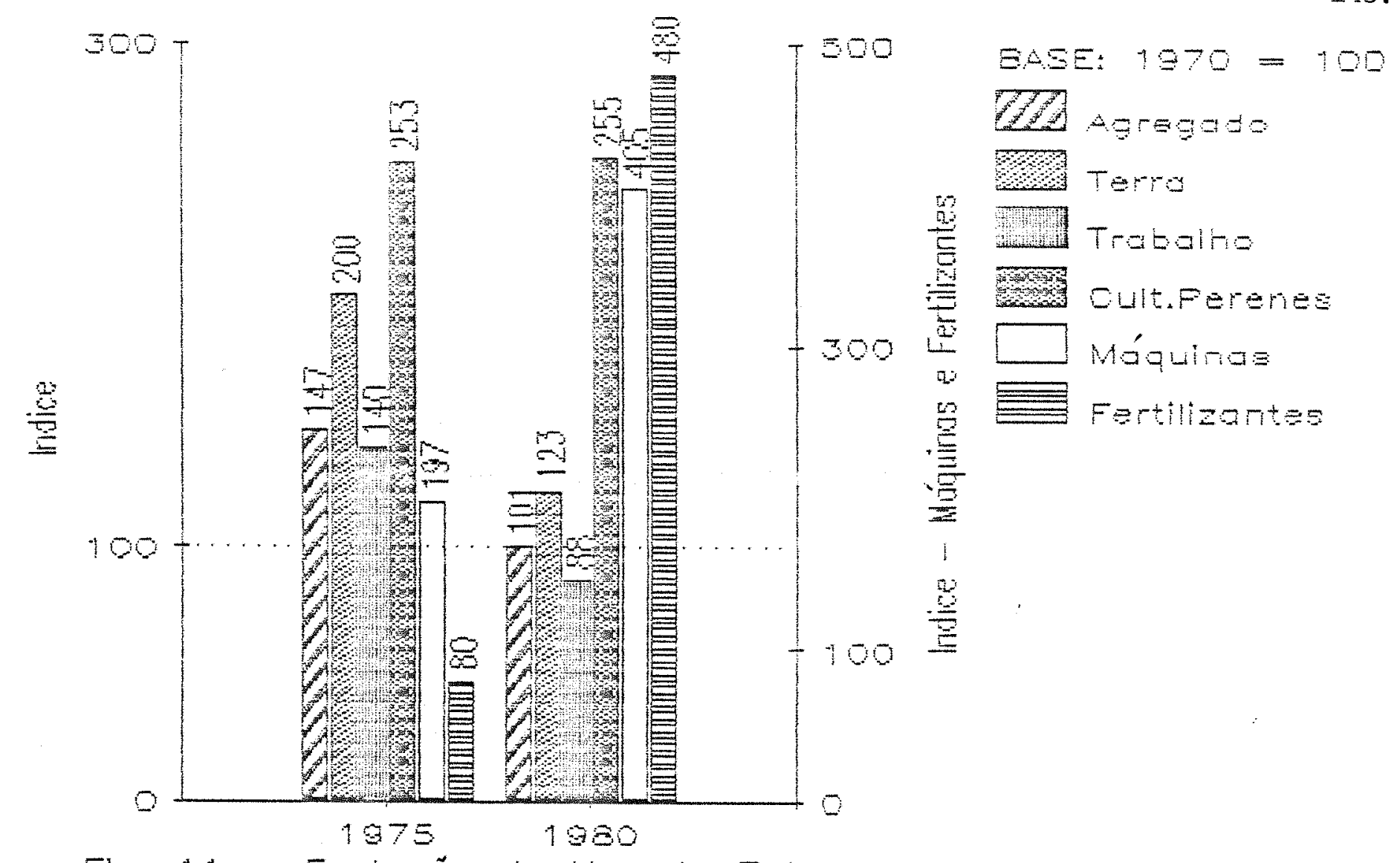

Fig. 11 - Evolupdo do Uao da Futoras, Estade da Faraba, $1970-80$.

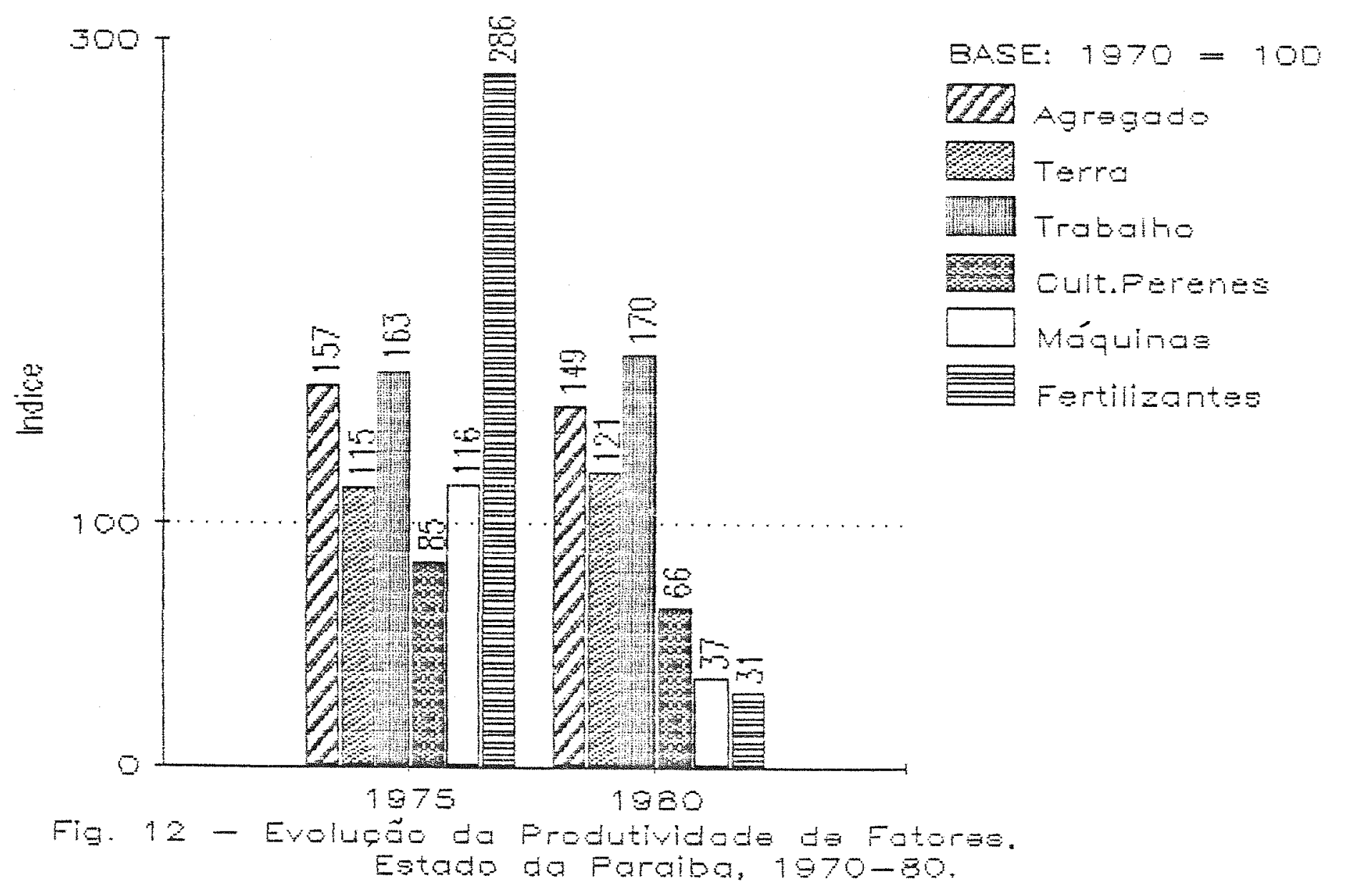


feijăo, mandioca, algodấo e milho); no periodo 1975-80, a manutenção dos indices deveu-se ao desempenho da cana-de-açúcar, uma vez que a produção das demais principais culturas diminuiu. A utilização de fatores manteve-se praticamente estável em termos agregados, com crescimento acentuado de máquinas e fertilizantes e diminuiçăo no uso de trabalho.

A produtividade agregada elevou-se tanto entre 1970 e 1975, como entre 1975 e 1980, destacando-se os fatores trabalho, terra e investimentos em culturas perenes (figuras 13,14 e 15).

\section{A.2.6. Piauí}

No Piaui a produção experimentou um aumento de 130 pontos no indice agregado entre 1970 e 1975, e, uma diminuição de 105 pontos entre 1975 e 1980; no primeiro caso observou-se aumento nas principais culturas, feijão, arroz, milho, algodão arbóreo e cana, com diminuições na produção de todos, com exceção do algodão arbóreo, no segundo período. A utilização de fatores cresceu 30\% em termos agregados, entre 1970 e 1975, caindo entre 1975 e 1980, com a intensificação do emprego de máquinas e fertilizantes sendo contrabalanceada pela diminuição no uso de terra e trabalho.

A produtividade agregada, em 1980, manteve-se próxima ao nível de 1970, com os ganhos do período 1970-75 sendo compensados pela queda ocorrida entre 


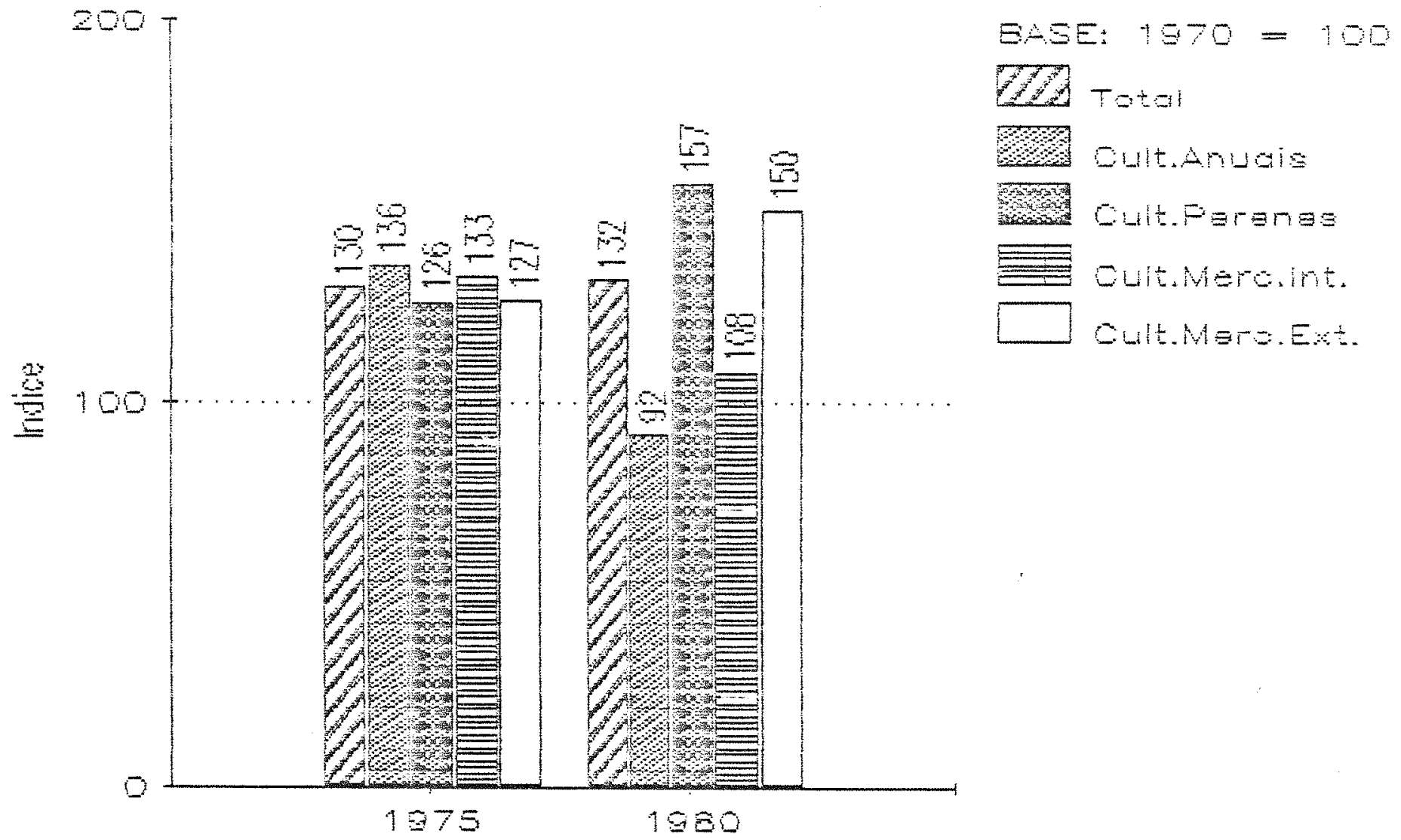

Fig. 13. - Evolução da Produção Agrícola, Estado de Pernambuco, 1970-80.

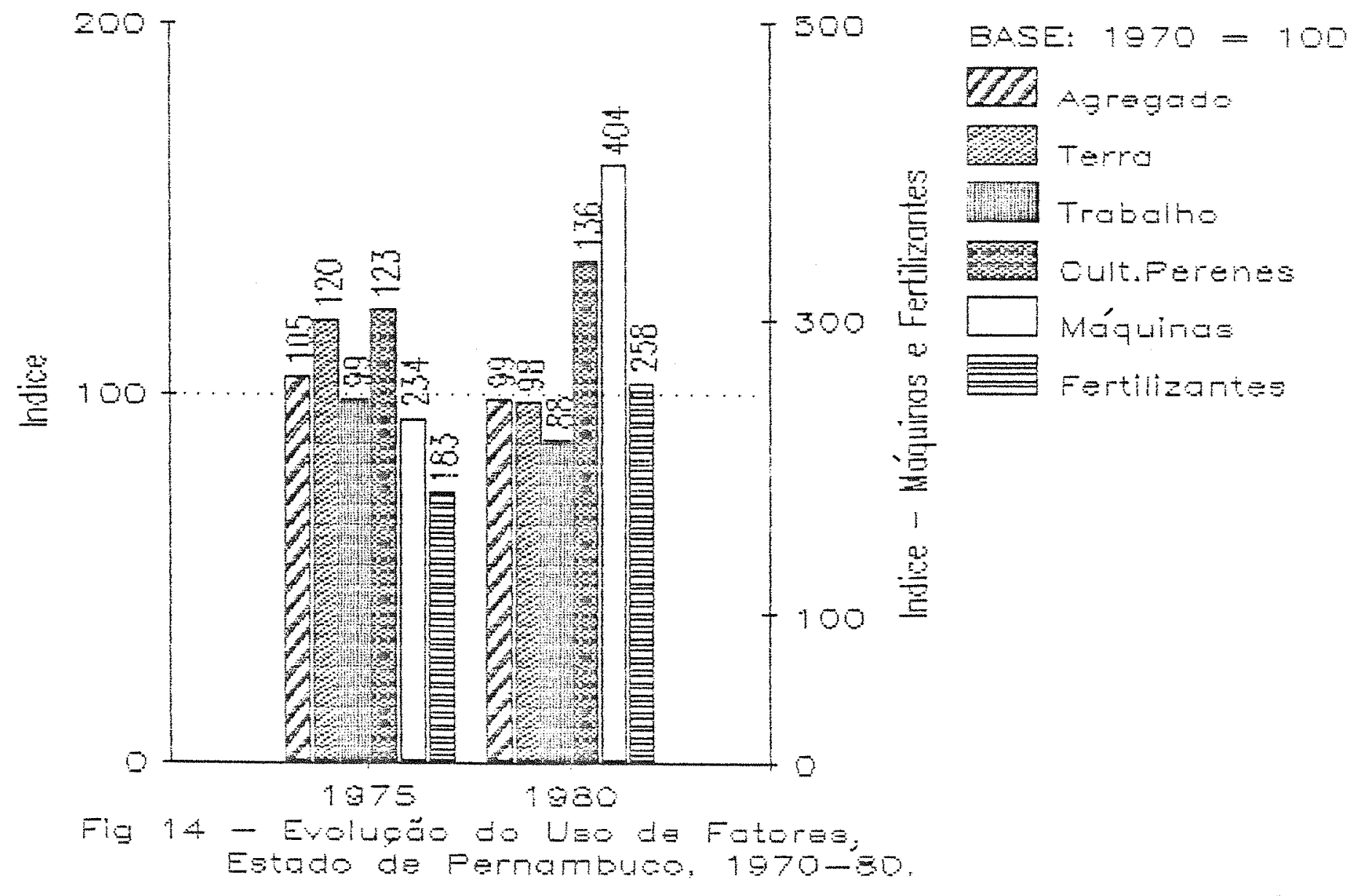




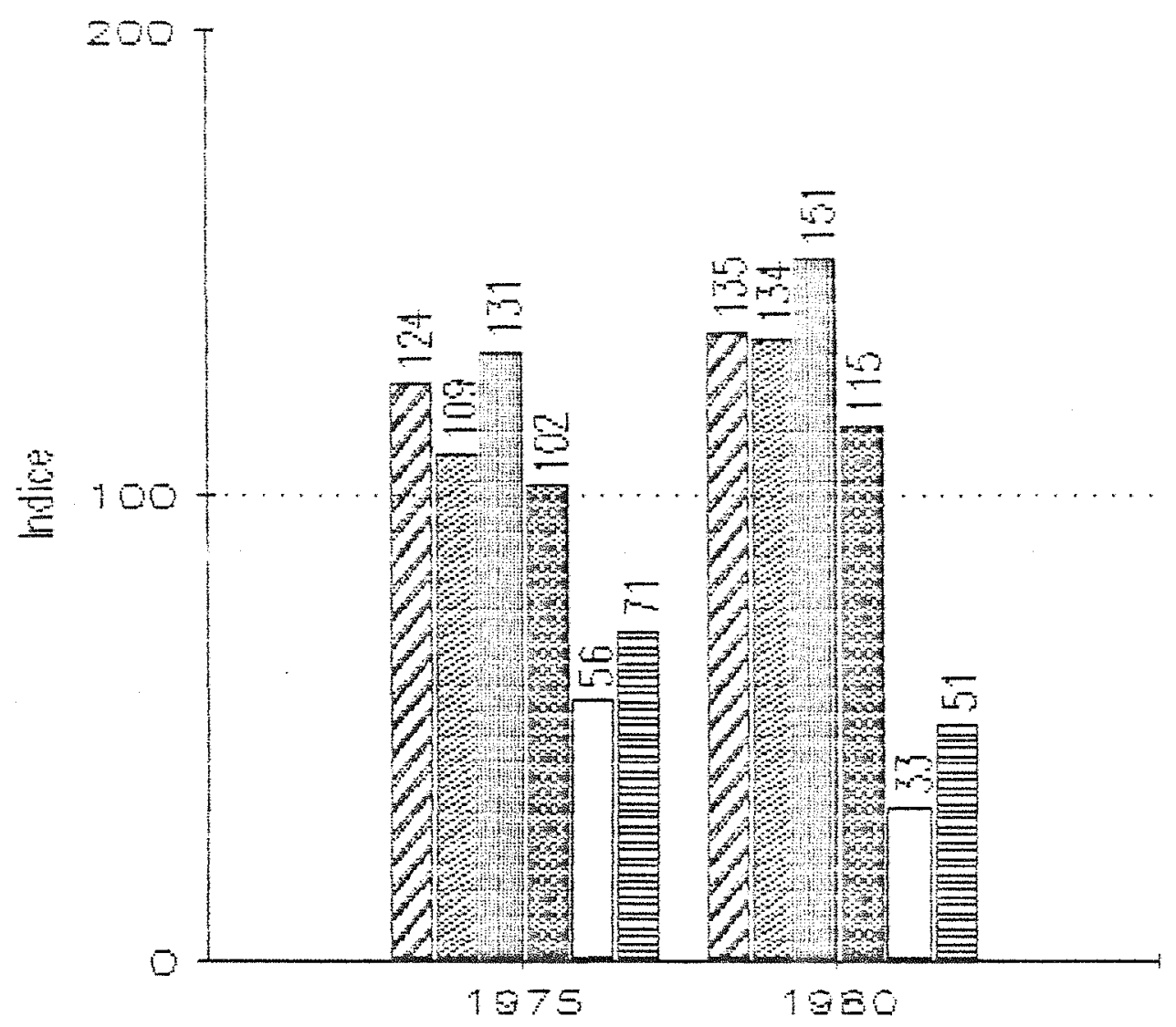

148.

EASE: $1970=100$

$\not 2 y+9=900$

PH Tarra

Hen Trobalto

Wh Cut.perenes

ए Máquiras

E Fertilizant?

Fig. 15 - Evoluga da Frodutidade da Fotores,

Estado de Fermambuco, 1970-80.

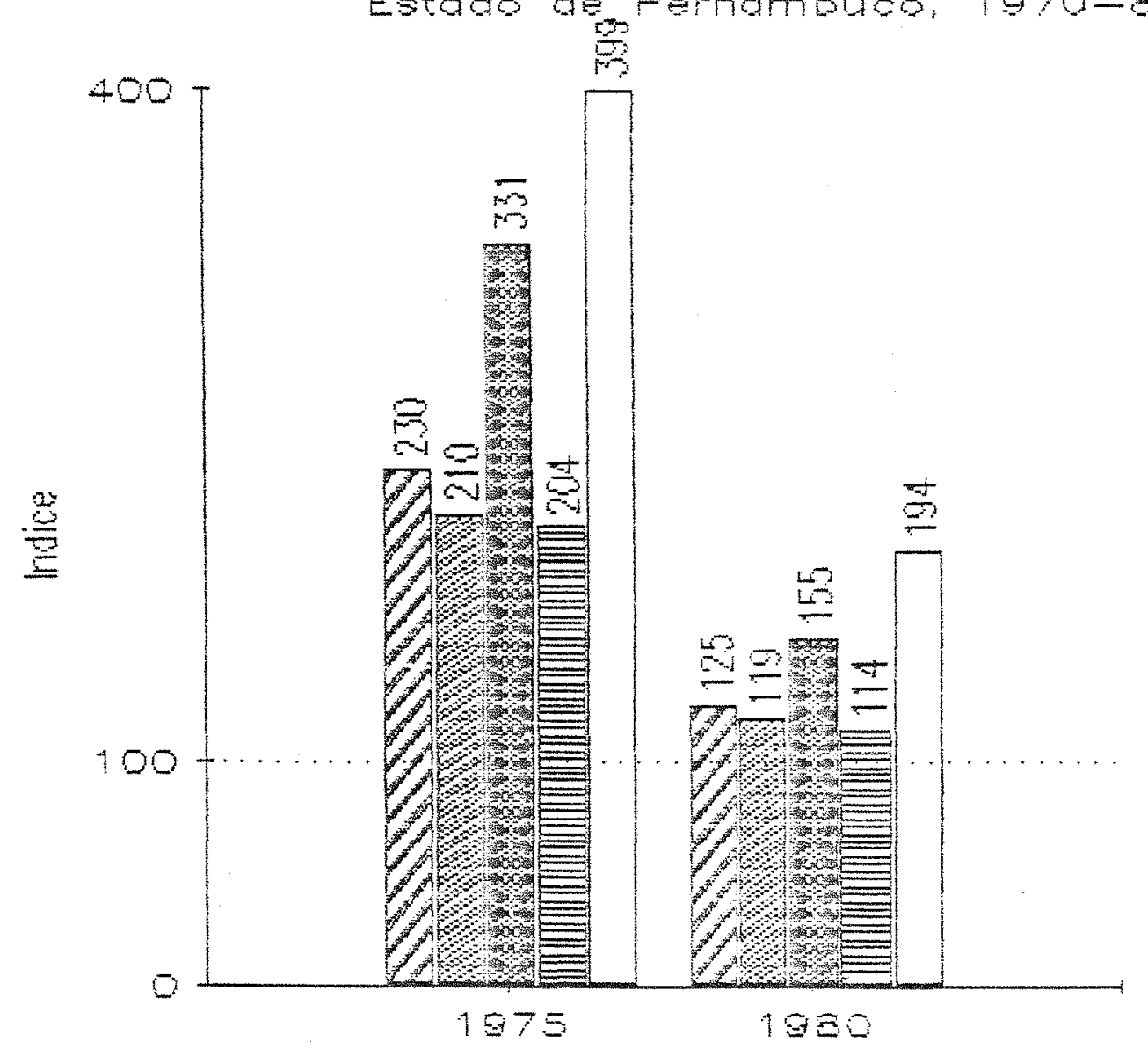

Fig. 16. - Evolução da Produção Agrỉcola, Estado do Piauî, 1970-80. 
1975 e 1980. Os fatores terra e trabalho seguiram essa tendência de relativa estagnaçăo, enquanto que a produtividade dos demais diminuiu (figuras 16, 17 e 18).

\section{A.2.7. Rio Grande do Norte}

No Rio Grande do Norte, a produçăo agricola agregada apresentou substanciais aumentos entre 1970 e 1975, com crescimento nas produções de cana, algodâo (arbóreo e herbáceo) e milho, apesar da pequena queda na produção de mandioca; entre 1975 e 1980, apenas a cana e a mandioca apresentaram algum crescimento de produçǎo. As culturas perenes e as de mercado externo tiveram os maiores aumentos de produção no período 1970-80, elevando o indice agregado, enquanto que as culturas de mercado interno permaneceram estagnadas. Todos os indices parciais de utilizaçăo de fatores aumentaram, embora o do trabalho tenha crescido muito menos do que os demais.

A produtividade de fatores apresentou em 1975 e em 1980 níveis superiores aos observados em 1970, graças ao crescimento da produtividade do trabalho, visto que os demais indices decresceram (figuras 19, 20 e 21).

\section{A.2.8. Sergipe}

- Estado de Sergipe apresentou elevação da produção agricola tanto entre 1970 e 1975, como entre 1975 e 1980; no primeiro caso, as culturas anuais e de mercado interno apresentaram crescimento, com maiores 

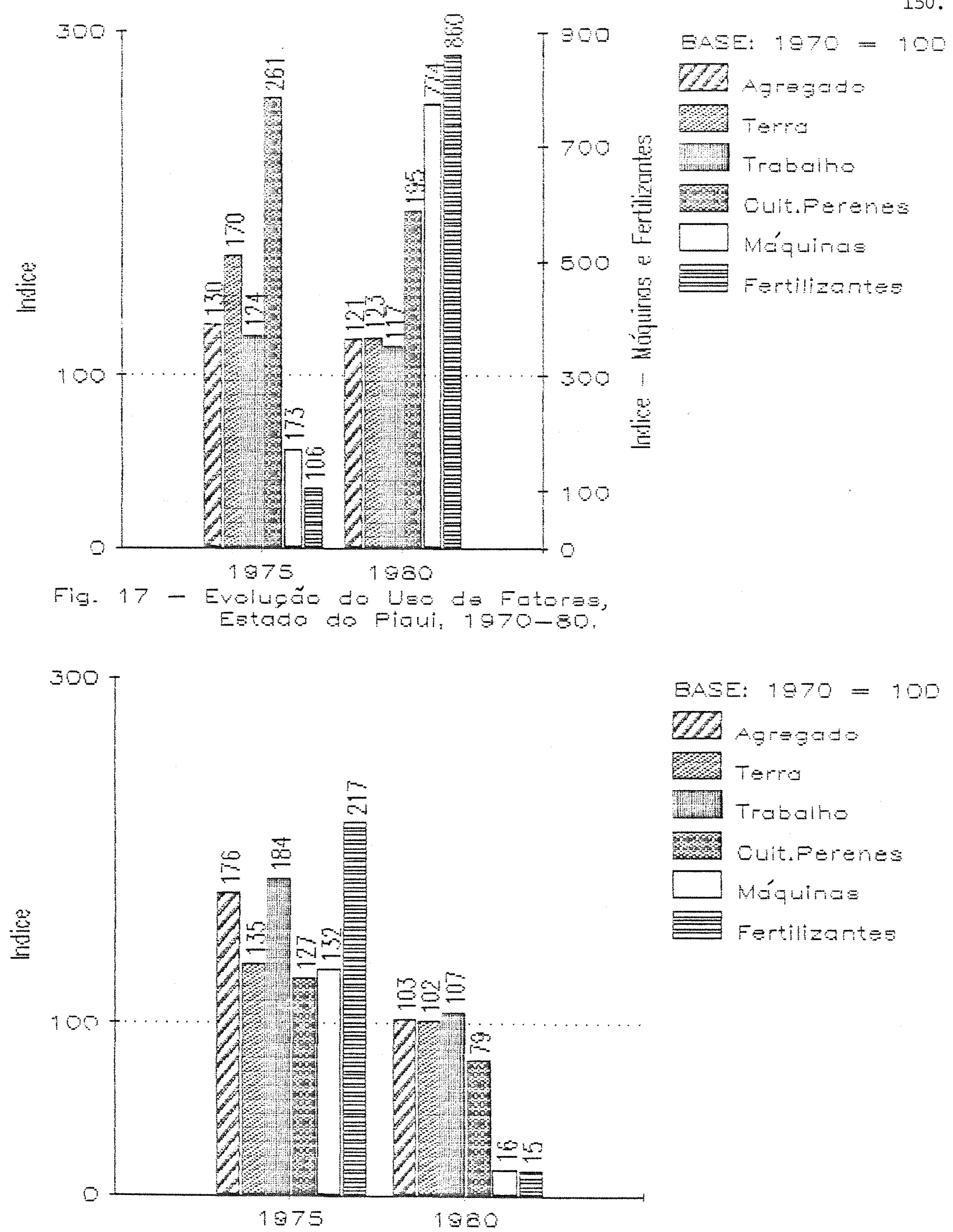

EASE: $1970=100$ ZRO Apregua Q8 $\mathrm{T}=\mathrm{rr}$

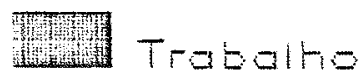
Wratererenes $\square$ Máquine Fertilizartes

Fig. ID - Evoluga da Produthdode de Fotorea, Estado do Plati, $1970-30$. 


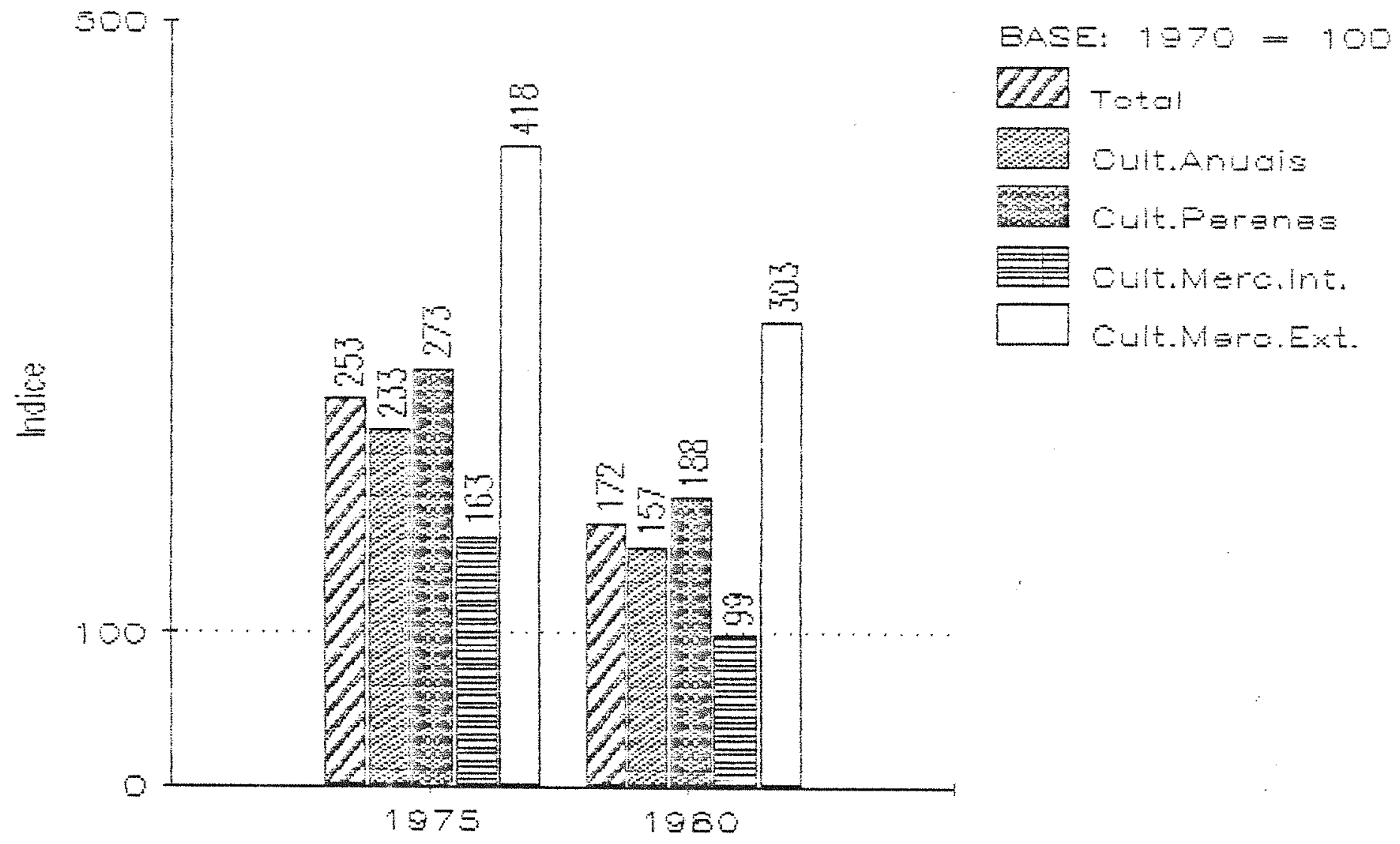

Fig. 19. - Evolução da Produção Agrīcola, Estado do Rio Grande do Norte, 1970-80

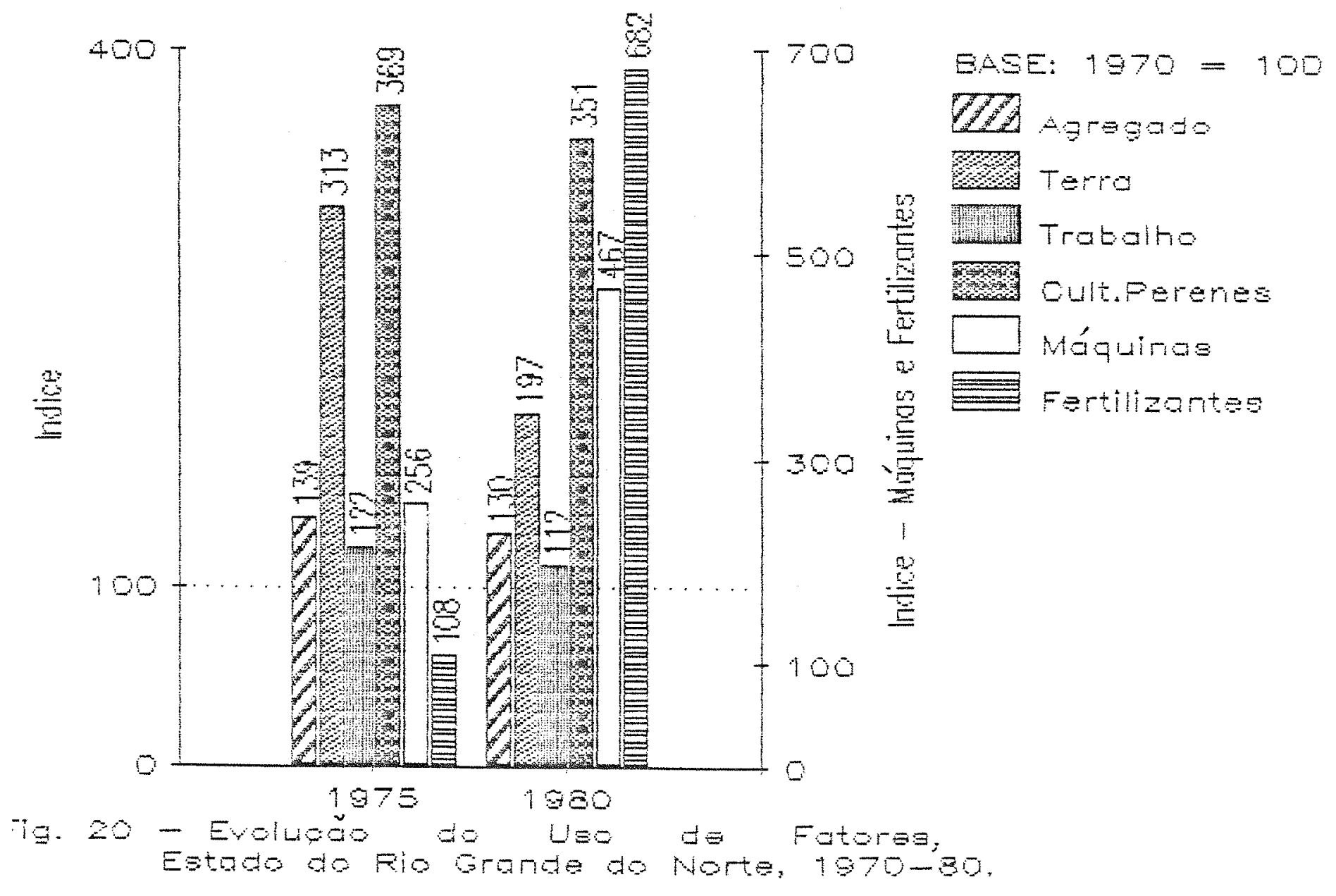




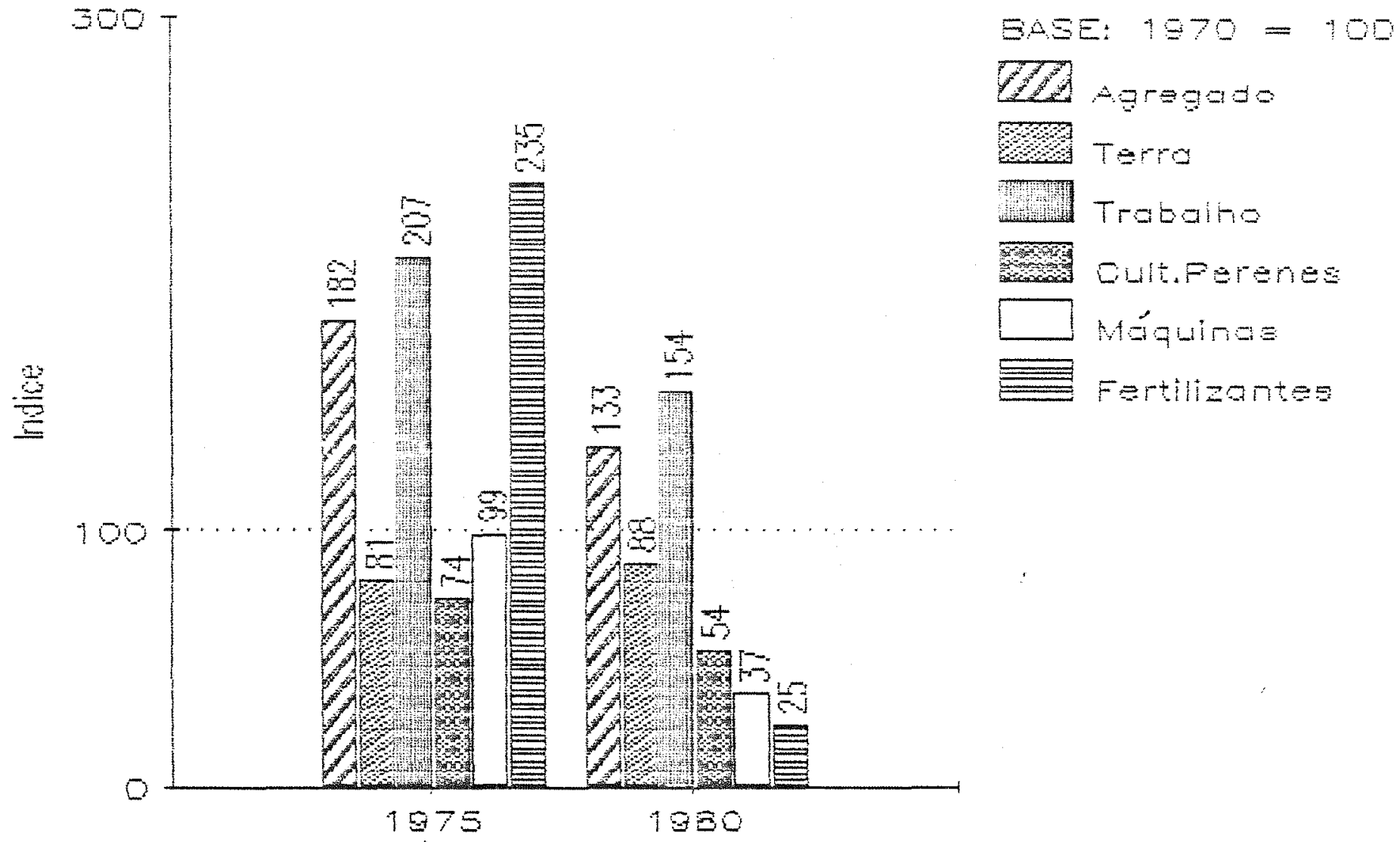

Fig. 21 - Evolucão da Frodutividade de Fotores, Estado do Rio Grande do Norte, $1970-30$.
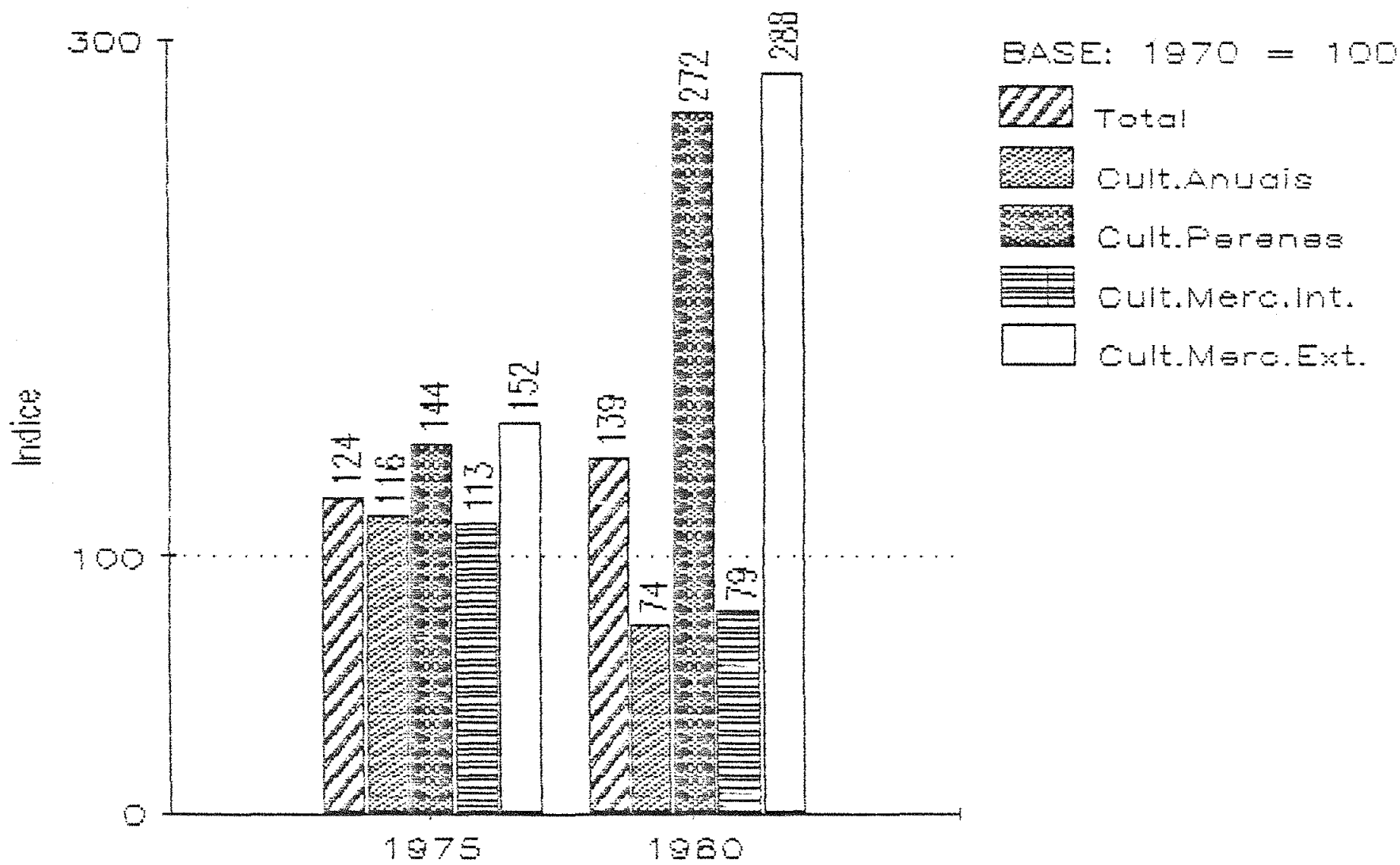

Fig. 22. - Evolução da Produção Agricola, Estado de Sergife, 1970-80. 
produçöes de feijăo, arroz e milho, situação que se reverteu no segundo período, deixando os indices desses grupos de culturas, em 1980, abaixo das marcas de 1970. As culturas perenes e de mercado externo cresceram nos dois casos, graça aos desempenhos da cara-de-açúcar e da laranja. O uso de fatores cresceu no primeiro periodo e decresceu no segundo, em termos agregados; a utilizzação dos fatores terra e trabalho atingiu em 1980 marcas inferiores às de 1970 .

A produtividace de fatores elevou-se tanto entre 1970 e 1975, quanto entre 1975 e 1980 , com os indices parciais de investimentos em culturas perenes, terra e trabalho apresentando niveis mais elevados em 1980 do que em 1970 (figuras 22,23 e 24 ).

\section{A.2.9. Maranhão}

No Maranhão o crescimento da produção agricola ocorreu de maneira uniforme entre os grupos de produtos e mais intensamente entre 1970 e 1975; o grupo de culturas perenes foi o que apresentou taxas mais modestas. Dos principais produtos do Estado, arroz, fejjão e milho cresceram tanto entre 1970-75 como entre 1975-80, enquanto a mandioca cresceu entre 1970-75 e diminuiu a produção entre 1975 e 1980. Entre os fatores de produção observou-se intensificaçấo de uso entre 1970 e 1980, mesmo nos fatores primários terra e trabalho; a única exceção foram os investimentos em culturas perenes. 


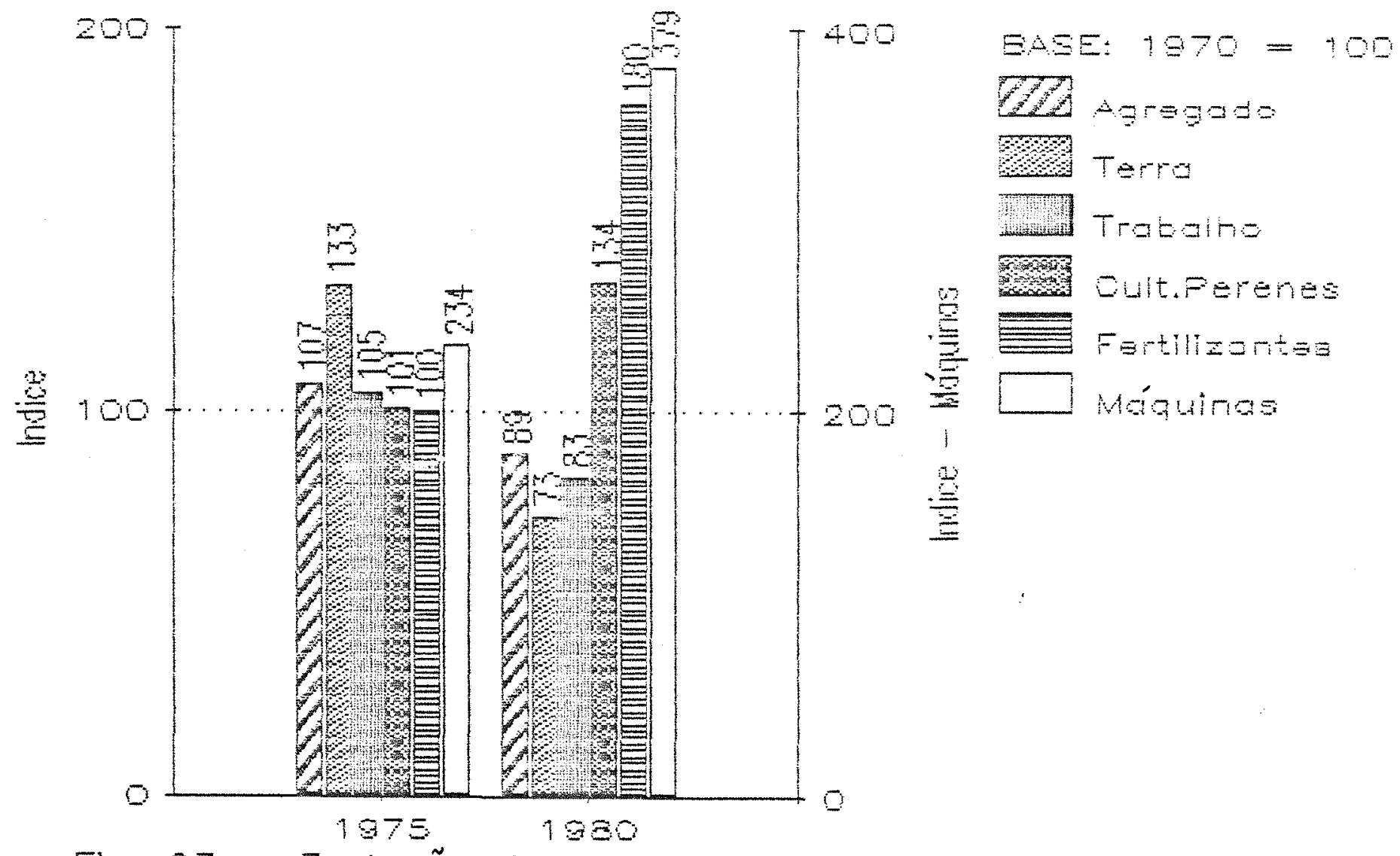

Fig. $2 z$ - Evoluga do Uso de Fotoras, Estado de Sergipe, $1970-80$.

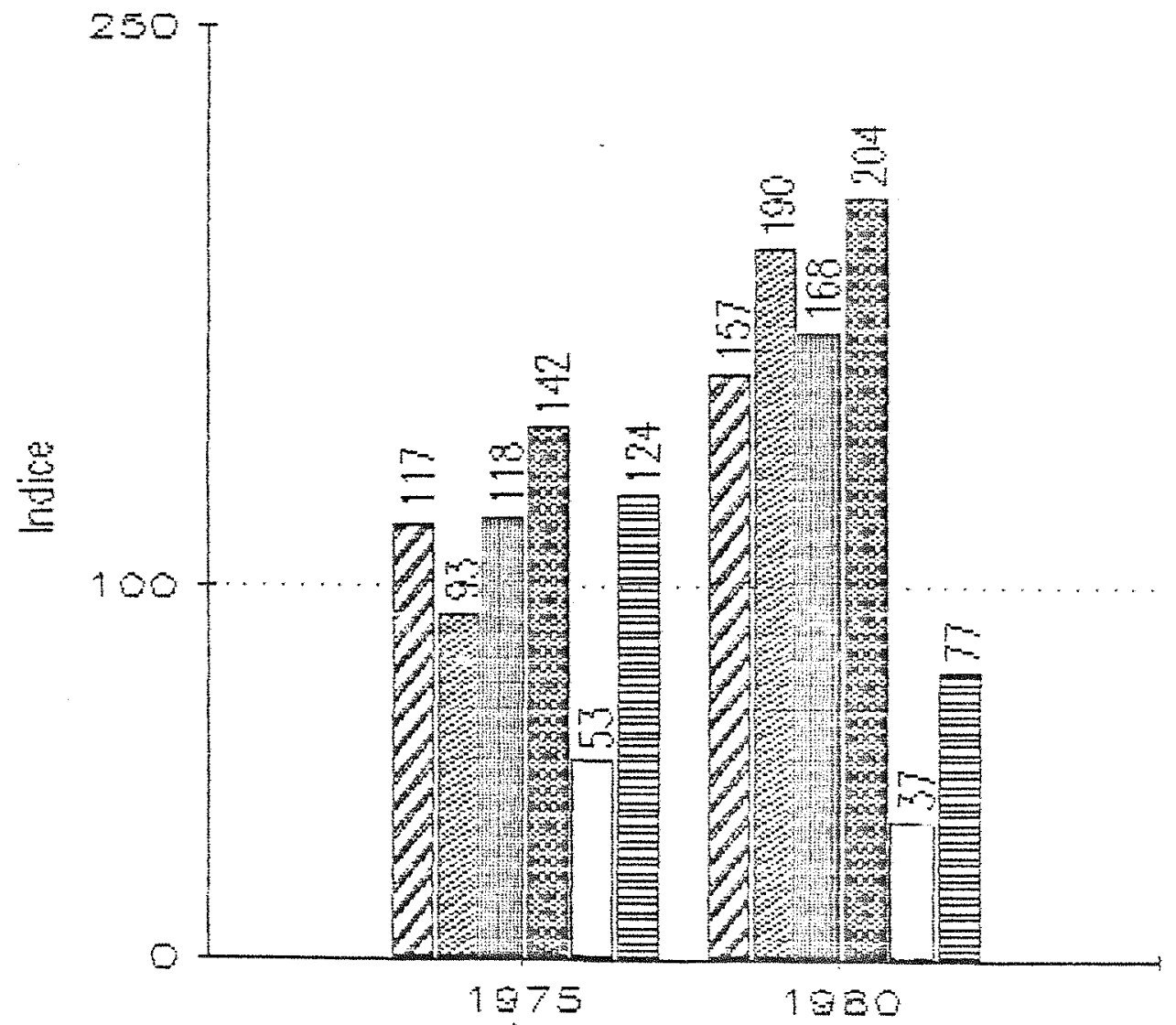

BASE: $1970=100$ QZ2 aregado \%? Terro Hefry Trabaino W cuit.perenes $\square$ Máquinas Fertilizantos

Fig. 24 - Evolupáda produtivede de fotores; Estado de Sergipe, $1970-30$. 
os indices de produtividade apresentaram pequenas alteraçốes nos dois periodos, em termos agregados, com os maiores incrementos acontecendo nos investimentos em culturas perenes e na terra (figuras 25,26 e 27).

\section{A.2.10. Acre}

A produçấo agricola do Acre apresentou decrêscimo entre 1970 e 1975, com ligeira recuperação entre 1975 e 1980, fixando-se em niveis algo inferiores a 1970; a principal responsável pela queda foi a mandioca, principal cultura do Estado, o que foi apenas parcialmente compensado pela estabilidade na produção de feijão e milho e aumentos na quantidade produzida de arroz e, sobretudo, cana-de-açúcar. O uso de fatores aumentou $66 \%$ entre 1970 e 1980, sem incluir o indice parcial de fertilizantes, pois a inexistência de dados de quantidade utilizada no ano base (1970) impede o cálculo do mesmo. Caso fosse incluído o fator fertilizantes, o indice de utilização de fatores atingiria niveis mais elevados. Entre 1975 e 1980, percebe-se grande intensificaçăo no uso de fatores, especialmente máquinas.

A produtividade decresceu durante os os dois períodos, com exceção do fator investimentos em culturas perenes, tendo o indice agregado atingido, em 1980, nivel pouco superior à metade do observado em 1970 (figuras 28,29 e 30 ). 

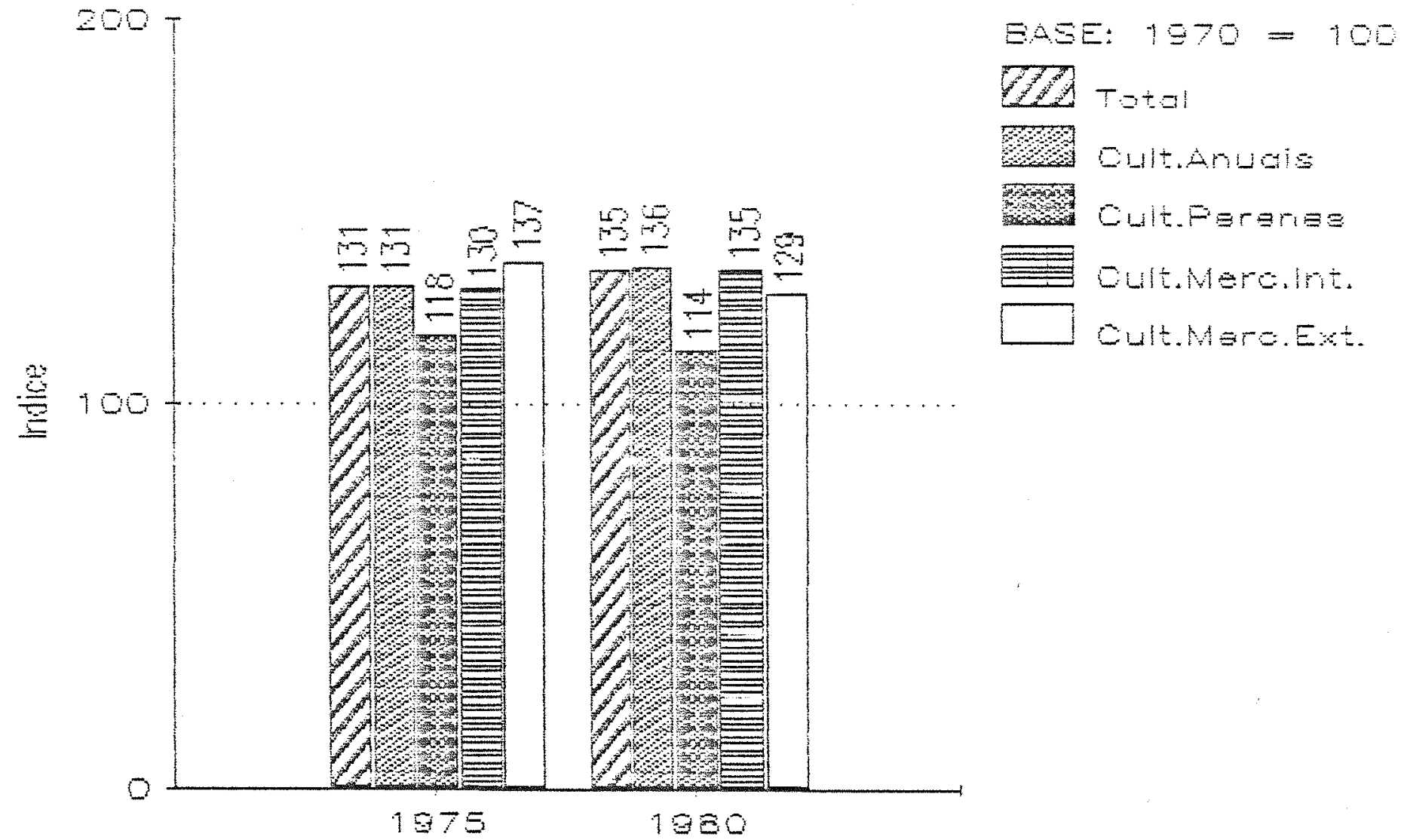

Fig. 25. - Evolução da Produção Agrīcola, Estado do Maranhão, 1970-80.

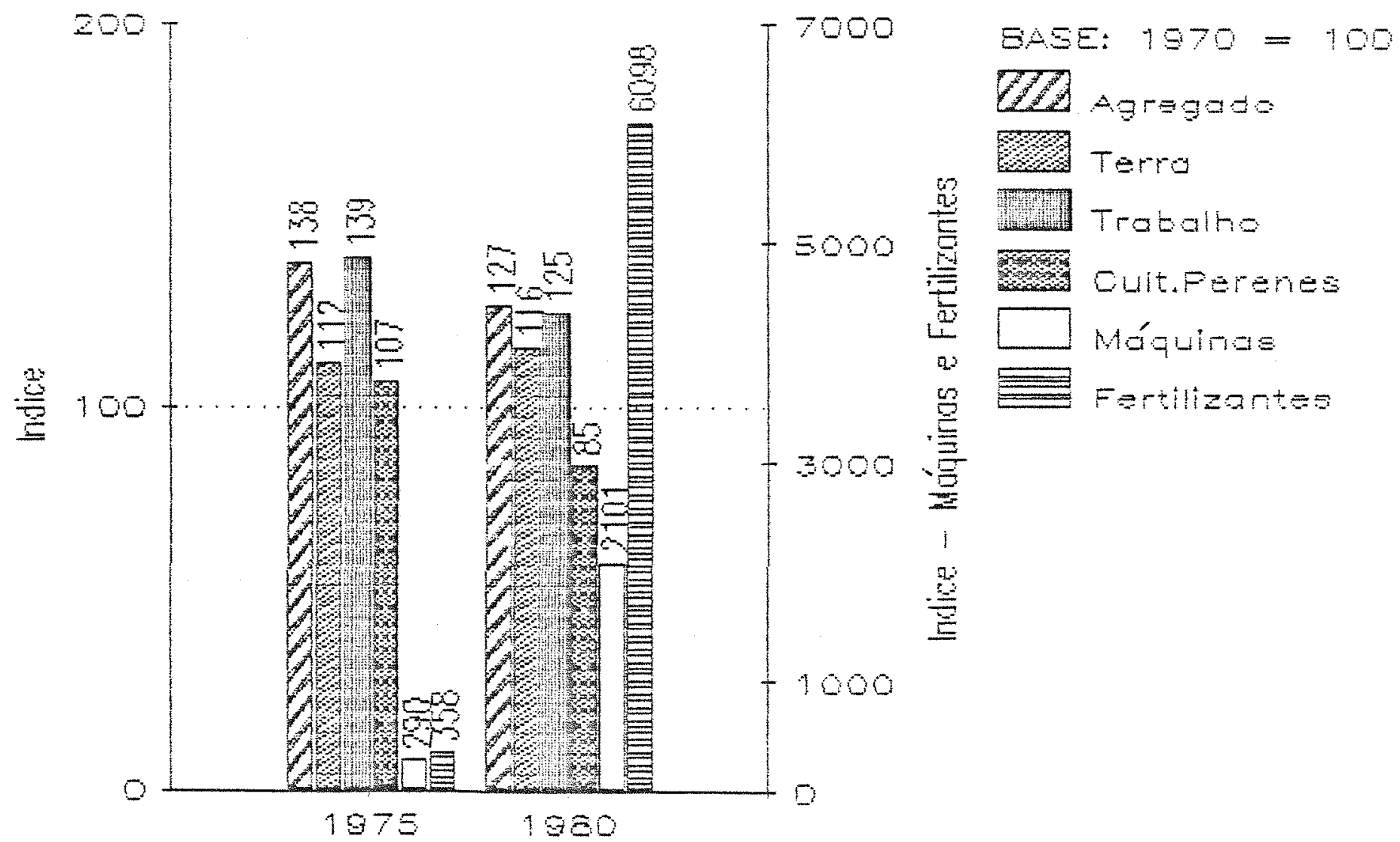

Fig. 20 - Evolugao do va de Fotores, Estado do Maraniá, $1970-30$. 


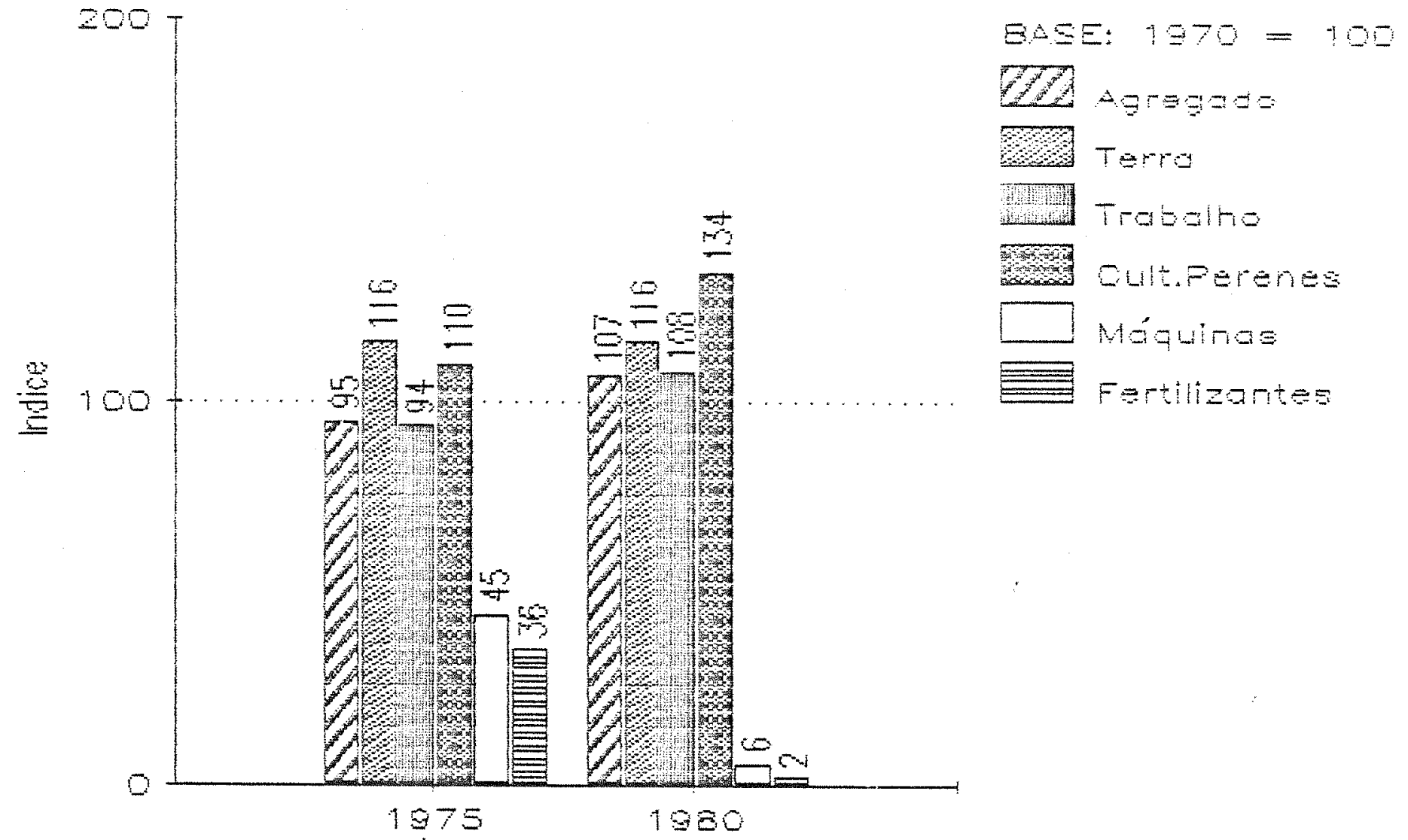

Fig. 27 - Evolugdo da Frodutividade da Fotorä,

Estado do Maranhäo, 1970-80.

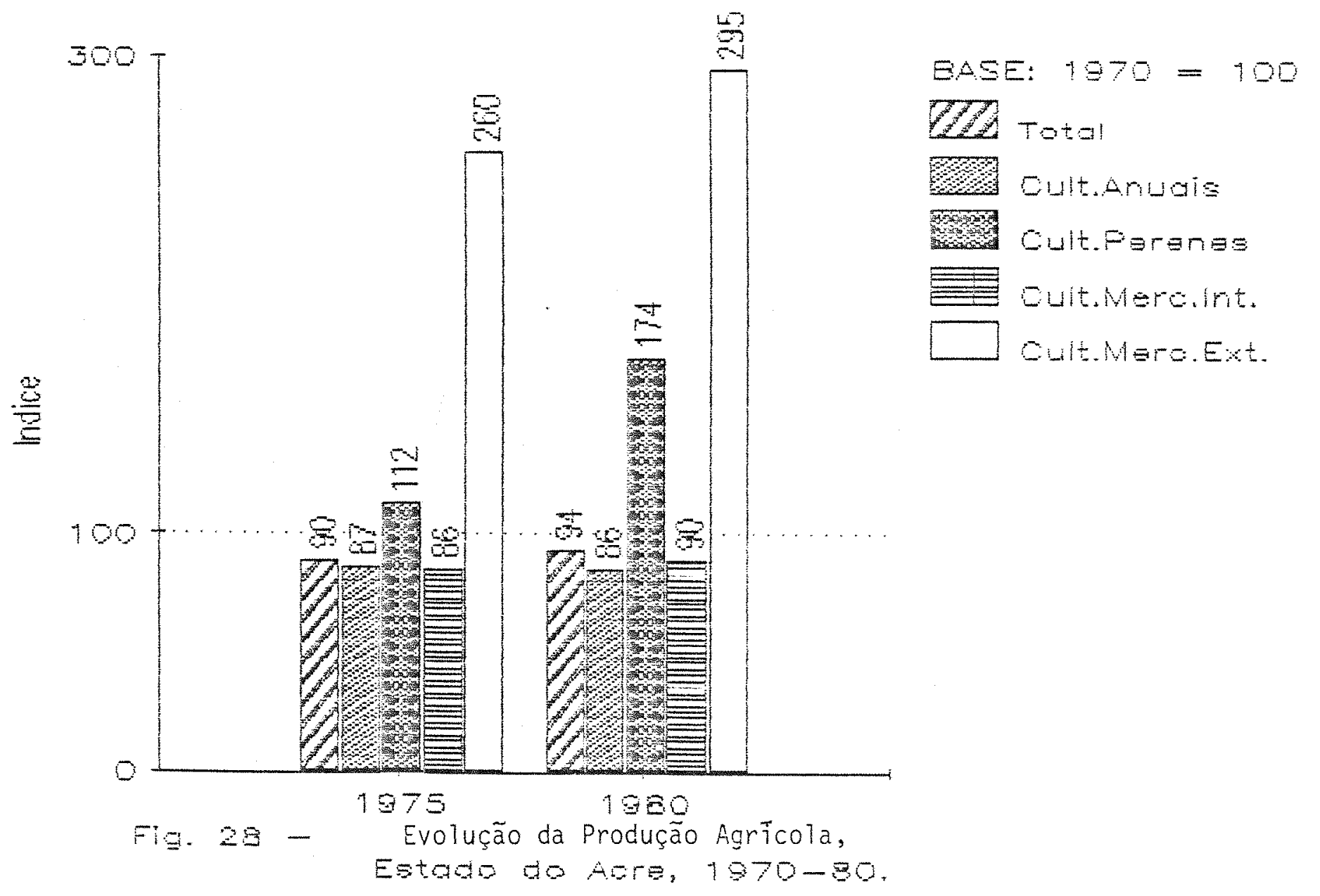



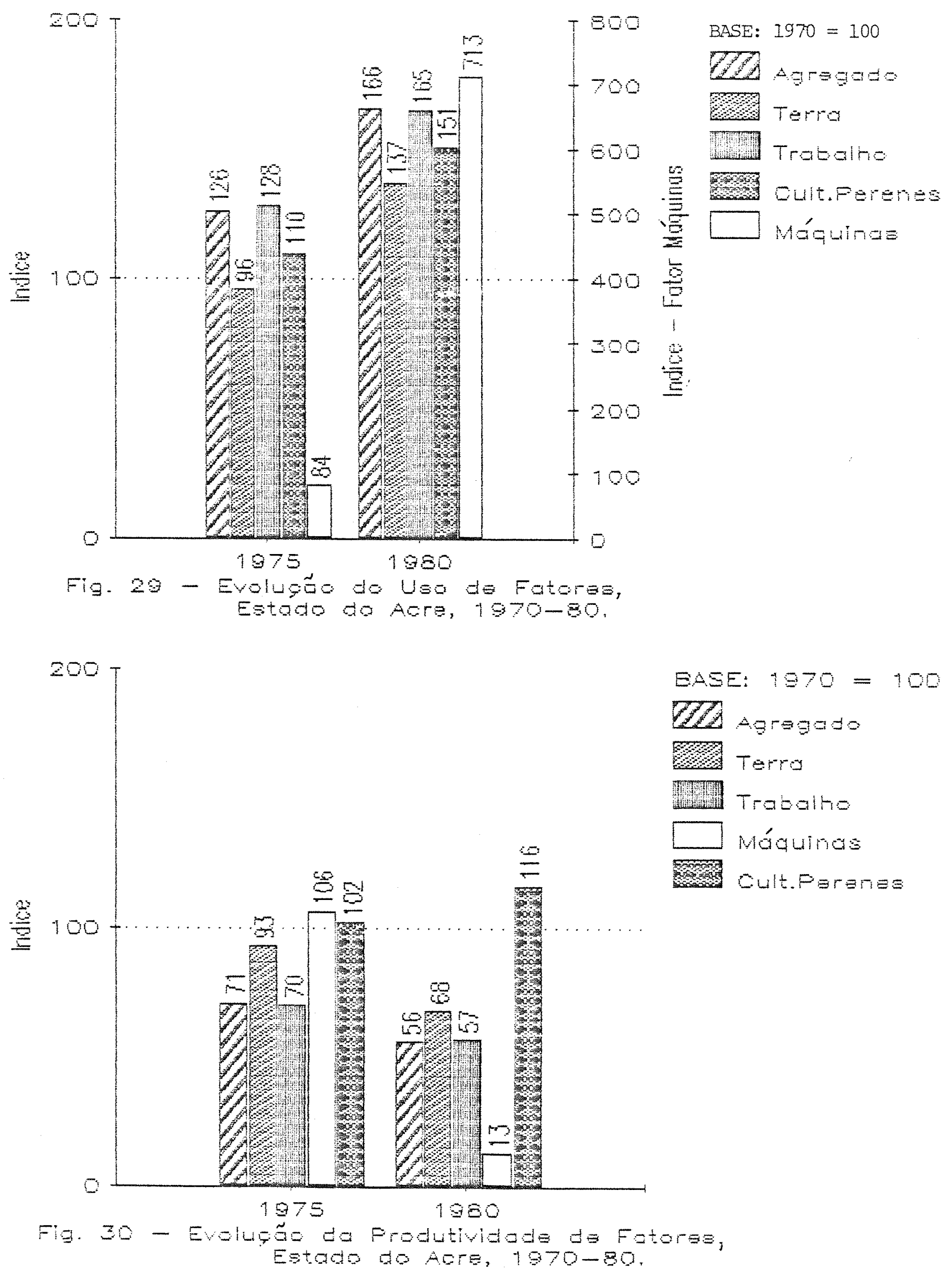


\section{A.2.11. Amazonas}

No Estado do Amazonas, a produção agrícola aumentou, tanto entre 1970 e 1975, como entre 1975 e 1980, devido ao crescimento das culturas anuais e culturas de mercado interno, principalmente mendioca e arroz; as culturas perenes decresceram, apesar do aumento da produçâo de mandioca, pela queda do cacau e da laranja e, entre 1970 e 1975, também da banana. A utilizaçăo de fatores, evidenciando o maior peso relativo do trabalho, acompanhou a elevação desse indice parcial, embora o uso dos fatores máquinas e fertilizantes tenha crescido a taxas elevadas entre 1975 e 1980.

Do mesmo modo que o uso agregado dos fatores, o indice de produtividade agregada refletiu o comportamento do indice parcial do trabalho, fixando-se em 1980, em nível inferior ao observado em 1970. Dos fatores considerados neste estudo, apenas investimentos em culturas perenes realizaram algum ganho de produtividade (figuras $31,32$ e 33$)$

\section{A.2.12. Amapá}

Entre 1970 e 1975, a produção agrícola do Território do Amapá experimentou acréscimo devido, principalmente, aos aumentos das produçốes de mandioca e banana, que diminuiram a quantidade produzida entre 1975 e 1980, embora sem voltar a atingir os niveis de 1970. O indice de uso agregado de fatores, também refletiu o 


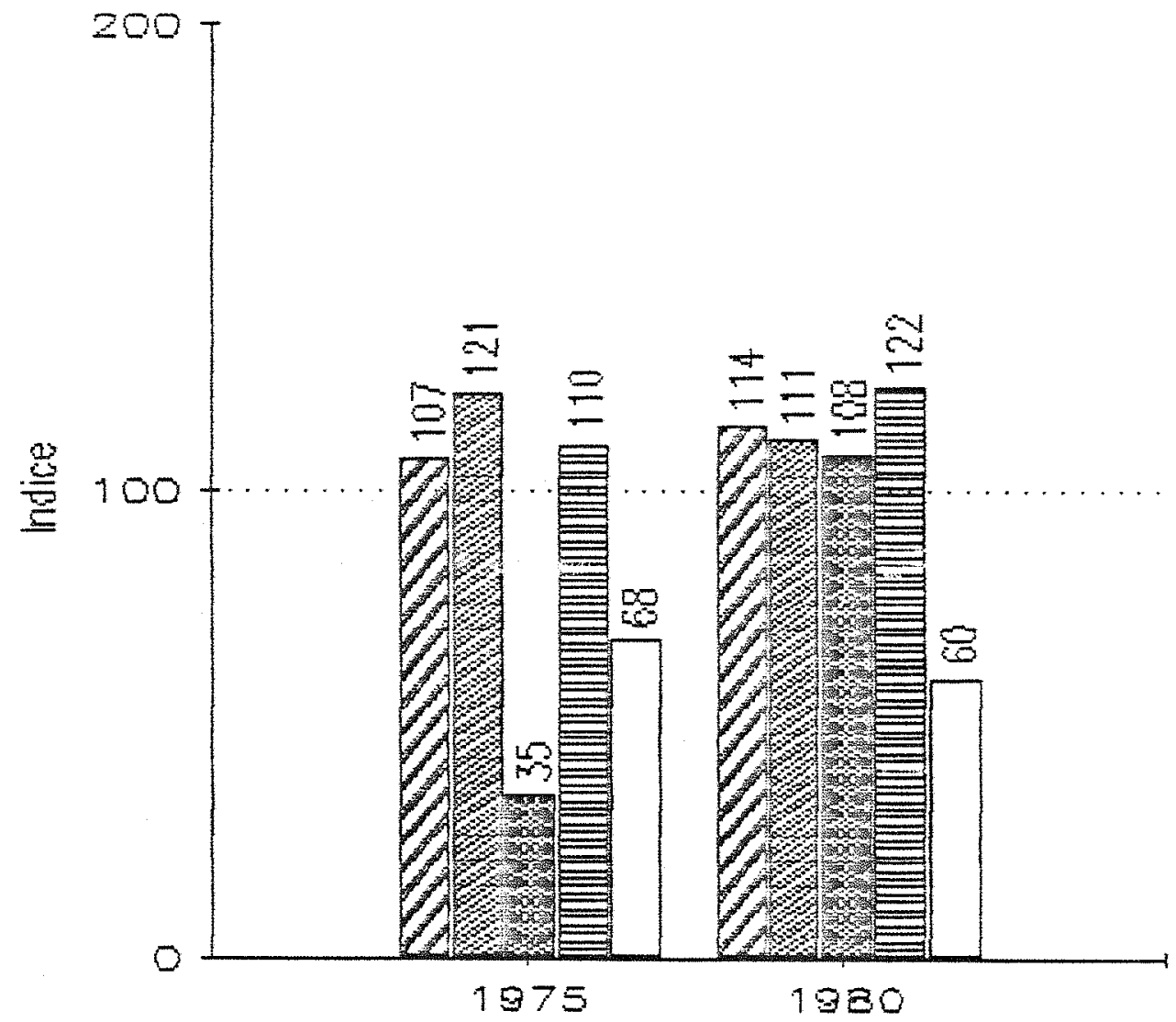

BASE: $1970=100$ LPA Total

$8 \%$ aut.Anuais

ris

Cult.Fiaran日s

Eult.Meroint.

$\square$ cult.Mere. Ext.

Fig. 31. - Evolução da Produção Agrỉcola, Estado do Amazonas, 1970-80.

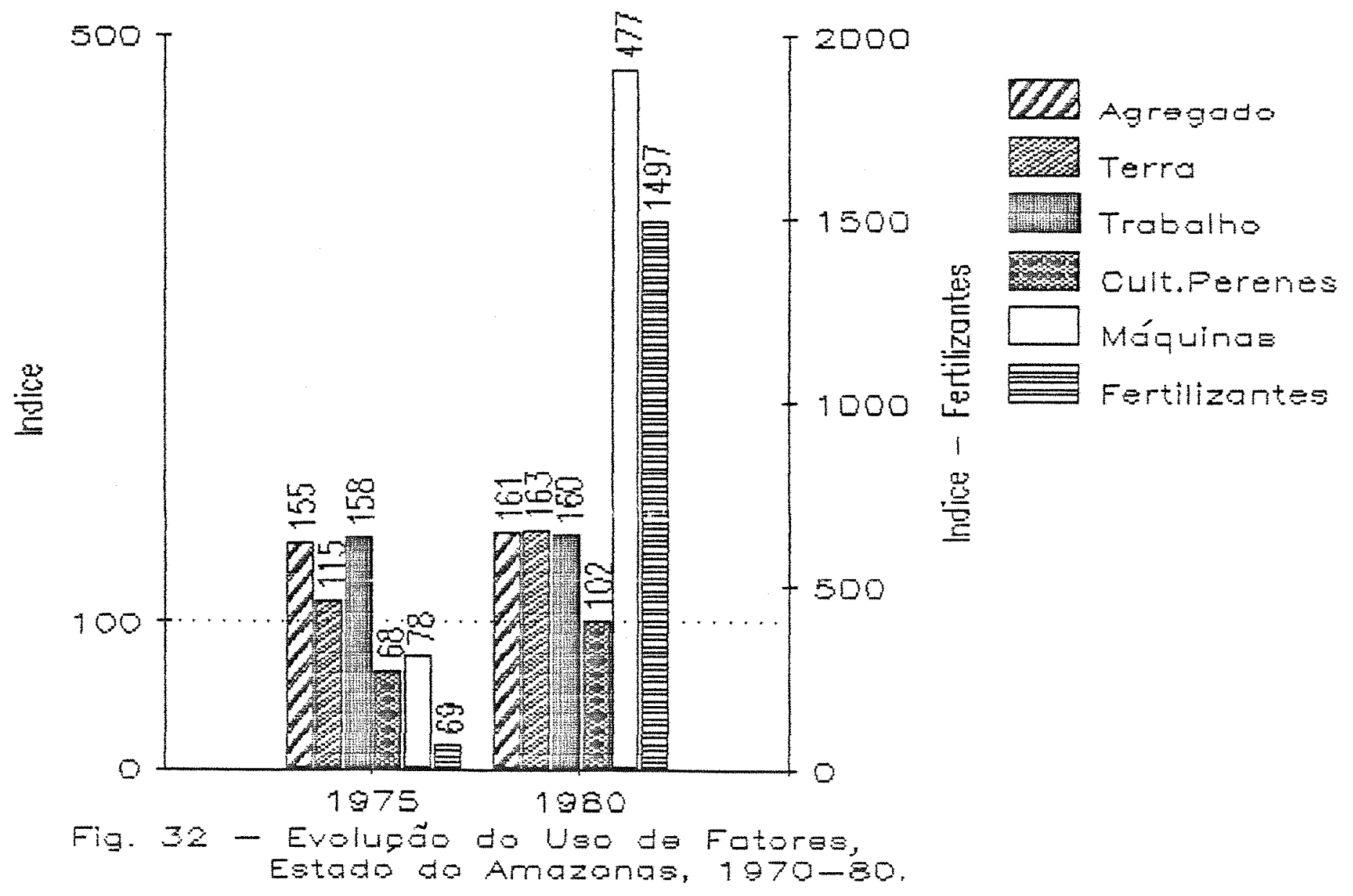




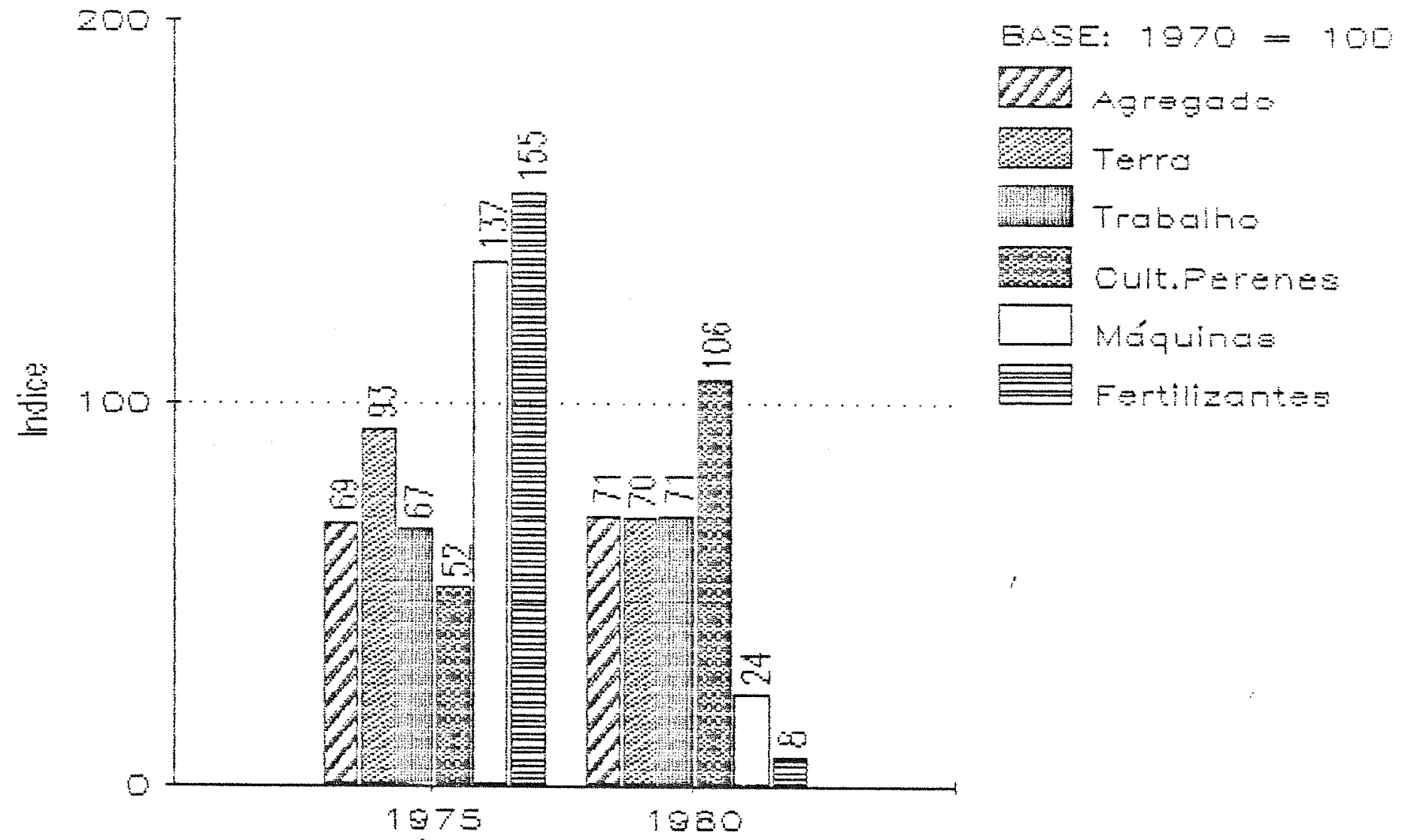

Fig. 33 - Evoluga da Produtividode da Fotoras:

Estado do Amazomas 1970-30.

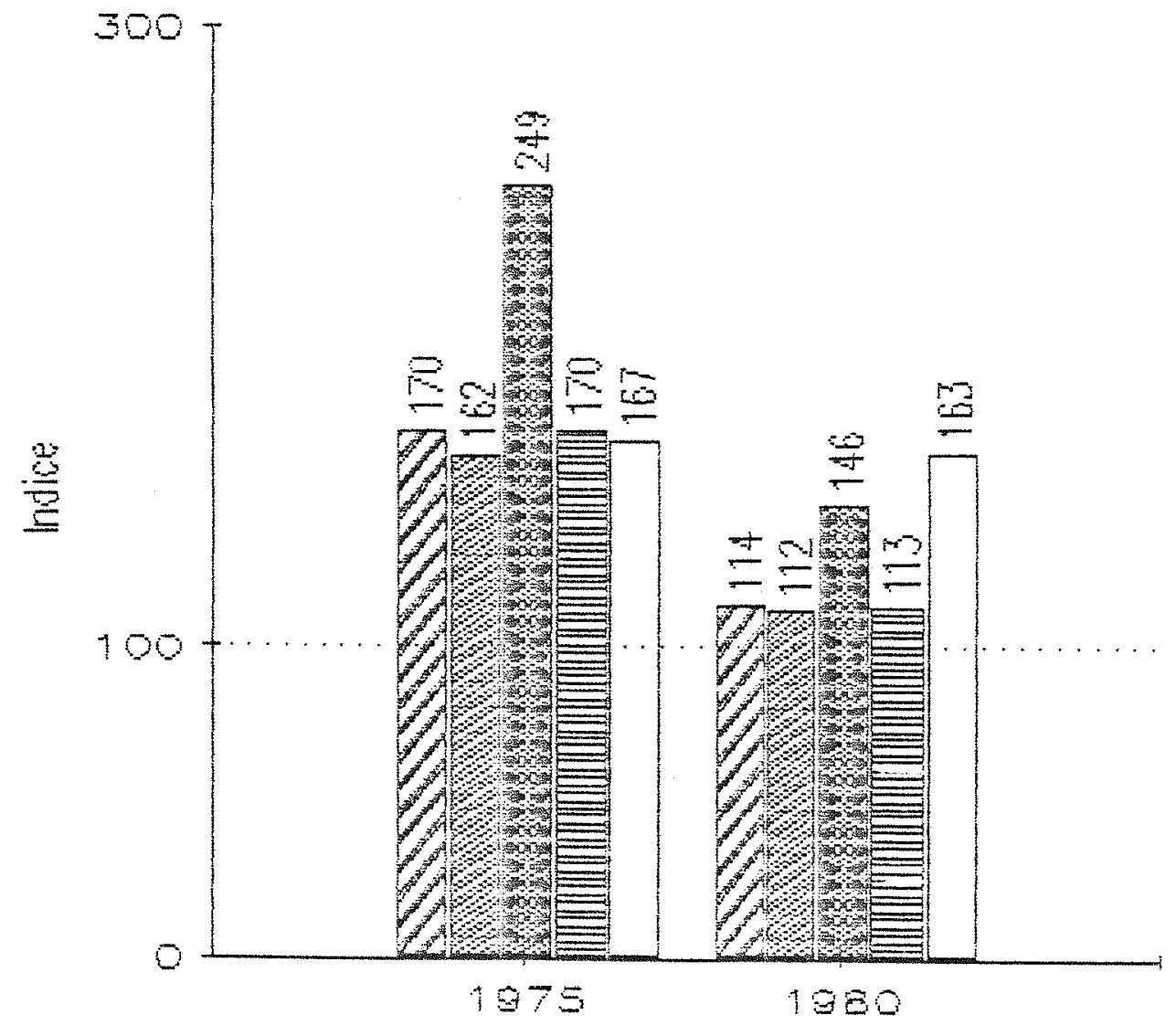

$E \triangle S E: 1970=100$ PQZ TOLI

$8 \%$ Oult.Anuals

Wult. Ferenga $\Longrightarrow$ Cult.Mercint.

$\square$ Cuthere.ext.

Fig. 34. - Evolução da Produção Agrīcola, Territōrio do Amapā, 1970-80. 
comportamento do indice parcial de uso do trabalho, com aumentos entre 1970 e 1975 e, diminuiçöes, embora menores, entre 1975 e 1980

A produtividade agregada de fatores, variou conforme a proautividade do trabaliso, estando tanto em 1975 como em 1980 abaixo do nível de 1970 (figuras 34, 35 e 36$)$.

\section{A.2.13. Pará}

Tanto entre 1970-75 como entre 1975-80, a produçăo agrícola do Pará apresentou crescimento, com aumentos nas produçốes de mandioca, arroz, milho, feijão e banana. Paralelamente, os indices de utilização de fatores também se elevaram, tanto os dos fatores primários terra e trabalho, como os de máquinas e fertilizantes.

A produtividade de fatores, em termos agregados, elevou-se entre esses dois períodos, com os indices parciais de trabalho, terra e, principalmente, investimentos em culturas perenes, atingindo marcas superiores às de 1970 (figuras 37,38 e 39).

\section{A.2.14. Roraima}

Entre 1970 e 1975, o valor da produção agricola do Territorio de Roraima praticamente dobrou, graças a aumentos nas produçóes de arroz, milho e cana, embora a mandioca tenha diminuido; entre 1975 e 1980, a produçấo agrícola cresceu a taxas ainda mais elevadas, 


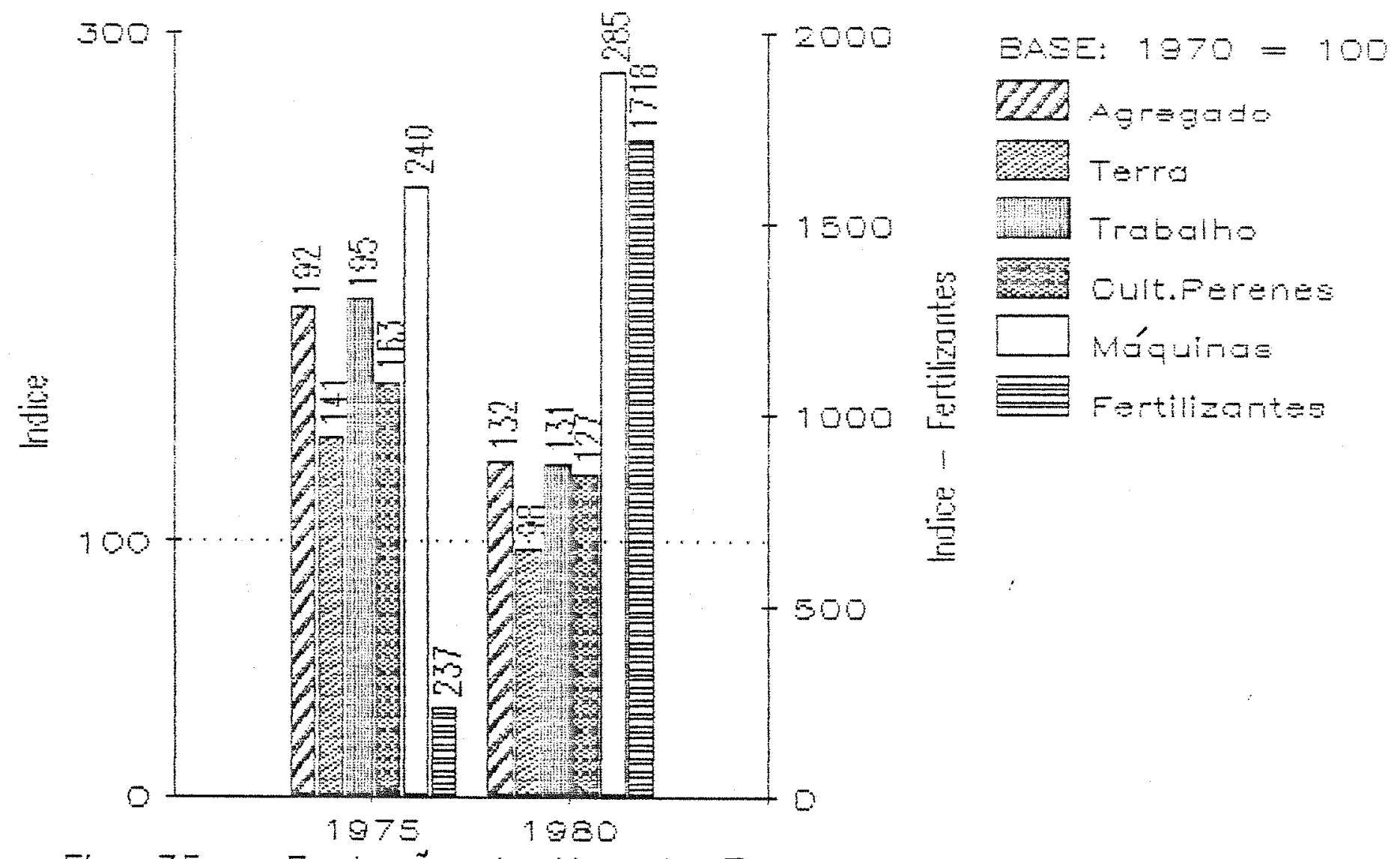

Fig. 35 - Evoluodo do las de Fotorea. Territorio do Amopa, $1970-30$.

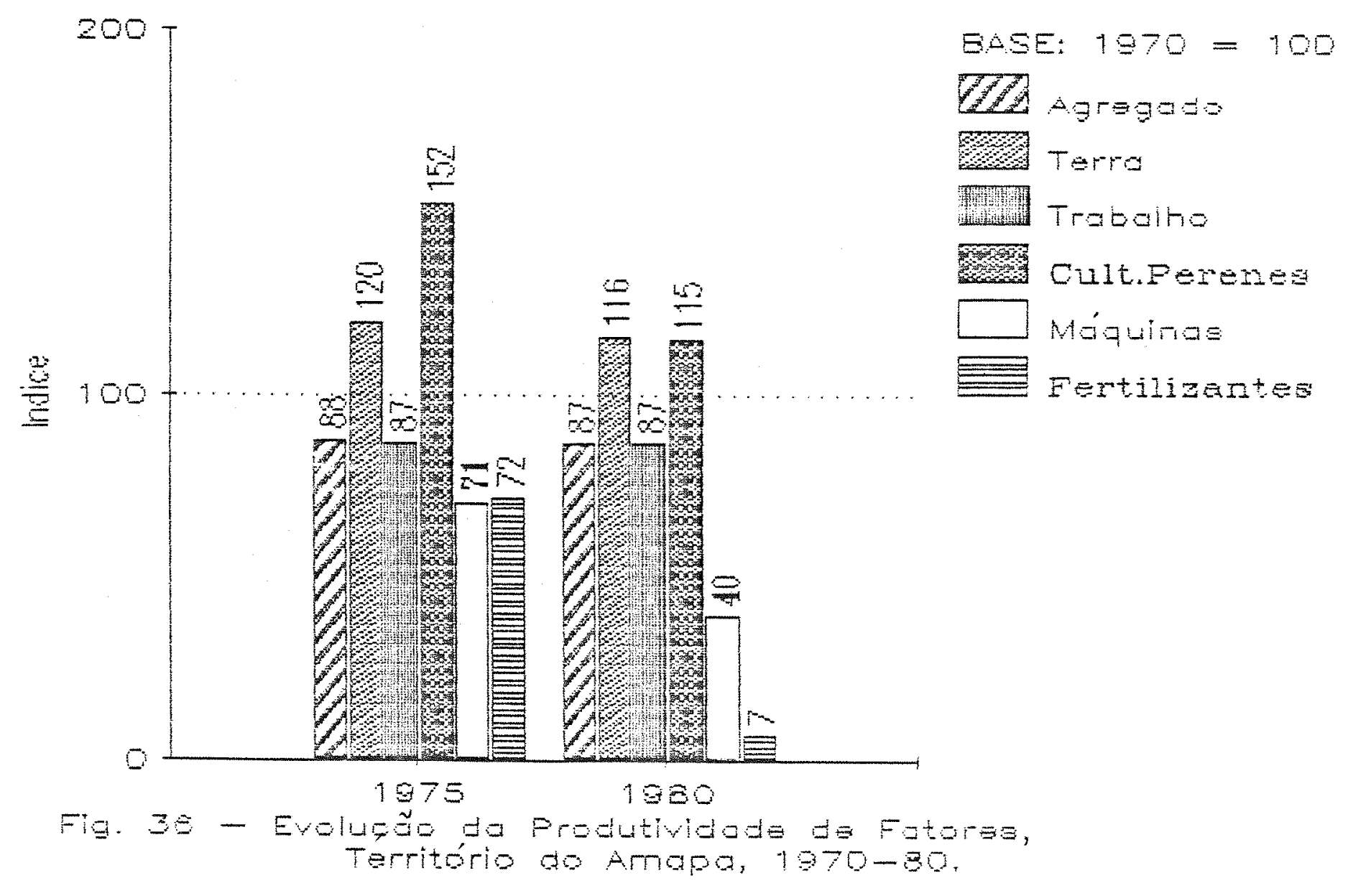



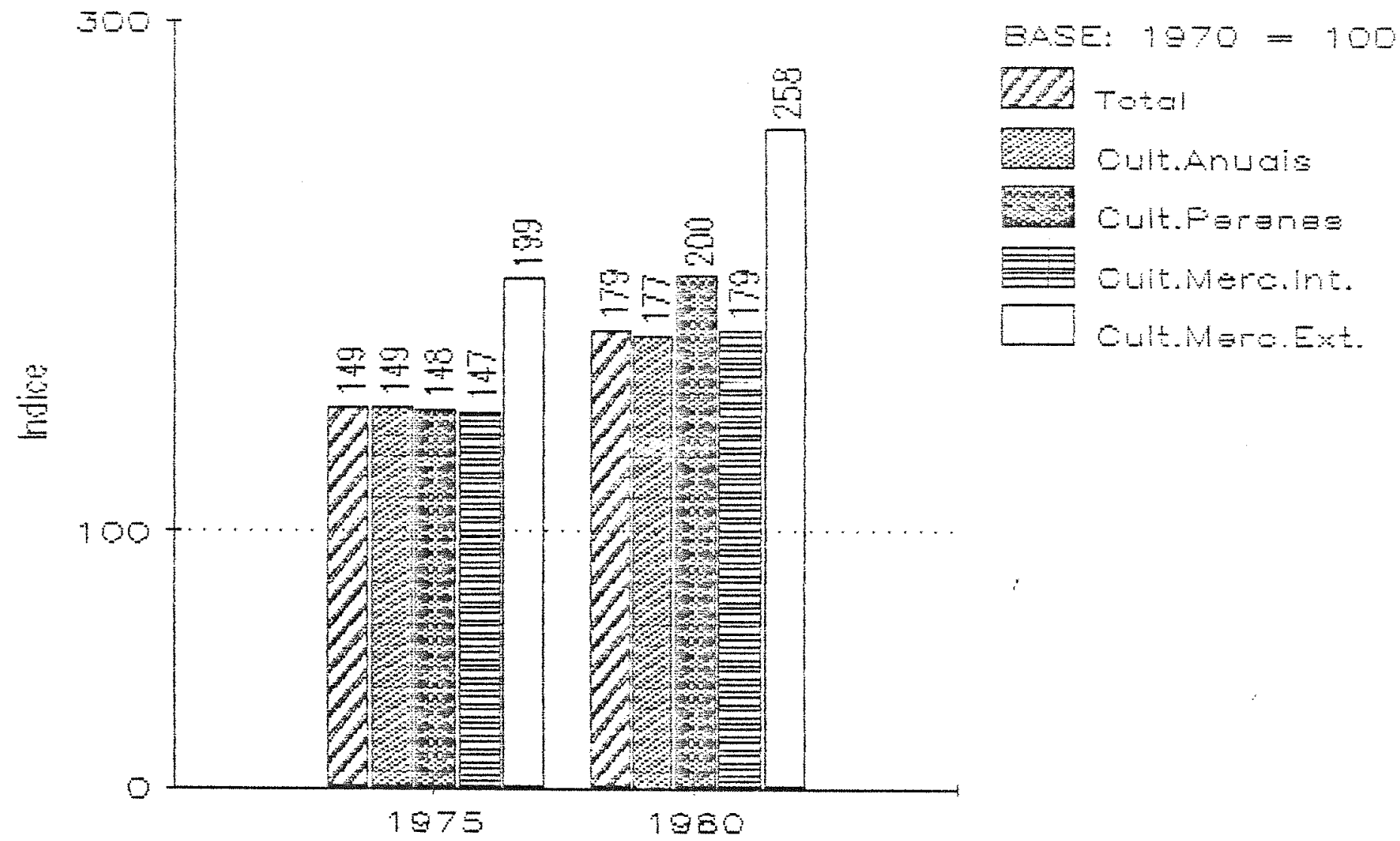

Fig. 37. - Evolução da Produção Agrícola, Estado do Parā, 1970-80.

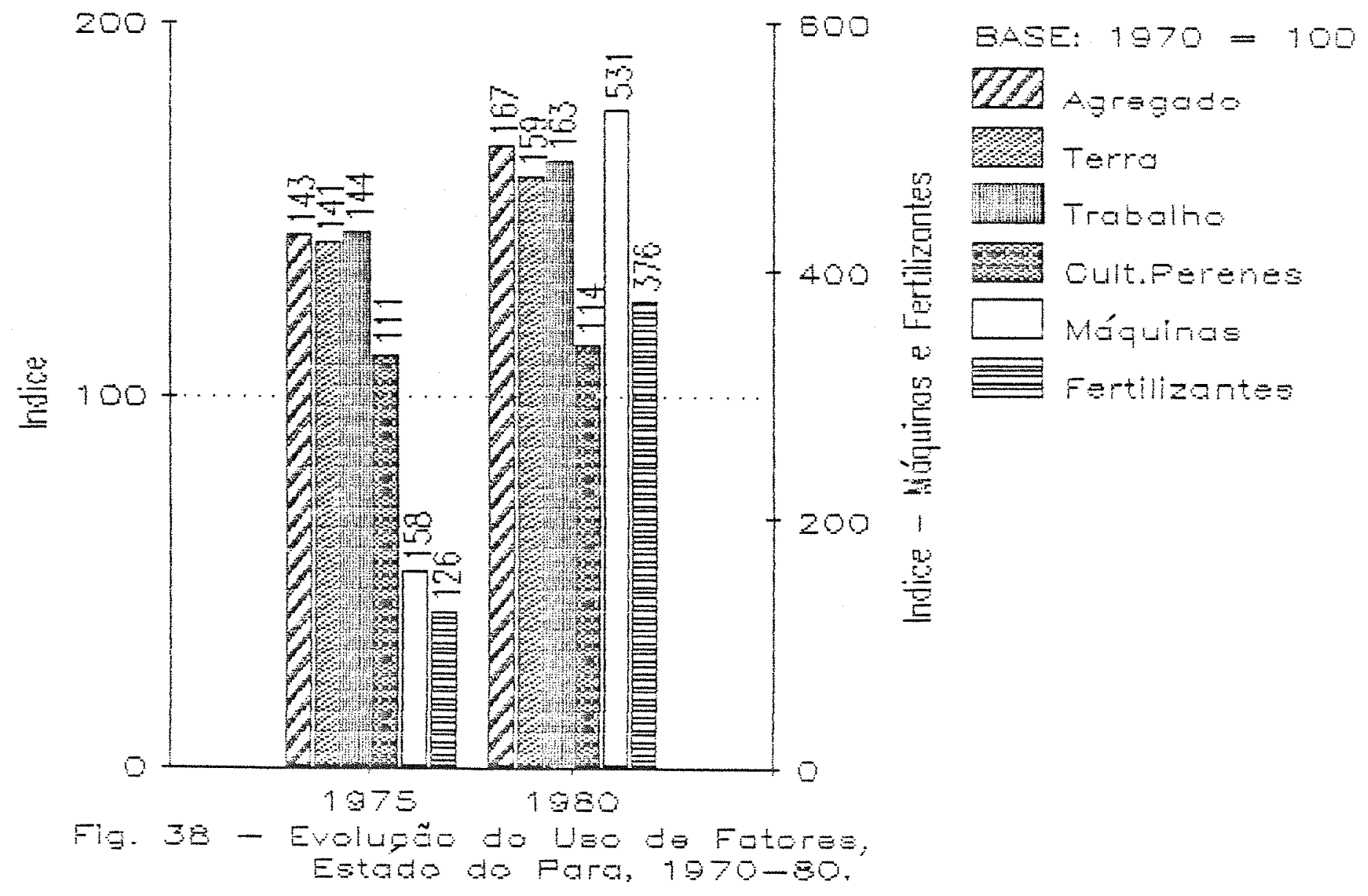




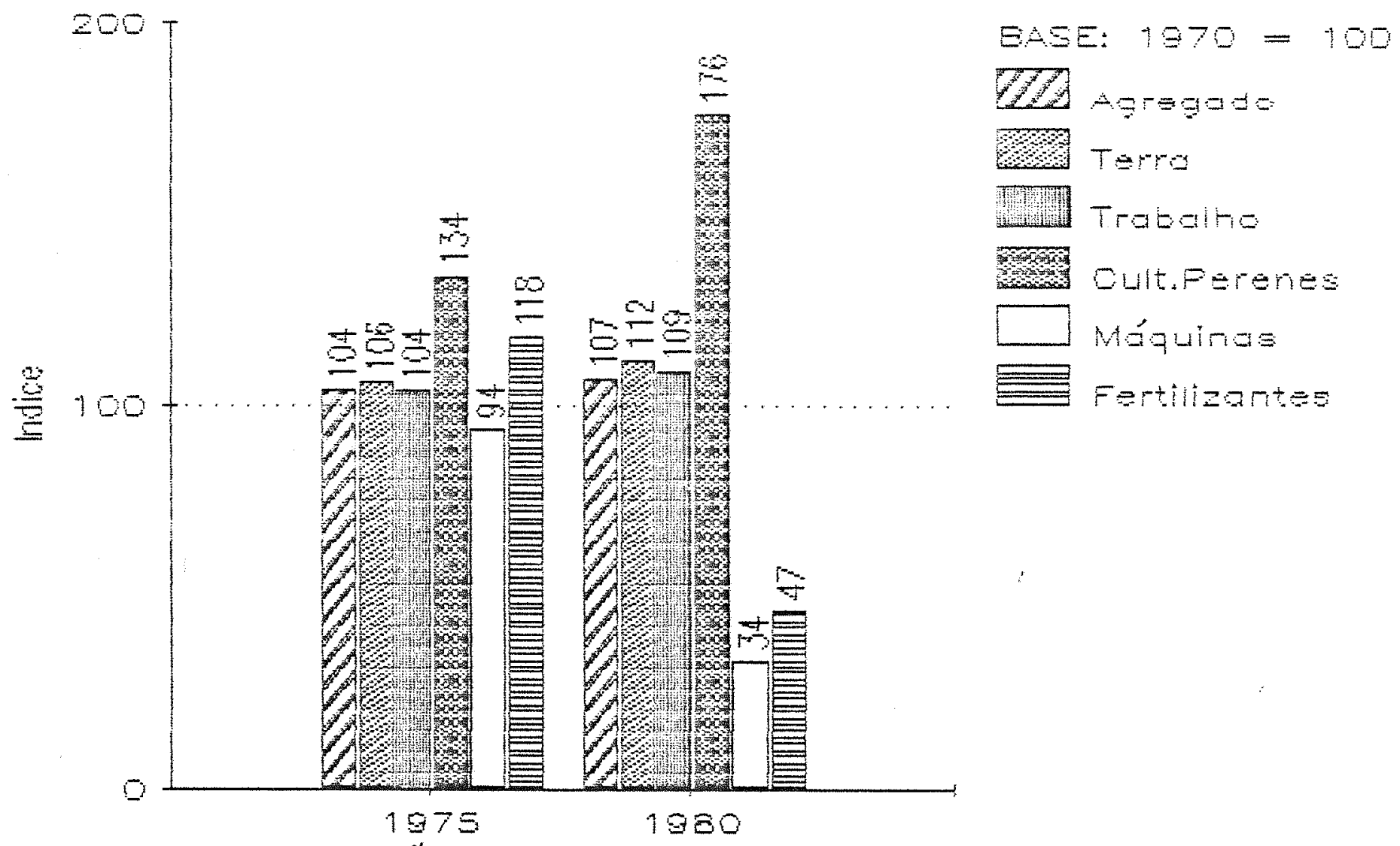

Fig. 39 - Evolugá da Frodutividade de Fatores, Estado do Fara, $1970-80$.

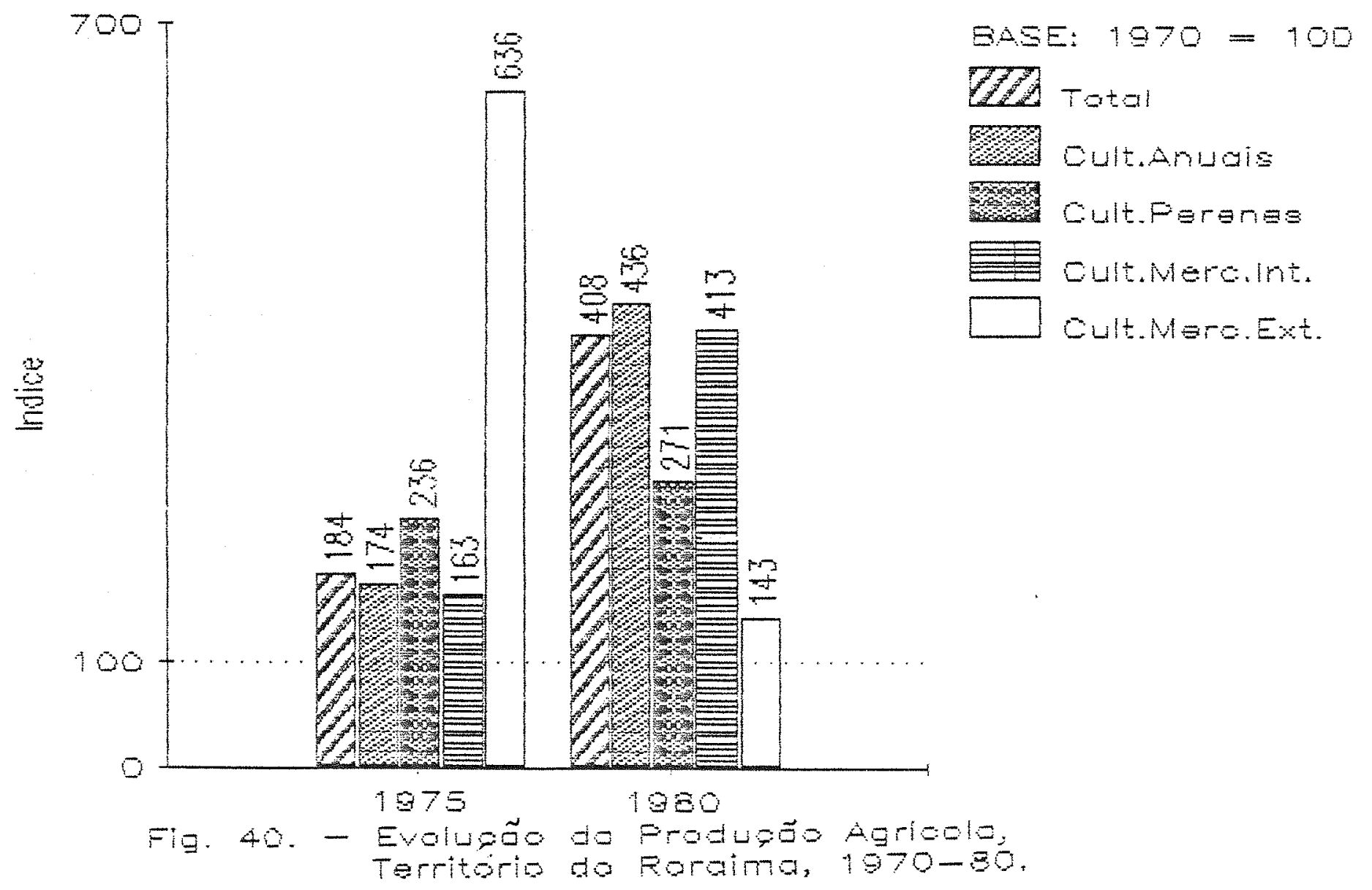


atingindo niveis quatro vezes maiores do que em 1970, com aumentos nas produções de arroz, mandioca, milho e banana. o uso de fatores cresceu também vertiginosamente, mas com algumas diferenças: 0 uso de trabalho cresceu entre 1970 e 1975, mas manteve-se no mesmo nivel entre 1975 e 1930 , enquanto que os outros fatores, exceto investimentos em culturas perenes, cresceram mais entre 1975 e 1980 do que entre 1970 e 1975.

A produtividade de fatores refletiu 0 comportamento do indice de produtividade do trabalho, decrescendo entre 1970 e 1975 e, crescendo entre 1975 e 1980, apresentando aumento de $24 \%$ no periodo $1970-80$ (figuras 40,41 e 42 ).

\section{A.2.15. Rondônia}

No Território de Rondônia, o crescimento da produçấo agrícola nos periodos $1970-75$ e 1975-80 foi o maior do País, com aumentos nas produçóes de arroz, feijão, café, milho e mandioca. o uso de fatores cresceu a taxas ainda maiores do que a produçấo, com grande intensificação no uso dos fatores terra e trabalho e, em 1980, também de investimentos em culturas perenes, máquinas e fertilizantes.

A produtividade de fatores decresceu naqueles dois periodos, comportamento similar aos dos indices parciais de produtividade do trabalho e da terra (figuras 43,44 e 45 ). 


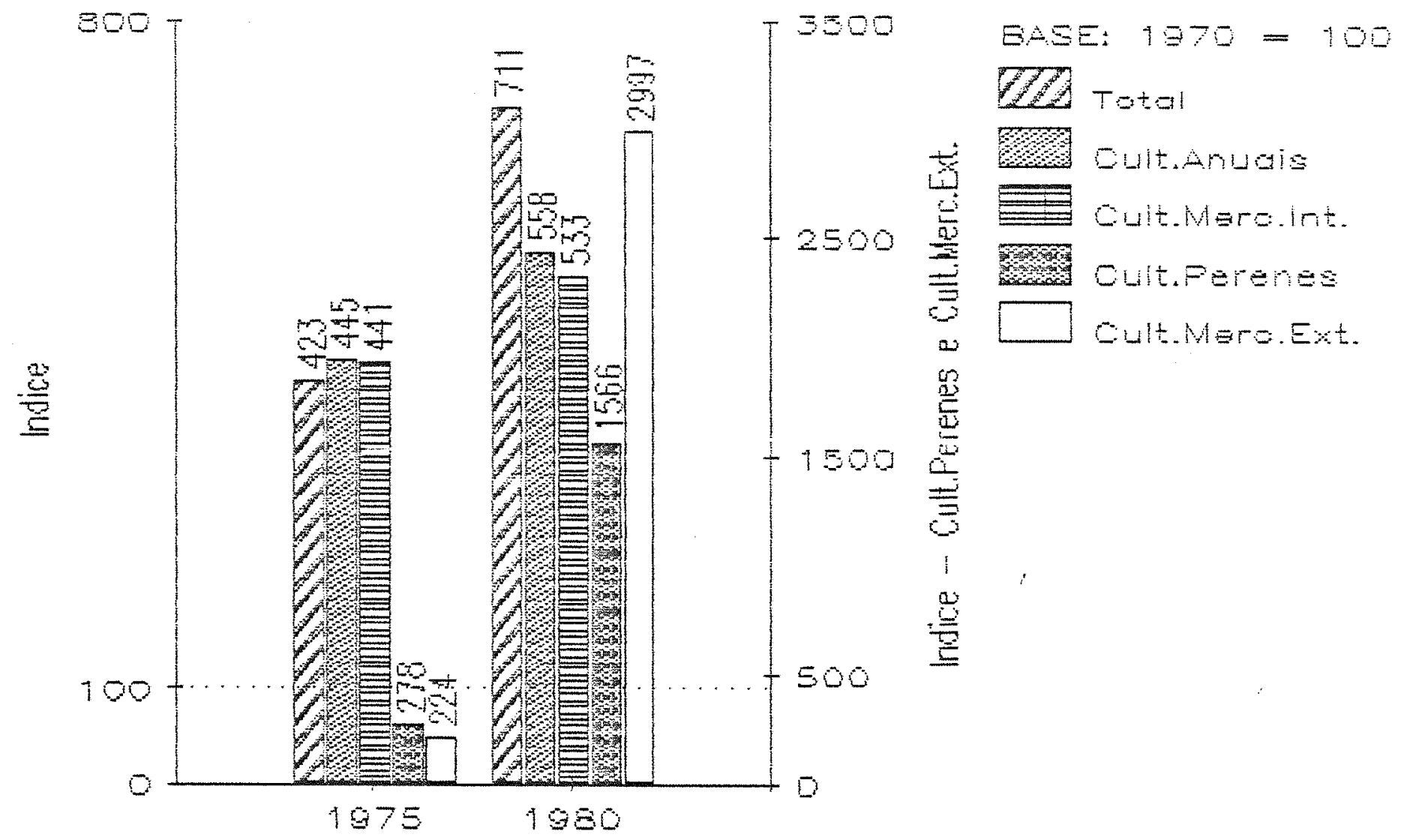

Fig. 43. - Evolução da Produção Agrīcola. Territōrio de Rondōnia, 1970-80.

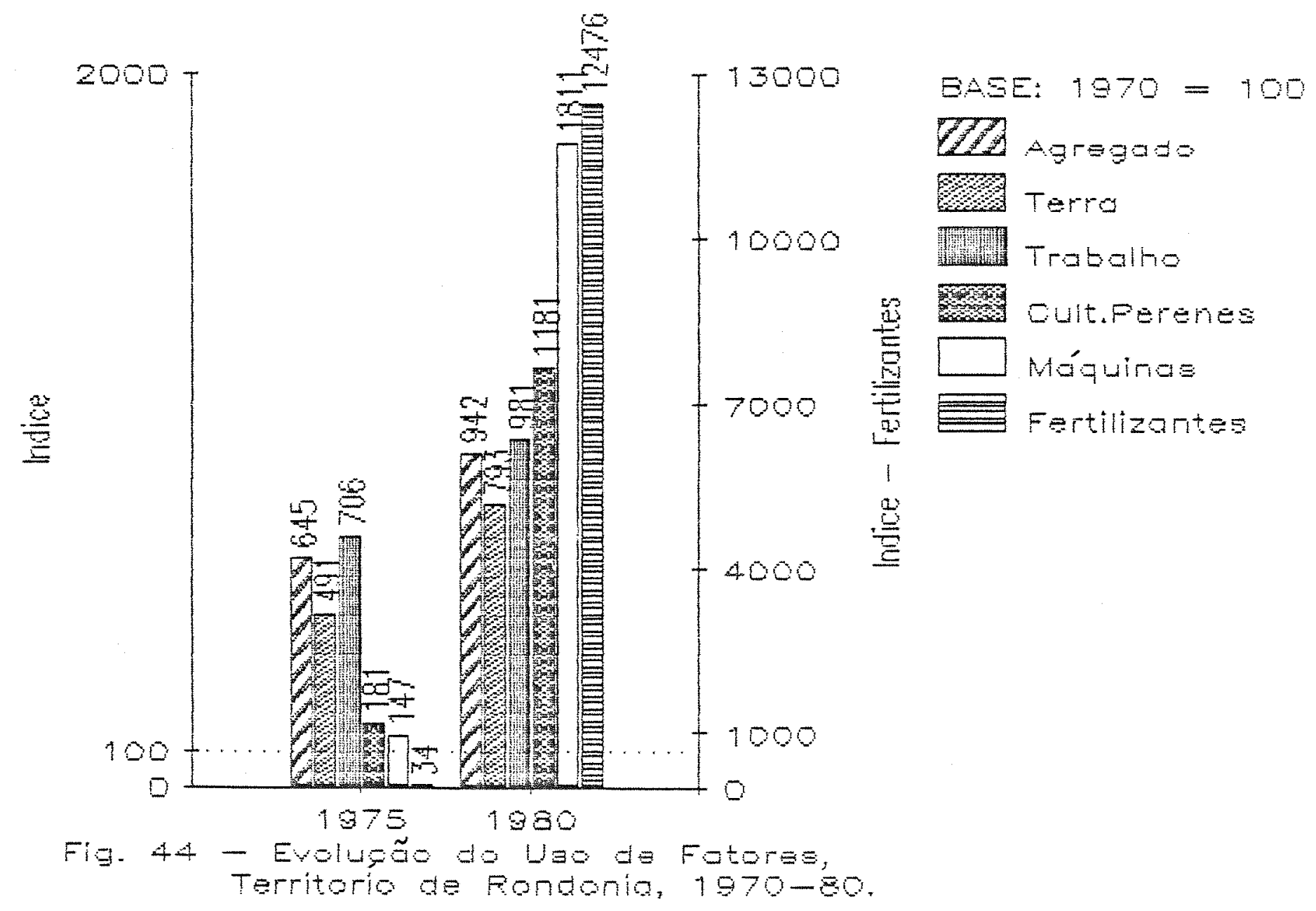




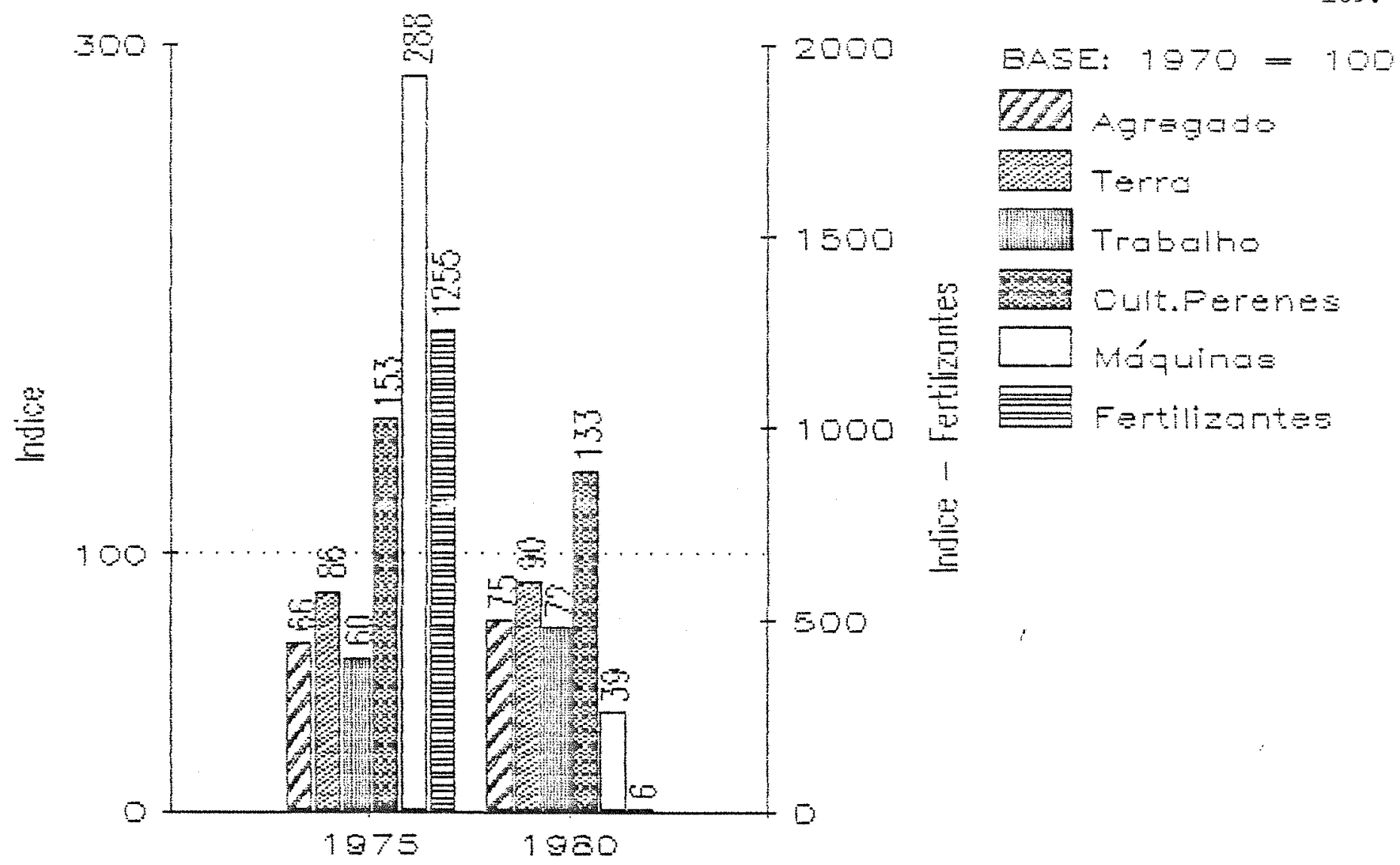

ヨ. 45 - Evoluda da Produtidade de Fatores.

Territorio de Fondonia, 1970-E0.

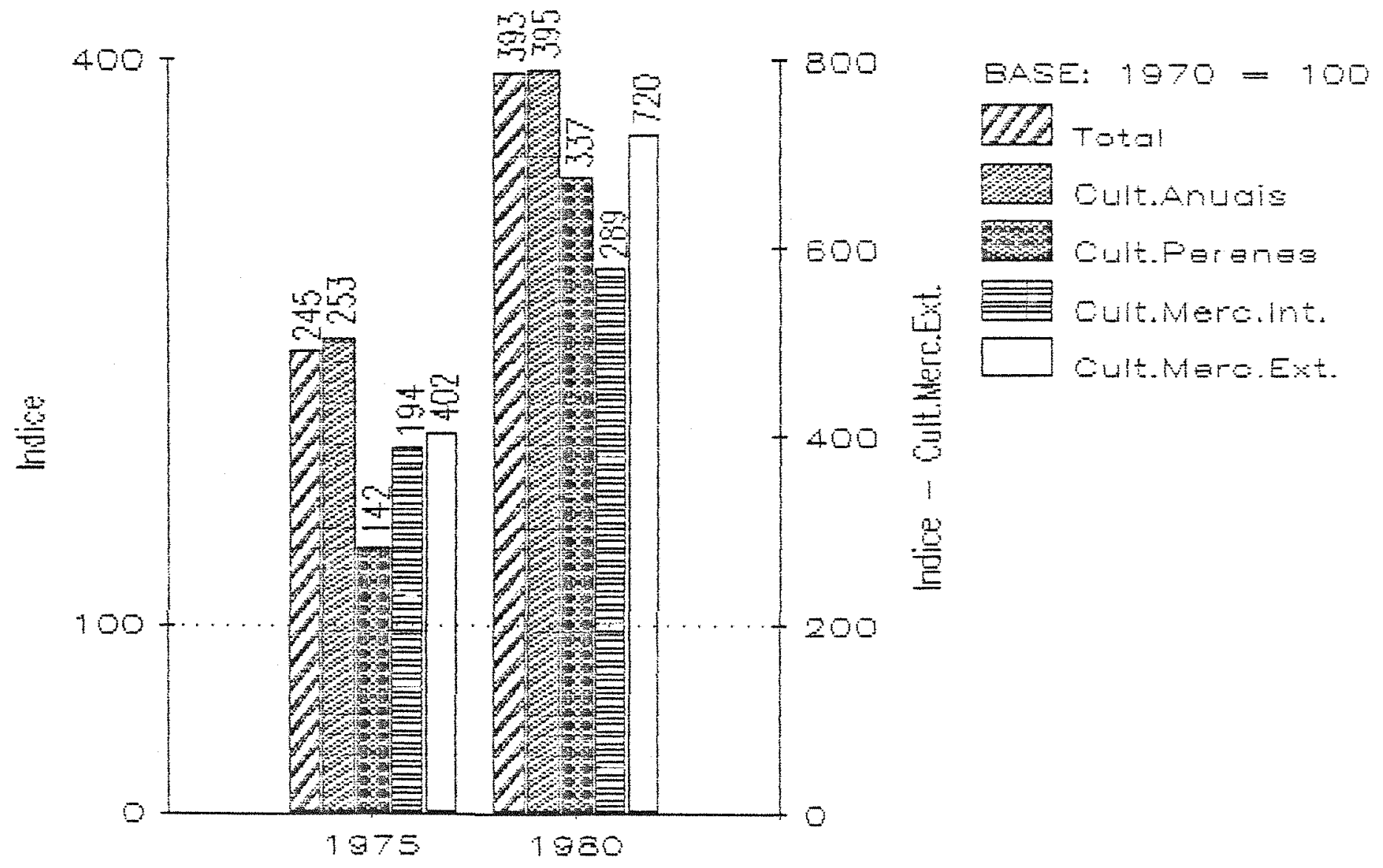

Fig. 46. - Evolução da Produção figrícola, Estado de Mato Grosso, 1970-80. 
A.2.16. Mato Grosso

Entre 1970 e 1975, a produção agrícola do Estado do Mato Grosso mais que dobrou, com as culturas de soja, arroz e, em menor escala, milho e algodão apresentando grande crescimento de produção. Entre 1975 e 1980, o indice de produção agregada cresceu mais de 50\%, fixando-se em nivel quatro vezes superior ao de 1970, com as culturas de cana-de-açúcar e soja experimentando os maiores aumentos de produção. o uso de fatores intensificou-se tanto entre 1970 e 1975 como entre 1975 e 1980, com exceção do trabalho, que decresceu entre 1975 e 1980, enquanto que os fatores máquinas e fertilizantes Iideraram os aumentos.

A produtividade de fatores aumentou nos dois periodos, tendo os indices parciais de produtividade do trabalho triplicado entre 1970 e 1980. É interessante observar que a terra aumentou de produtividade tanto entre 1970 e 1975 como entre 1975 e 1980, apesar da intensificação do uso desse fator (figuras 46, 47 e 48).

A.2.17. Distrito Federal

No Distrito Federal os indices de produção agrícola agregada apresentaram em 1975 e, principalmente, em 1980, niveis superiores aos observados em 1970, com crescimento, nesses períodos, das produçóes de 


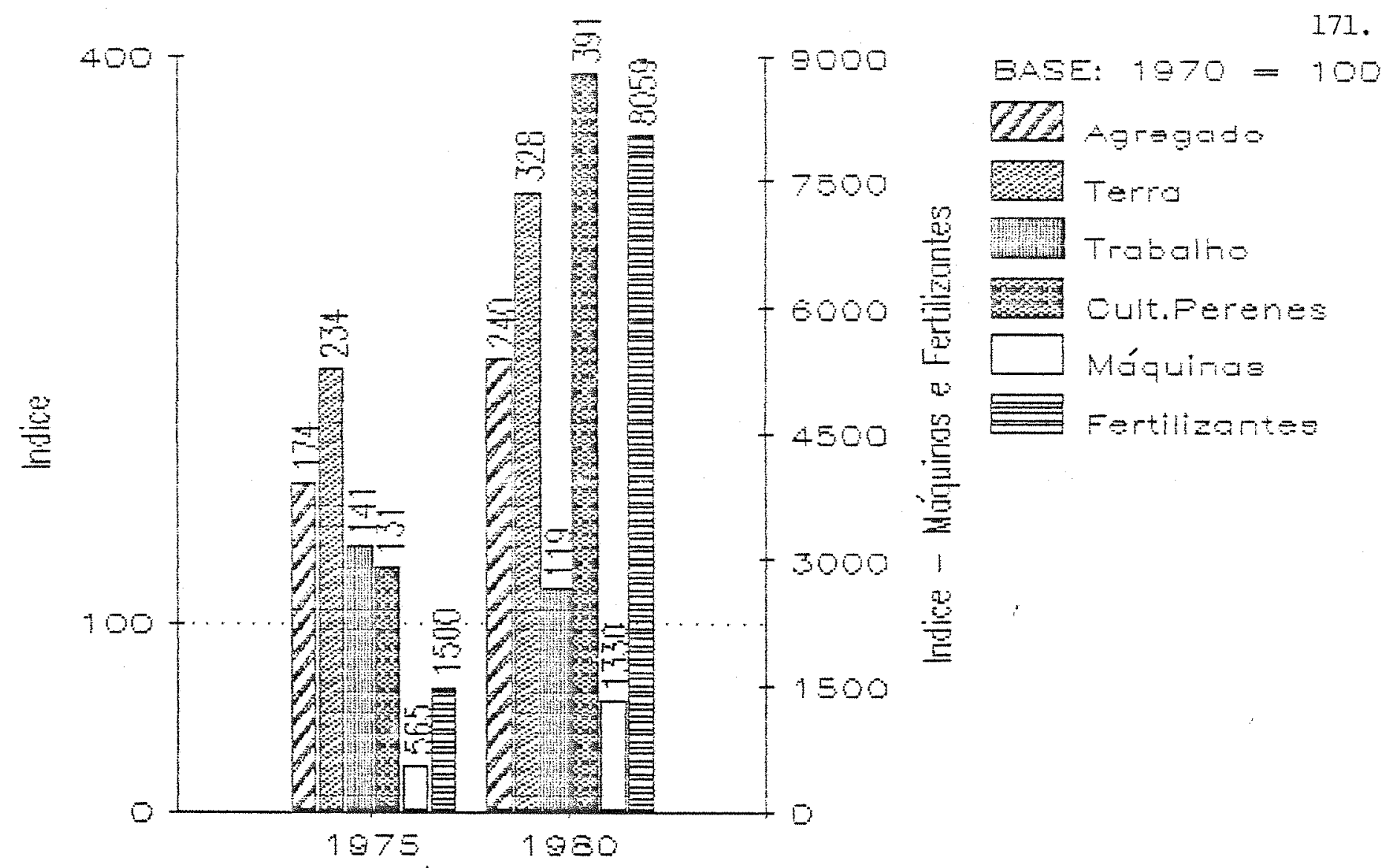

Fig. 47 - Evolugad do Uas de Fatores. Estado do Mato Srosso. $1970-30$.

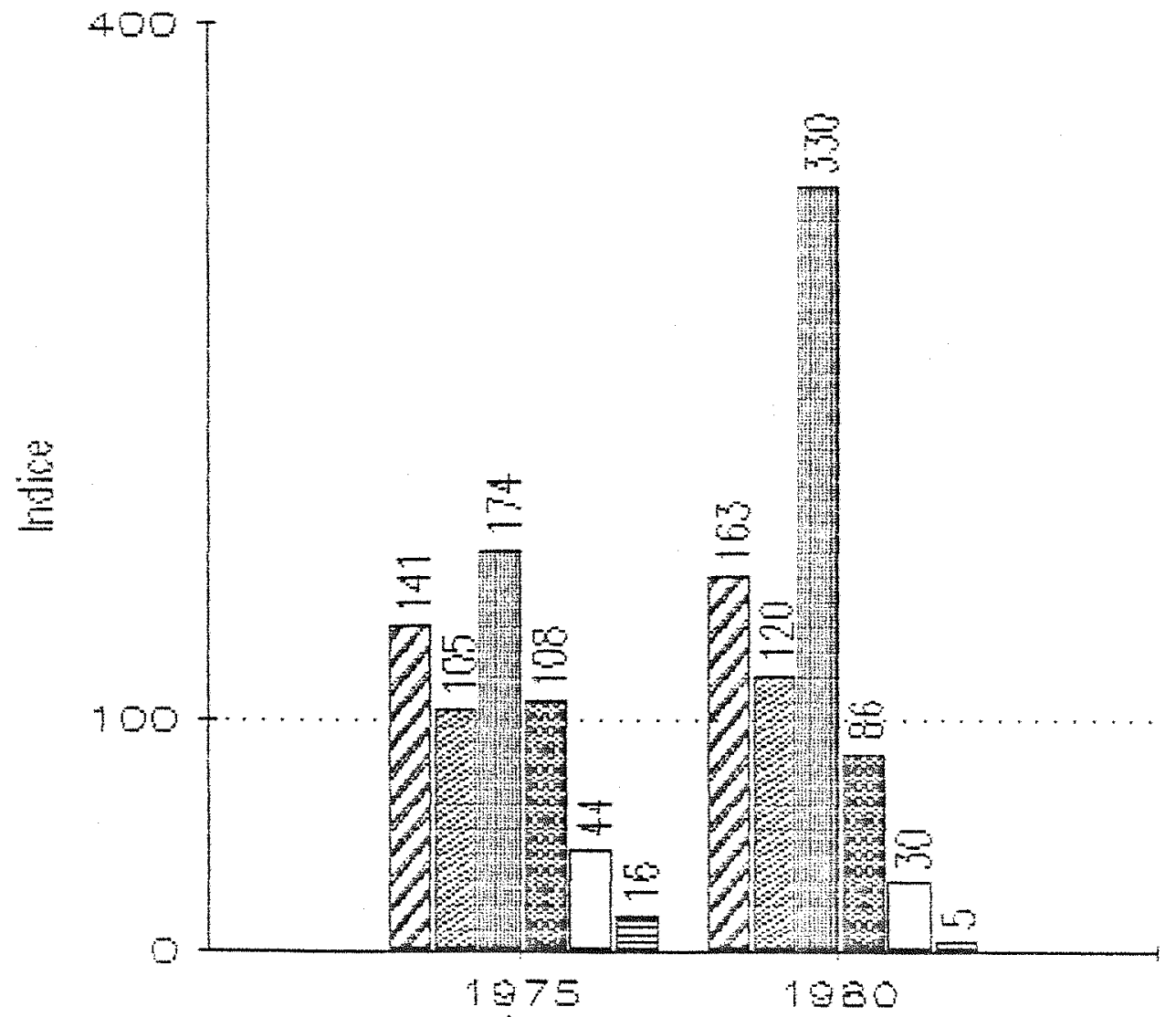

BASE: $1970=100$ QL Agrsgads 福 Terro

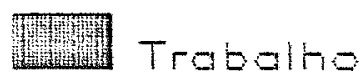

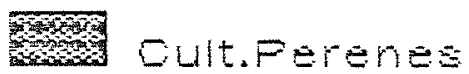
$\square$ Máquines Eertilizantes

Fig. 48 - Evoluba do Produtidade de Fotorea, Estado de Mato Grosso. 1970-30. 
soja, arroz e milho. O uso de fatores seguiu a mesma tendència, com máquinas, fertilizantes e terra liderando os aumentos.

A produtividade de fatores atingiu em 1975 marcas cerca de 50\% superiores às de 1970, tendo experimentado alguma queda entre 1975 e 1980; o fator terra apresentou entre 1970 e 1975 ganhos de produtividade que năo se repetiram entre 1975 e 1980 (figuras 49, 50 e 51).

\section{A.2.18. Goiás}

Entre 1970 e 1975, a produção agricola do Estado de Goiás cresceu quase que uniformemente nos quatro grupos de produtos, apesar da queda das culturas perenes, uma vez que o aumento na produção de cana foi mais do que compensado pelas diminuiçôes na mandioca, banana e laranja; das culturas anuais, os maiores aumentos ocorreram em milho, soja e arroz. Já entre 1975 e 1980, os indices apresentaram comportamentos distintos, uma vez que as culturas de mercado externo cresceram bem mais que as de mercado interno, graças ao aumento de produçäo da soja. o uso de fatores mostra aumento em termos agregados nesses dois periodos, puxado pelos aumentos nos indices parciais de máquinas, fertilizantes e terra; o trabalho apresentou em 1980 nivel inferior aos atingidos em 1975 e 1970.

A produtividade de fatores elevou-se tanto entre 1970 e 1975 como entre 1975 e 1980 , com o indice parcial do trabalho apresentando os maiores aumentos 


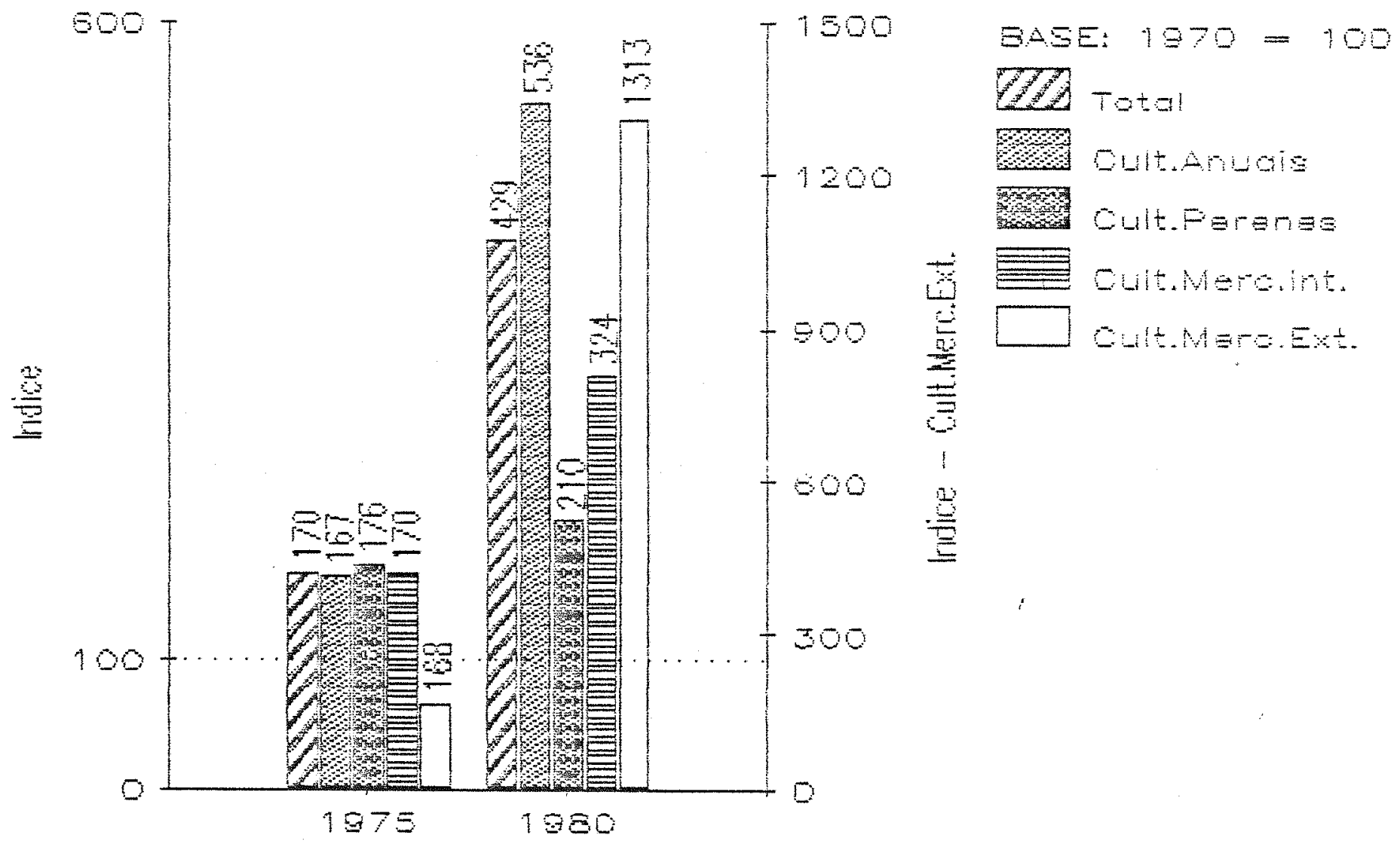

Fig. 49. - Evolução da Produção Agricola, Distrito Federa1, 1970-80.

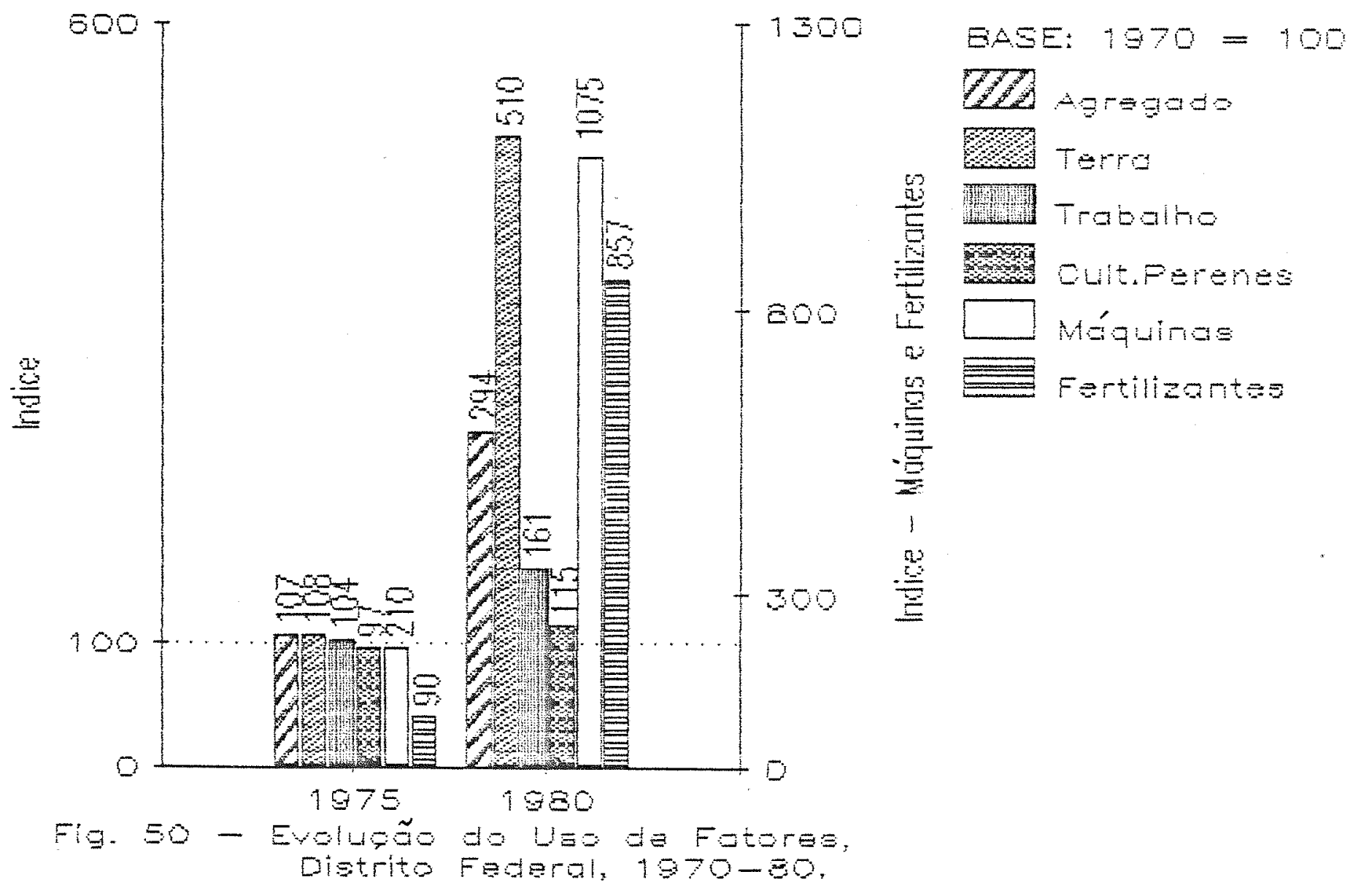




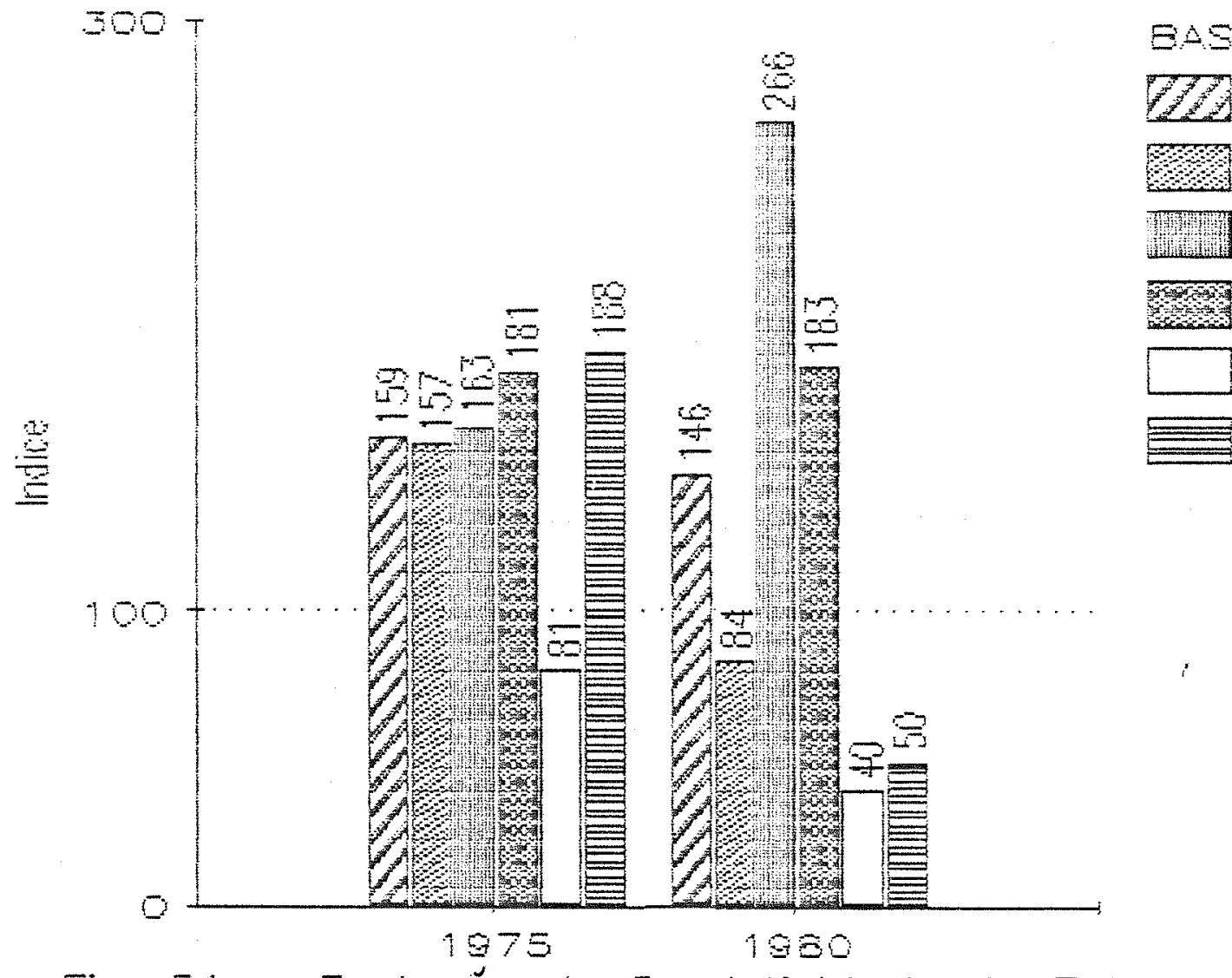

s: $1970=100$

$\Delta-9 r a g d 0$

$\forall$ Terro

Heiln Trabalte

Dutcopenes

Méquinas

Fertilizantes

Fig. E1 - Evolupdo da Frodutvidode de Fotoras, Distrito Federal, $1970-80$.

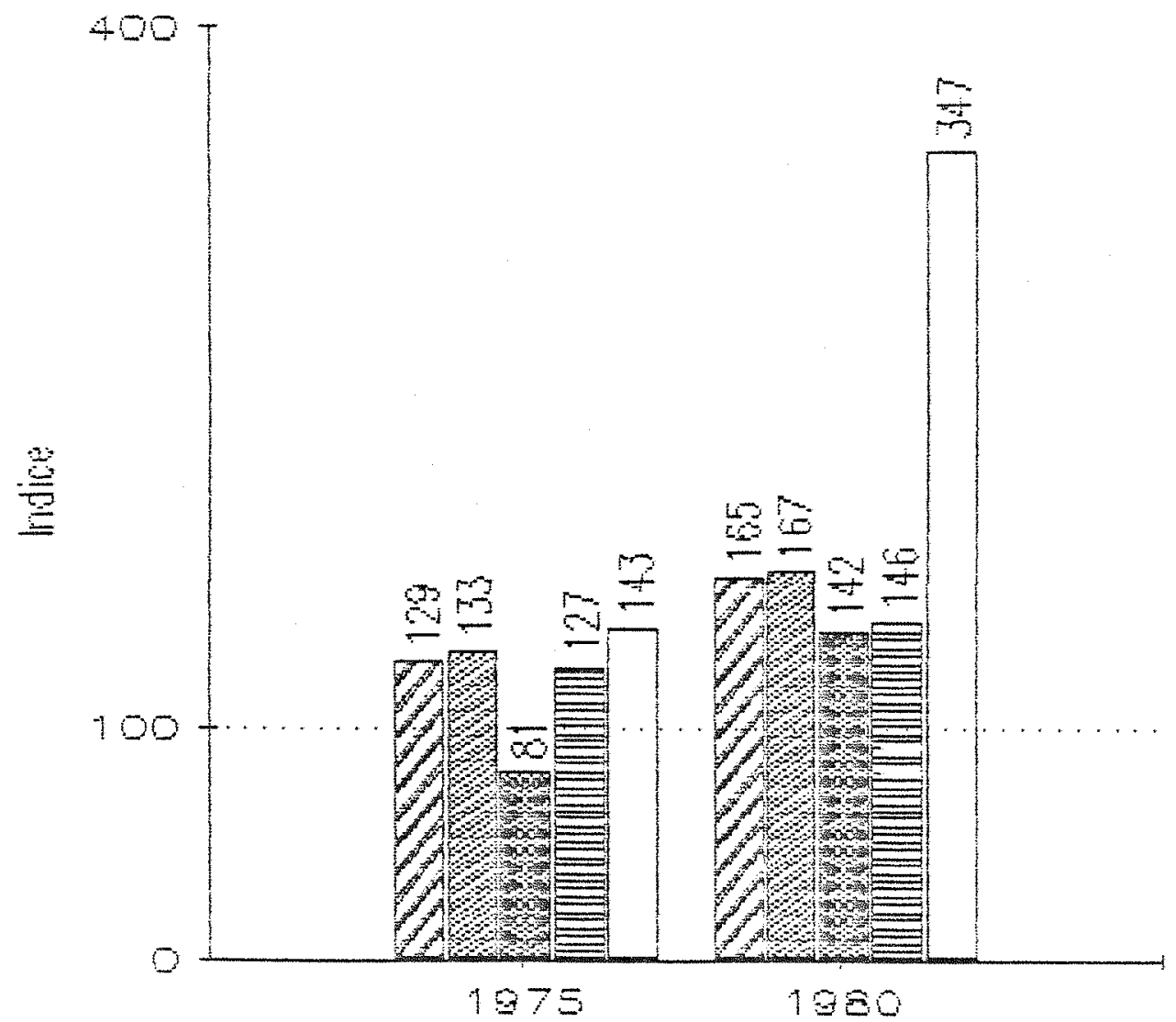

BASE: $1970=100$ $\mathbb{Z U}$ Total

₹⁄ cut.Anugis X. Cut.Ferengs ¿ult.Meroint. $\square$ cult.Mero.Ext.

Fig. 52. - Evolução da Produção Agrícola, Estado de Coiās, 1970-80. 
e ofator terra mantendo comportamento próximo ao do índice agregado (figuras 52,53 e 54 ).

\section{A.2.19. Minas Gerais}

- Estado de Minas Gerais, após apresentar decréscimo na produçăo agrícola entre 1970 e 1975, recuperou-se no período 1975-80, com aumentos nas produçốes de cana, café, laranja, milho, feijäo e batata, principalmente. 0 uso de fatores manteve-se estagnado entre 1970 e 1975 e cresceu entre 1975 e 1980 , em termos agregados.

- indice de produtividade agregada foi inferior, em 1975, ao de 1970, enquanto que em 1980 esteve em nível superior aos desses dois anos, com o indice parcial de trabalho apresentando os maiores ganhos do periodo (figuras 55,56 e 57).

\section{A.2.20. Espirito Santo}

Entre 1970 e 1975 o Estado do Espirito Santo apresentou queda na produção agrícola, devido, principalmente, a menores produçöes de café, banand, milho e mandioca; essa situação reverteu-se entre 1975 e 1980 , quando café, cacau, feijäo e banana, os principais produtos agrícolas do Estado, aumentaram de produçăo. o uso de fatores mostrou, em termos agregados, relativa estagnaçăo entre 1970 e 1975 e, crescimento entre 1975 e 1980, com intensificações nos fatores máquinas e fertilizantes, 

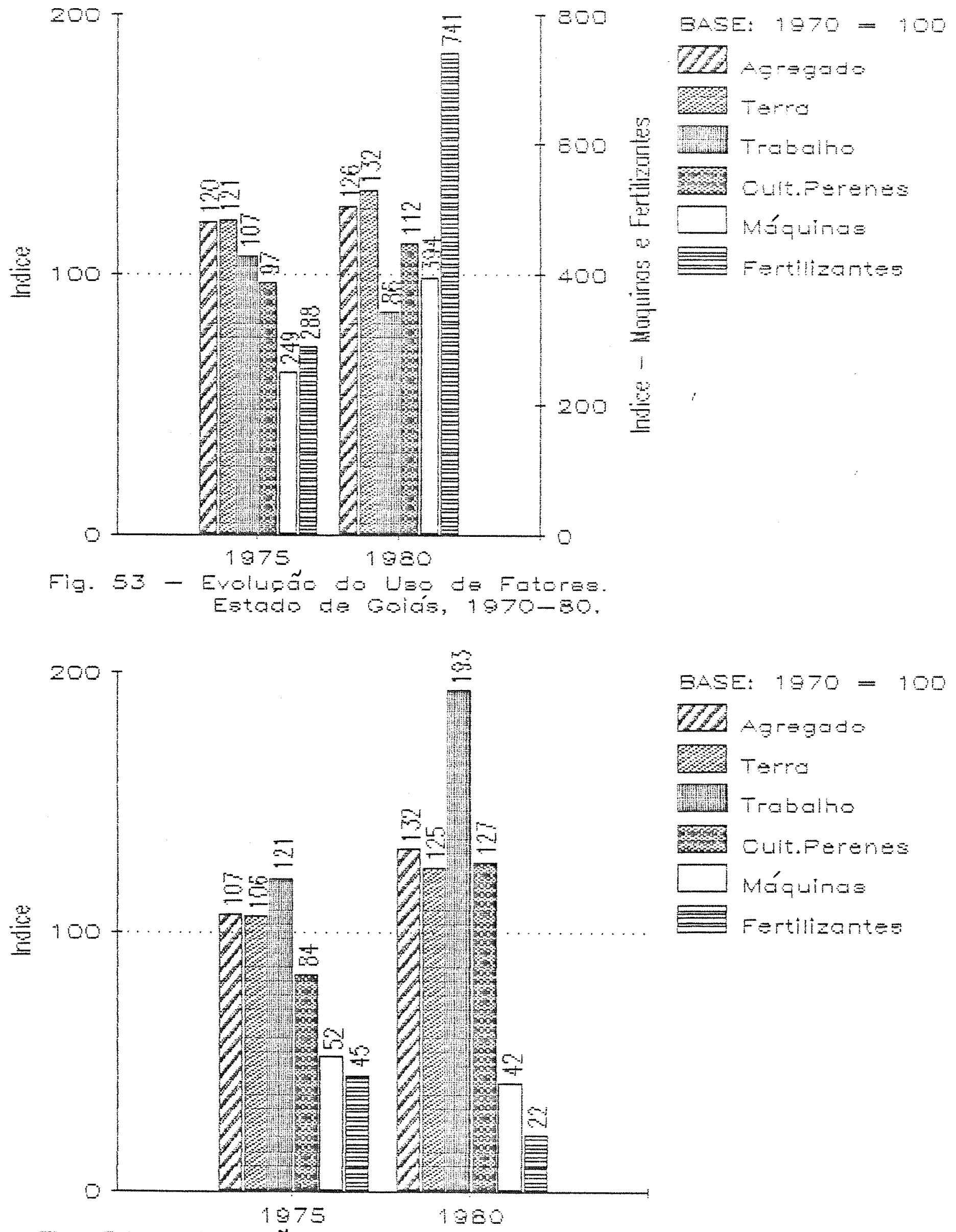

Fig. 54 - Evolupa da Produtridade de Fotores;

Estado de Golós, $1970-30$. 


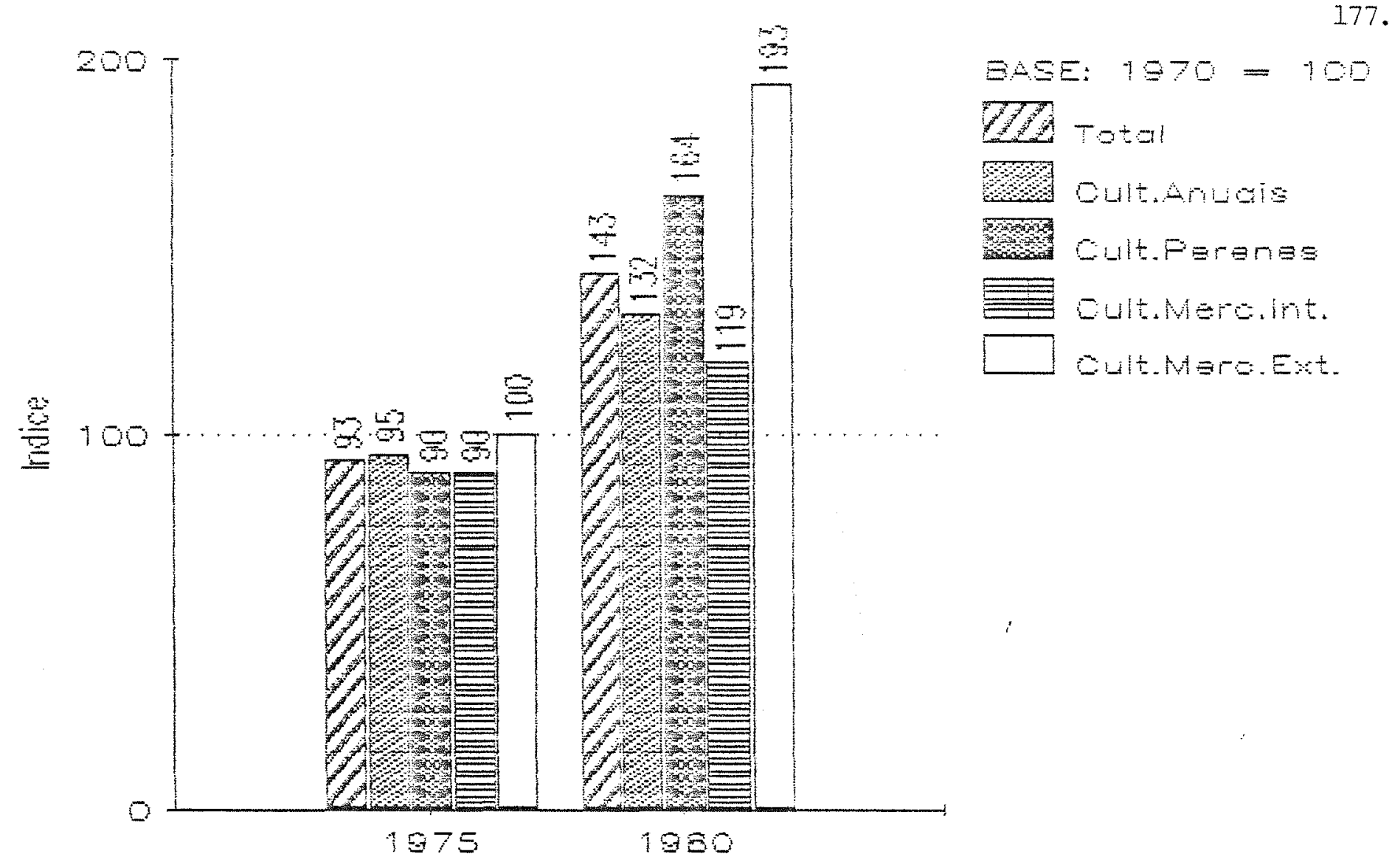

Fig. 55. - Evolução da Produção Agrícola, Estado de Minas Gerais, 1970-80.

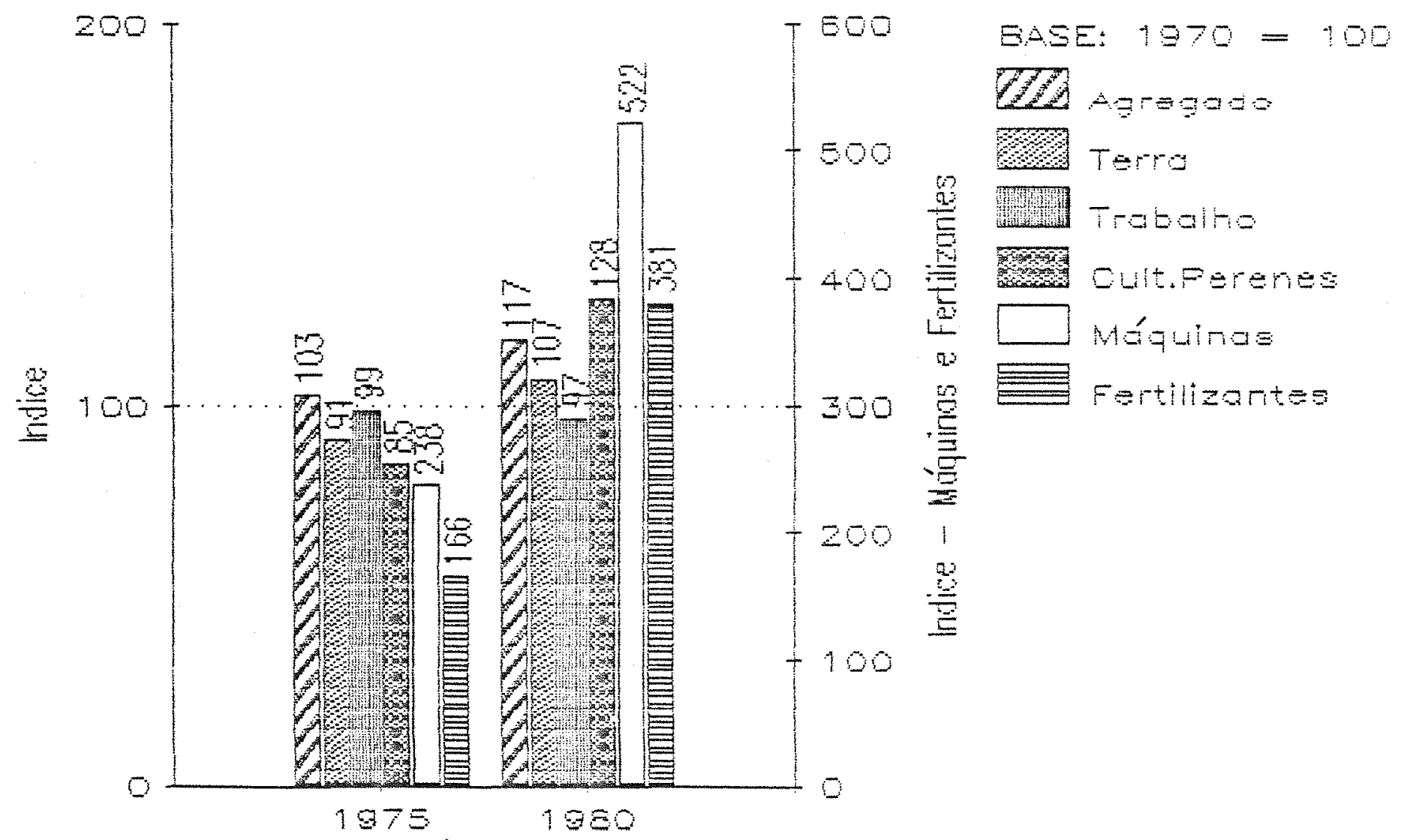

Fig. Se - Evolupdo do Uso da Fotores,

Estado de Minde Gerais, $1970-80$. 


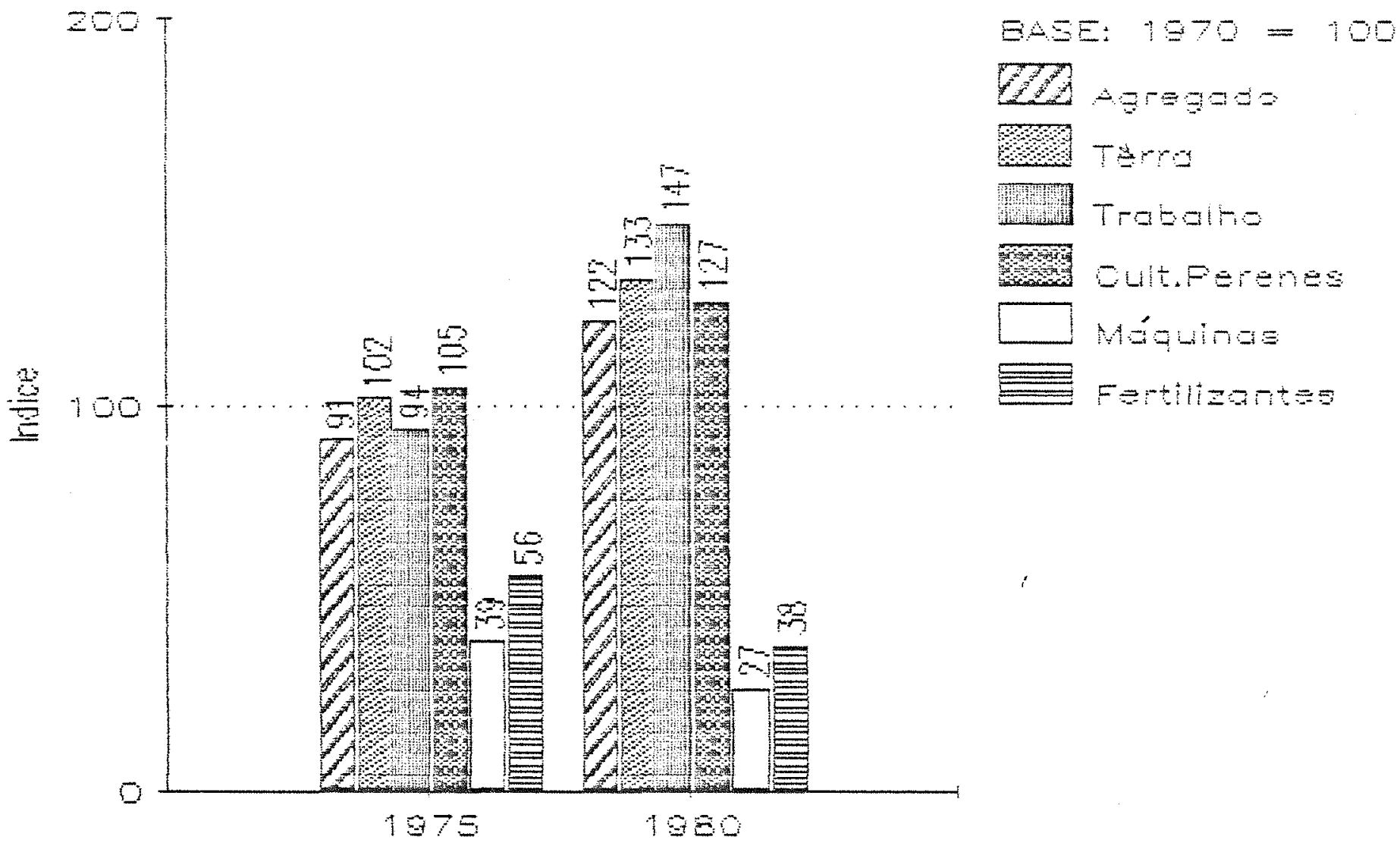

Fig. 57 - Evoluga do Froduthdode de Fotores. Estado de Miras Gergis, $1970-80$.

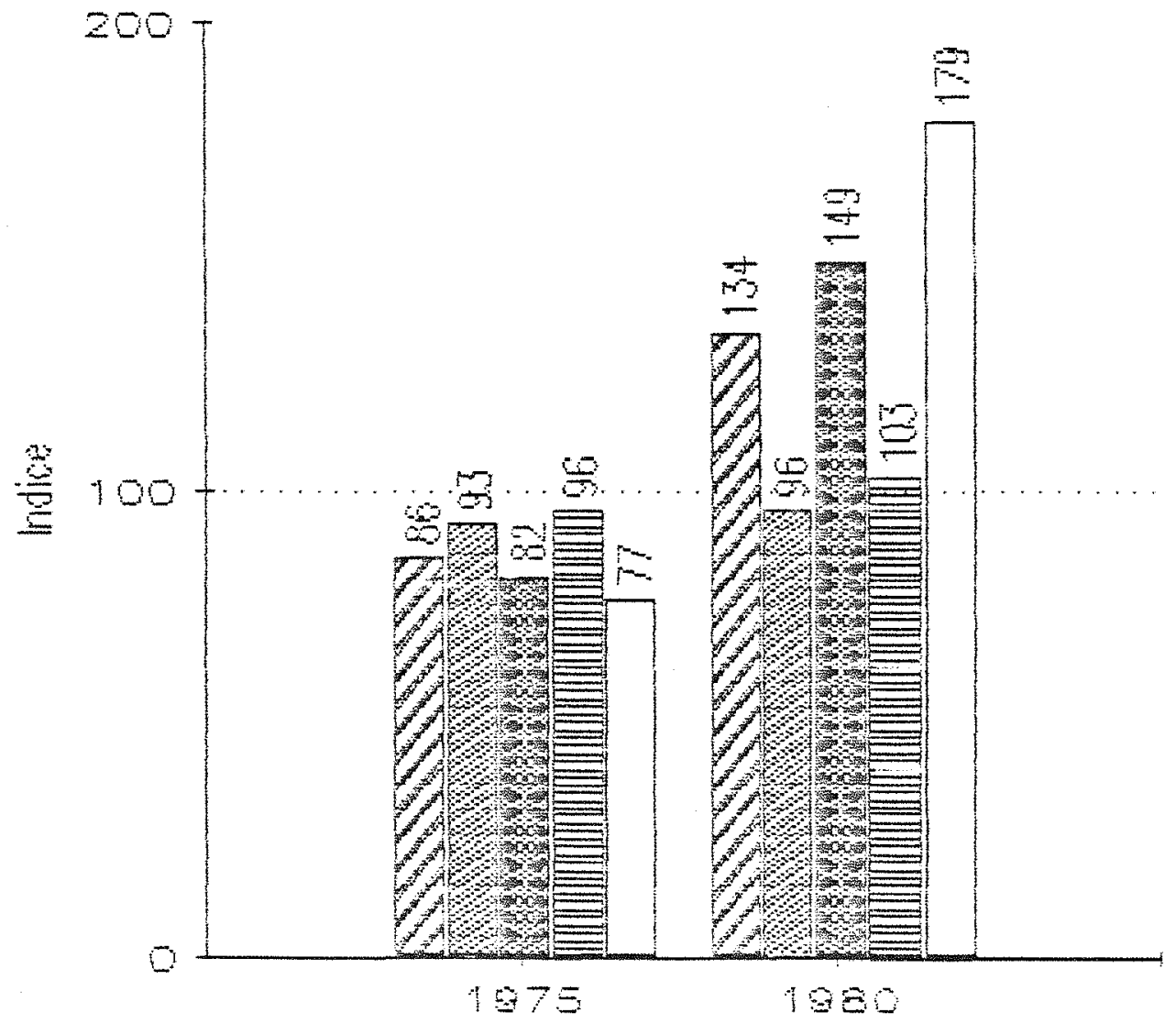

EASE: $1970=100$ Q2D Total

\$\% Gut.anudis

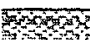

Wuit.Ferenea

Eut.Meroint.

$\square$ Cult.Mare.Ext.

Fig. 58. - Evolução da Produção Agrīcola, Estado do Espịirito Santo, 1970-80. 
principalmente.

A produtividade de fatores, após decréscimo entre 1970 e 1975, apresentou em 1980 nível praticamente igual ao de $1970(+5 \%)$, com $\circ$ indice parcial de produtividade da terra crescendo a taxas superiores as do trabalho e dos investimentos em culturas perenes (figuras 58,59 e 60 ).

\section{A.2.21. Rio de Janeiro}

No período 1970-75, a produçăo agrícola do Estado do Rio de Janeiro diminuiu cerca de $20 \%$, situaçấo que se manteve estável entre 1975 e 1980; nas principais culturas do Estado, aconteceram quedas nas produções de laranja, banana e tomate, com aumento em cana-de-açúcar. o uso de fatores manteve-se em 1975 e em 1980 abaixo do nivel observado em 1970, tanto no agregado como nos índices parciais, com exceçăo das máquinas, que cresceram naqueles dois períodos.

A produtividade dos fatores, em relação a 1970, atingiu níveis menores tanto em 1975 como em 1980; as exceções foram os fatores terra e, em 1975, investimentos em culturas perenes $(61,62$ e 63$)$.

\section{A.2.22. São Paulo}

$\begin{array}{ll} & \text { Em São Paulo, a produçắ agricola } \\ \text { agregada cresceu entre } 1970 \text { e } 1975 \text { e entre } 1975 \text { e 1980, } \\ \text { especialmente as culturas perenes e de mercado externo, }\end{array}$



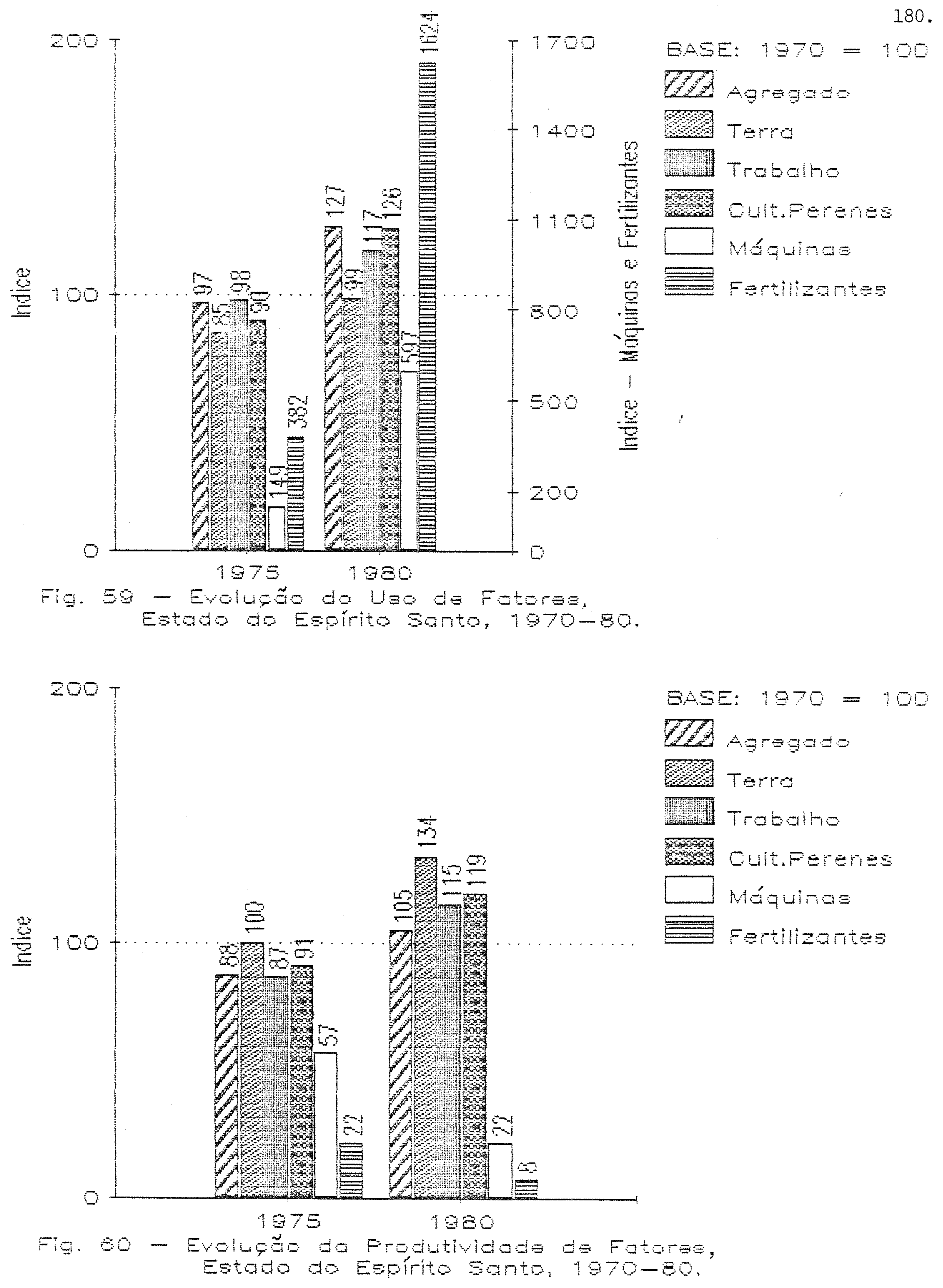


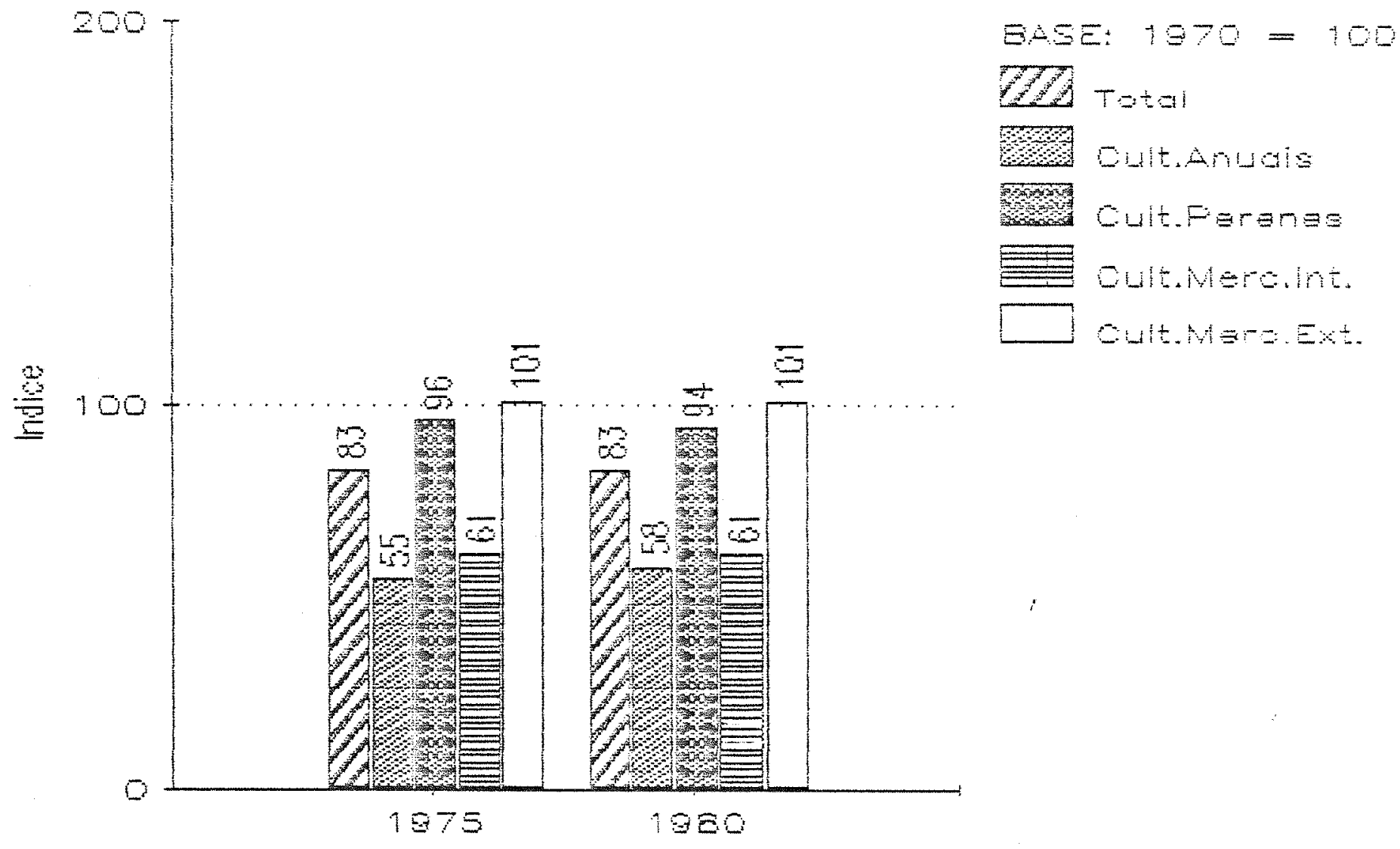

Fig. 61. - Evolução da Produção Agrícola, Estado do Rio de Janeiro, 1970-80.

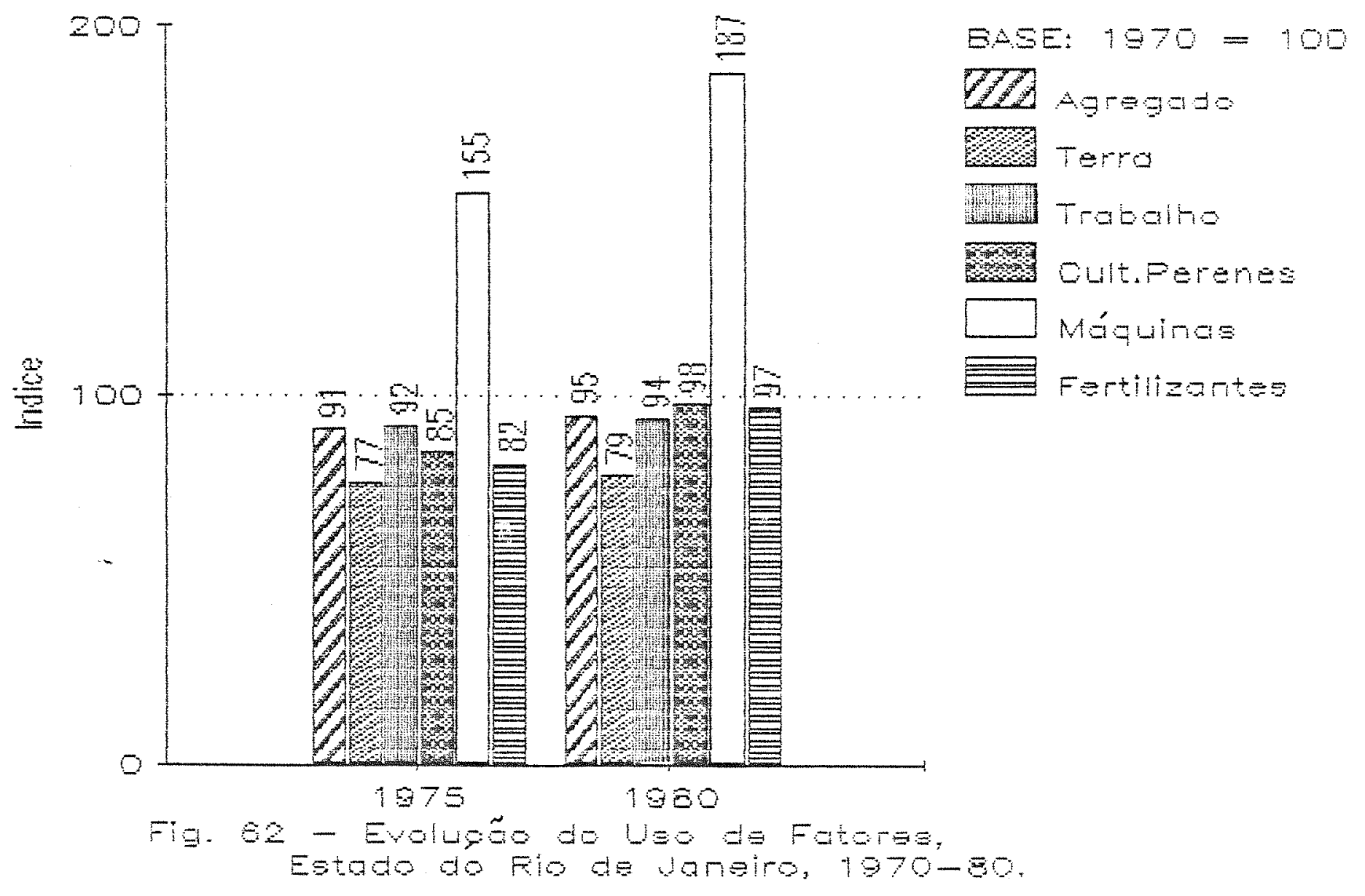




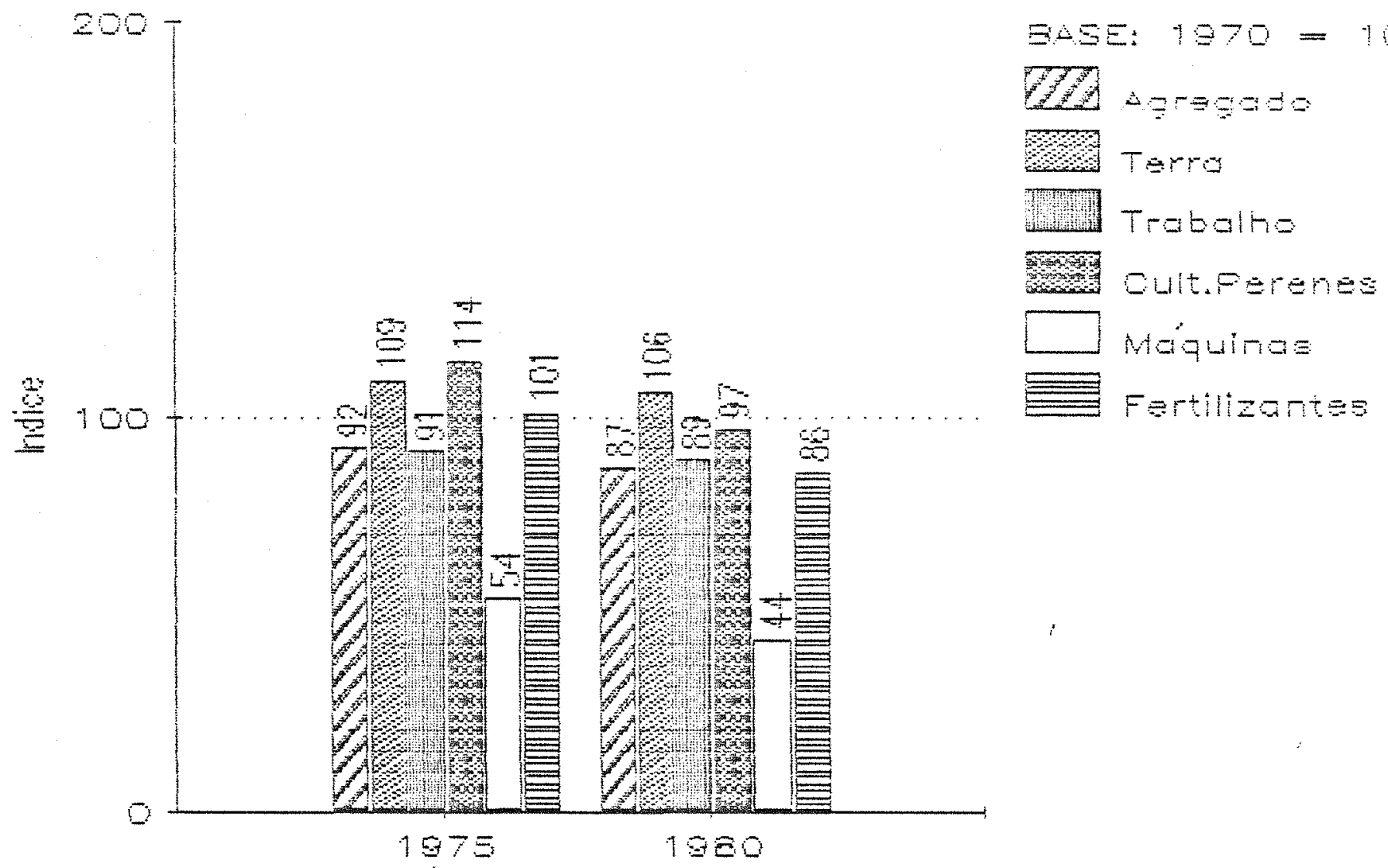

Fig. oz - Evolucad da Frodutidade da Fotoras.

Etado do fio de laneiro, $1970-30$.

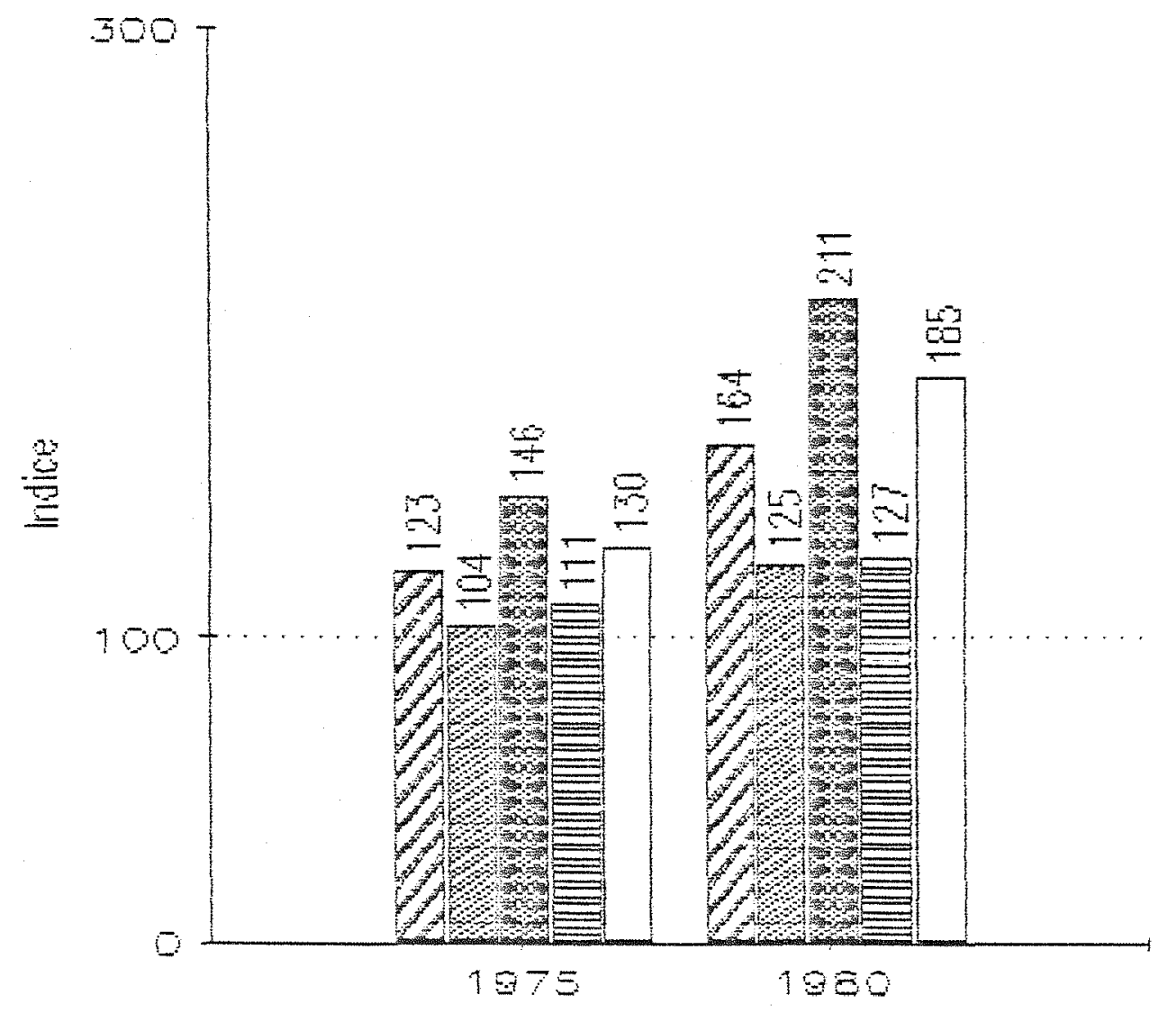

$B A B: 1970=100$ $22+0+a$

\&\& Gult.Anuals Whalt.Fingren Eut.Moromt. $\square$ Cut.MEr Ext.

Fig. 64. - Evolução da Produção Agrīcola, Estado de São Paulo, 1970-80. 
impulsionadas pelo comportamento da cana, café, laranja e soja; além dessas, o feijấo também apresentou crescimento, enquanto o milho e o algodão decresceram. A utilização de fatores decresceu ligeiramente entre 1970 e 1975 , em termos agregados, comportamento que se alterou entre i975 e 1980, com crescimento de cerca de 15\% no periodo 1970-80; ao contrário dos demais Estados, em são Paulo o fator fertilizantes, por ser largamente empregado já em 1970, apresentou crescimento menor do que os investimentos em culturas perenes, com esse último indice refletindo, principalmente, a maior área cultivada com cana-de-açúcar e laranja.

A produtividade de fatores atingiu tanto em 1975 como em 1980, niveis superiores a 1970, com o Indice de produtividade parcial do trabalho praticamente dobrando entre 1970 e 1980; 0 indice de produtividade parcial da terra seguiu de perto o comportamento do indice agregado (figuras 64,65 e 66 ).

\section{A.2.23. Paraná}

No Estado do Parará, a produçăo agrícola agregada mais do que dobrou entre 1970 e 1980 ; entre 1970 e 1975 a queda na produção do feijẫo e a estabilidade na de milho, foi mais do que compensada pelos aumentos na soja, no trigo e, principalmente, no café, enquanto que, entre 1975 e 1980, apesar do crescimento da soja e do trigo, o indice agregado apresentou ligeira queda, devido a grande 


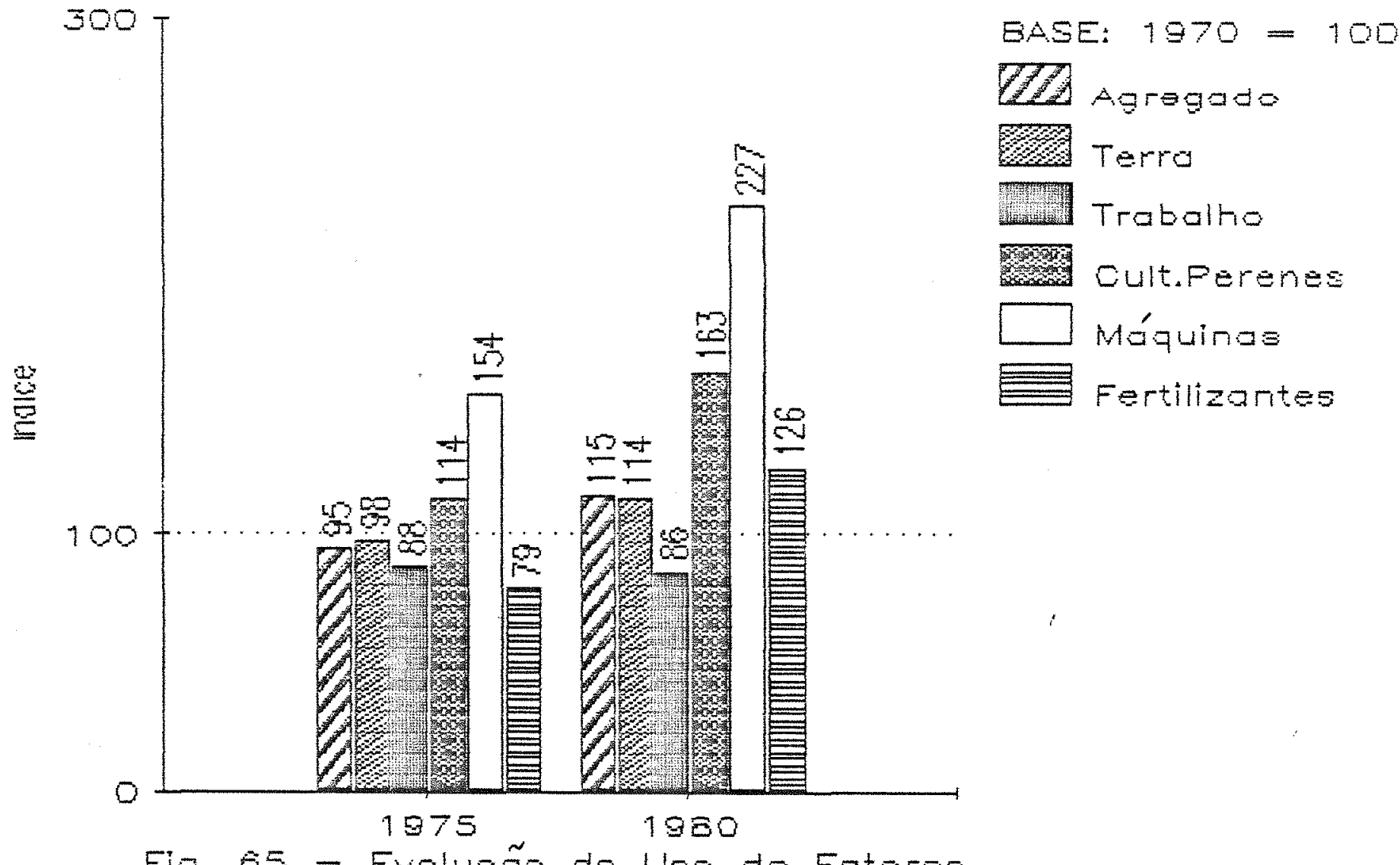

BASE: $1970=100$

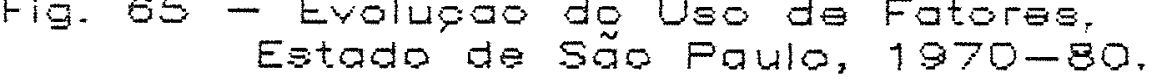

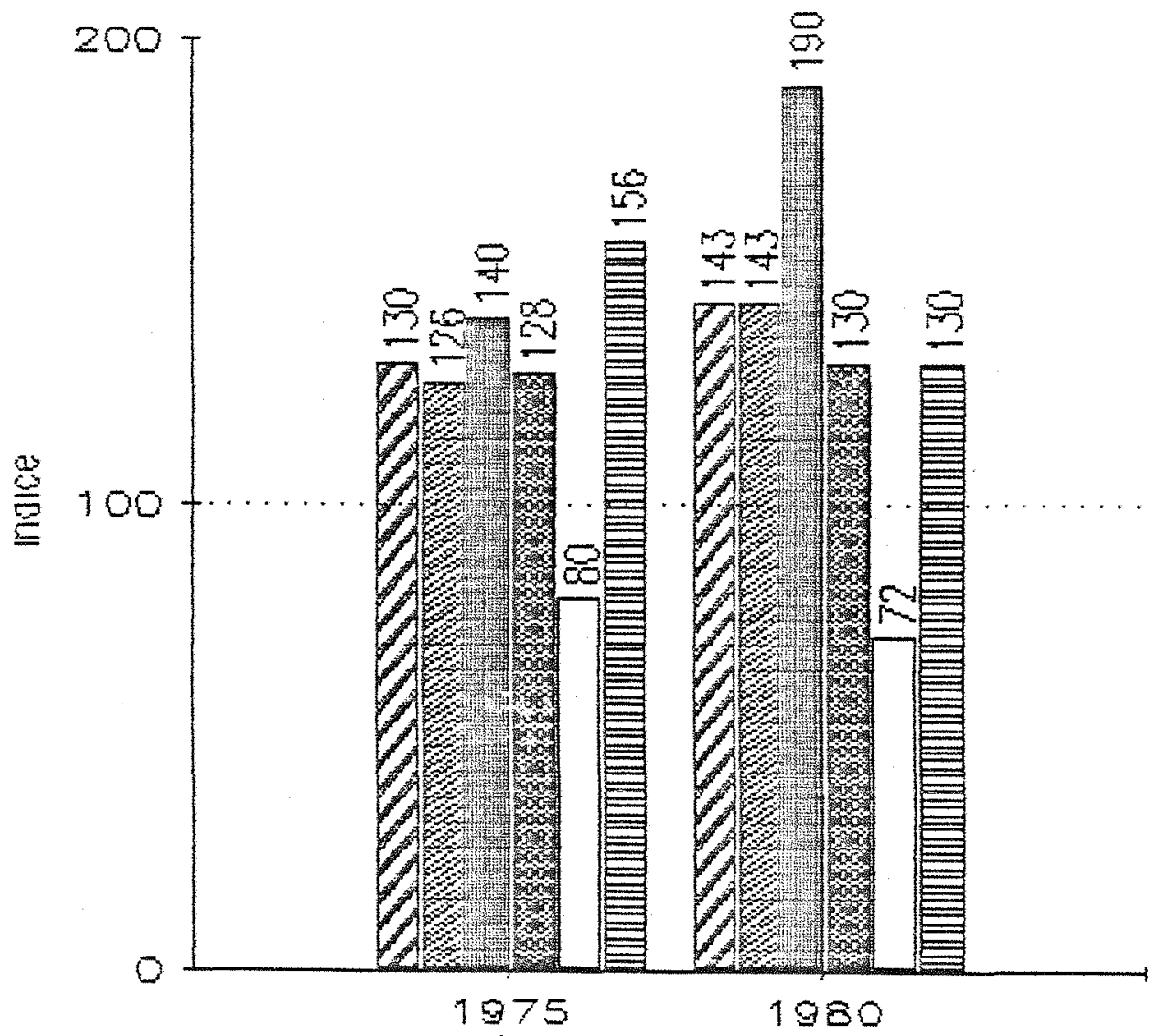

$B A S E: 1970=100$

QL Agregado

W. Terra

Mrobalho

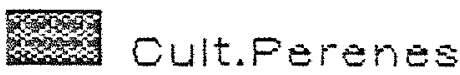

$\square$ Máquinas

Fertilizantes

Fig. $6 \epsilon$ - Evolugão da Frodutividada de Fotoras, Estado de São Paulo, 1970-30. 
diminuiçấo na produçấo do café. o uso de fatores manteve-se acima do observado em 1970, tanto em 1975 como em 1980, com o indice parcial de uso de máquinas apresentando o maior crescimento no periodo 1970-80.

A produtividacie de fatores quase dobrou entre 1970 e 1975, resultado que se manteve entre 1975 e 1980, com os investimentos em culturas perenes ie o trabalho apresentando os resultados mais expressivos (figuras 67,68 e 69).

\section{A.2.24. Santa Catarina}

Em Santa catarina a produçấo agrícola em 1975 e em 1980 atingiu niveis superiores aos de 1970, com aumento nas quantidades produzidas de milho, soja, feijăo e arroz, enquanto que a mandioca sofreu quedas nesses dois períodos. O uso de fatores, especialmente máquinas e fertilizantes apresentou o mesmo comportamento.

A produtividade agregada também se elevou, Iiderada pelas produtividades parciais do trabalho e culturas perenes (figuras 70,71 e 72).

\section{A.2.25 Rio Grande do SuI}

No Estado do Rio Grande do Sul, os aumentos da produção agrícola agregada observados entre 1970 e 1975 e, em menor escala, entre 1975 e 1980, refletiram, basicamente, os aumentos na produçăo de soja. o uso de fatores, em termos agregados, após atingir nivel 


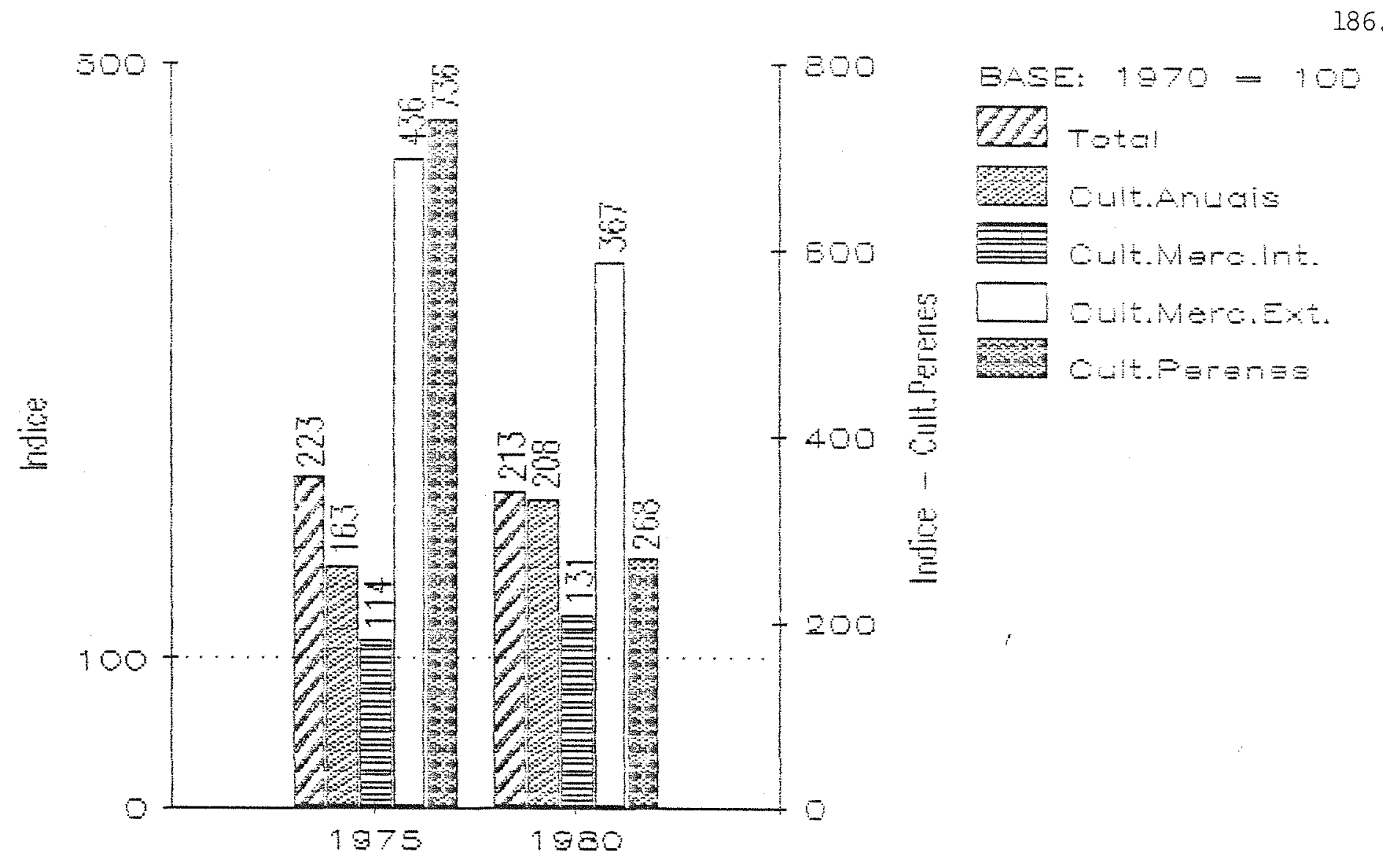

Fig. 67. - Evolução da Produção Agrīcola, Estado do Paranā, 1970-80.

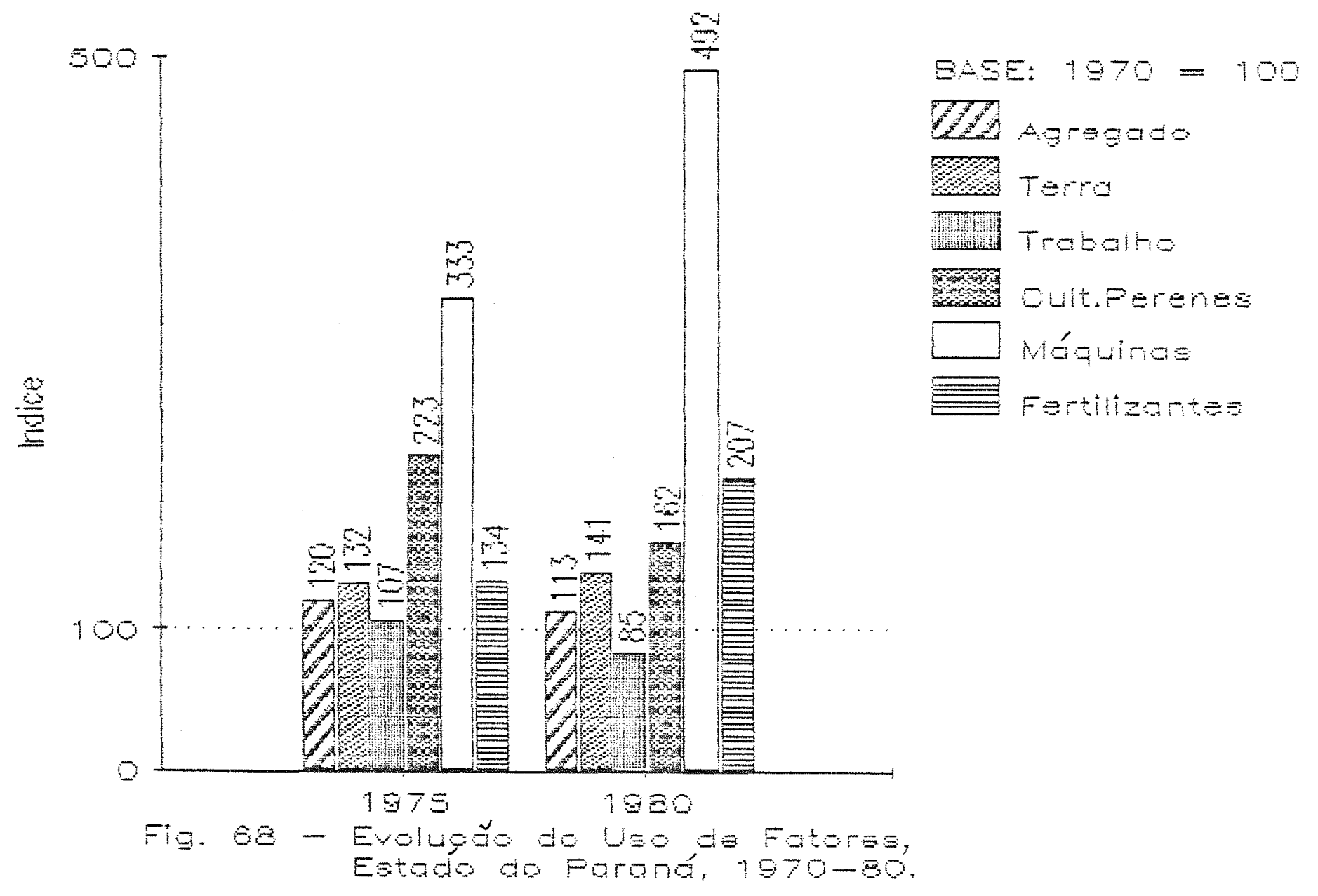




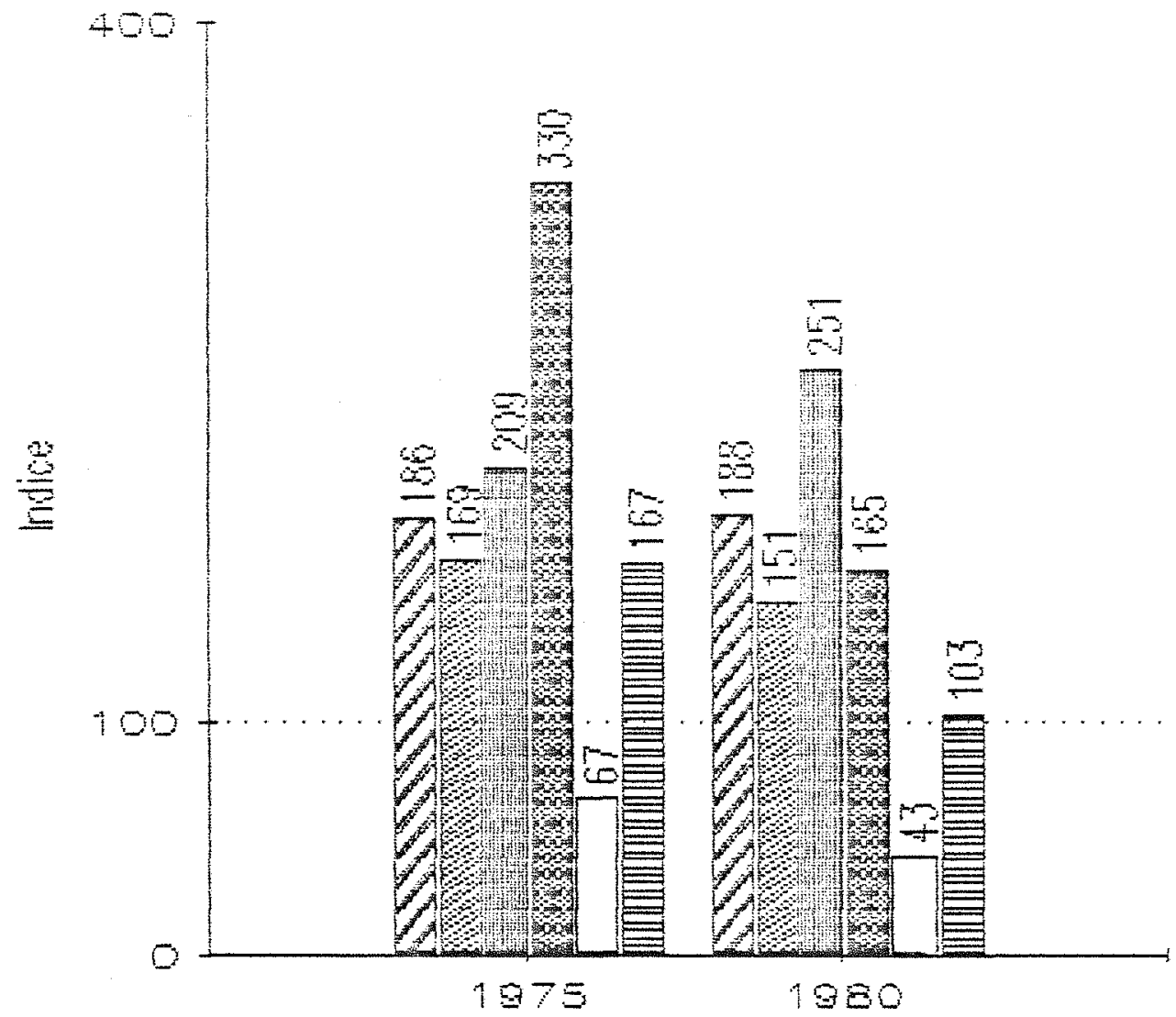

SASE: $1970=100$

272 - $250=0$

ชै Terra

का कासा

Unum Trabaino

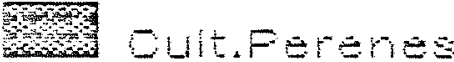

ए Máquines

Fertilartos

Fig. 69 - Evolupa do Produtidade de Fotoras.

Estado do parard, $1970-80$.

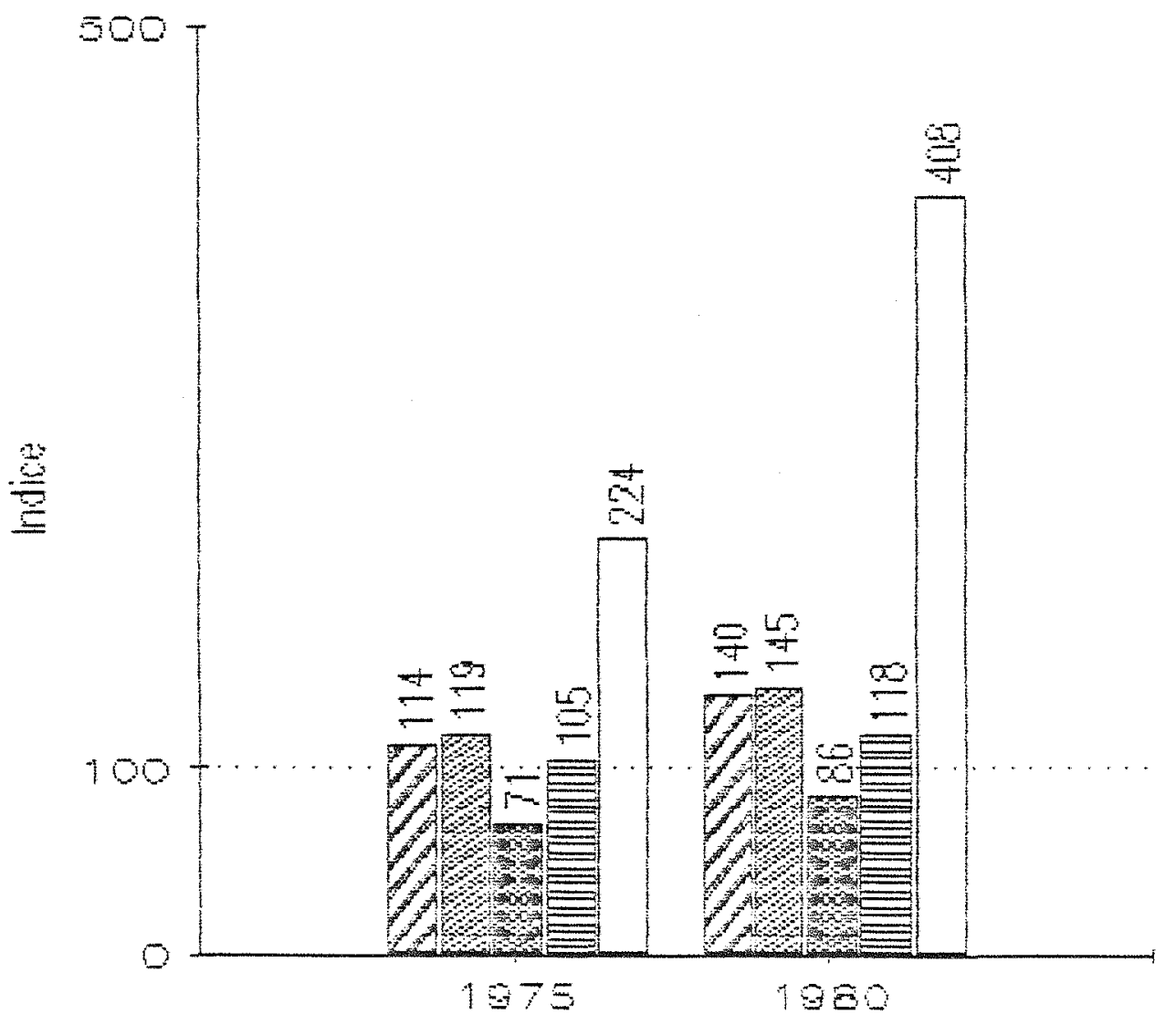

EASE: $1970=100$ ZZL $\mathrm{T}+\mathrm{+}=1$

8\% Qut.Anums

Prin out Faranga

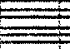

Eut.Mero.int.

$\square$ Cut.Mero.Ext.

Fig. 70. - Evolução da Produção Agrīcola, Estado de Santa Catarina, 1970-80. 


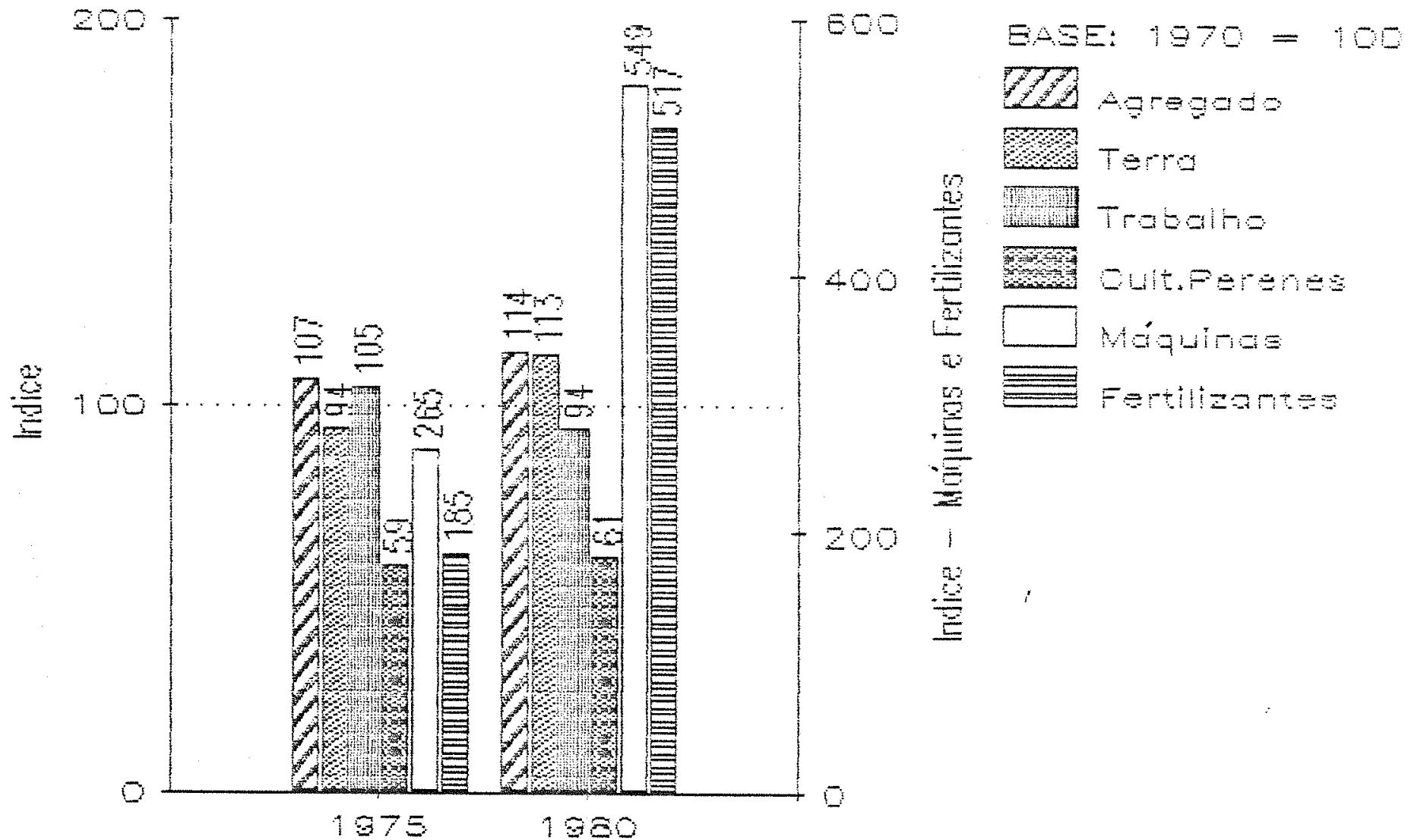

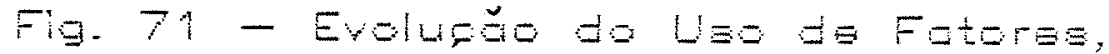

Estado de Santa Gotaring, $1970-30$.

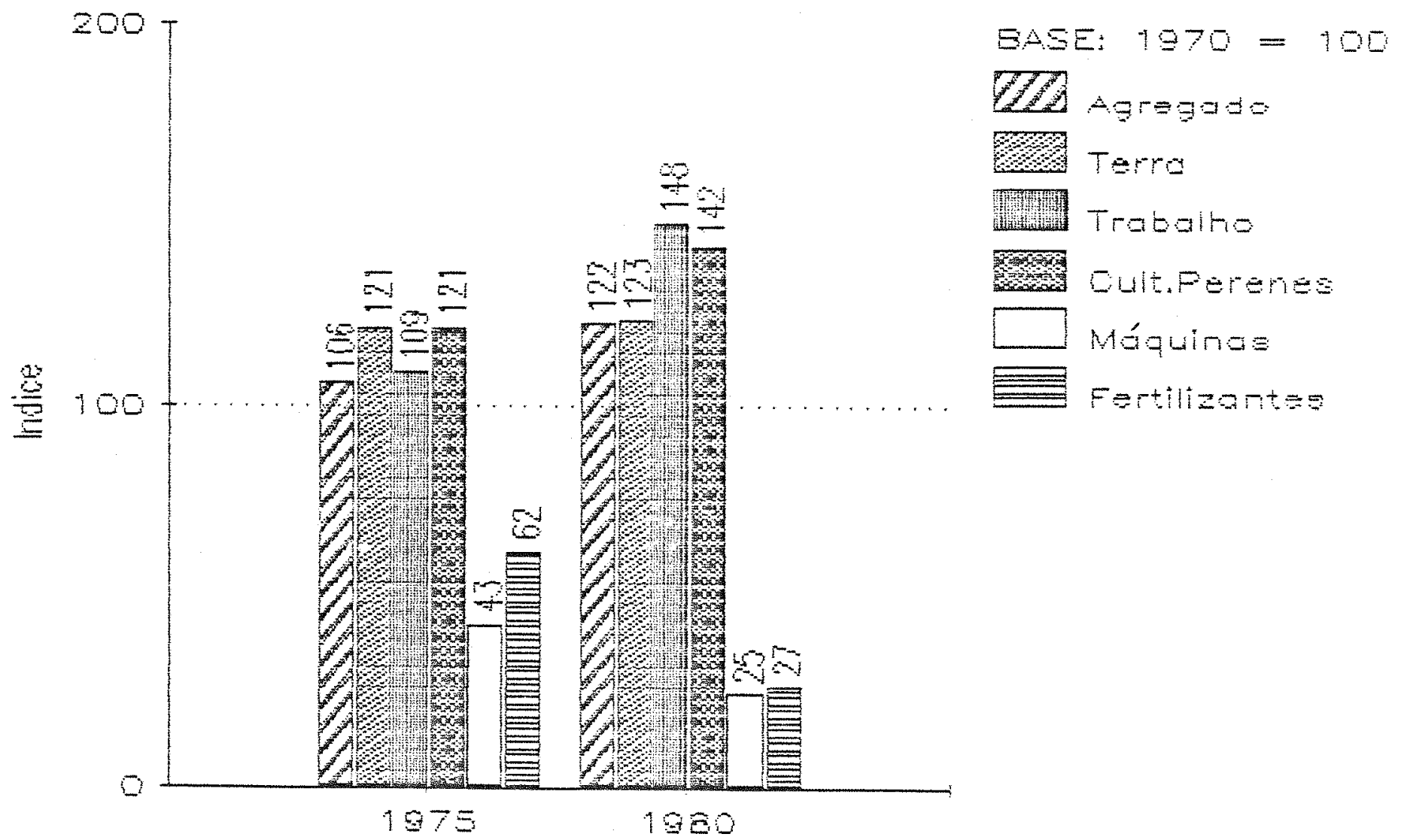

Fig. 72 - Evolupad do Produtidude de Fotorea,

Estads de Santo Eataring,1970-30. 
42\% superior ao de 1970 em 1975, manteve-se estável entre 1975 e 1980, com máquinas e fertilizantes apresentando os maiores indices de crescimento no periodo 1970-80.

A produtividade agrícola, tanto entre 1970 e 1975, como entre 1975 e 1980, experimentou Iigeiro crescimento, destacando-se o comportamento dos fatores trabalho e terra (figuras 73,74 e 75). 


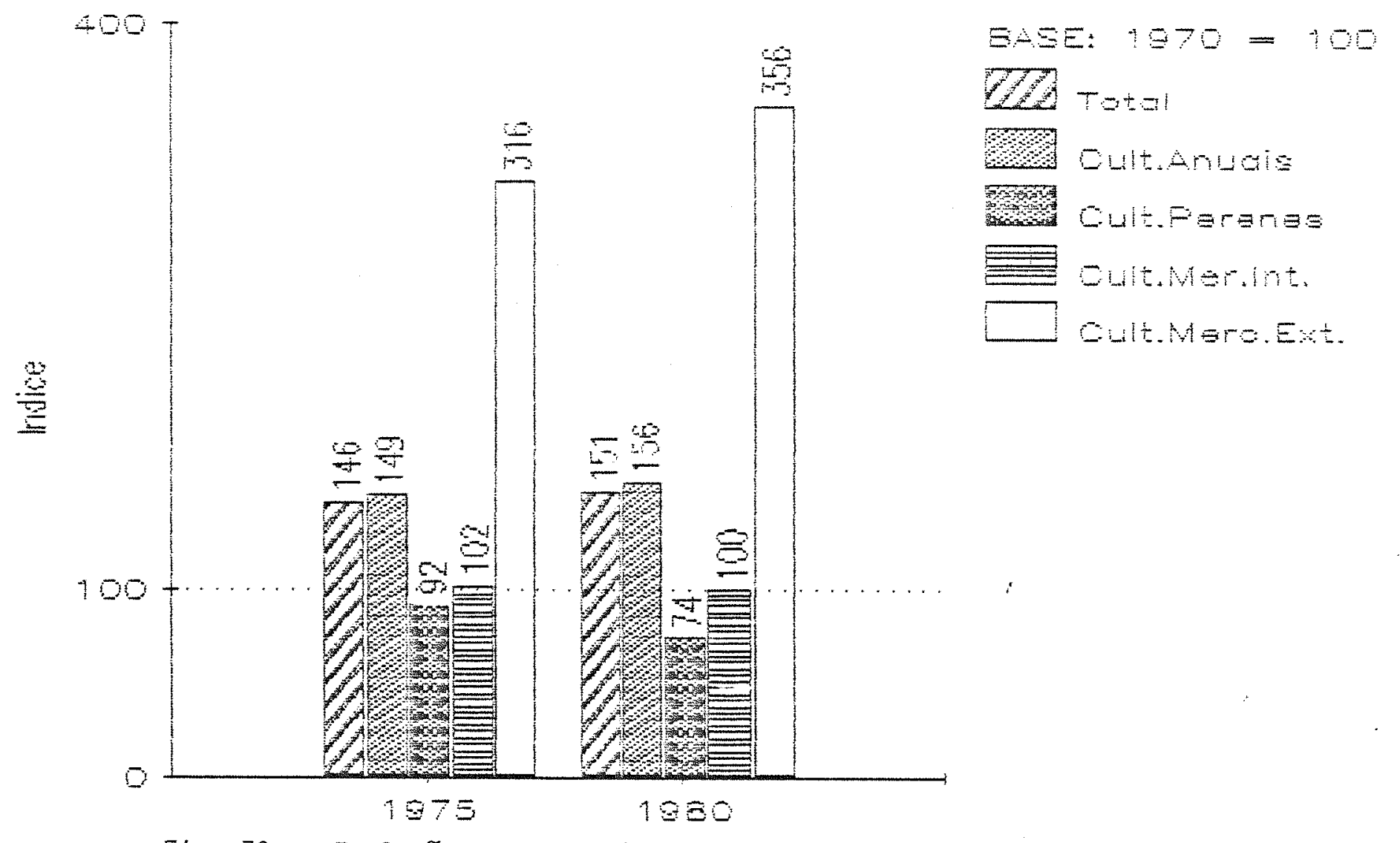

Fig. 73. - Evolução da Produção Agrícola, Estado do Rio Grande do Sul, 1970-80.

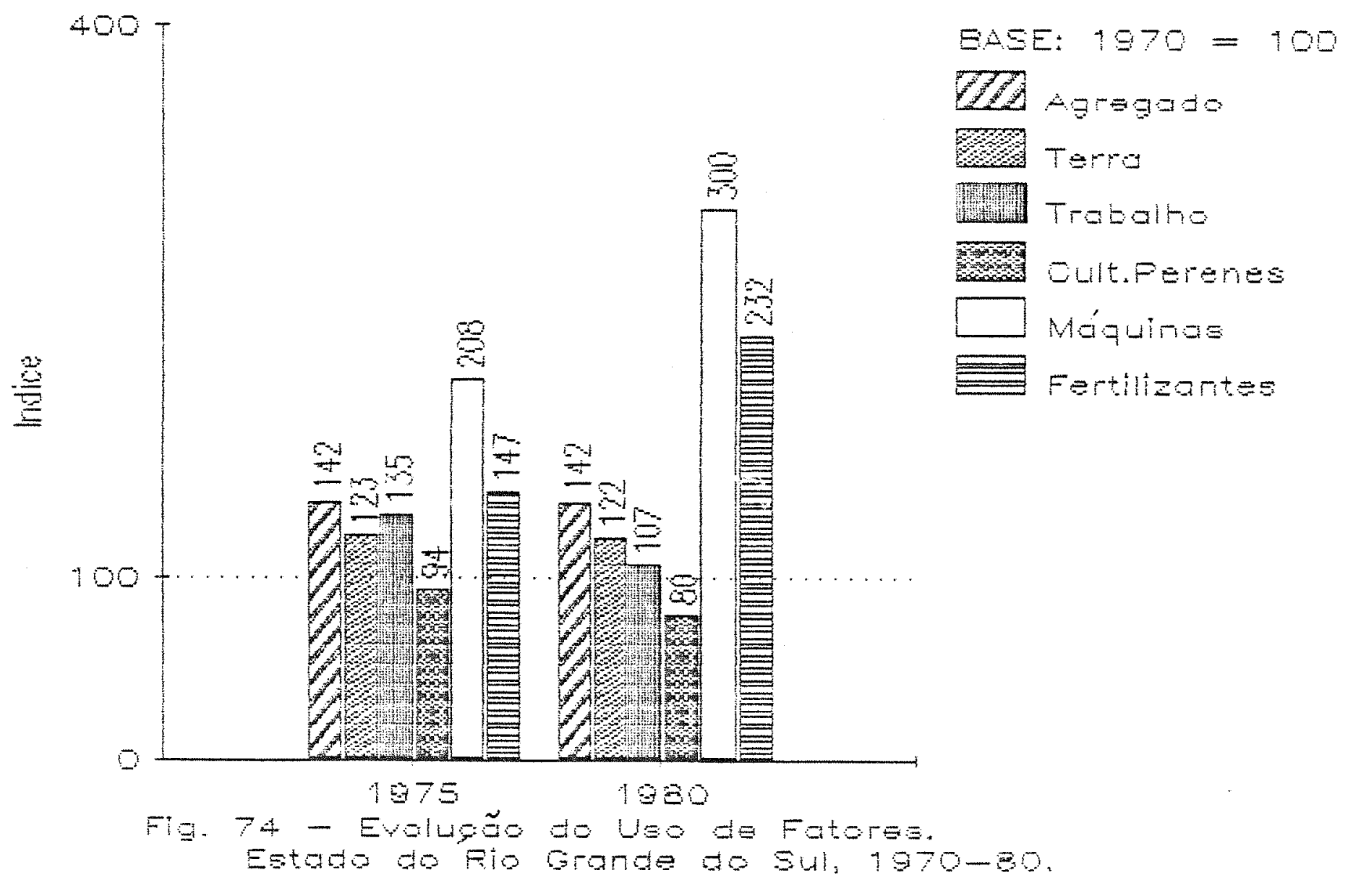




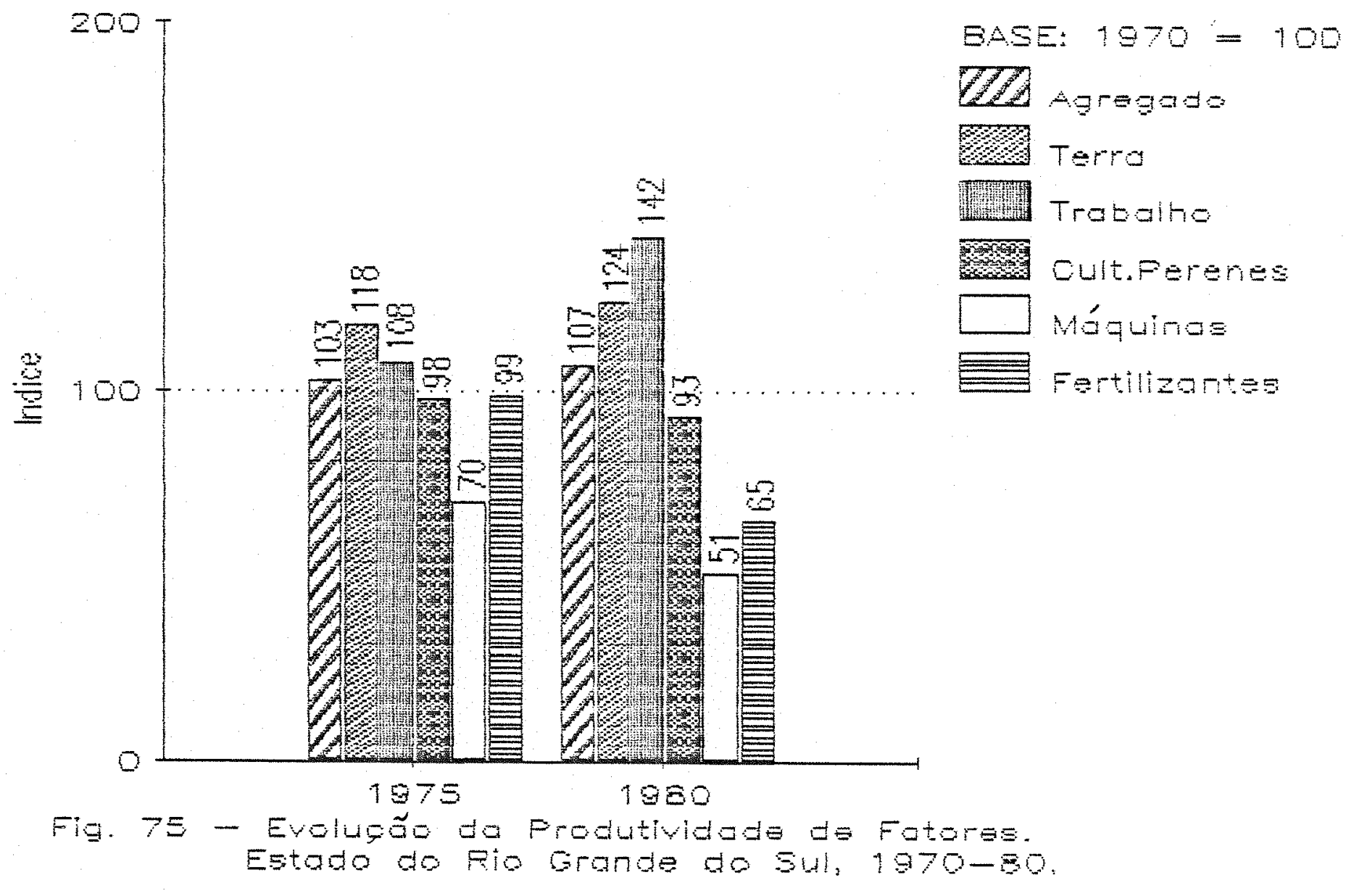


APêNDICE 3. Equaçóes Adicionais Ajustadas 
TABELA A.3.1.-Equações Adicionais com Pesquisa, Assistência Técnica, Educação, condiçốes do Tempo e Aptidăo Edafo-Climática como Variáveis Explicativas do Indice de Produtividade Agregada, da Terra e do Trabalho na Agricultura, Brasil, 1970-80. (1)

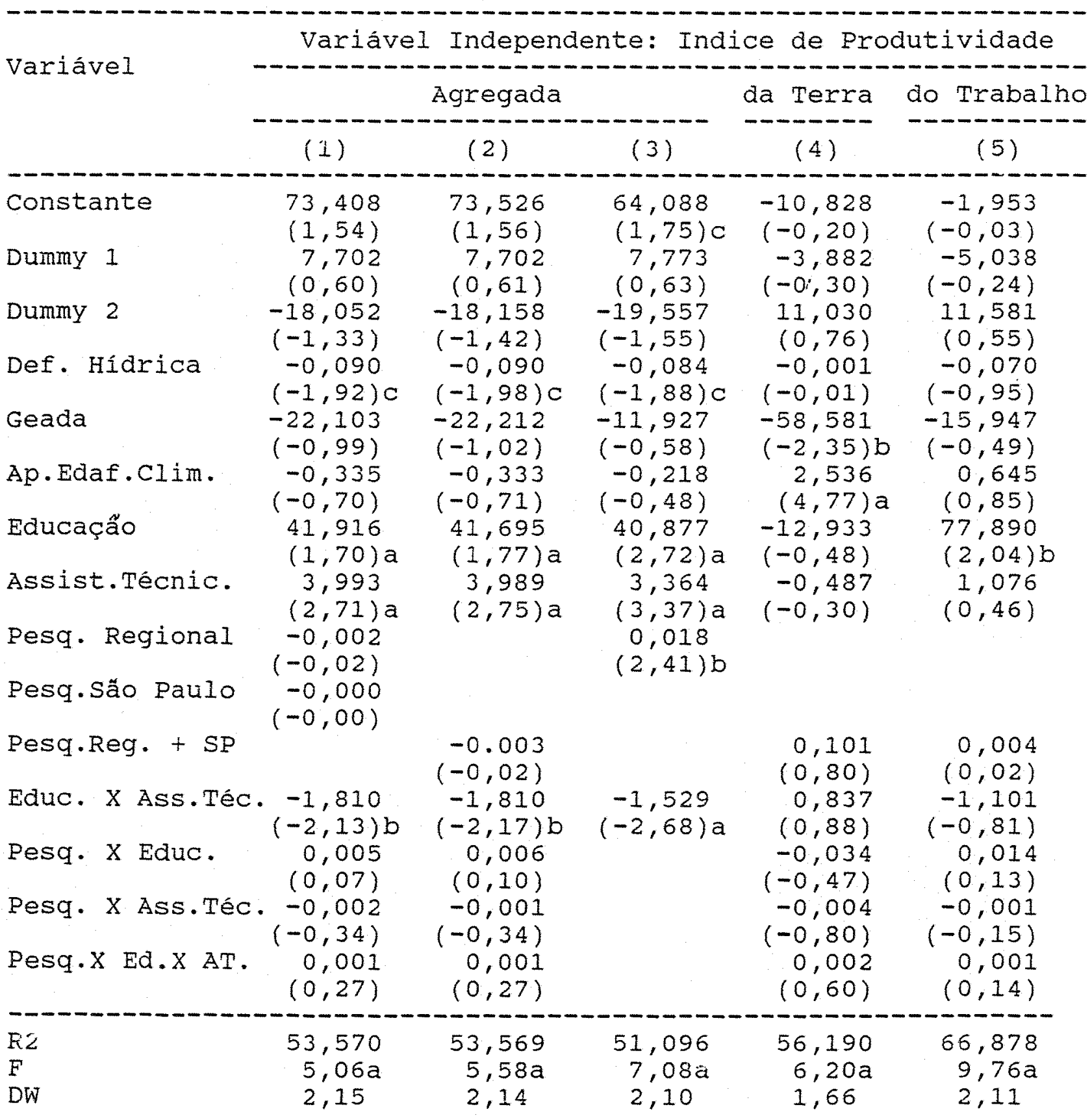

(1) Detalhes sobre a construção das variáveis encontram-se no capitulo 2. Entre parênteses, valores da estatística "t"; niveis de significância: $a=1 \% ; b=5 \% ; c=10 \%$.

FONTE: Elaborado a partir de dados básicos da Fundação Instituto Brasileiro de Geografia e Estatistica (IBGE), da Fundaçăo Getúlio Vargas (FGV) e do Instituto de Economia Agricola (IEA). 